\title{
Validation of a Spectroscopic Screening Method for Secondary Metabolites from New Zealand Extremophilic Microbes
}

\author{
by \\ Chriselle Deborah Braganza
}

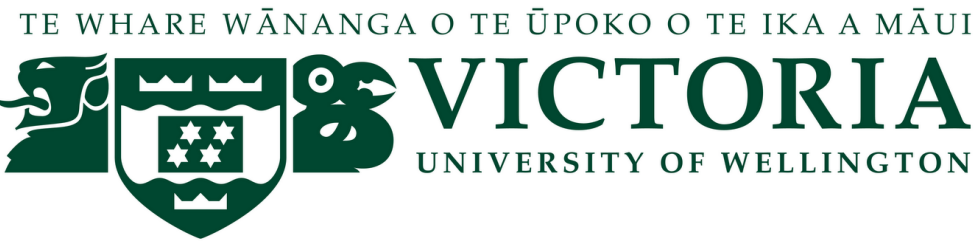

\author{
A thesis \\ submitted to Victoria University of Wellington \\ in partial fulfilment of the requirements \\ for the degree of \\ Master of Biomedical Science.
}

Victoria University of Wellington 


\begin{abstract}
The existing protocol for the screening of natural products from marine invertebrates and macroalgae has been demonstrated successfully at VUW on multiple occasions. This study describes the evaluation of an adapted version of the protocol to screen liquid microbial cultures. The adapted protocol was carried out using an NMR-guided approach and was used to screen 10 New Zealand extremophilic microbes. Investigation of the bacteria Anoxybacillus flavithermus led to the isolation of the known compound 1-acetyl$\beta$-carboline (25), which was briefly evaluated for its biological activity. A detailed investigation on the marine bacteria Shewanella sp. resulted in the isolation of indole3-carboxaldehyde (93) and 14 known 2,5-diketopiperazines $(\mathbf{3 6}, \mathbf{3 8}, \mathbf{4 1 - 4 4 , ~ 5 3 , ~ 5 4 , ~ 9 4 - ~}$ 99). Three of the isolated 2,5-DKPs were tested against Saccharomyces cerevisiae to evaluate their antifungal activity, the results of which are also described. Overall, the use of the adapted screening method proved successful to guide the isolation of secondary metabolites from microbial cultures.
\end{abstract}

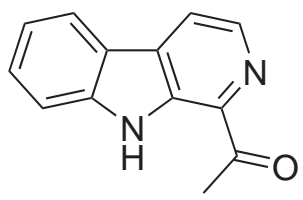

25

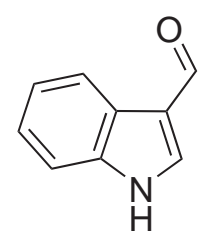

93<smiles>O=C1N[C@H](Cc2ccccc2)C(=O)N2CCC[C@H]12</smiles>

36 Cyclo(L-Phe-D-Pro)<smiles>[R]c1ccc(C[C@@H]2NC(=O)[C@@H]3CC([R6])CN3C2=O)cc1</smiles>

$38 \quad \mathrm{R}_{1}=\mathrm{OH}, \mathrm{R}_{2}=\mathrm{H} \quad$ Cyclo(L-Tyr-L-Pro)

$43 \quad \mathrm{R}_{1}=\mathrm{H}, \mathrm{R}_{2}=\mathrm{OH} \quad$ Cyclo(L-Phe-L-4-Hyp)<smiles>CC(C)[C@H]1NC(=O)[C@@H]2CCCN2C1=O</smiles>

41 Cyclo(L-Val-L-Pro)<smiles>[R]C1C[C@H]2C(=O)N[C@@H](CC(C)C)C(=O)N2C1</smiles>

$42 \mathrm{R}=\mathrm{OH} \quad \mathrm{Cyclo}(\mathrm{L}-\mathrm{Leu}-\mathrm{L}-4-\mathrm{Hyp})$

$44 \quad \mathrm{R}=\mathrm{H} \quad$ Cyclo(L-Leu-L-Pro)<smiles>O=C1N[C@@H](Cc2c[nH]c3ccccc23)C(=O)N2CCC[C@H]12</smiles>

53 Cyclo(L-Trp-L-Pro) 


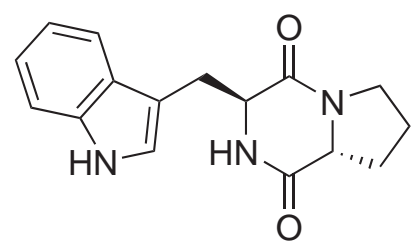

54 Cyclo(L-Trp-D-Pro)<smiles>[R]C12CCCN1C(=O)C(Cc1ccccc1)NC2=O</smiles>

$95 \mathrm{R}=\mathrm{OH}$ Cyclo(Phe-6-Hyp)

$96 \mathrm{R}=\mathrm{H} \quad$ Cyclo(Phe-Pro)<smiles>CC1NC(=O)C(Cc2c[nH]c3ccccc23)NC1=O</smiles>

98 Cyclo(Trp-Ala)<smiles>O=C1NC(Cc2ccccc2)C(=O)N2CC(O)CC12</smiles>

94 Cyclo(Phe-4-Hyp)<smiles>CC(C)CC1NC(=O)C(Cc2ccccc2)NC1=O</smiles>

97 Cyclo(Phe-Leu)

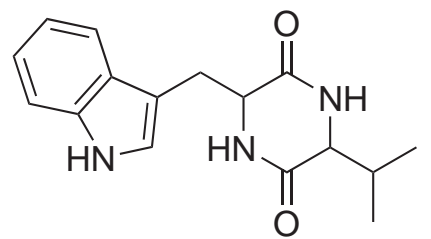

99 Cyclo(Trp-Val) 


\section{Acknowledgements}

During my years as a postgraduate student, I have been lucky enough to meet many knowledgeable people and have also made some great friends, all of whom contributed to this thesis in some way.

First and foremost, I would like to thank my supervisor, Dr. Rob Keyzers, for all of his guidance, patience and for always being positive, enthusiastic and encouraging no matter what. Thank you for also always making time for me despite how busy you were. A giant thank you goes out to all the members of our lab group - Emma Aitken, Nathaniel Dasyam, Vidhiya Damodaran, Danica Carter, Laura Walker, Tate Bicknell, Simon Berberich, Andy Woerle, Sarah Moore, Ben Baker and Michael Göttel, all of you have made the last two years a fun and unforgettable experience, which I will cherish forever. Emma, thank you for introducing me to the dynamics of the lab and teaching me how to work with cultures. Nathaniel (Sunny), thank you for always making time to help me and for teaching me pretty much everything else I needed to know, and also for your constant words of wisdom and encouragement. Thank you to Vidhiya for being a great lab mate and confidant, for all the rides home and also for all your help with ${ }^{2} \mathrm{~T}_{\mathrm{E}} \mathrm{X}$.

I would also like to thank Associate Professor Peter Northcote for all his advice throughout my research, especially on NMR-related problems. Your extraordinary ability to solve a structure within minutes of looking at the NMR data never ceases to amaze me! Thank you also to the members of the Marine Natural Products group for your advice and lending me equipment. A special thank you to Dr. Jonathan Singh for your help with NMR and for many, sometimes crazy, bus-ride chats. Thank you also to Helen Woolner for being a great listener, we have had some great chats that I will not forget!

I am very grateful to Matthew Stott from GNS Science and Jason Ryan from Callaghan Innovation for providing me with the microbial cultures that I worked on during my research, without which I would not have a project. A big thank you to Dr. Penny Truman from ESR for performing monoamine oxidase assays. Thank you also to Arun Kanakkanthara for performing the anticancer assays, Nathaniel for the antibacterial assays, and Mona Mokhtari and her supervisor Dr. Andrew Munkacsi for the yeast bioassay work. I am also grateful to Ian Vorster for all his help with the NMR instrument.

I would also like to acknowledge the Curtis-Gordon Scholarship and the NZIC Student Travel Award for providing funding during my postgraduate study.

To my fellow postgraduates, thank you for the memorable times and help whenever I needed advice. To Jessie Bird and Amy Foster, I will miss our heated chemistry debates and will never forget the fun times and talks we shared, especially organising NZIC events and the quiz. Thank you for taking that road with me, it was definitely rewarding. Dalilah Dzulkefly, thank you for all the dinner dates and for always listening to me venting, you are a great friend. To Jessica Chin, thank you for always being available to talk and just being there, and for all the rides to and from uni.

To Dad, Mum, Cassey and Pebble, thank you so much for being so supportive and such a great family to come home to. Dad, thank you so much for all the times you drove all the way to uni to pick me up and/or drop me off. Mum, I am so lucky to come home to such amazing food, thank you so much for always spoiling me with my favourite foods. Thank you Cassey for always being available to play Halo, Dance Central or any other video 
game when I wanted to take a break from my work. To Pebble (even though you cannot read this), no matter how bad my day was, all I had to do was come home and spend some time with you, and it would instantly make me feel a hundred times better, thank you. Lastly, to Kenji, thank you for being so supportive, understanding, patient, encouraging and loving no matter how unreasonable I was, and for never giving up on me, I could not have done this without you. 


\section{Table of Contents}

Abstract

Acknowledgements iii

Table of Contents $\quad$ v

List of Figures $\quad$ viii

$\begin{array}{ll}\text { List of Schemes } & \mathbf{x}\end{array}$

List of Tables $\quad$ xi

Glossary $\quad$ xii

1 Introduction 1

1.1 The Role of Natural Products in Drug Discovery . . . . . . . . . . . . . . 1

1.2 Microbes as Sources of Natural Products . . . . . . . . . . . . . . . 3

1.2.1 Terrestrial and Freshwater Microbes . . . . . . . . . . . . 3

1.2.2 Marine Microbes . . . . . . . . . . . . . . 6

1.2.3 Extremophilic Microbes .............. 7

1.3 Isolation Guidance for Natural Products . . . . . . . . . . . . . . . . . . 9

1.3.1 Bioassay-Guided Isolation . . . . . . . . . . . . . . 9

1.3.2 NMR Spectroscopy-Guided Isolation . . . . . . . . . . . . 11

1.4 Techniques for Isolation of Secondary Metabolites _ . . . . . . . . . . 12

1.4.1 Cyclic Loading and Back Loading . . . . . . . . . . . . . . . . 12

1.4.2 VUW Screening Method . . . . . . . . . . . . . 15

1.5 Research Aims . . . . . . . . . . . . . . . . 15 
2.1 Taupo Volcanic Zone . . . . . . . . . . . . . . . . . . . . . 17

2.2 Adapted Screening Method . . . . . . . . . . . . . . . . . . . . . . 19

2.3 Investigation of Thermus filiformis (NGM11.1) . . . . . . . . . . 20

2.4 Investigation of Geobacillus stearothermophilus

(NGM22.9) . . . . . . . . . . . . . . . . . 21

2.5 Investigation of Anoxybacillus amylolyticus

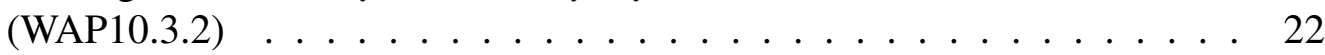

2.6 Investigation of Thermomyces lanuginosus (WC14) . . . . . . . . . . . 23

2.7 Investigation of Anoxybacillus flavithermus (WK1) . . . . . . . . . . 23

2.7.1 Isolation of a Known Compound from A. flavithermus . . . . . . 25

2.7.2 Biological Activity of 1-Acetyl- $\beta$-carboline . . . . . . . . 26

2.8 Investigation of Chthonomonas calidirosea (T49) . . . . . . . . . . . . . 28

2.9 Investigation of Pyrinomonas methylaliphatogenes

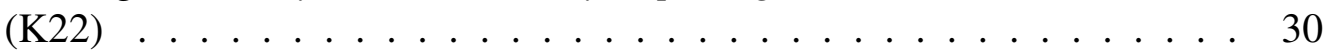

2.10 Investigation of $\mathrm{P} 373 \ldots \ldots \ldots \ldots \ldots$

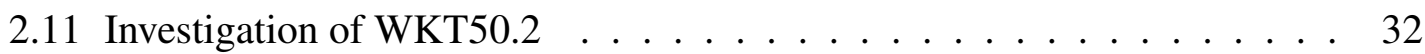

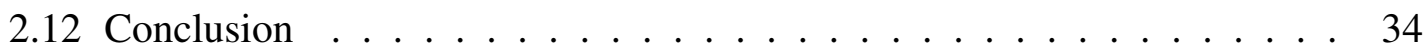

$3 \quad$ 2,5-Diketopiperazines from Shewanella sp. 35

$3.12,5$-Diketopiperazines . . . . . . . . . . . . . 35

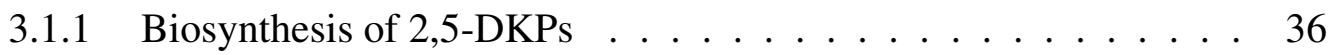

3.1.2 Biological Activity of 2,5-DKPs . . . . . . . . . . . . 39

3.2 The Genus Shewanella . . . . . . . . . . . . . . . . . . 49

3.2.1 Pathogenicity of Shewanella spp. . . . . . . . . . . 51

3.2.2 Reported Bioactive Metabolites from Shewanella spp. . . . . . . 52

3.3 Isolation of Secondary Metabolites from Shewanella sp. . . . . . . . . . 54

3.3.1 Compounds from the $75 \% \mathrm{Me}_{2} \mathrm{CO} / \mathrm{H}_{2} \mathrm{O}$ fraction $\ldots . . . . .54$

3.3.2 Compounds from the $30 \% \mathrm{Me}_{2} \mathrm{CO} / \mathrm{H}_{2} \mathrm{O}$ fraction . . . . . . . 60 
3.4 Biological Testing at VUW . . . . . . . . . . . . . 73

4 Concluding Remarks $\quad 76$

5 Experimental $\quad 78$

5.1 General Experimental . . . . . . . . . . . . . . . . 78

5.2 Screening Protocol for Microbial Cultures . . . . . . . . . . . . . . 79

5.3 Isolation of 1 -acetyl- $\beta$-carboline from A. flavithermus . . . . . . . . . . . 80

5.4 Isolation of Compounds from Shewanella sp. . . . . . . . . . . . . . . 81

5.4.1 Isolation of Indole-3-carboxaldehyde and Cyclo(L-Trp-L-Pro) . . 82

5.4.2 Isolation of 2,5-DKPs from the $30 \%$ Fraction $\ldots \ldots . . . . .83$

$\begin{array}{ll}\text { A Microbial Culture Conditions } & 91\end{array}$

A.1 Culture Media Components . . . . . . . . . . . . . . . . . . . . 91

B NMR Spectra of 1-Acetyl- $\beta$-carboline $\quad 94$

C NMR Spectra of Indole-3-carboxaldehyde 99

D NMR Spectra of 2,5-DKPs $\quad 104$

$\begin{array}{ll}\text { References } & 141\end{array}$ 


\section{List of Figures}

1.1 Typical mass distribution in a microbial culture or extract eluted from a reversed-phase stationary phase. . . . . . . . . . . . 13

1.2 Cyclic loading. . . . . . . . . . . . . . . . . . . . . . 14

2.1 Taupo Volcanic Zone (highlighted in red) in the North Island, New Zealand. 18

2.2 Isolation site of NGM11.1 and NGM22.9 . . . . . . . . . . . . . 20

2.3 Spectral comparison of the $75 \% \mathrm{Me}_{2} \mathrm{CO}$ fractions from the NGM11.1 culture filtrate (top) and cell mass extract (bottom) with unique resonances highlighted $\left(600 \mathrm{MHz}, \mathrm{CD}_{3} \mathrm{OD}\right) \ldots \ldots \ldots . \ldots . \ldots 21$

2.4 ${ }^{1} \mathrm{H}$ NMR spectrum of the $75 \% \mathrm{Me}_{2} \mathrm{CO}$ fraction from the WAP10.3.2 cell mass extract with unique resonances highlighted $\left(600 \mathrm{MHz}, \mathrm{CD}_{3} \mathrm{OD}\right) . \quad$. 22

2.5 Isolation site of A. flavithermus WK1. . . . . . . . . . . . . . . 24

2.6 COSY and HMBC correlations confirming the connection between C-5 and $\mathrm{C}-8$ in CDB01_68E. . . . . . . . . . . . . . . . 25

2.7 COSY and HMBC correlations establishing the 1,2-disubstituted benzene ring in CDB01_68E. . . . . . . . . . . . . . . . 26

2.8 Isolation site of T49. . . . . . . . . . . . . . . . . . . . . . 29

2.9 ${ }^{1} \mathrm{H}$ NMR spectrum of the $75 \% \mathrm{Me}_{2} \mathrm{CO}$ fraction from the culture filtrate of T49 showing antifoam peaks from 3.3-4 ppm (600 MHz, $\left.\mathrm{CD}_{3} \mathrm{OD}\right)$. . . 29

2.10 Isolation site of K22. . . . . . . . . . . . . . . . . . 30

2.11 TEM image showing latitudinal and longitudinal cross-section views of K22 cell morphology (scale bar: $1 \mu \mathrm{m}) \ldots \ldots . \ldots 31$

2.12 Light microscope phase contrast images of P373 cells (scale bar: $20 \mu \mathrm{m}$ ). $\quad 31$

2.13 Isolation site of P373 and WKT50.2 . . . . . . . . . . . . . 32

$2.14{ }^{1} \mathrm{H}$ NMR spectrum of the $75 \% \mathrm{Me}_{2} \mathrm{CO}$ fraction from the $\mathrm{P} 373$ culture filtrate with unique resonances highlighted $\left(600 \mathrm{MHz}, \mathrm{CD}_{3} \mathrm{OD}\right) . \ldots 33$

2.15 Cryogenic TEM of a WKT50.2 cell, showing the typical Gram-positive cell wall structure (scale bar: $200 \mathrm{~nm}) \ldots \ldots$. . . . . . . . . . . . 33

3.1 General structure of a $2,5-D K P \ldots \ldots \ldots . \ldots . \ldots . \ldots 35$

3.2 Shewanella assay against $V$. harveyi (left) and Y. ruckeri (right). . . . . . . 52 
3.3 COSY and HMBC correlations establishing the 1,2-disubstituted benzene substructure in indole-3-carboxaldehyde. . . . . . . . . . . 56

3.4 HMBC correlations establishing the indole moiety and the connection to the aldehyde group in indole-3-carboxaldehyde. . . . . . . . . . . 56

3.5 COSY and HMBC correlations establishing indole in cyclo(L-Trp-L-Pro). 58

3.6 COSY and HMBC correlations establishing the connections between C-3 and C-14 in cyclo(L-Trp-L-Pro) . . . . . . . . . . . . . . 58

3.7 COSY and HMBC correlations establishing the connections between C15 and C-11 in cyclo(L-Trp-L-Pro). . . . . . . . . . . . . . . 59

3.8 Connection between the two established substructures for cyclo(L-Trp-LPro). . . . . . . . . . . . . . . . . . . 5 59

3.9 COSY and HMBC correlations establishing the connections between C-3 and C-5 in cyclo(L-Phe-L-4-Hyp).

3.10 COSY and HMBC correlations establishing amino acid 4-hydroxyproline in cyclo(L-Phe-L-4-Hyp). . . . . . . . . . . . . . . . . . . . 63

3.11 COSY and HMBC correlations establishing the connections between the monosubstituted benzene ring and 4-hydroxyproline in cyclo(L-Phe-L-4Нyp). . . . . . . . . . . . . . . . . . 63

3.12 COSY and HMBC correlations establishing leucine in cyclo(L-Leu-L-4Нур). . . . . . . . . . . . . . . . . . . 65

3.13 Growth curve for cyclo(L-Leu-L-4-Hyp) (42) against wild-type $S$. cerevisiae. . . . . . . . . . . . . . . . . . . . . 74

3.14 Growth curve for cyclo(L-Phe-L-4-Hyp) (43) against wild-type $S$. cerevisiae. . . . . . . . . . . . . . . . . . . 75

3.15 Growth curve for cyclo(L-Leu-L-Pro) (44) against wild-type S. cerevisiae. 75 


\section{List of Schemes}

3.1 NRPS biosynthesis of cyclomarin C and side product cyclomarazine A. . 38

3.2 Biosynthesis pathways of a) albonoursin, b) pulcherrimin, c) mycocyclosin and d) cyclo(L-Trp-L-Trp)-Me/Me $\mathrm{Me}_{2}$ by CDPSs. . . . . . . . . . 38

3.3 Isolation of indole-3-carboxaldehyde and cyclo(L-Trp-L-Pro). . . . . . . 55

3.4 Isolation of more 2,5-DKPs from the 30\% fraction of Shewanella sp.. . . 61 


\section{List of Tables}

$2.1{ }^{1} \mathrm{H}(600 \mathrm{MHz})$ and ${ }^{13} \mathrm{C}(150 \mathrm{MHz}) \mathrm{NMR}$ data for 1 -acetyl- $\beta$-carboline $\left(\mathrm{DMSO}_{6} \mathrm{~d}_{6}\right) \ldots \ldots \ldots \ldots \ldots . \ldots \ldots \ldots$

3.1 $\mathrm{IC}_{50}$ values of some complex DKPs against the cell cycle progression of mouse tsFT210 cells. . . . . . . . . . . . . . . . 45

3.2 Taxonomic classification of species from the genus Shewanella from order Alteromonadales. . . . . . . . . . . . . . . . 50

3.3 List of tested strains and their activity against $V$. harveyi and Y. ruckeri. . . 52

$3.4{ }^{1} \mathrm{H}(600 \mathrm{MHz})$ and ${ }^{13} \mathrm{C}(150 \mathrm{MHz}) \mathrm{NMR}$ data for indole-3-carboxaldehyde

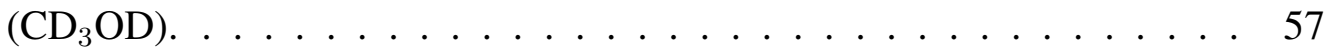

3.5 ${ }^{1} \mathrm{H}(600 \mathrm{MHz})$ and ${ }^{13} \mathrm{C}(150 \mathrm{MHz}) \mathrm{NMR}$ data for cyclo(L-Trp-L-Pro) $\left(\mathrm{CD}_{3} \mathrm{OD}\right) \ldots \ldots \ldots \ldots \ldots \ldots$

3.6 ${ }^{1} \mathrm{H}(600 \mathrm{MHz})$ and ${ }^{13} \mathrm{C}(150 \mathrm{MHz}) \mathrm{NMR}$ data for cyclo(L-Phe-L-4-Hyp) $\left(\mathrm{CD}_{3} \mathrm{OD}\right) \ldots \ldots \ldots \ldots \ldots \ldots$

$3.7{ }^{1} \mathrm{H}(600 \mathrm{MHz})$ and ${ }^{13} \mathrm{C}(150 \mathrm{MHz}) \mathrm{NMR}$ data for cyclo(L-Leu-L-4-Hyp) $\left(\mathrm{CD}_{3} \mathrm{OD}\right) \ldots \ldots \ldots \ldots \ldots \ldots$

3.8 MS/MS data for cyclo(Phe-6-Hyp). . . . . . . . . . . . . . . . . 67

3.9 MS/MS data for cyclo(Trp-Ala). . . . . . . . . . . . . . 72

3.10 MS/MS data for cyclo(Trp-Val). . . . . . . . . . . . . . 72

A.1 Aerobic culture conditions for the extremophilic microbes. . . . . . . . . 91 


\section{Glossary}

\begin{tabular}{|c|c|}
\hline$\delta$ & Chemical shift(ppm). \\
\hline${ }^{13} \mathrm{C}$ NMR & Carbon nuclear magnetic resonance. \\
\hline${ }^{1} \mathbf{H}$ NMR & Proton nuclear magnetic resonance. \\
\hline AHL & Acylated homoserine lactone. \\
\hline AI & Autoinducer. \\
\hline ATP & Adenosine triphosphate. \\
\hline C18 & Octadecyl derivatised silica. \\
\hline $\mathrm{CD}_{3} \mathrm{OD}$ & Deuterated methanol. \\
\hline $\mathbf{C D C l}_{3}$ & Deuterated chloroform. \\
\hline CDP & Cyclodipeptide. \\
\hline CDPS & Cyclodipeptide synthase. \\
\hline CID & Collision-induced dissociation. \\
\hline COSY & Correlation spectroscopy $\left({ }^{1} \mathrm{H}\right.$ to $\left.{ }^{1} \mathrm{H}\right)$. \\
\hline d & Doublet. \\
\hline DAD & Diode array detector. \\
\hline DBE & Double bond equivalent. \\
\hline dd & Doublet of doublets. \\
\hline ddd & Doublet of doublet of doublets. \\
\hline DIOL & 2,3-Dihydroxy-propoxypropyl-derivatised silica gel. \\
\hline DKP & Diketopiperazine. \\
\hline DMSO & Dimethyl sulfoxide. \\
\hline DNA & Deoxyribonucleic acid. \\
\hline EA & Ethyl acetate. \\
\hline ELSD & Evaporative light scattering detector. \\
\hline EPA & Eicosapentaenoic acid. \\
\hline ESR & $\begin{array}{l}\text { Environmental Science and Research (located in Kenepuru, } \\
\text { Wellington). }\end{array}$ \\
\hline EtOH & Ethanol. \\
\hline FDA & United States Food and Drug Administration. \\
\hline HIV & Human immunodeficiency virus. \\
\hline HMBC & Heteronuclear multiple-bond correlation $\left({ }^{1} \mathrm{H}\right.$ to $\left.{ }^{13} \mathrm{C}\right)$. \\
\hline HP20/HP20ss & Poly(styrene-divinylbenzene) stationary support. \\
\hline HPLC & High-performance liquid chromatography. \\
\hline HRESIMS & High-resolution electrospray ionisation mass spectrometry. \\
\hline HSQC & Heteronuclear single-quantum coherence $\left({ }^{1} \mathrm{H}\right.$ to $\left.{ }^{13} \mathrm{C}\right)$. \\
\hline $\mathbf{I C}_{50}$ & Concentration at which $50 \%$ of cell growth was inhibited. \\
\hline in vacuo & In a vacuum. \\
\hline in vivo & In a living organism. \\
\hline$J$ & Scalar coupling constant $(\mathrm{Hz})$. \\
\hline LH-20 & Size-exclusion chromatography media. \\
\hline $\mathbf{M}$ & Moles per litre. \\
\hline $\mathbf{m}$ & Multiplet. \\
\hline$m / z$ & Mass to charge ratio. \\
\hline MAO & Monoamine oxidase. \\
\hline Me & Methyl. \\
\hline $\mathrm{Me}_{2} \mathrm{CO}$ & Acetone. \\
\hline $\mathrm{MeCN}$ & Acetonitrile. \\
\hline МeOH & Methanol. \\
\hline MIC & Minimum inhibitory concentration. \\
\hline
\end{tabular}




$\begin{array}{ll}\text { MRSA } & \text { Methicillin-resistant Staphylococcus aureus. } \\ \text { MS } & \text { Mass spectrometry. } \\ \text { MS/MS } & \text { Tandem mass spectrometry. } \\ \text { mult } & \text { Multiplicity. } \\ \text { NIWA } & \text { The National Institute of Water and Atmospheric Research } \\ & \text { (located in Wellington). } \\ \text { NMR } & \text { Nuclear magnetic resonance spectroscopy. } \\ \text { NRPS } & \text { Nonribosomal peptide synthetase. } \\ \text { PCR } & \text { Polymerase chain reaction. } \\ \text { PDB } & \text { Potato dextrose broth (media). } \\ \text { ppm } & \text { Parts per million. } \\ \text { PSDVB } & \text { Poly(styrene-divinylbenzene). } \\ \text { PYM } & \text { Peptone-yeast extract-malt extract (media). } \\ \text { QS } & \text { Quorum sensing. } \\ \text { Q-TOF } & \text { Quadrupole time-of flight. } \\ \text { rRNA } & \text { Ribosomal ribonucleic acid. } \\ \text { S } & \text { Singlet. } \\ \text { SAR } & \text { Structure-activity relationship. } \\ \text { t } & \text { Triplet. } \\ \text { td } & \text { Triplet of doublets. } \\ \text { TEM } & \text { Transmission electron microscope. } \\ \text { TLC } & \text { Thin layer chromatography. } \\ \text { tRNA } & \text { Transfer ribonucleic acid. } \\ \text { TSB } & \text { Tryptic soy broth (media). } \\ \text { TVZ } & \text { Taupo Volcanic Zone. } \\ \text { UV/Vis } & \text { Ultraviolet-visible spectroscopy. } \\ \text { VRE } & \text { Vancomycin-resistant enterococci. } \\ \text { VUW } & \text { Victoria University of Wellington. }\end{array}$




\section{Chapter 1}

\section{Introduction}

\subsection{The Role of Natural Products in Drug Discovery}

Natural resources have been used as herbal remedies for pain and disease for thousands of years. The active constituents of these remedies were unknown at the time and led scientists to explore the medical use of plants in more detail. ${ }^{1}$ In 1785 , Withering described the use of a cardiotonic foxglove extract to treat heart patients, which later led to the discovery of digoxin (1), a drug for treating cardiac arrhythmias and congestive heart failure. ${ }^{2}$ Shortly after, in 1804, Sertürner isolated morphine (2) from opium and found it to be an analgesic and a sedative, which made it the first naturally derived substance to be commercialised. ${ }^{1}$ Following the discovery of $\mathbf{2}$, several other natural products were identified including salicin (3) from Salix alba, quinine (4) from Cinchona ledgeriana, nicotine (5) from Nicotiana tabacum and many more. ${ }^{1}$ These compounds have displayed significant biological activities in humans, with many still in use. This highlights the important role that natural products play as drugs or potential drug leads. Fleming's discovery of penicillin (6) in 1928 illustrated that plants were not the only source of bioactive natural products. ${ }^{3}$ His discovery brought about the onset of the "Golden Age of Antibiotics" during which microbes were largely screened for new bioactive compounds. ${ }^{4}$

The ability of natural products to exert a biological effect on humans and other organisms has long been questioned. Organisms that exist in close proximity to one another can produce small, diverse molecules known as secondary metabolites. The production of these compounds is metabolically expensive and hence they must have some advantage to the producer such as aiding in defending themselves from their neighbours, communicating with their population or even interfering with competing neighbours. ${ }^{5}$ Natural selection over time causes these secondary metabolites to evolve and become more bioactive and bioavailable. ${ }^{1}$ The small molecular size of these metabolites and their inherent bioactivity allows them to bind to receptors and exert various effects in humans. ${ }^{5}$ 
<smiles>C[C@@H]1O[C@H](O)C[C@H](O)[C@@H]1OC1C[C@H](O)[C@@H](O)[C@H](C)O1</smiles>

3<smiles>C=CC1CC2CCN(C1)C[C@@H]2[C@H](O)c1ccnc2ccc(OC)cc12</smiles>

4

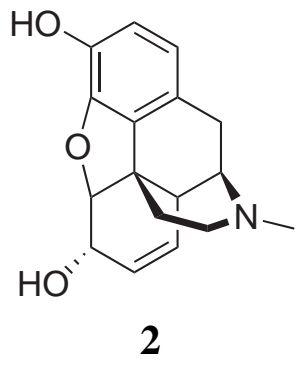<smiles>CN1CCC[C@H]1c1ccccc1</smiles>

5<smiles>CC1(C)SC2N(C(=O)O)C(=O)N2C1NC(=O)P</smiles>

6

The increase in knowledge and tools for analytical and structural chemistry in the $20^{\text {th }}$ century has led to the discovery of a large number of bioactive natural products from plants and microbes. These compounds have contributed largely to the field of drug design by providing novel chemical scaffold targets that can be synthesised and modified in order to enhance bioactivity. ${ }^{1}$ Although natural products are a strong source of drug leads, over the last decades, many pharmaceutical companies decided to switch their attention to combinatorial chemistry and high-throughput screening for identifying new drug candidates. This was due to long purification time frames and lack of access to new sources of natural products. ${ }^{6}$ However, in a recent review of new drugs approved by the FDA from 1981-2010, it was reported that over 50\% of all new approved drugs were either natural products or derived from natural products. ${ }^{7}$ Also highlighted was the important role that these compounds play as anticancer, anti-infective and antidiabetic agents. Therefore, despite the few disadvantages mentioned above, it is due to the almost everlasting supply of unique chemical scaffolds provided by natural products that scientists have switched their attention back to natural product research in the past few years. ${ }^{8}$ 


\subsection{Microbes as Sources of Natural Products}

\subsubsection{Terrestrial and Freshwater Microbes}

The discovery of penicillin (6) led to the extensive screening of microbes, particularly soil actinomycetes and fungi, for more antibiotics. The genus Streptomyces has not only provided almost $75 \%$ of currently commercialised antibiotics, it has also provided compounds with anticancer activity. ${ }^{9}$ Bleomycin (7), a non-ribosomal glycopeptide isolated from Streptomyces verticillus, obtained FDA approval in 1973 as an anticancer agent. ${ }^{10}$ Daunorubicin (8), an antibiotic isolated from Streptomyces peucetius and doxorubicin (9), the semi-synthetic version, are both DNA intercalating drugs that were commonly used against a wide range of cancers before issues of cardiotoxicity arose in 1967. ${ }^{11}$ Despite this, 9 is still used as an orphan drug for the treatment of acute lymphocytic leukaemia. ${ }^{5}$ Several other anticancer agents isolated from actinomycetes are currently undergoing different phases of clinical trials.

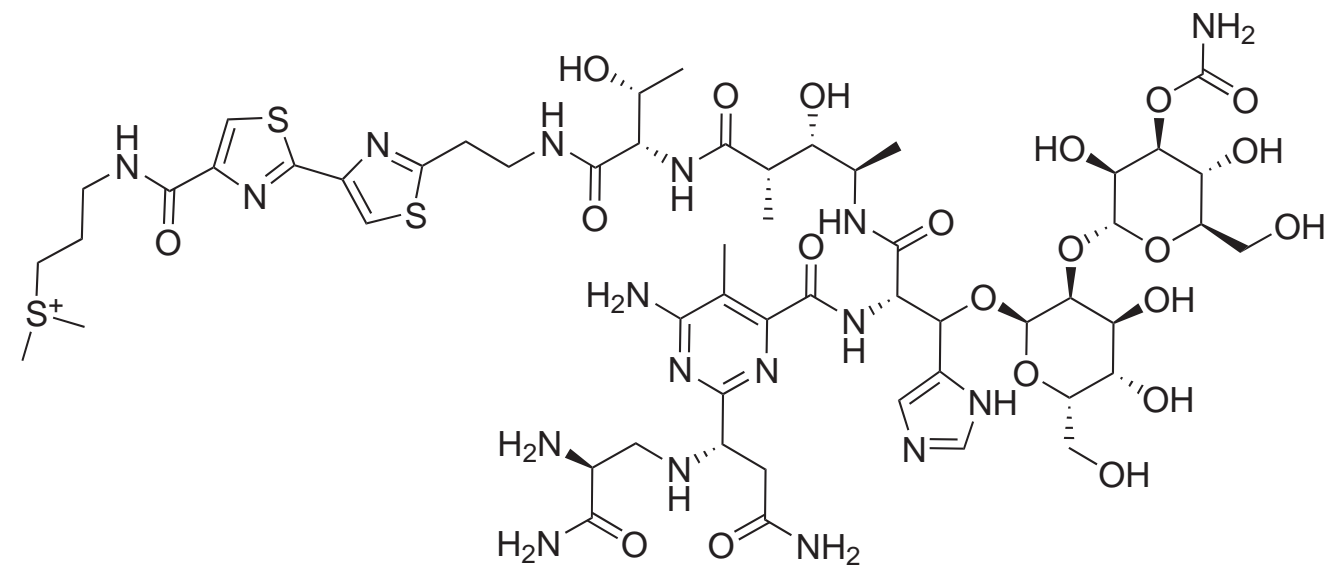

7<smiles>[R]C(=O)C1(O)Cc2c(O)c3c(c(O)c2[C@@H](O[C@@H]2C[C@H](N)[C@H](O)[C@H](C)O2)C1)C(=O)c1c(OC)cccc1C3=O</smiles>

$8 \mathrm{R}=\mathrm{Me}$

$9 \mathrm{R}=\mathrm{CH}_{2} \mathrm{OH}$ 
Cyanobacteria are another leading source of bioactive secondary metabolites. The prokaryotic cellular organisation of these microbes resembles bacteria but they can perform photosynthesis similar to algae. ${ }^{12}$ Cyanobacteria are known to produce both harmful and beneficial molecules. In 1878, George Francis observed an algal bloom of Nodularia spumigena in an estuary of the Murray River in Australia. It was reported that wildlife that consumed this water died a terrible and rapid death. This was the first reported incidence of cyanotoxins. ${ }^{13}$ Since then, several cyanotoxins have been isolated from various species including microcystin (10) and nodularin (11) which are hepatotoxic, and neurotoxins such as anatoxin (12) and saxitoxin (13). ${ }^{14}$ Despite their production of toxins, these bacteria are still considered important sources of novel drug leads that exhibit various activities including antibiotic, antiviral, antifungal, cytotoxic, immunosuppressive and more. ${ }^{13}$ Antiviral compounds that have been isolated include chlorinated $\beta$-carbolines (14) from the terrestrial cyanobacterium Dichotrix baueriana, which act against Herpes simplex virus $2,{ }^{15}$ and the protein cyanovirin-N from Nostoc ellipsosporum that inhibits cell to cell transmission of HIV. ${ }^{16}$ Cryptophycin (15) is a cytotoxic agent that is currently undergoing clinical trials. ${ }^{14}$ It was originally isolated from a Nostoc sp. as an antifungal agent but development was abandoned due to toxicity. ${ }^{17}$ It was later isolated again from another Nostoc sp. and demonstrated powerful cytotoxicity against tumor cell lines, up to 1000 fold greater than the chemotherapeutic agent paclitaxel, making it a promising anticancer agent. ${ }^{14}$

Myxobacteria are another group of microbes that have been screened for their production of bioactive compounds. They have an unusual life cycle that includes the ability to glide and to form multicellular fruiting bodies. ${ }^{18}$ Ambruticin (16), an orally active antifungal agent, was the first metabolite reported from the myxobacterium Sorangium cellulosum in $1977 .{ }^{19}$ The genus Sorangium is responsible for producing almost $50 \%$ of the bioactive natural products that have been isolated from this group of bacteria. ${ }^{20}$ Epothilones isolated from the genus Sorangium are a well known class of structurally unique anticancer agents. All six isolated so far act in a similar way to paclitaxel, by stabilising mictrotubules and interfering with cell division. ${ }^{21}$ Epothilone B (17) and its analogues are currently under various phases of clinical trials. ${ }^{21}$ 


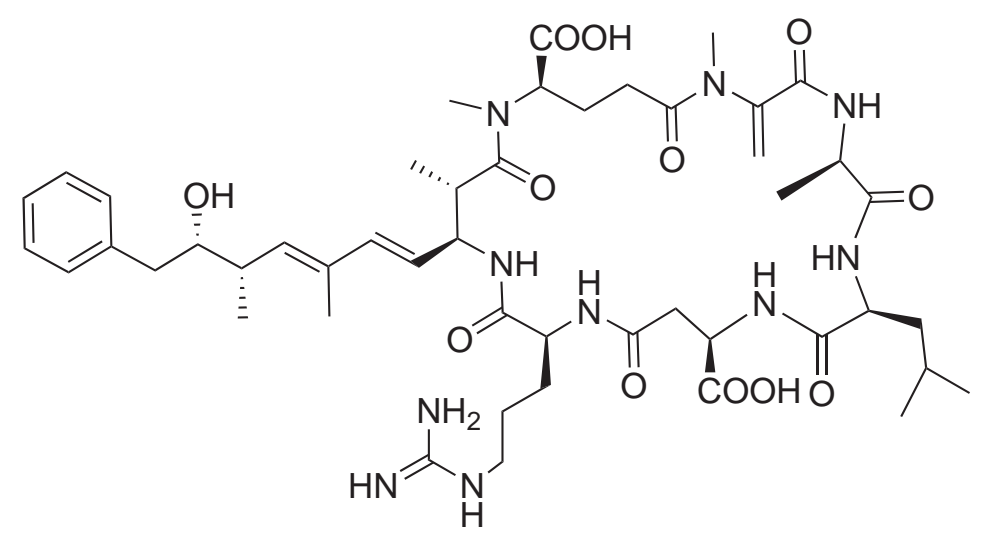

10

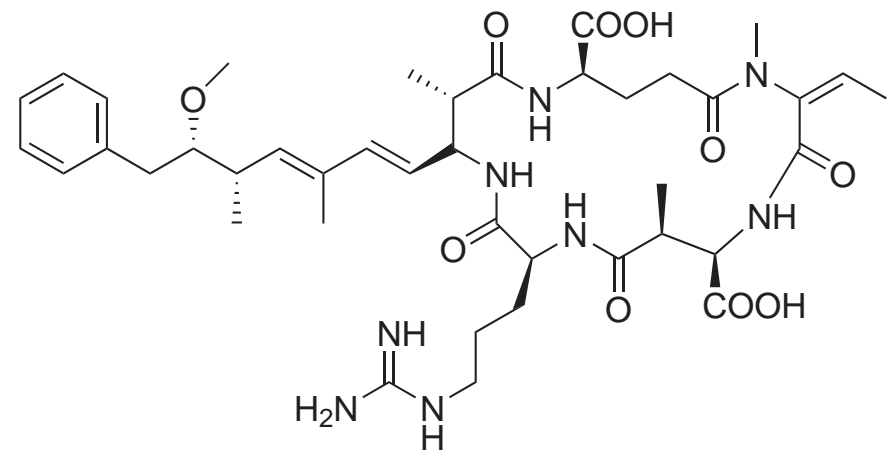

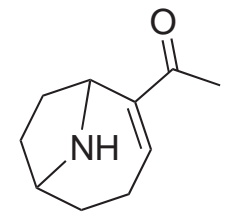

12

11

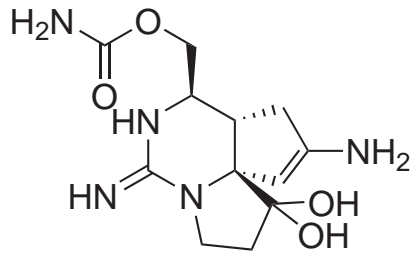

13<smiles>[R2]c1nccc2c3ccc(Cl)c([R])c3n(C)c12</smiles>

14<smiles></smiles>

15

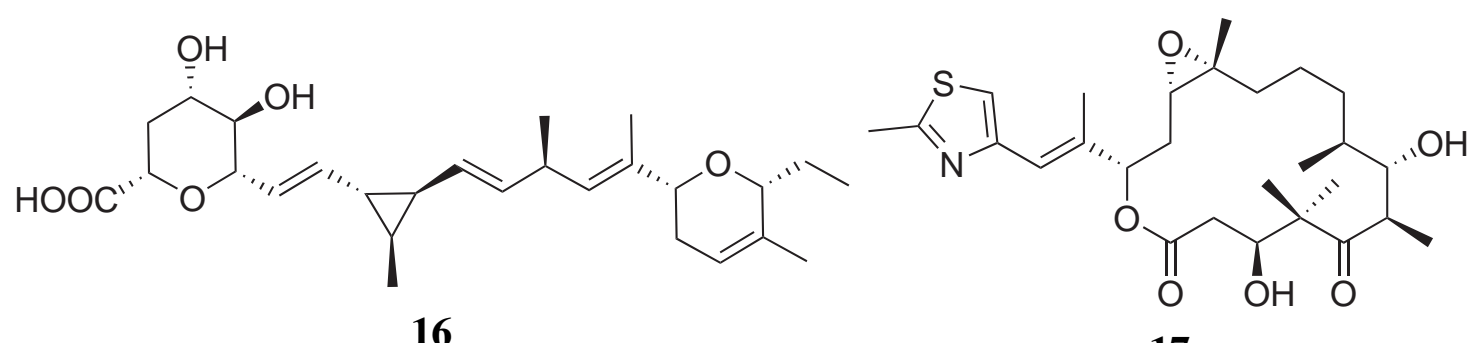




\subsubsection{Marine Microbes}

Marine organisms have been investigated over several decades for their production of natural products, with the focus being on marine invertebrates. ${ }^{22}$ Only a small percent of the overwhelming numbers of marine microbes have been researched in the past as these microbes were "uncultivable" in the laboratory. ${ }^{23}$ However, recent developments in culture technologies have overcome this limitation and made previously unculturable microbes accessible in culture. ${ }^{23}$ Hence, these microbes have recently been given the spotlight for natural product investigation. The high salt and potentially high pressure environment that these microbes live in allow them to produce interesting metabolites that help them survive and compete in these conditions. ${ }^{24}$

A large number of bioactive metabolites have been isolated from marine microbes and are currently undergoing preclinical studies or clinical trials. Two examples are the compounds thiocoraline (18) and salinosporamide A (19), isolated from marine actinomycetes Micromonospora marina and Salinospora tropica, respectively. ${ }^{25,26}$ Compound 18 is a potent DNA polymerase inhibitor and shows strong activity against several tumor cell lines. It also exhibits strong antimicrobial activity against Gram-positive microorganisms and is currently undergoing preclinical trials. ${ }^{27,28}$ Compound $\mathbf{1 9}$ is a potent proteasome inhibitor and has high cytotoxic activity against cancer cell lines. ${ }^{26}$ It is currently undergoing Phase I human clinical trials for multiple myeloma. ${ }^{29}$

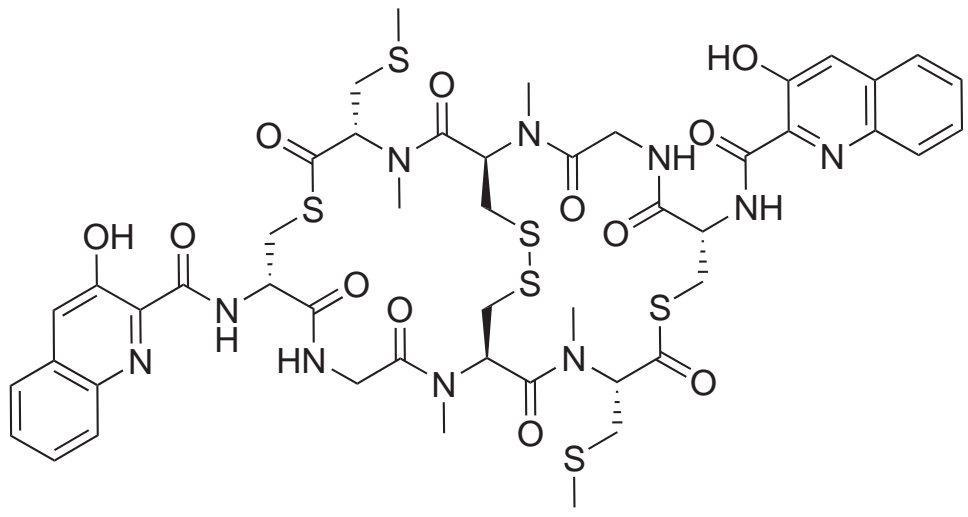<smiles>C[C@]12OC(=O)C1([C@H](O)C1C=CCCC1)NC(=O)[C@@H]2CCCl</smiles>

19

18

Marine invertebrates such as sponges can host various symbiotic microbes. It has been reported that several bioactive compounds previously thought to be produced by sponges were actually produced by their symbionts. ${ }^{30}$ Examples include diketopiperazines pro- 
duced by Micrococcus sp. previously ascribed to the host sponge Tedania ignis, ${ }^{31}$ and brominated biphenyl ethers produced by the bacterium Vibrio sp. formerly attributed to the host sponge Dysidea sp.. ${ }^{32}$ Since only about $0.01 \%$ of the marine biodiversity has been explored, this remains an active area of research for novel drug leads. ${ }^{22}$

\subsubsection{Extremophilic Microbes}

In 1969, Brock and Freeze discovered the thermophilic bacterium Thermus aquaticus in the hot springs of Yellowstone National Park. ${ }^{33}$ Although thermophiles that could thrive at temperatures up to $60^{\circ} \mathrm{C}$ were known before this time, the ability of T. aquaticus to grow at temperatures greater than $70{ }^{\circ} \mathrm{C}$ caused it to be named the first extreme thermophile. ${ }^{33}$ Shortly after, the hyperthermophile Sulfolobus acidocaldarius was discovered by the same group from extremely hot and acidic springs in the same area. It was found that it could survive at a $\mathrm{pH}$ range of $2-3$ and temperatures up to $85^{\circ} \mathrm{C}$ making it acidophilic as well as thermophilic. ${ }^{34}$ Following the discovery of these microbes, the term "extremophile" was coined by MacElroy to describe organisms that can thrive in extreme environments. ${ }^{35}$ It is important to note that "extreme environment" is a relative term, since environments that are extreme for one organism may be essential for the survival of another organism. Thus, extremophiles can be defined as organisms that can grow and reproduce under conditions that would kill most other creatures, and include some that cannot survive in the normal anthropogenic global environments. To date, several classes of extremophiles have been discovered including thermophiles $\left(50\right.$ to $\left.>80^{\circ} \mathrm{C}\right)$, psychrophiles $\left(<10^{\circ} \mathrm{C}\right)$, alkaliphiles $(\mathrm{pH}>10)$, acidophiles $(\mathrm{pH}<4)$ and halophiles $(>2.5 \mathrm{M} \mathrm{NaCl}) .{ }^{36}$

Although extremophiles were discovered over 30 years ago, they have been given the spotlight for research over the past two decades as scientists realised that the molecules that allow these microbes to survive in extreme conditions could potentially be useful for several applications. This led to extremophiles being investigated for their enzymes, which are termed "extremozymes", as they are active and stable under extreme conditions. ${ }^{37}$ Thermostable DNA polymerases from extremophiles have successfully demonstrated their use in the polymerase chain reaction (PCR), with the most widely 
used extremozyme being Taq polymerase, named for its isolation from T. aquaticus. ${ }^{38}$ Extremozymes have also been used in the food, pharmaceutical, paper and textile industries and have potential applications for bioremediation. ${ }^{38}$

Over the past few years, Don and Andrea Stierle have reported the isolation of several bioactive metabolites from extremophiles present in the Berkeley Pit Lake. In 2003, they isolated four new tyrosine derivatives from an extremophilic fungus, Pithomyces ellis. ${ }^{39}$ They found that a prenylated phenol (20) was a 5-HT receptor ligand, suggesting that it could have antihypertensive properties. Soon after, in 2004, they isolated two novel hybrid polyketide-terpenoid metabolites from Penicillium rubrum from the same lake. ${ }^{40}$ Both berkeleydione (21) and berkeleytrione (22), inhibited matrix metalloproteinase-3 and caspase-1, indicating that they could be potential anti-inflammatory or anticancer agents. In 2006, the novel spiroketal berkelic acid (23) was isolated from another Penicillium sp., and showed anti-inflammatory activity and selective inhibition of ovarian cancer cell lines. ${ }^{41}$ The Stierles have gone on to isolate many more bioactive metabolites from $P$. rubrum. ${ }^{42,43}$ These findings demonstrate that a single extreme environment can be home to various extremophilic microorganisms that produce several unique metabolites covering a range of activities. To date, hundreds of unique bioactive secondary metabolites have been isolated from all the major classes of extremophiles, ${ }^{35}$ making these microbes a very attractive source for novel drugs leads.

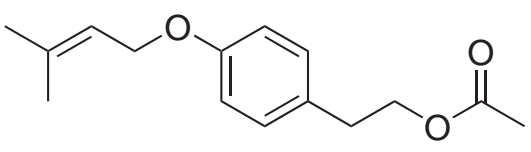

20

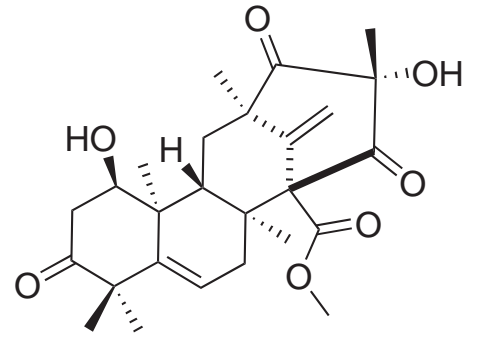

22

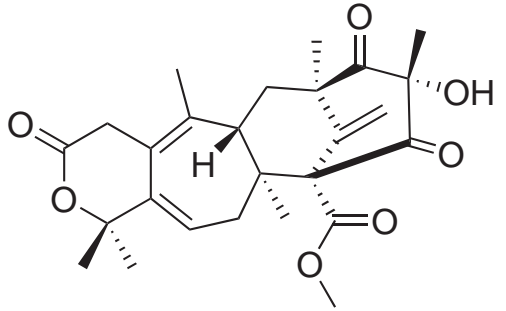

21<smiles>CCCCC[C@@H]1Cc2c(O)c(C(=O)O)cc3c2[C@@H](C[C@@]2(OC[C@H](CC(=O)[C@](C)(CC)C(=O)OC)[C@@H]2C)O3)O1</smiles>

23 


\subsection{Isolation Guidance for Natural Products}

The aim of natural products research is to provide chemists with novel unique chemical structures that possess potentially useful biological activity. In order to prioritise which cultures or organisms contain interesting secondary metabolites, an initial screen is carried out on the cultures or extracts to scan for the presence of such compounds. Semipurified fractions from the screen or a bulk-scale processing of the chosen organism(s) are then further fractionated using various types of chromatography to isolate the desired metabolite(s) until they are pure enough for structure elucidation and biological profiling. The purification process is aided by a technique that can identify the presence of the desired metabolite at each step of fractionation. The technique used to initially screen for interesting metabolites is usually also used to guide the isolation process. Bioassayguided and Nuclear Magnetic Resonance (NMR) spectroscopy-guided isolation are two contrasting techniques that are currently used to aid natural product isolation at VUW. The advantages and disadvantages of both techniques are discussed below.

\subsubsection{Bioassay-Guided Isolation}

Bioassay-guided isolation is the most commonly used guidance technique for isolating novel and bioactive secondary metabolites from microorganisms. ${ }^{44}$ The main goal of this technique is to screen for the presence of bioactive compounds. After each step of fractionation, a bioassay is carried out on every fraction and only those possessing bioactivity are further purified and screened using the same bioassay, thus allowing purification of the compound responsible for the bioactivity. The obvious advantage of using this technique is that a compound that possesses some type of bioactivity is almost always isolated. The type of bioactivity exhibited by the compound depends on the type of bioassay(s) used to track the isolation process. ${ }^{45}$ An ideal bioassay would be highly sensitive to small amounts of active material, selective to the specific bioactivity, cost effective and easy to run and maintain. ${ }^{46}$ In general, there are two broad classes of bioassays that can be used for screening: cell-based (cytotoxicity) and enzyme-based bioassays. $^{46}$ 
Cell-based assays test the interactions of the compounds within a fraction with whole intact cells. These assays measure cytotoxicity, or the ability of the compounds present to simply kill or inhibit the proliferation of cells in culture. ${ }^{45}$ An advantage of cell-based assays is that they eliminate fractions containing compounds that are unable to enter or that are rapidly metabolised by the cell, characteristics which are unwanted in a drug. ${ }^{47}$ Though it is usually not possible to determine the exact mode of action of the compounds with these assays, a wide range of active compounds can be detected, giving these assays a higher hit rate than enzyme-based assays. ${ }^{46}$ The ability to screen for a wide variety of active compounds can also serve as a disadvantage in that it makes these assays much less specific and compounds present in low concentrations may not be detected even if they are bioactive, due to the presence of other bioactive compounds in higher concentrations. Another disadvantage of these assays is that they are much more time consuming than enzyme-based assays and often take a few days instead of a few hours. However, the use of whole cells in these assays makes them much more comparable to in vivo processes and serves as the major advantage in using them for bioactive natural product screening. ${ }^{44}$

Enzyme-based assays measure interactions of the compounds in a fraction with a single drug target, usually a specific enzyme or receptor protein. These assays are highly sensitive and only take a few hours to carry out, making them amenable to highthroughput screening and automation. ${ }^{48}$ Although there is an advantage of obtaining a compound with a known target and potential mechanism of specific activity, ${ }^{46}$ this method has several disadvantages. Compounds that are not active in the enzyme-based assay may be active in vivo if the compound acts by a different mechanism or if the inactive compound is metabolised in vivo to an active analogue. Conversely, compounds that are active in the assay may not be active in vivo if the compound does not penetrate the cell membrane. ${ }^{47}$ Despite these disadvantages, enzyme-based assays are still widely used due to their higher specificity and efficiency over cell-based assays.

As mentioned above, bioassay-guided isolation almost always leads to the isolation of a bioactive compound. However, this technique suffers from several drawbacks. The cost of running bioassays on each fraction after each step can be quite high depending on the type of bioassay. There is no way to eliminate the isolation of known compounds with 
this technique since structure elucidation is only carried out after the active compound is isolated. Additionally, novel compounds that do not exhibit bioactivity in the selected assays will not be isolated. The major disadvantage however, is that valuable amounts of the active compound are being wasted after each step of fractionation since samples cannot be recovered after a bioassay, and this could lead to an insufficient amount of the pure compound for structural identification at the end, be it novel or known.

\subsubsection{NMR Spectroscopy-Guided Isolation}

NMR-guided isolation is a useful technique for isolating novel chemotypes. The premise of this method is that novel chemotypes should possess novel biological activity as secondary metabolites are biochemically expensive to produce and therefore production of inactive natural products should have been lost via natural selection. ${ }^{1}$ After each step of fractionation, 1D ( ${ }^{1} \mathrm{H}$ NMR) or 2D (COSY, HSQC, HMBC) NMR spectra are obtained for each fraction. The isolation process is tracked by comparing NMR signals from parent fractions with their daughter fractions, with further fractionation of only those daughter fractions that contain the NMR signals of the interesting compounds highlighted in the original fraction. Using 1D and 2D NMR spectra, substructures of compounds present in a single fraction can be identified and these can be submitted to database searches (MarinLit, ${ }^{49}$ AntiBase, ${ }^{50}$ Scifinder Scholar, ${ }^{51}$ etc.) resulting in a list of known compounds. If a compound in the fraction shows similar NMR signals to a compound in the list, the purification process of this compound can be discontinued. This allows for the identification of known compounds as early as possible during the isolation process to avoid unnecessary work on uninteresting compounds, a process known as dereplication, and thus is a major advantage of the NMR-guided method over bioassayguided isolation. ${ }^{52}$

The NMR-guided isolation technique also allows for the targetting of more than one novel compound from a single fraction. Moreover, there is no loss of valuable amounts of the novel compound as samples can be recovered after obtaining NMR spectra. ${ }^{53}$ After purification and structure identification of the novel compounds, bioassays such as those 
discussed above can be run to establish their activity, if any. This method provides an efficient way of isolating several, if not all, novel potentially bioactive secondary metabolites from a bacterial culture. The disadvantages of this method are that it is slower and less amenable to automation. It is also possible that any isolated novel compounds may not possess bioactivity in the chosen bioassays. However, this should not be seen as a major disadvantage as it still leads to the discovery of novel unique chemical structures that potentially exhibit a novel biological activity, which can be tested by using modern genome wide screens such as yeast chemical genetics that are good for broad bioactivity determination. ${ }^{54}$ Due to the advantages of this method over bioassay-guided isolation and for the purpose of isolating novel secondary metabolites from microbes, NMR spectroscopy-guided isolation is used during this project.

\subsection{Techniques for Isolation of Secondary Metabolites}

A bioactive secondary metabolite must usually possess both hydrophobic and hydrophilic (i.e. they must be amphiphilic) characteristics that enable the molecule to easily transverse through cell membranes and other biological barriers. ${ }^{55}$ Cultures and crude extracts of organisms will initially contain a wide range of compounds with varying degrees of polarity, ranging from polar amino acids, salts and sugars to non-polar fats, lipids and steroids. ${ }^{52}$ Due to their amphiphilic nature, most secondary metabolites will elute between the polar and non-polar extremes from a chromatographic stationary phase. This is best explained in terms of a mass window (Figure 1.1), where the intermediate region of the window usually contains most of the secondary metabolites but only a small amount of mass due to the absence of primary metabolites. This feature makes the mass window an ideal target during the first stage of fractionation of a culture or extract.

\subsubsection{Cyclic Loading and Back Loading}

Cyclic loading is a technique developed by Northcote and West to fractionate crude extracts of marine invertebrates by separating the undesirable highly polar salts and primary 


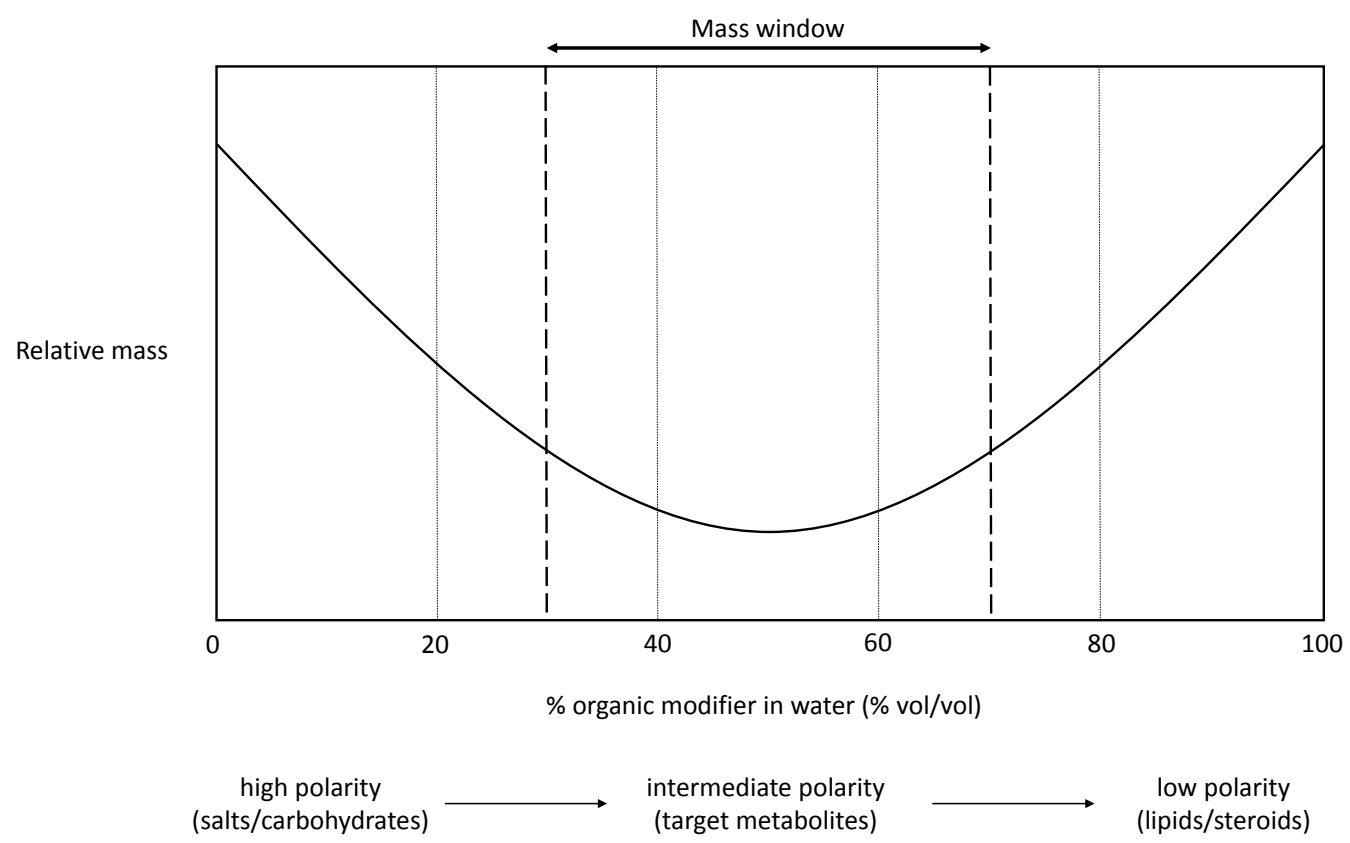

Figure 1.1. Typical mass distribution in a microbial culture or extract eluted from a reversed-phase stationary phase.

metabolites (both polar and non-polar) from amphiphilic compounds of interest. ${ }^{52,56}$ The technique utilises reversed-phase poly(styrenedivinylbenzene) (PSDVB) as the stationary phase. PSDVB is an inexpensive, chemically inert, crosslinked polymeric resin that is highly porous, lacks polar sites, and is stable over a large $\mathrm{pH}$ range. It is also fully reusable and provides reproducible chromatography. ${ }^{52}$

The first stage of cyclic loading involves passing the extract through the PSDVB column. This allows most of the non-polar compounds in the extract to adhere to the PSDVB beads. The eluent is then diluted to $50 \%(\mathrm{v} / \mathrm{v})$ of its concentration by the addition of water. Addition of water to a crude extract would usually result in the precipitation of non-polar compounds but this does not happen with cyclic loading, as most of the nonpolar fats and triglycerides would have adsorbed to the column during the first pass and will no longer be present in the diluted extract. The diluted extract is then passed through the same column again, with the mid polar compounds adsorbing to the PSDVB (Figure 1.2). As the eluent is gradually made more polar by each dilution with water, more polar compounds in the extract are adsorbed to the column. The cyclic process is repeated until all the compounds of interest are adhered to the PSDVB, usually when the extract is $25 \%$ or $12.5 \%(\mathrm{v} / \mathrm{v})$ of its original solvent concentration. The column is then washed with water to remove any salts, and then eluted using a stepwise or a gradient system 


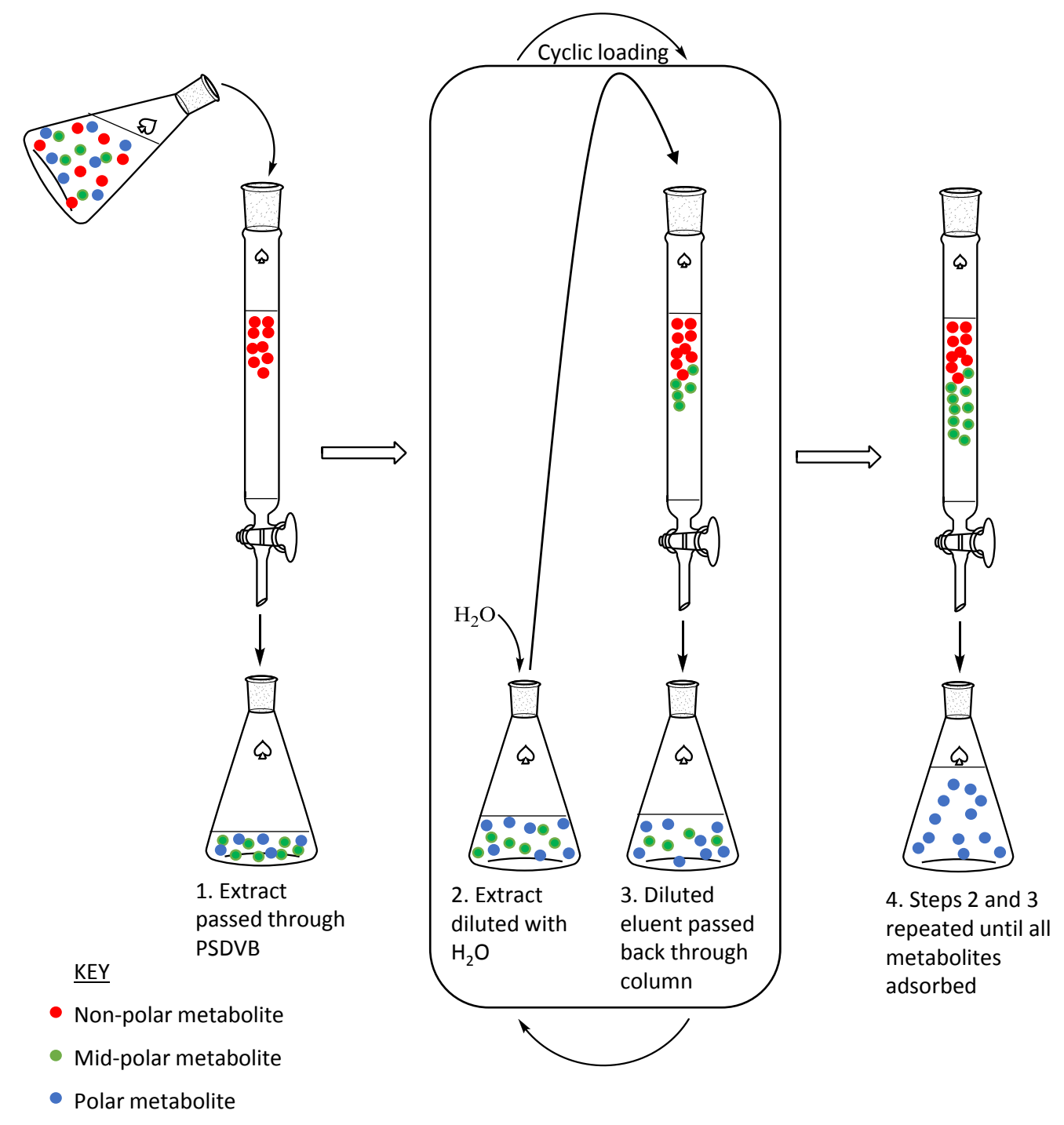

Figure 1.2. Cyclic loading.

of increasing organic modifier $\left(\mathrm{Me}_{2} \mathrm{CO}\right.$ or $\left.\mathrm{MeOH}\right)$ in water, which results in fractions of decreasing polarity. Thus, the earlier fractions will contain polar metabolites and the later fractions will contain non polar metabolites, with the mid polar secondary metabolites contained in the fractions collected in between.

Reversed-phase chromatography often generates many samples with high water content, which are time-consuming and sometimes difficult to evaporate under reduced pressure as they often "bump". This problem can be overcome by using an extension of the cyclic loading method, back loading. The technique involves cyclic loading the fraction that contains water onto a smaller PSDVB column as described above. A smaller column can be used as the mass contained within the fraction of interest will only be a small proportion of that contained in the original parent fraction. The column is then eluted 
with a small amount of pure organic solvent, generating a fraction which is much easier to evaporate with less bumping. Back loading can also be used to adsorb compounds in a fraction to a small amount of stationary phase, which can then be transferred as a slurry to a larger column for better chromatographic separation of the fraction. ${ }^{52}$

\subsubsection{VUW Screening Method}

Our approach to screening organisms and isolating interesting novel compounds is to analyse their extracts by 1D and 2D NMR spectroscopy. The cyclic loading method is used to pass the extracts through a PSDVB column. For the initial crude separation, the column is eluted with $30 \% \mathrm{Me}_{2} \mathrm{CO} / \mathrm{H}_{2} \mathrm{O}, 75 \% \mathrm{Me}_{2} \mathrm{CO} / \mathrm{H}_{2} \mathrm{O}$ and $100 \% \mathrm{Me}_{2} \mathrm{CO}$ to give three fractions. As discussed above, the $30 \%$ fraction should contain the most polar compounds and the $100 \%$ fraction should contain the most non-polar compounds. The secondary metabolites of interest should, therefore, elute in the mid-polar $75 \%$ fraction. The back loading technique is used to reduce water content in the $30 \%$ and $75 \%$ $\mathrm{Me}_{2} \mathrm{CO} / \mathrm{H}_{2} \mathrm{O}$ fractions. Fractions obtained from the screens are then further fractionated, with emphasis on the mid-polar fractions. Fractionation is carried out using different types of chromatography including normal and reversed-phase, size exclusion and HPLC for final steps of purification. NMR spectra are obtained for all fractions following each stage of purification.

\subsection{Research Aims}

Bioactive natural products have been isolated from a multitude of microbial species. As terrestrial and freshwater microbes were easily available and culturable, initial natural product research was focussed on these microbes which led to the isolation of many novel drugs and drug leads. However, due to the realisation that there are large numbers of unexplored microbial species in the marine and extreme environments, these microbes have recently been given the spotlight for natural product research. Moreover, their ability to survive in their unique environments allows them to produce unique metabolites 
that serve as novel scaffolds for drugs and drug leads. Many bioactive metabolites have already been isolated from these microbes, and many more are left to be discovered. It is due to this reason that this research was aimed at validating and extending the use of the VUW NMR-guided screening method for the isolation of secondary metabolites from New Zealand extremophilic microbes.

Isolation of the secondary metabolites was carried out using an adapted version of the VUW screening method (described in Chapter 2) and was guided by NMR spectroscopy. Once a compound was purified, structure elucidation was carried out using mass spectrometry (MS) and both 1D and 2D NMR spectroscopy. After structure elucidation, interesting compounds were tested for their bioactivity using one or both classes of bioassays discussed in Section 1.3.1. 


\section{Chapter 2}

\section{Extremophilic Microbes Investigated by Spectroscopic}

\section{Screening}

The microbes investigated in this research were chosen according to their availability as cultures from GNS Science and Callaghan Innovation. During the course of this research, a total of 10 microbial strains (nine bacteria and one fungus) were screened to establish their secondary metabolic profiles. The details of nine microbial strains that were isolated from areas in the Taupo Volcanic Zone (TVZ) and the results of their screens are described in this chapter. A detailed investigation of a marine Shewanella sp. was also carried out during this research and led to the isolation and identification of several 2,5-diketopiperazines. These results are discussed in detail in Chapter 3. The culture conditions for all the investigated microbes are presented in Appendix A.

For strains NGM11.1, NGM22.9, WAP10.3.2, WC14 and WK1, the isolated strain met the phylogenetic requirements to be considered the same as species described (based on $16 \mathrm{~S}$ rRNA gene sequence similarity), and therefore for the purposes of the following sections were treated as having the same general genetic and phenotypic characteristics. However, it should be noted that some phenotypic and genotypic characteristics may vary from the described strain due to horizontal gene transfer and other evolutionary factors.

\subsection{Taupo Volcanic Zone}

The TVZ stretches from Mount Ruapehu in Tongariro National Park, through Rotorua, to White Island in the Bay of Plenty (Figure 2.1), and is responsible for most of New Zealand's current volcanic activity. The zone is approximately $300 \mathrm{~km}$ long and up to $60 \mathrm{~km}$ wide and consists of numerous volcanic vents and geothermal fields. It includes three frequently active cone volcanoes (Mount Ruapehu, Mount Ngauruhoe and White Island), and two of the most productive calderas (large, deep craters caused by volcanic 


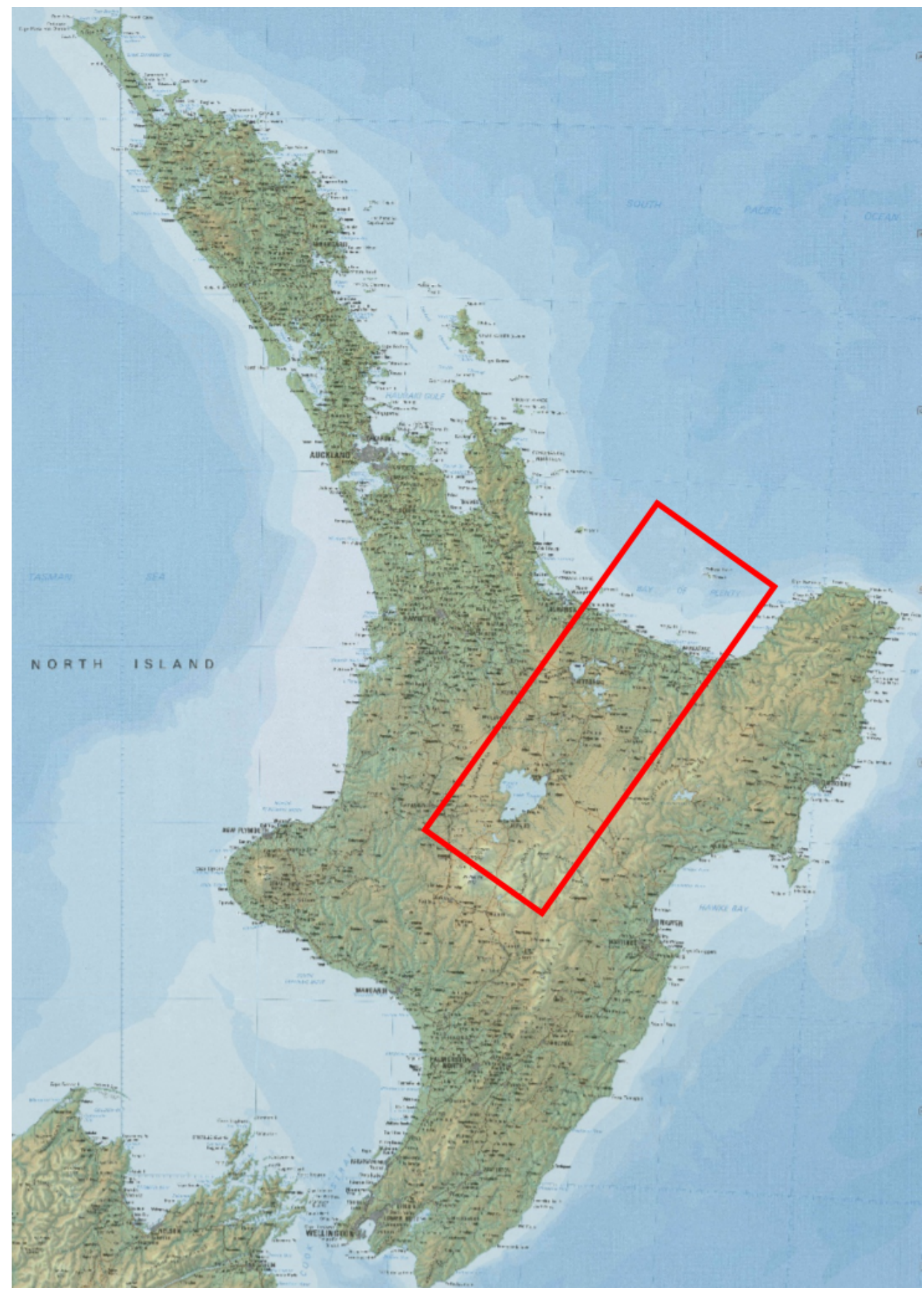

Figure 2.1. Taupo Volcanic Zone (highlighted in red) in the North Island, New Zealand. Sourced from Land Information New Zealand.

eruptions) in the world (Okataina and Taupo). The geothermal fields within this region exhibit a wide range of geothermal features including hot and boiling springs and streams, geysers, silica sinter deposits, mudpools, fumaroles, hot and steaming ground, altered ground and hydrothermal eruption craters, and many more. The hot water from these areas may form underground reservoirs that can be drilled to provide hot water and steam for electricity generation (e.g. Wairakei Power Station, which has now been operating for 
almost 50 years) or other industrial and heating applications. However, these features are very susceptible to damage from activities associated with all forms of land modification, but particularly farming, forestry and mining (e.g. for sulphur). These geothermal regions contain organisms that have evolved to withstand high temperatures and/or highly acidic conditions, and are potentially unique to these areas. As there have been no reports of secondary metabolites from microbes that reside in the geothermal fields of the TVZ, they remain an attractive target for natural product research. Moreover, it is important to explore these microbes in terms of their metabolic profiles before their habitats are compromised due to land modification.

\subsection{Adapted Screening Method}

The VUW screening method described in Section 1.4.2 has been used successfully in the VUW Natural Products laboratory for screening extracts of marine invertebrates and macroalgae. However, this method has not been tested on microbial cultures and, therefore, had to be adapted for the screening of microbes. The microbial cultures containing the metabolites were water-based and also contained some cell mass. To separate the cell mass from the supernatant, each microbial culture was filtered using filter paper and celite. The supernatant was passed through a PSDVB column. The cyclic loading method was not used for loading the supernatant as it was essentially water-based and thus could not be made more polar. Instead, the supernatant was passed through the column more than once to ensure that all or most of the compounds had adsorbed onto the PSDVB resin by increasing the residence time of the supernatant. The filtered cell mass was extracted in $\mathrm{MeOH}$ and the cyclic loading method was used to pass the cell mass extract through another PSDVB column. The columns were then batch eluted separately with $30 \% \mathrm{Me}_{2} \mathrm{CO} / \mathrm{H}_{2} \mathrm{O}, 75 \% \mathrm{Me}_{2} \mathrm{CO} / \mathrm{H}_{2} \mathrm{O}$ and $100 \% \mathrm{Me}_{2} \mathrm{CO}$ and the fractions were analysed by NMR. This initial crude separation step was carried out for both the supernatant and cell mass from all the cultures. 


\subsection{Investigation of Thermus filiformis (NGM11.1)}

Thermus filiformis is a Gram-negative, thermophilic, filamentous bacterium that was first isolated in 1987 by Hudson et al. from a New Zealand hot spring. ${ }^{57}$ Following its isolation, research on this bacterium was focussed on the characterisation of its enzymes such as nucleases, DNA polymerases, ligases and $\alpha$-amylases for applications in DNA replication. ${ }^{58-60}$ NMG11.1 was isolated from Radiata Pool (Figure 2.2) at the Ngatamariki Power Station located $17 \mathrm{~km}$ northeast of Taupo. At the time of isolation, the pool water was at a temperature of $68^{\circ} \mathrm{C}$ and a pH of 7.2. Phylogenetic studies of this isolate carried out at GNS Science identified it as T. filiformis.

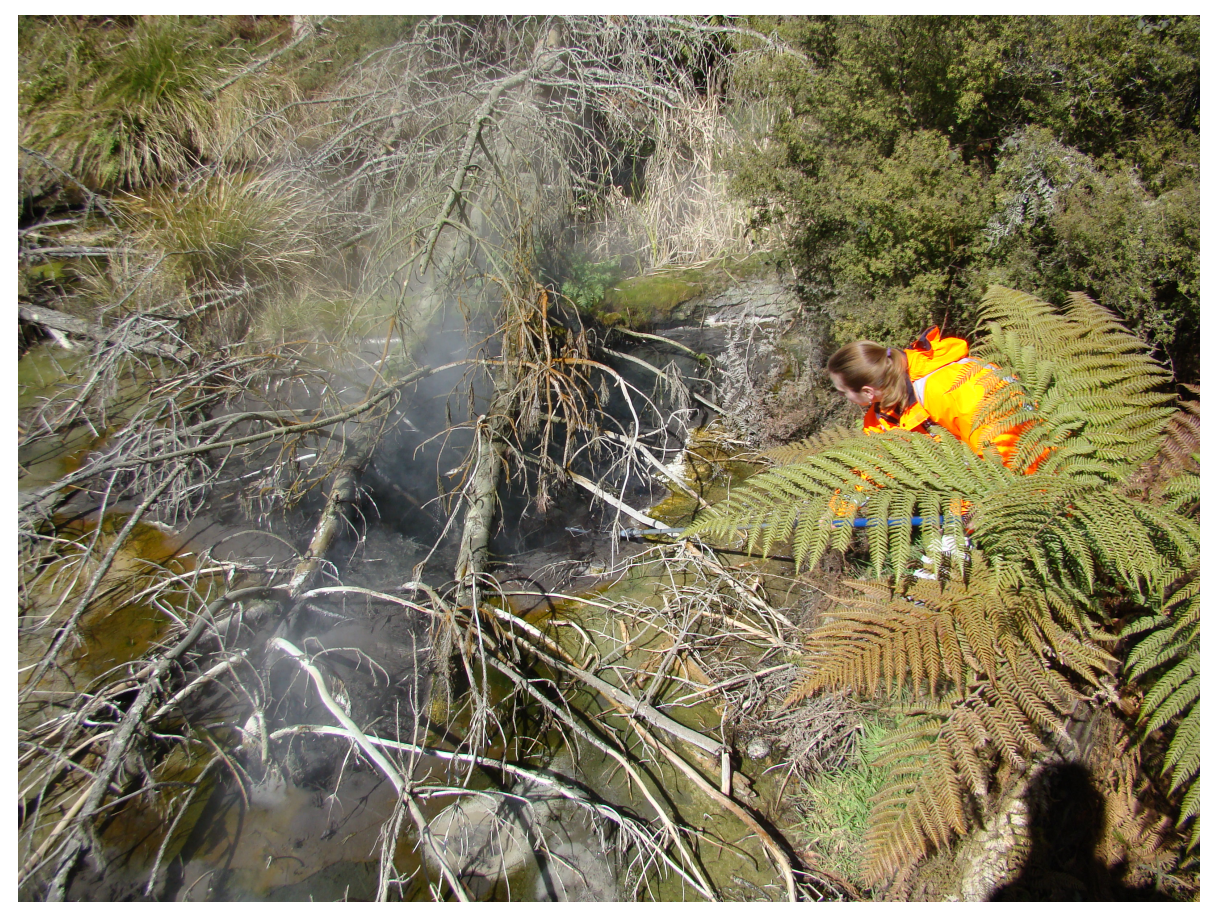

Figure 2.2. Isolation site of NGM11.1 and NGM22.9. Image courtesy of Matthew Stott, GNS Science.

A 3 L culture of NGM11.1 and cell mass extract were screened as described above. The

${ }^{1} \mathrm{H}$ NMR spectra of the $75 \% \mathrm{Me}_{2} \mathrm{CO}$ fractions from the culture filtrate (CDB02_09E) and cell mass extract (CDB02_11E) showed many major resonances pertaining to the culture medium, which masked possible metabolite signals. However, a few unique peaks were observed (highlighted in Figure 2.3), but these were not pursued further due to lack of available biomass. 


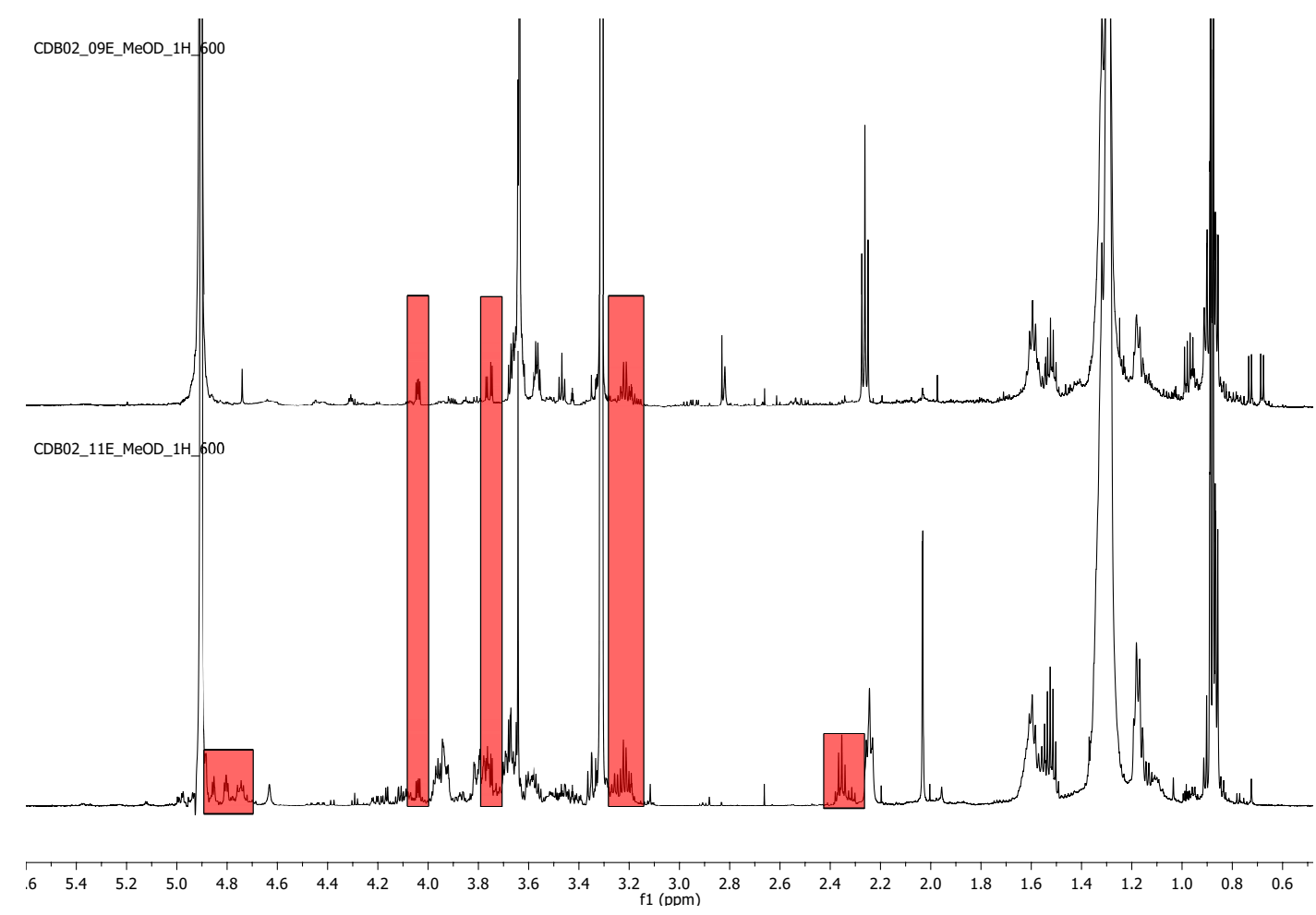

Figure 2.3. Spectral comparison of the $75 \% \mathrm{Me}_{2} \mathrm{CO}$ fractions from the NGM11.1 culture filtrate (top) and cell mass extract (bottom) with unique resonances highlighted $\left(600 \mathrm{MHz}, \mathrm{CD}_{3} \mathrm{OD}\right)$.

\subsection{Investigation of Geobacillus stearothermophilus (NGM22.9)}

Geobacillus stearothermophilus is a Gram-positive, thermophilic, rod-shaped bacterium. Since its first isolation in $1920,{ }^{61}$ it has been extensively researched for its thermostable enzymes. However, over the past few years, research on G. stearothermophilus has focussed on its role in the spoilage of food. The spores of this bacterium are highly heat-resistant and this property makes it useful as a biological indicator for evaluation of sterilisation processes. ${ }^{62}$ NMG22.9 was isolated at the same site as NGM11.1 (Figure 2.2). Phylogenetic studies of this isolate carried out at GNS Science identified it as $G$. stearothermophilus.

A 1 L culture of NGM22.9 and cell mass extract were screened as described above. The ${ }^{1} \mathrm{H}$ NMR spectrum of the $75 \% \mathrm{Me}_{2} \mathrm{CO}$ fraction from the culture filtrate showed no significant peaks other than those belonging to the culture medium. As a result, no further investigation was done on this microbe. 


\subsection{Investigation of Anoxybacillus amylolyticus}

\section{(WAP10.3.2)}

Anoxybacillus amylolyticus is a Gram-positive, rod-shaped, thermophilic bacterium that was first isolated in 2006 by Poli et al. from geothermal soil at Mount Rittmann in Antartica. ${ }^{63}$ Its very recent identification makes it a relatively unexplored microbe. In the past few years, research on this bacterium has been focussed on the effects of heavy metals on its $\alpha$-amylase production. ${ }^{64}$ WAP10.3.2 was isolated from lake-side sediments and gravel found at the Waipahihi foreshore in Taupo. The sediments at the isolation site were at a temperature of $66.9^{\circ} \mathrm{C}$ and a $\mathrm{pH}$ of 6.5. Phylogenetic studies of this isolate carried out at GNS Science identified it as A. amylolyticus.

A $1 \mathrm{~L}$ culture of WAP10.3.2 and cell mass extract were screened as described above. Some unique proton resonances were seen in the ${ }^{1} \mathrm{H}$ NMR spectrum of the $75 \% \mathrm{Me}_{2} \mathrm{CO}$ fraction (CDB01_92E) from the cell mass extract (highlighted in Figure 2.4). However, due to lack of biomass, this microbe was not investigated further.

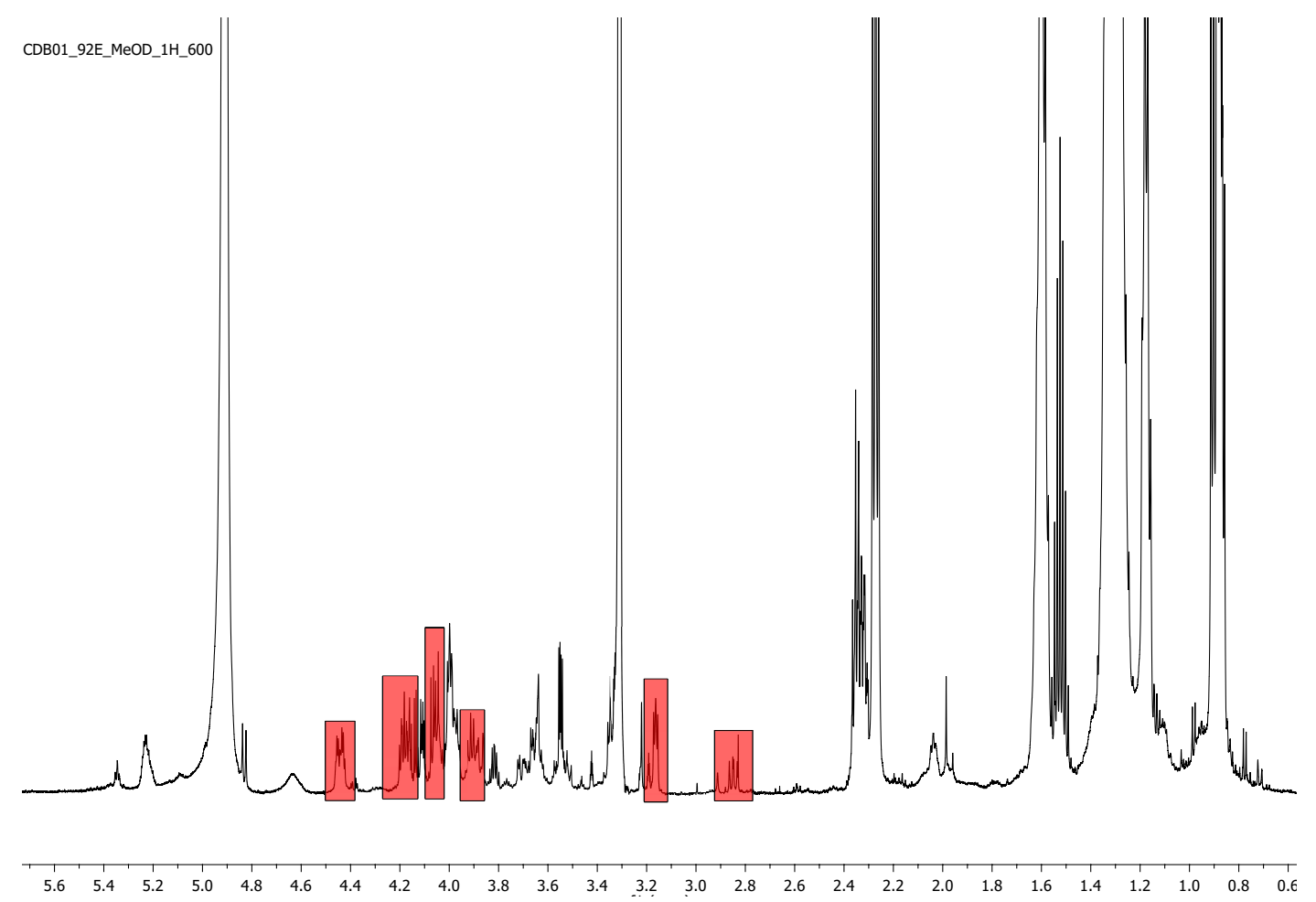

Figure 2.4. ${ }^{1} \mathrm{H}$ NMR spectrum of the $75 \% \mathrm{Me}_{2} \mathrm{CO}$ fraction from the WAP10.3.2 cell mass extract with unique resonances highlighted $\left(600 \mathrm{MHz}, \mathrm{CD}_{3} \mathrm{OD}\right)$. 


\subsection{Investigation of Thermomyces lanuginosus (WC14)}

Thermomyces lanuginosus, previously named Humicola lanuginosa, is a thermophilic fungus that was first isolated by Tsiklinskaya in 1899 from a potato that had been inoculated with garden soil and then kept at $52-53{ }^{\circ} \mathrm{C} .{ }^{65}$ This fungus has been studied over several decades for its production of thermostable enzymes. To date, a very large number of thermostable $T$. lanuginosus enzymes have been purified and characterised including lipases, amylases, xylanases, galactosidases, invertases, mannases, pectinases and many more. ${ }^{65-68}$ Many of these enzymes play an important role in the biochemical, food and paper industries. ${ }^{65}$ WC14 was isolated from a heated wood-chip pile in Taupo. Phylogenetic studies carried out at GNS Science identified it as T. lanuginosus.

A $2 \mathrm{~L}$ culture of $\mathrm{WC} 14$ and cell mass extract were screened as described above. The ${ }^{1} \mathrm{H}$ NMR spectrum of the $75 \% \mathrm{Me}_{2} \mathrm{CO}$ fraction from the culture filtrate showed no significant peaks other than those belonging to the culture medium. As a result, no further investigation was done on this microbe.

\subsection{Investigation of Anoxybacillus flavithermus (WK1)}

Anoxybacillus flavithermus is a species of Gram-positive, rod shaped, alkaliphilic and thermophilic bacteria that was first isolated from manure samples by Pikuta et al. in 2000. ${ }^{69}$ These bacteria form dark yellow colonies due to accumulation of a carotenoid pigment in their cell membrane. ${ }^{70}$ Different strains of A. flavithermus have been isolated from thermophilic environments in New Zealand. ${ }^{69,70}$ This species has been investigated for its production of moderately alkali-stable and heat-stable lignocellulolytic enzymes, particularly cellusases and xylanases. ${ }^{71}$ These enzymes have numerous uses in industrial applications, such as biobleaching of pulp and production of economical and environmentally friendly biofuels. This is also the only species of Anoxybacillus that produces these enzymes. ${ }^{71}$ In 2011, Liu et al. reported the isolation of the metabolite cyclo(L-Gly-L-Pro) (24) from A. flavithermus strain SX-4 via bioassay-guided fractionation of the culture broth. ${ }^{72}$ Compound $\mathbf{2 4}$ showed immunostimulatory effects in 
carp by significantly increasing phagocytic activity, superoxide anion production, serum lysozyme activity and immune-related gene expression. ${ }^{72}$ Since then, no other metabolites have been reported from this species.<smiles>O=C1NCC(=O)N2CCCC12</smiles>

A. flavithermus strain WK1 was isolated from silica-rich geothermal well water in a drain in the Wairakei Geothermal Power Station (Figure 2.5) located a few kilometres north of Taupo. At the time of isolation, the water was at a temperature of $65^{\circ} \mathrm{C}$ and a $\mathrm{pH}$ of 8.2.

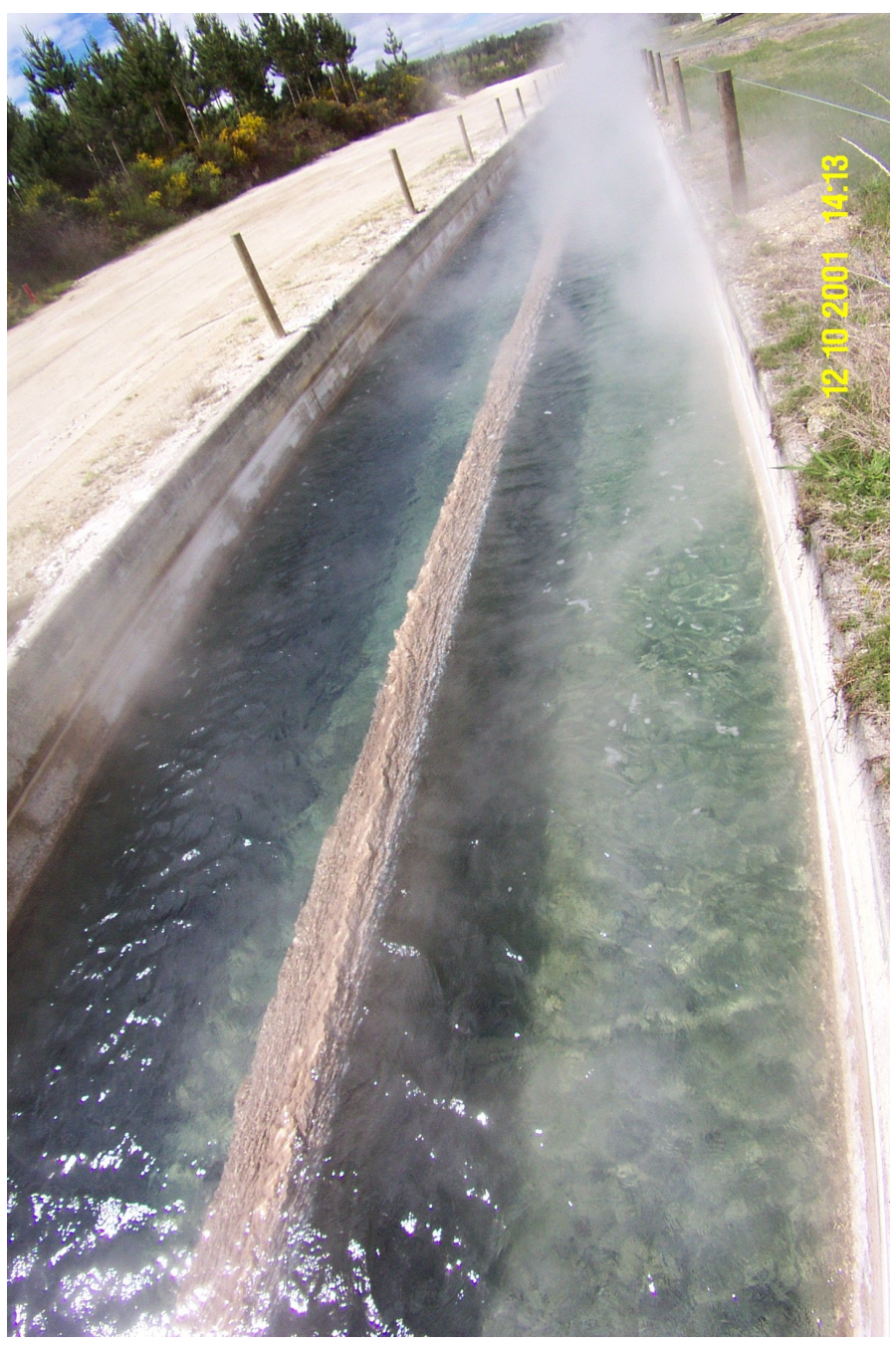

Figure 2.5. Isolation site of A. flavithermus WK1. Image courtesy of Matthew Stott, GNS Science. 


\subsubsection{Isolation of a Known Compound from A. flavithermus}

A $2 \mathrm{~L}$ culture of $A$. flavithermus was screened as described above. The $75 \% \mathrm{Me}_{2} \mathrm{CO} / \mathrm{H}_{2} \mathrm{O}$ fraction from the culture filtrate was then further separated on a reversed-phase column (HP20ss) using $\mathrm{MeOH} / \mathrm{H}_{2} \mathrm{O}$ mixtures of decreasing polarity with the final elution in $100 \% \mathrm{MeOH} .{ }^{1} \mathrm{H} \mathrm{NMR}$ spectra were obtained on all fractions and the spectrum of the final $\mathrm{MeOH}$ fraction, CDB01_68E, showed aromatic signals belonging to a single compound. 1D and 2D NMR spectroscopic analysis of this fraction identified the compound as a known $\beta$-carboline compound.

The molecular formula $\mathrm{C}_{13} \mathrm{H}_{10} \mathrm{~N}_{2} \mathrm{O}$ was determined for CDB01_68E by positive ion HRESIMS from the $[\mathrm{M}+\mathrm{H}]^{+}$adduct at $\mathrm{m} / z 211.0868(\mathrm{~m} / z \Delta=0.0002)$, requiring 10 double bond equivalents (DBEs). The ${ }^{13} \mathrm{C}$ NMR spectrum contained 13 signals, accounting for all the carbons in the molecule. The ${ }^{1} \mathrm{H}$ NMR spectrum (DMSO- $\mathrm{d}_{6}$ ) showed eight distinct proton signals that accounted for all 10 protons in the molecule. An HSQC experiment confirmed the attachment of six protons to different carbon atoms and three protons to one carbon atom, confirming the presence of a methyl group. This indicated that the one remaining proton resonance was that of an exchangeable proton $\left(\delta_{H}\right.$ 11.90). Six aromatic proton signals were seen in the ${ }^{1} \mathrm{H}$ NMR spectrum, with four of these signals belonging to one spin system $\left(\delta_{H} 8.30,7.81,7.59,7.30\right)$, and the other two to another spin system $\left(\delta_{H} 8.51,8.45\right)$. COSY correlations between aromatic protons H-5 $\left(\delta_{H} 8.30 ; \delta_{C} 121.9\right)$ and H-6 $\left(\delta_{H} 7.30 ; \delta_{C} 120.2\right), \mathrm{H}-6$ and H-7 $\left(\delta_{H} 7.59 ; \delta_{C} 129.0\right)$, and H-7 and H-8 $\left(\delta_{H} 7.81 ; \delta_{C} 113.1\right)$ established the connection between C-5 and C-8. HMBC correlations from H-5 to C-7, H-6 to C-8, H-7 to C-5 and H-8 to C-6 confirmed the presence of this connection and the presence of the four aromatic protons in the same spin system (Figure 2.6).

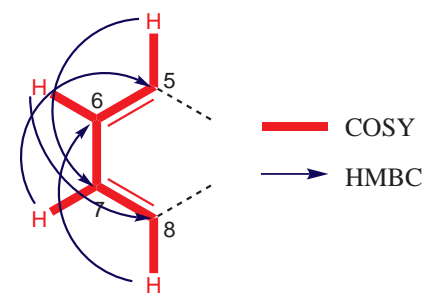

Figure 2.6. COSY and HMBC correlations confirming the connection between C-5 and C-8 in CDB01_68E. 
HMBC correlations were also seen from H-6 and H-8 to non-protonated C- $4 \mathrm{~b}\left(\delta_{C} 119.9\right)$ along with HMBC correlations from H-5 and H-7 to non-protonated C- $8 \mathrm{a}\left(\delta_{C} 141.9\right)$. These correlations confirmed the presence of a 1,2-disubstituted benzene substructure in the molecule (Figure 2.7).

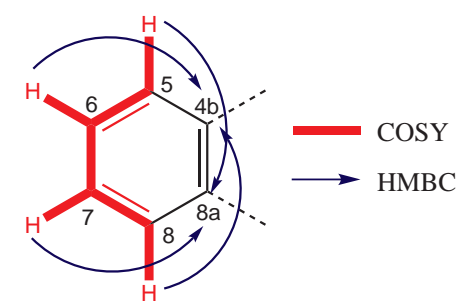

Figure 2.7. COSY and HMBC correlations establishing the 1,2-disubstituted benzene ring in CDB01_68E.

A strong HMBC correlation was observed between methyl $\mathrm{CH}_{3}-11\left(\delta_{H} 2.79 ; \delta_{C} 26.0\right)$ and non-protonated deshielded C-10 $\left(\delta_{C} 201.4\right)$, suggesting the presence of an acetyl group in the molecule. Furthermore, the highly deshielded exchangeable proton resonance $\left(\delta_{H}\right.$ 11.90) with no COSY correlations was indicative of a secondary amine moiety. A database search was carried out using MarinLit and Scifinder Scholar in order to find compounds that contained a disubstituted benzene ring, an acetyl group and a secondary amine. The search yielded 1 -acetyl- $\beta$-carboline (25) as a candidate compound with 10 double bond equivalents. Comparison of NMR data in the literature ${ }^{73}$ to those obtained with 1-acetyl- $\beta$-carboline (Table 2.1) showed that the data were identical, confirming that the compound isolated was 1 -acetyl- $\beta$-carboline (25).

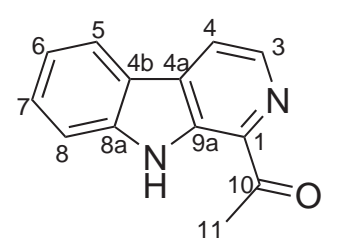

25

\subsubsection{Biological Activity of 1-Acetyl- $\beta$-carboline}

$\beta$-Carbolines are a subclass of indole alkaloids that are commonly found in plants but can also be produced by some animals and microorganisms. Due to the large number of substituents and/or substitution patterns found in $\beta$-carbolines, these alkaloids display a large variety of physiological and pharmacological properties. ${ }^{74} 1$-Acetyl- $\beta$-carboline 
Table 2.1. ${ }^{1} \mathrm{H}(600 \mathrm{MHz})$ and ${ }^{13} \mathrm{C}(150 \mathrm{MHz}) \mathrm{NMR}$ data for 1 -acetyl- $\beta$-carboline (25) (DMSO-d $\mathrm{d}_{6}$ )

\begin{tabular}{|c|c|c|c|c|c|c|c|}
\hline \multirow[b]{2}{*}{ Position } & \multicolumn{2}{|c|}{${ }^{13} \mathrm{C}$} & \multicolumn{3}{|c|}{${ }^{1} \mathrm{H}$} & \multirow[b]{2}{*}{ COSY } & \multirow{2}{*}{$\begin{array}{c}\text { HMBC } \\
\left({ }^{1} \mathrm{H} \text { to }{ }^{13} \mathrm{C}\right)\end{array}$} \\
\hline & $\delta(\mathrm{ppm})$ & mult & $\delta(\mathrm{ppm})$ & mult & $J(\mathrm{~Hz})$ & & \\
\hline 1 & 136.0 & $\mathrm{C}$ & - & - & - & - & - \\
\hline 3 & 137.5 & $\mathrm{CH}$ & 8.51 & $\mathrm{~d}$ & 4.8 & 4 & $1,4,4 \mathrm{a}$ \\
\hline 4 & 119.5 & $\mathrm{CH}$ & 8.45 & $\mathrm{~d}$ & 4.8 & 3 & $1,3,4 b, 9 a$ \\
\hline $4 a$ & 131.0 & $\mathrm{C}$ & - & - & - & - & - \\
\hline $4 \mathrm{~b}$ & 119.9 & $\mathrm{C}$ & - & - & - & - & - \\
\hline 5 & 121.9 & $\mathrm{CH}$ & 8.30 & d & 7.9 & 6 & $4 a, 7,8 a$ \\
\hline 6 & 120.2 & $\mathrm{CH}$ & 7.30 & $\mathrm{t}$ & 8.1 & 5,7 & $4 \mathrm{~b}, 8$ \\
\hline 7 & 129.0 & $\mathrm{CH}$ & 7.59 & $\mathrm{t}$ & 7.7 & 6,8 & $5,8 \mathrm{a}$ \\
\hline 8 & 113.1 & $\mathrm{CH}$ & 7.80 & d & 7.5 & 7 & $4 b, 6$ \\
\hline $8 a$ & 141.9 & $\mathrm{C}$ & - & - & - & - & - \\
\hline 9 & - & - & 11.90 & $\mathrm{~s}$ & - & - & $4 a, 4 b, 8 a, 9 a$ \\
\hline $9 a$ & 134.0 & $\mathrm{C}$ & - & - & - & - & - \\
\hline 10 & 201.4 & $\mathrm{C}$ & - & - & - & - & - \\
\hline 11 & 26.0 & $\mathrm{CH}_{3}$ & 2.79 & s & - & - & 1,10 \\
\hline
\end{tabular}

was first reported in 1977 from the plant Ailanthus malabarica. ${ }^{75}$ Since then, it has been reported as a metabolite of a marine sponge, T. ignis, ${ }^{75}$ and several marine and soil microorganisms. ${ }^{75-78}$ This compound has been shown to have cytotoxic effects on brine shrimp but possesses only marginal antimicrobial activity. ${ }^{75}$ Shin et al. recently described the antibacterial activity of 1-acetyl- $\beta$-carboline against methicillin-resistant Staphylococcus aureus (MRSA). ${ }^{79}$ The study concluded that 1 -acetyl- $\beta$-carboline and ampicillin can act synergistically against MRSA and that this combination could aid in reducing the emergence of MRSA in the future. ${ }^{79}$

Many $\beta$-carboline compounds function as monoamine oxidase (MAO) inhibitors. ${ }^{74}$ MAO is an enzyme responsible for breaking down monoamine neurotransmitters such as dopamine, serotonin, epinephrine, and many more. Inhibitors of this enzyme can thus be used for treatments of psychiatric disorders such as depression and schizophrenia as they prevent the breakdown of these neurotransmitters in the brain. ${ }^{80} 1$-Acetyl- $\beta$-carboline is structurally similar to the $\beta$-carboline compounds norharman (26) and harman (27), both of which are reversible inhibitors of human MAO. ${ }^{80}$ Consequently, CDB01_68E was investigated for its MAO inhibitory activity in assays carried out at Environmental Science and Research (ESR). However, no significant inhibition of the enzyme was observed. 


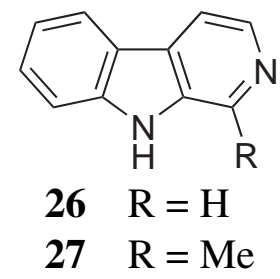

CDB01_68E was also submitted for testing at the School of Biological Sciences, VUW. Assays were carried out against the 1A9 ovarian cancer, S. aureus, Escherichia coli and Mycobacterium smegmatis cell lines. However, no significant cytotoxic or antimicrobial activity was seen at any of the tested concentrations, including the highest concentrations of $20 \mu \mathrm{M}$ (for the $1 \mathrm{~A} 9$ ovarian cancer cell lines) and $238 \mu \mathrm{M}$ (for the bacterial cell lines).

\subsection{Investigation of Chthonomonas calidirosea (T49)}

Strain T49 was isolated from steam-heated soil at Hell's Gate, Tikitere, in Rotorua (Figure 2.8). At the time of isolation, the soil was at a temperature of $62.6{ }^{\circ} \mathrm{C}$ and a $\mathrm{pH}$ of 4.5. Phylogenetic studies carried out at GNS Science revealed that this strain represents a new genus and species of Gram-negative, thermophilic bacteria. It was characterised and named Chthonomonas calidirosea by Lee et al. in 2010. ${ }^{81}$ An investigation into the fatty acid and lipid composition from the bacterial biomass was published by the same group in 2011. ${ }^{82}$ No other publications on this species of bacteria were found in the literature.

A $20 \mathrm{~L}$ culture of T49 and cell mass extract were screened as described above. The ${ }^{1} \mathrm{H}$ NMR spectrum of the $75 \% \mathrm{Me}_{2} \mathrm{CO}$ fraction from the culture filtrate was dominated by resonances belonging to the antifoam $\left(\delta_{H} 3.3-4 \mathrm{ppm}\right)$ used for culturing (Figure 2.9). To separate the antifoam from possible masked metabolites, size-exclusion chromatography (LH-20) was carried out on this fraction. ${ }^{1} \mathrm{H}$ NMR analysis showed that the antifoam had streaked through the column into all collected fractions. One of the LH-20 fractions (CDB01_79C) was subjected to further fractionation on a DIOL column. However,

${ }^{1} \mathrm{H}$ NMR analysis showed the antifoam to be the major component in all fractions and confirmed that no further separation was achieved. Due to the difficult mid-polar nature of the antifoam and the inability to separate it from any other compounds, further 
investigation on this microbe was discontinued.

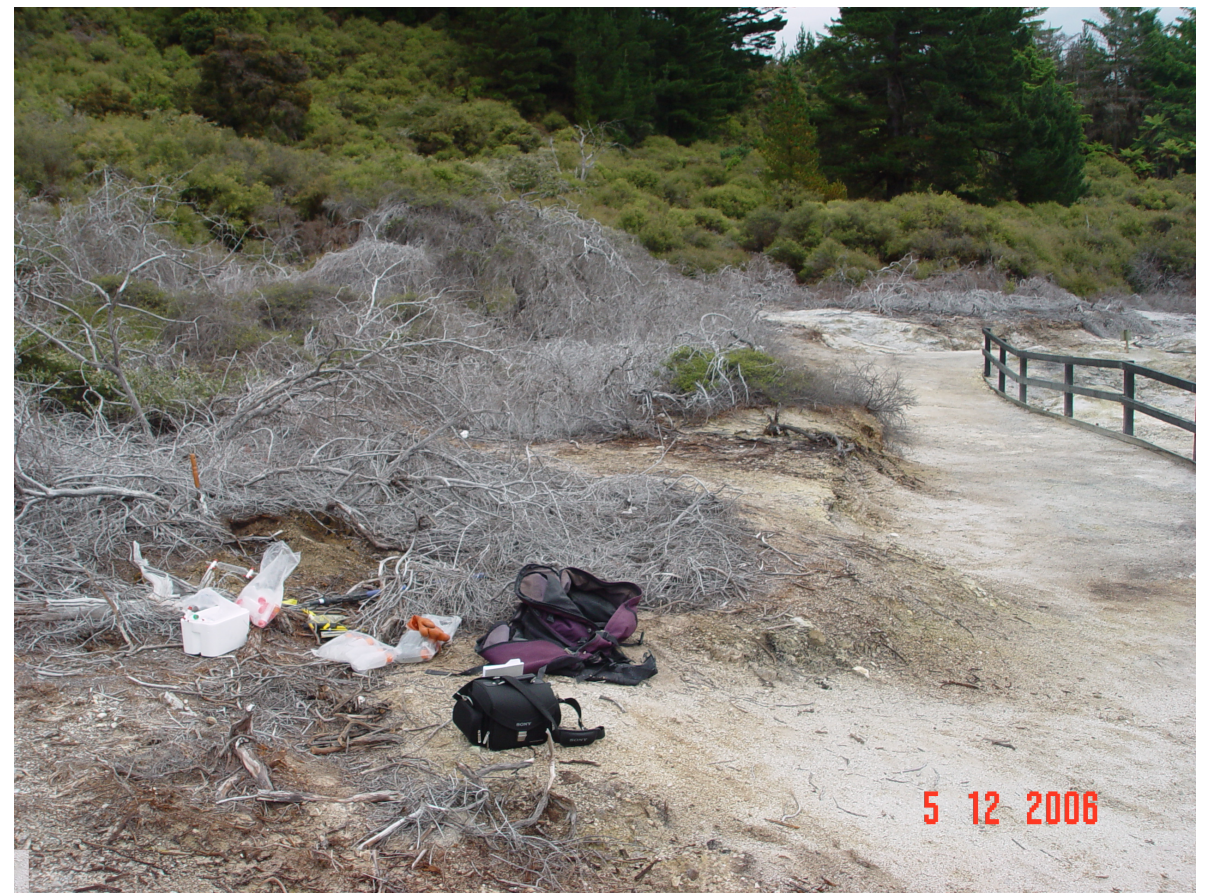

Figure 2.8. Isolation site of T49.

Image courtesy of Matthew Stott, GNS Science.

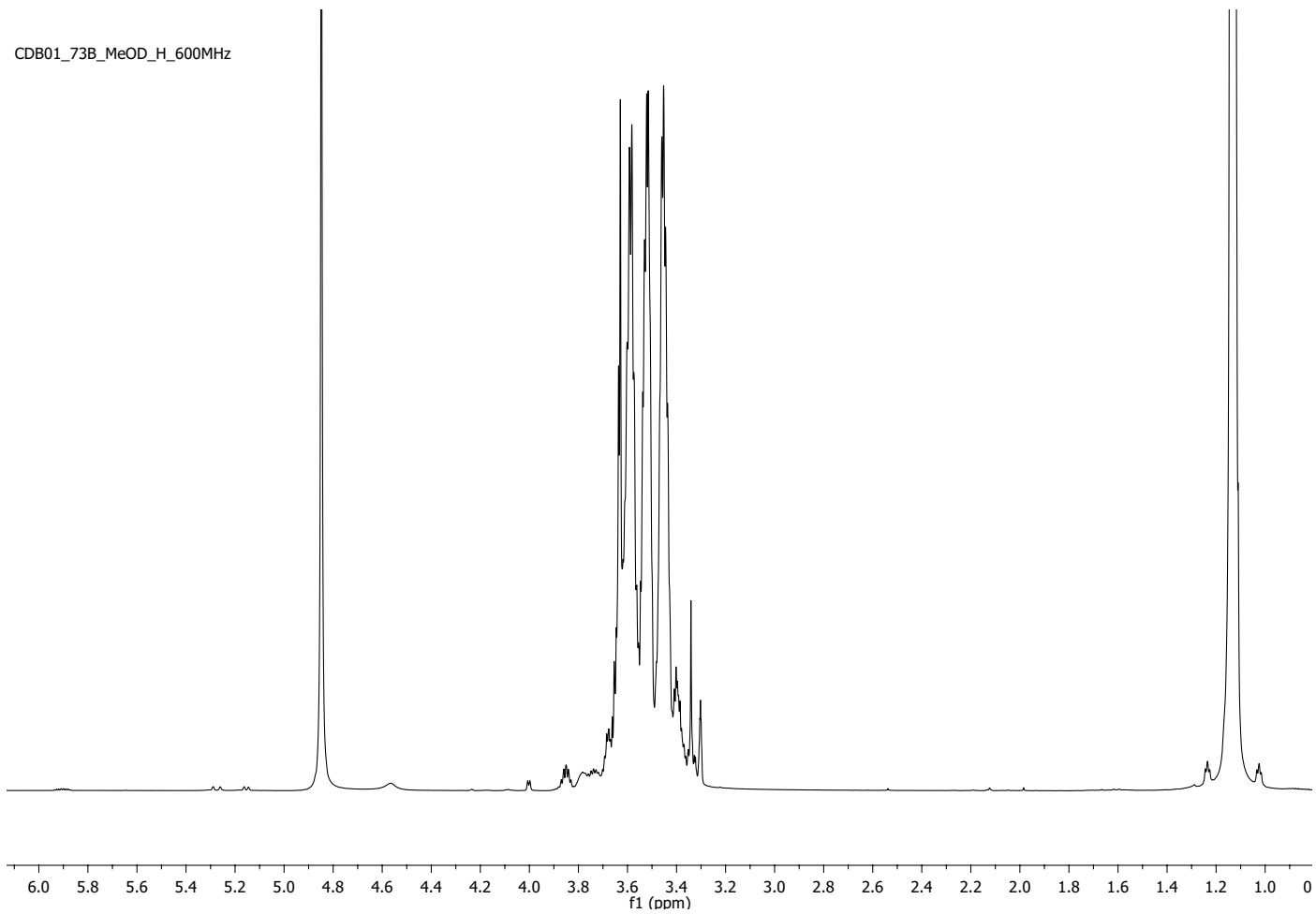

Figure 2.9. ${ }^{1} \mathrm{H}$ NMR spectrum of the $75 \% \mathrm{Me}_{2} \mathrm{CO}$ fraction from the culture filtrate of T49 showing antifoam peaks from 3.3-4 ppm (600 MHz, $\left.\mathrm{CD}_{3} \mathrm{OD}\right)$. 


\subsection{Investigation of Pyrinomonas methylaliphatogenes}

\section{(K22)}

Strain K22 was isolated from steam-heated soil on Mount Ngauruhoe (Figure 2.10) located $25 \mathrm{~km}$ south of the southern shore of Lake Taupo. At the time of isolation, the soil was at a temperature of $67.8^{\circ} \mathrm{C}$ and a pH of 6.88. Phylogenetic studies carried out at GNS Science revealed that this strain represents a new genus and species of Gram-negative, thermophilic, moderately acidophilic bacteria (Figure 2.11). It was characterised and named Pyrinomonas methylaliphatogenes by Crowe et al. in September $2013 .{ }^{83}$ The very recent isolation of this new strain means that there has been no research reported on it in the literature.

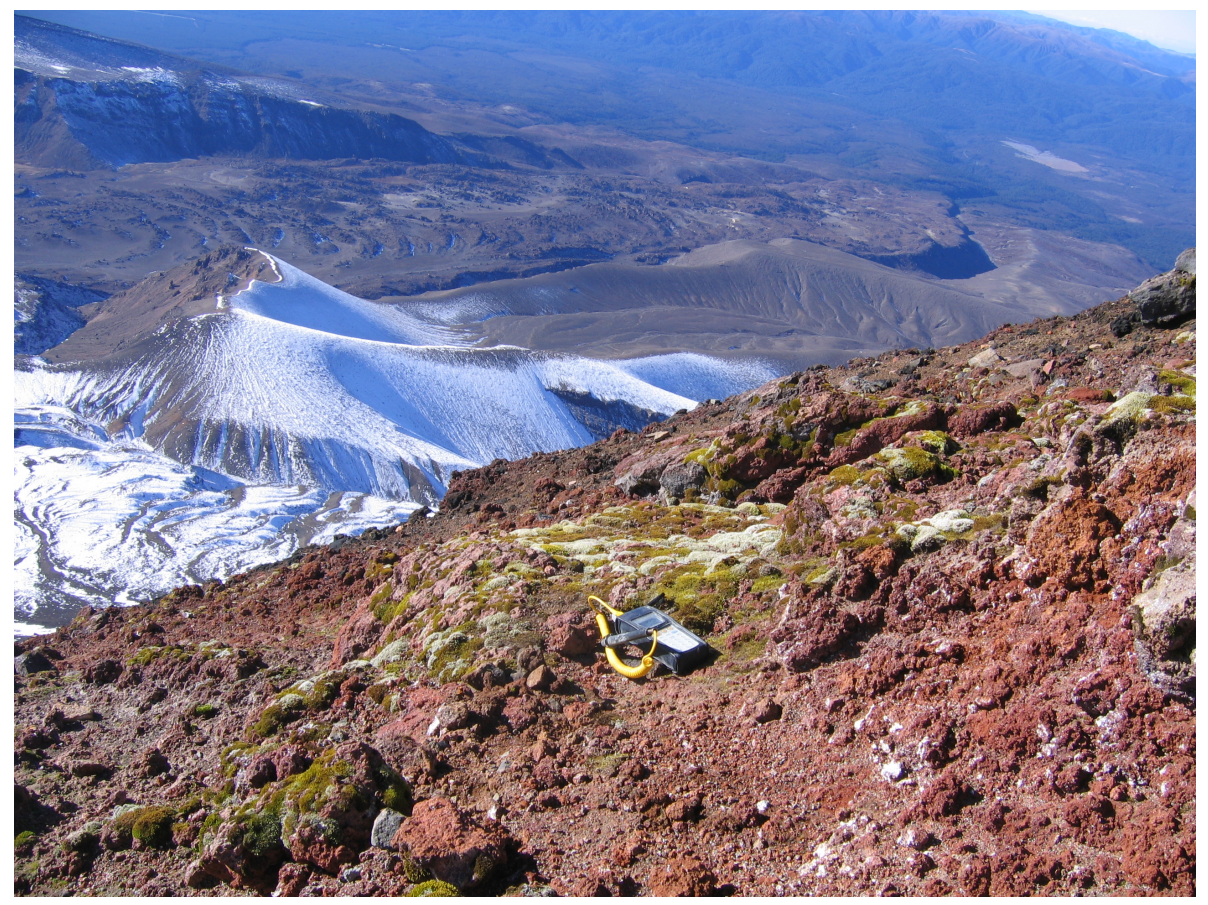

Figure 2.10. Isolation site of $\mathrm{K} 22$.

Image courtesy of Matthew Stott, GNS Science.

A $1 \mathrm{~L}$ culture of $\mathrm{K} 22$ and cell mass extract were screened as described above. The ${ }^{1} \mathrm{H}$ NMR spectrum of $75 \% \mathrm{Me}_{2} \mathrm{CO}$ fraction from the culture filtrate showed no significant peaks other than those belonging to the culture medium. As a result, no further investigation was done on this microbe. 


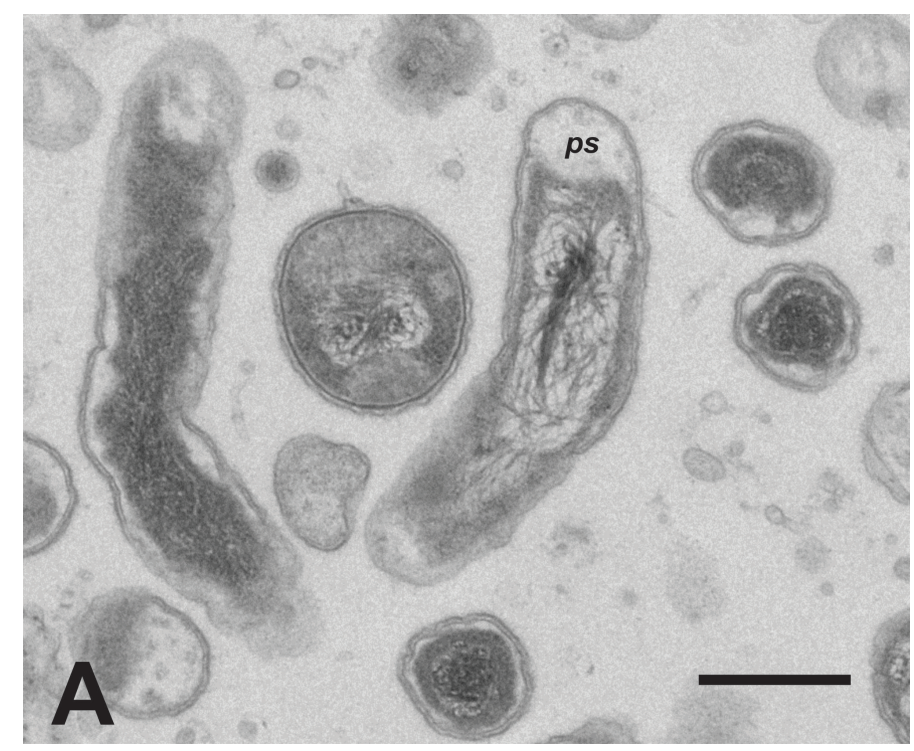

Figure 2.11. TEM image showing latitudinal and longitudinal cross-section views of K22 cell morphology (scale bar: $1 \mu \mathrm{m}$ ).

Image courtesy of Matthew Stott, GNS Science.

\subsection{Investigation of P373}

Strain P373 are Gram-positive, rod-shaped bacteria (Figure 2.12) that were isolated from steam-heated soil found at Waikite in Rotorua (Figure 2.13). At the time of isolation, the soil was at a temperature of $65^{\circ} \mathrm{C}$ and a $\mathrm{pH}$ of 4.54 . Phylogenetic studies carried out at GNS Science revealed that this strain is phylogenetically dissimilar to others in the microbial strain database and current studies are being undertaken to characterise and name the new strain.

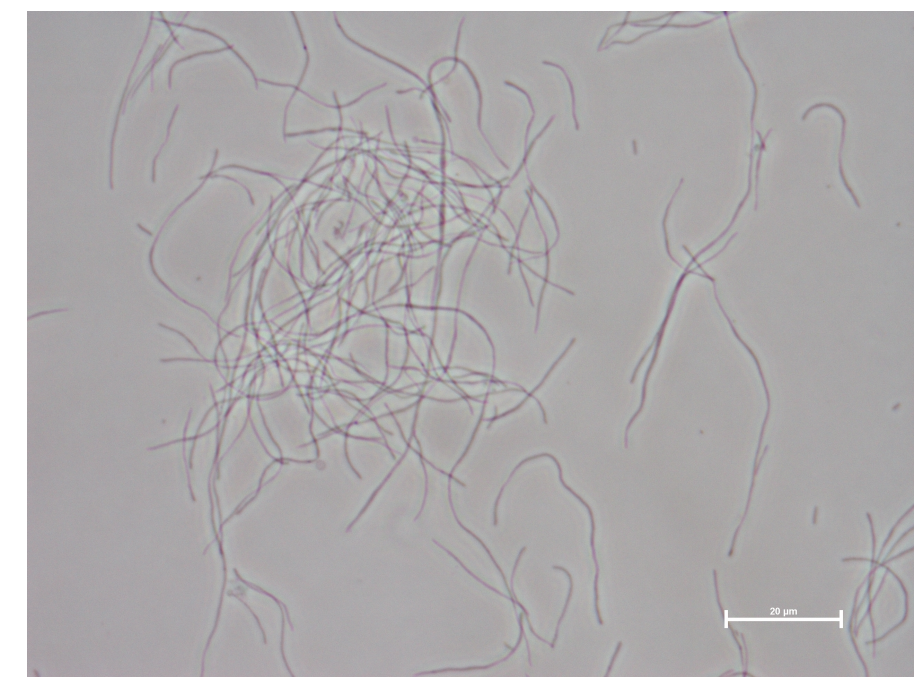

Figure 2.12. Light microscope phase contrast images of P373 cells (scale bar: $20 \mu \mathrm{m}$ ). Image courtesy of Matthew Stott, GNS Science. 
A $3 \mathrm{~L}$ culture of P373 and cell mass extract were screened as described above. Some unique proton resonances were seen in the ${ }^{1} \mathrm{H}$ NMR spectrum of the $75 \% \mathrm{Me}_{2} \mathrm{CO}$ fraction (CDB01_85B) from the culture filtrate (highlighted in Figure 2.14). However, due to lack of biomass, this microbe was not investigated further.

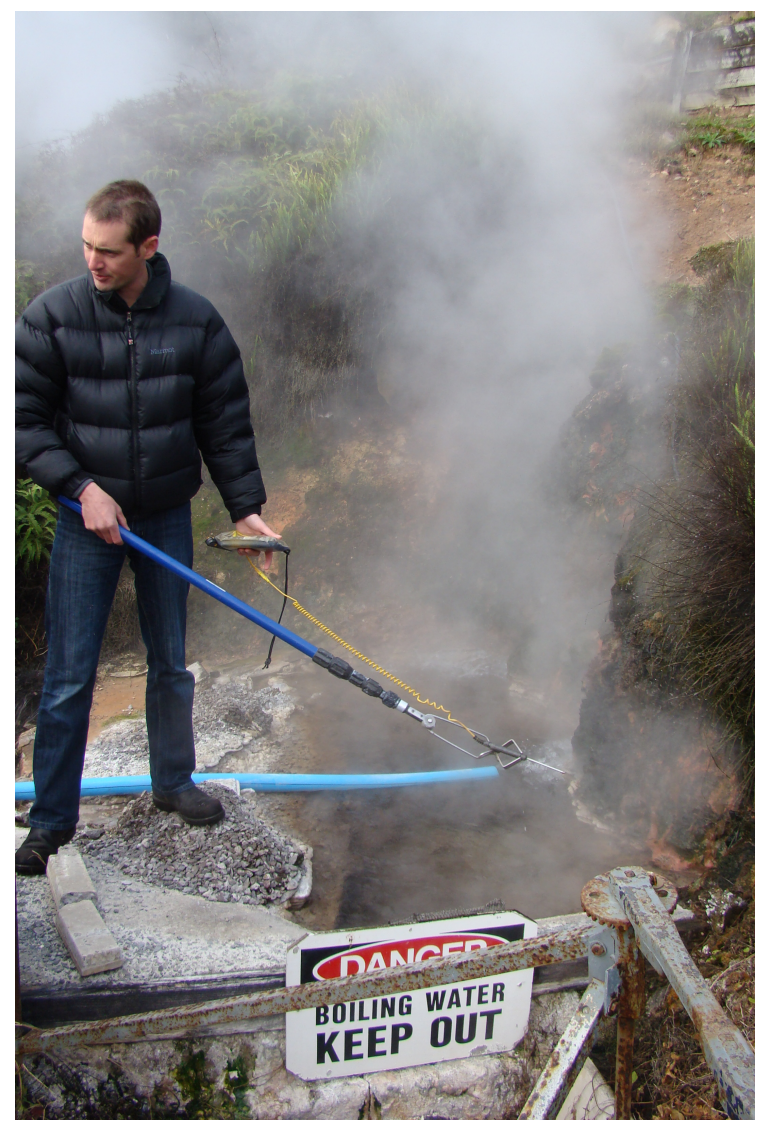

Figure 2.13. Isolation site of P373 and WKT50.2. Image courtesy of Matthew Stott, GNS Science.

\subsection{Investigation of WKT50.2}

Strain WKT50.2 are Gram-positive bacteria (Figure 2.15) that were isolated from the same site as P373 (Figure 2.13). Phylogenetic studies carried out at GNS Science revealed that this strain is phylogenetically dissimilar to others in the microbial strain database and current studies are being undertaken to characterise and name the new strain.

A $3 \mathrm{~L}$ culture of WKT50.2 and cell mass extract were screened as described above. The ${ }^{1} \mathrm{H}$ NMR spectrum of the $75 \% \mathrm{Me}_{2} \mathrm{CO}$ fraction of the culture filtrate (CDB02_05E) showed proton signals pertaining to one or more steroids. HPLC purification of this 


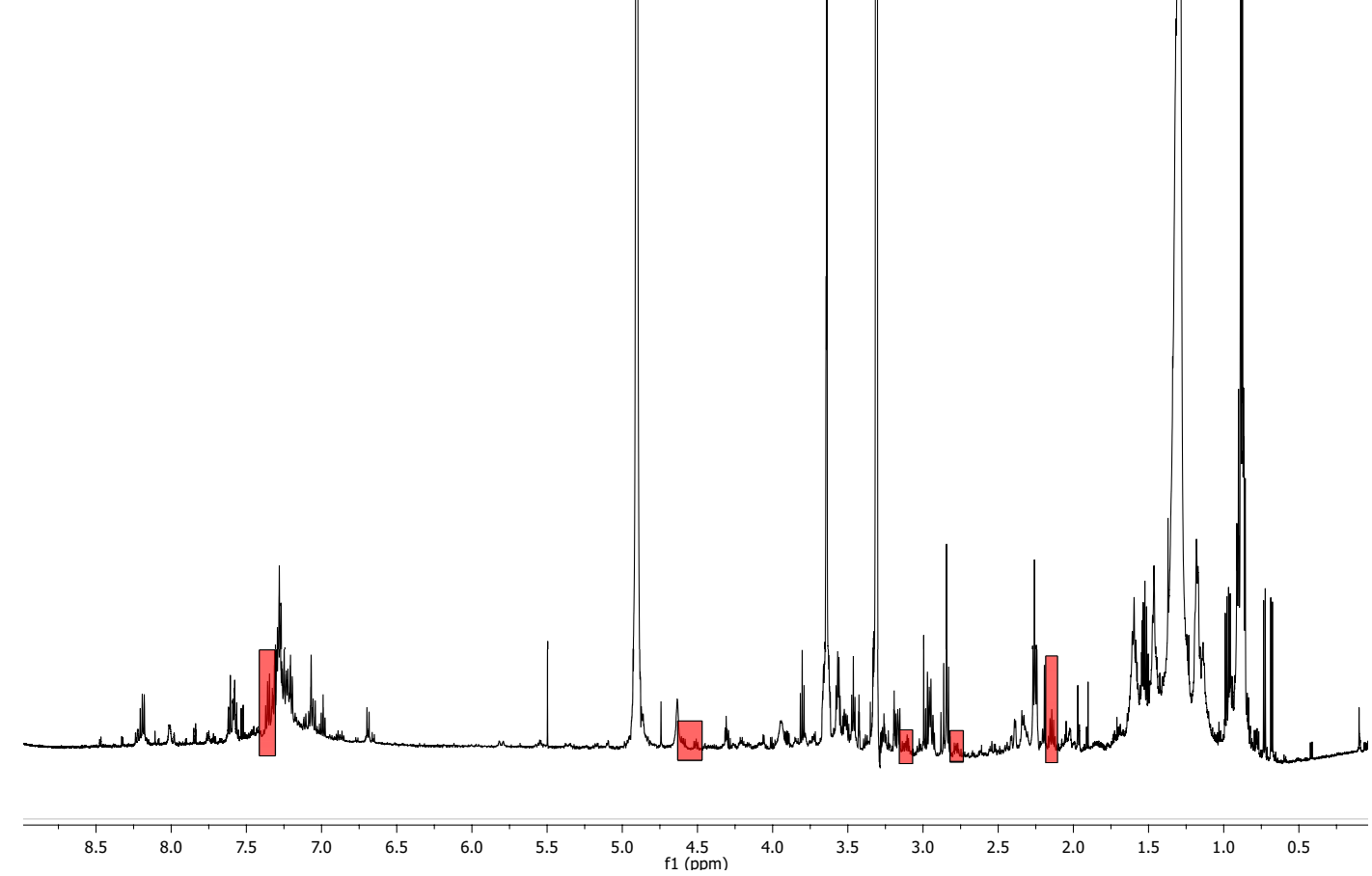

Figure 2.14. ${ }^{1} \mathrm{H}$ NMR spectrum of the $75 \% \mathrm{Me}_{2} \mathrm{CO}$ fraction from the $\mathrm{P} 373$ culture filtrate with unique resonances highlighted $\left(600 \mathrm{MHz}, \mathrm{CD}_{3} \mathrm{OD}\right)$.

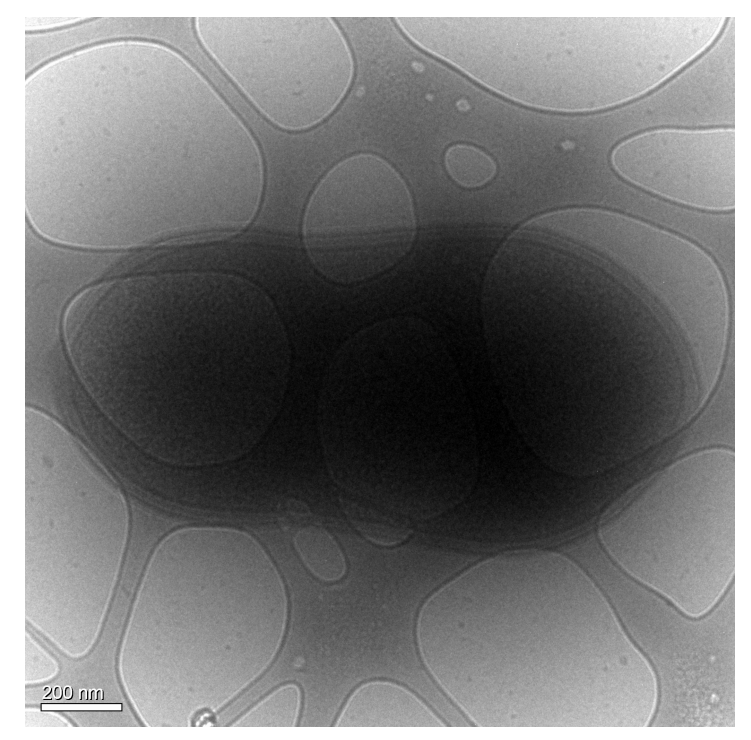

Figure 2.15. Cryogenic TEM of a WKT50.2 cell, showing the typical Gram-positive cell wall structure (scale bar: $200 \mathrm{~nm}$ ).

Image courtesy of Matthew Stott, GNS Science.

fraction and subsequent NMR and MS analysis revealed that it contained a mixture of two steroids, cholic acid (28) and deoxycholic acid (29). However, NMR spectral comparison with the $75 \% \mathrm{Me}_{2} \mathrm{CO}$ fraction from the sterile culture medium showed that the steroids were a component of the medium. It is thought that these steroids are an additive in the peptone used for this medium. 


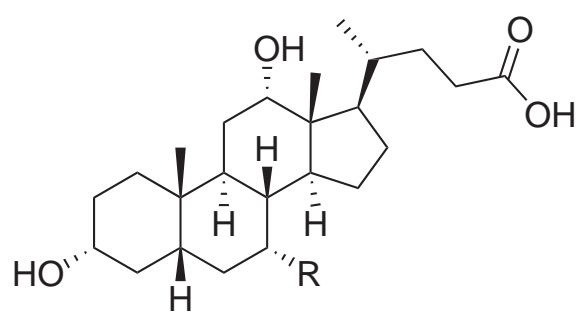

$28 \mathrm{R}=\mathrm{OH}$

$29 \mathrm{R}=\mathrm{H}$

\subsection{Conclusion}

Over the course of this research, 10 different extremophilic microbes were screened, nine of which are described above. For most of the strains, only a few milligrams were obtained in the mid-polar fractions from 1 or $2 \mathrm{~L}$ of culture, with the majority of mass being from culture medium components. This outcome was not surprising, as extremophiles often produce low amounts of biomass. ${ }^{84}$ The lack of isolated biomass did, however, serve as a major limitation. Subsequent identification of new compounds from the screen fractions was difficult due to masking of the metabolite NMR signals by culture media signals and sometimes, antifoam signals that would dominate the spectra. This made it difficult to target new metabolites and purify any fractions further. 


\section{Chapter 3}

\section{2,5-Diketopiperazines from Shewanella sp.}

\subsection{2,5-Diketopiperazines}

2,5-Diketopiperazines (DKPs) (Figure 3.1) are the smallest cyclic dipeptides that result from the condensation of two $\alpha$-amino acids. They are abundant in nature and have been isolated from fungi, bacteria, plants, processed foods and many other sources. ${ }^{85}$ These small, conformationally constrained molecules contain a six-membered heterocycle in which diversity can be introduced at up to four positions, with stereochemical control at two positions. Moreover, they are resistant to proteolysis and mimic peptidic pharmacophoric groups as they contain constrained amino acids. They contain two cisamide bonds and as a result possess two $\mathrm{H}$-bond acceptor and two $\mathrm{H}$-bond donor sites, which allows them to bind to a wide variety of receptors. ${ }^{86}$ These characteristics make them ideal for medicinal chemistry, where the unwanted physical properties of peptides can cause challenges.<smiles></smiles>

Figure 3.1. General structure of a 2,5-DKP.

The DKP scaffold can also be synthesised easily by conventional methods owing to its structural simplicity. The successful syntheses of many DKPs, which cover a wide range of approaches to synthesise the DKP ring, have been extensively reviewed. ${ }^{85-87}$ DKPs have also been used as chiral catalysts and auxiliaries during synthesis due to their structural and functional diversity, and their facile accessibility from chiral amino acids. ${ }^{85}$ Numerous naturally occuring and synthetic DKPs have been subjected to structureactivity relationship (SAR) studies, which has led to the development of clinical drugs such as Tadalafil (30), Aplaviroc (31), Retosiban (32) and Epelsiban (33), all of which 
contain the DKP scaffold. ${ }^{85}$ The majority of DKPs that have been isolated contain Lamino acids but many DKPs that contain D-amino acids have also been characterised. DKPs containing D-amino acids have often been isolated from bacteria, which is expected as these amino acids are an abundant component of the peptidoglycan cell walls. ${ }^{88}$ The DKP scaffold has often been found alone but also occurs embedded in many modified and complex natural products. The amino acid proline is regularly found in DKPs due to its ability to form a favoured cis-tertiary amide bond in the DKP ring with other amino acids, which makes it prone to 2,5-DKP formation. ${ }^{85}$<smiles>CN1CC(=O)N2[C@@H](Cc3c([nH]c4ccccc34)[C@@H]2c2ccc3c(c2)OCO3)C1=O</smiles>

30<smiles>CCCCN1C(=O)[C@@H](C(O)C2CCCCC2)NC(=O)C12CCN(Cc1ccc(Oc3ccc(C(=O)O)cc3)cc1)CC2</smiles>

31<smiles>[R]C(C(=O)N1CCOCC1)N1C(=O)[C@@H](C2Cc3ccccc3C2)NC(=O)[C@H]1C(C)CC</smiles><smiles>[R]=C=[W]</smiles>

\subsubsection{Biosynthesis of 2,5-DKPs}

It was previously thought that the biosynthesis of all 2,5-DKPs was catalysed by nonribosomal peptide synthetases (NRPSs) in microbes. Only recently has it come to light that enzymes known as cyclodipeptide synthases (CDPSs) are also involved in the biosynthesis of some DKPs, either as targets or as intermediates to other compounds. ${ }^{89}$

NRPSs are large multienzyme complexes made up of different modules, with each module responsible for the incorporation of one amino acid into the final peptide. ${ }^{90}$ Each module is divided further into domains that represent the enzymatic units responsible for catalysing the individual steps of nonribosomal peptide synthesis. There are three 
essential domains. These are the adenylation domain (A) that recognises and activates the substrate, the peptidyl carrier protein domain $(\mathrm{T})$ that binds the activated substrate through a thioester linkage via a phosphopantetheinyl arm, and the condensation domain (C) that forms the peptide bond (Scheme 3.1). DKPs can be synthesised either by dedicated NRPSs or as truncated side products during the synthesis of larger peptides, with the former being responsible for the biosynthesis of majority of all DKPs. ${ }^{90}$ NRPSs that are dedicated to DKP synthesis lack the thioesterase termination domain (TE) and instead contain a $\mathrm{C}$ domain that cyclises the linear dipeptidyl thioester, which then releases the DKP. During the synthesis of large peptides, spontaneous intramolecular cyclisation can occur to form a DKP side product. In these DKPs, cyclisation is favoured when a sterically constrained residue, such as a prolyl or $N$-methyl-amino acyl group, is present to allow for a cis conformation of the peptide bond that is necessary for formation of the DKP ring. ${ }^{90,91}$ For example, cyclomarazine A is released as a side product during the biosynthesis of cyclomarin C (Scheme 3.1). ${ }^{92}$ DKPs synthesised by NRPSs can be modified by accessory enzymes that are present in some domains. A range of chemical modifications can be applied to the DKP before it is released by the NRPS. These include configuration changes, indole prenylation as seen in tryprostatins, methylation (M) as seen in fumitremorgins and many more. ${ }^{90,91}$

CDPSs are a recently described family of small enzymes that can synthesise various cyclodipeptides (CDPs). ${ }^{89}$ These enzymes are unrelated to those of NRPSs and use aminoacyl-tRNAs as substrates by hijacking them, thereby eliminating the need to activate the amino acids. ${ }^{90,91}$ As a result, they are limited to the $20 \mathrm{~L}$-amino acids that are charged on tRNAs. CDPSs have also been associated with CDP-tailoring enzymes that play a role in modifying the CDPs. Unlike NRPSs that can modify the DKP before it is released, chemical modifications by tailoring enzymes can only be introduced into CDPs after they have been produced by CDPSs. ${ }^{91}$ The first report of the characterisation of a CDPS biosynthetic pathway for a CDP was that of an antibacterial and antitumour compound, albonoursin, isolated from Streptomyces noursei in $2002 .{ }^{93}$ AlbC is the CDPS that mainly produces cyclo(L-Phe-L-Leu), which is then converted to albonoursin by the tailoring enzymes CDP oxidases $a l b A$ and $a l b B$ (Scheme 3.2). Since the discovery of the albonoursin pathway, three more individual CDPS-dependent pathways have 


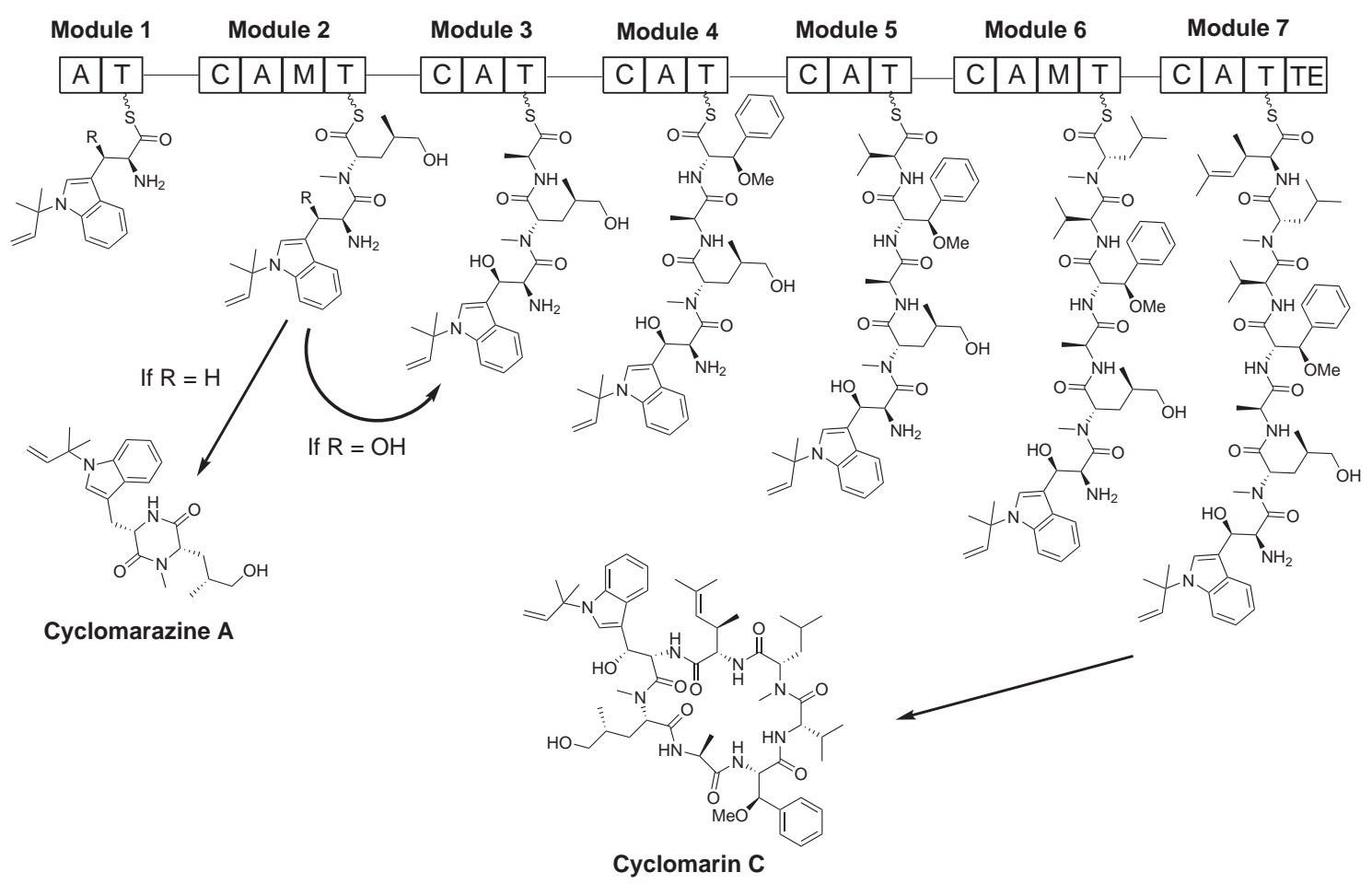

Scheme 3.1. NRPS biosynthesis of cyclomarin $C$ and side product cyclomarazine A. Enzymatic domain abbreviations: A, adenylation; T, thiolation (peptidyl carrier protein); $\mathrm{C}$, condensation; $\mathrm{M}$, methyltransferase; and TE, thioesterase.

a<smiles>CC(C)C=c1[nH]c(=O)c(=Cc2ccccc2)[nH]c1=O</smiles>

b

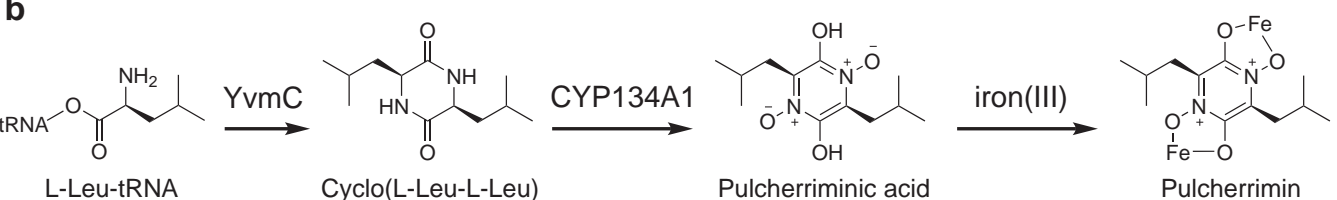

C<smiles>NC(Cc1ccc(O)cc1)C(=O)ON=[W]</smiles><smiles>O=C1NC(Cc2ccc(O)cc2)C(=O)NC1Cc1ccccc1</smiles>
$\stackrel{\text { CYP121 }}{\longrightarrow}$<smiles>CC(=O)CC1CC(=O)NC(Cc2ccc(O)c(-c3ccc(O)cc3)c2)C1=O</smiles>

d

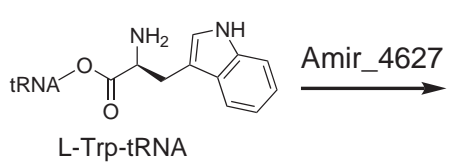<smiles>O=C1NC(Cc2c[nH]c3ccccc23)C(=O)NC1Cc1ccc2[nH]ccc2c1</smiles>
Cyclo(L-Trp-L-Trp)

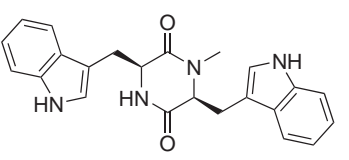

Cyclo(L-Trp-L-Trp)-Me

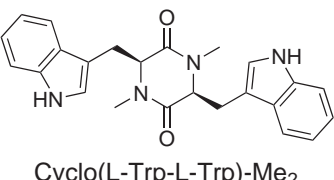

Scheme 3.2. Biosynthesis pathways of a) albonoursin, b) pulcherrimin, c) mycocyclosin and d) cyclo(L-Trp-L-Trp)-Me/Me $\mathrm{M}_{2}$ by CDPSs. 
been fully characterised for pulcherriminic acid from Bacillus subtilis, mycocyclosin from Mycobacterium tuberculosis and cyclo(L-Trp-L-Trp)-Me/Me $\mathrm{M}_{2}$ from Actinosynnema mirum (Scheme 3.2), each with their own tailoring enzymes. ${ }^{89,90,94,95}$

\subsubsection{Biological Activity of 2,5-DKPs}

There have been an overwhelming number of reports on the isolation of both simple and modified DKPs from various sources over the past few decades. These DKPs have covered a variety of bioactivities ranging from antibacterial, antifungal, cytostatic and quorum sensing activity to bioherbicidal, neuroprotective, cardiovascular and blood clotting alteration, and many more. The different bioactivities of both simple and complex DKPs have been extensively reviewed in the literature, ${ }^{85,86,96,97}$ and as a result, the discussion below focusses on the antibiotic, cytostatic and quorum sensing activities of some microbial proline and tryptophan based 2,5-DKPs that are relevant to the research described in this thesis.

\section{$\underline{\text { Antibiotic DKPs }}$}

Kumar et al. recently reported the isolation of cyclo(L-Leu-D-Pro) (34), cyclo(LMet-L-Pro) (35), cyclo(L-Phe-D-Pro) (36), cyclo(L-Phe-L-Pro) (37), cyclo(L-Tyr-LPro) (38) and cyclo(D-Tyr-L-Pro) (39) from Streptomyces sp. strain N and found that all compounds showed good activity against Staphylococcus aureus and B. subtilis bacteria, and showed superior antifungal activity than the standard fungicide Bavistin against Fusarium oxysporum, Rhizoctonia solani and Pencillium expansum fungi. ${ }^{98}$ All compounds also showed inhibition of Aspergillus flavus and Candida albicans. The highest antifungal activity of $2 \mu \mathrm{g} / \mathrm{mL}$ was exhibited by 37 against the plant pathogen P. expansum. All compounds except 39 showed activity against E. coli, with $\mathbf{3 7}$ having the lowest MIC of $8 \mu \mathrm{g} / \mathrm{mL}$. DKPs 35, 36 and 37 also showed moderate inhibition against Pseudomonas aeruginosa. DKP 38, also known as maculosin, has previously been isolated from a Gram-negative bacterial strain 679-2 and showed no significant antibiotic activity. ${ }^{99}$ However, when combined with other compounds isolated from the 
same strain, it showed synergistic activity against Aspergillus niger, M. smegmatis and Saccharomyces cerevisiae. DKP 37 has also been isolated from Aspergillus fumigatus, along with DKPs cyclo(L-Gly-L-Pro) (24), cyclo(L-Pro-L-Pro) (40), cyclo(L-Val-L-Pro) (41), cyclo(L-Leu-L-4-Hyp) (42), cyclo(L-Phe-L-4-Hyp) (43) and cyclo(L-Leu-L-Pro) (44). ${ }^{100}$ It was found that all the isolated compounds inhibited the growth of S. aureus and Micrococcus luteus at the concentration of $2.9 \mathrm{mM}$. DKP 41 has been isolated from several microbes including Pseudomonas aurantiaca, Streptomyces sp. H7372, Psychrobacter sp., Chromocleista sp. and many others. ${ }^{101-104}$ It was also isolated from Pseudomonas rhizosphaerae along with DKPs 37, 38, and 44. ${ }^{105}$ Antibacterial assays revealed that $\mathbf{3 7}$ was active against Loktanella hongkongensis and Ruegeria sp. at 200 $\mu \mathrm{g} / \mathrm{mL}$ and M. luteus and Bacillus cereus at $100 \mu \mathrm{g} / \mathrm{mL}$. DKP 38 was active against Ruegeria sp. at $200 \mu \mathrm{g} / \mathrm{mL}$ and 41 was active against L. hongkongensis at $200 \mu \mathrm{g} / \mathrm{mL}$. Both 37 and 43 have also been isolated from Lactobacillus plantarum and showed antifungal activities against a range of fungi and yeasts including Aspergillus nidulans, C. albicans and S. cerevisiae. ${ }^{106}$ The antifungal activity of some proline based 2,5-DKPs against S. cerevisiae has previously been researched and was also briefly studied during<smiles>CC(C)C[C@@H]1NC(=O)[C@@H]2CCCN2C1=O</smiles>

34<smiles>CSCC[C@H]1NC(=O)[C@@H]2CCCN2C1=O</smiles>

35<smiles>O=C1N[C@@H](Cc2ccccc2)C(=O)N2CCC[C@H]12</smiles>

36<smiles>O=C1N[C@@H](Cc2ccccc2)C(=O)N2CCC[C@H]12</smiles>

37<smiles>O=C1N[C@H](Cc2ccc(O)cc2)C(=O)N2CCC[C@H]12</smiles>

38<smiles>CC(C)[C@H]1NC(=O)[C@@H]2CCCN2C1=O</smiles>

41<smiles>O=C1N[C@H](Cc2ccc(O)cc2)C(=O)N2CCCC12</smiles>

39<smiles>O=C1[C@@H]2CCCN2C(=O)[C@@H]2CCCN12</smiles>

40 
this project, both of which are discussed in Section 3.4. The cyclo(L-Phe-D-4-Hyp)

isomer of $\mathbf{4 3}$ has been isolated from Aureobasidium pullulans, Psychrobacter sp. and A. fumigatus, with no reports of any significant antibiotic activity. ${ }^{107,108}$ The cyclo(L-PheD-6-Hyp) (46) and cyclo(L-Phe-L-6-Hyp) (47) isomers of 43 have been isolated from Chromocleista sp. but failed to show any activity against $S$. aureus when tested at 50 $\mu \mathrm{g} / \mathrm{mL} .{ }^{104}$ DKP 44 has also been isolated from Streptomyces sp. KH-614 and showed activity against a range of fungi including $C$. albicans, A. fumigatus, $R$. solani at MIC values ranging from $5-50 \mu \mathrm{g} / \mathrm{mL}$, with the highest activity against Pyricularia oryzae at $2.5 \mu \mathrm{g} / \mathrm{mL} .{ }^{109}$ Both $\mathbf{3 7}$ and $\mathbf{4 4}$ have showed activity against vancomycin-resistant enterococci (VRE) strains of bacteria at 25 and $12.5 \mu \mathrm{g} / \mathrm{mL}$, respectively. ${ }^{110,111}$ It was also reported that when combined, the two DKPs exhibited a synergistic effect against many VRE, Gram-positive and Gram-negative bacteria. ${ }^{112}$ In 2003, five D-D DKPs, cyclo(DPhe-D-Pro) (48), cyclo(D-Leu-D-Pro) (49), cyclo(D-Val-D-Pro) (50), cyclo(D-Ile-D-Pro) (51) and cyclo(D-Phe-D-4-Hyp) (52), were isolated from bacterial strains CF-20 and C148, which were associated with cultures of Pecten maximus. ${ }^{113}$ The L-L enantiomers of these compounds were synthesised along with some D-L and L-D isomers and all compounds were tested against the fish pathogen Vibrio anguillarum. All five isolated DD DKPs showed remarkable inhibitory activity against $V$. anguillarum with MIC values ranging from $0.03-0.07 \mu \mathrm{g} / \mathrm{mL}$, whereas the L-L enantiomers lacked activity altogether. It was also found that when only one D-amino acid was present in the DKP, the activity was not completely lost and the MIC values were 2-3 times higher than those of the D-D isomers. This effect was seen in DKP 36, which had an MIC of $0.1 \mu \mathrm{g} / \mathrm{mL}$. Cyclo(LTrp-L-Pro) (53), also known as brevianamide F, has been isolated from many sources including Penicillium brevi-compactum and Streptomyces fungicidicus. ${ }^{114,115}$ DKP 53 isolated from Streptomyces sp. strain TN58 showed activity against $M$. luteus and $S$. aureus. ${ }^{116}$ The cyclo(L-Trp-D-Pro) (54) isomer of $\mathbf{5 3}$ was recently isolated from the endophytic fungus Penicillium sp. HS-3, with no report on its biological activity. ${ }^{117}$ Cyclo(L-Trp-L-Val) (55) and cyclo(L-Trp-L-Ala) (56) are tryptophan-containing 2,5DKPs that have been isolated from Roseobacter sp., with no report on their activity. ${ }^{118}$ DKP 56 has also been isolated from Eurotium herbariorum and showed weak activity against Enterobacter aerogenes, B. subtilis, E. coli, P. aeruginosa and C. albicans. ${ }^{19}$ 
<smiles>O=C1N[C@H](Cc2ccccc2)C(=O)N2C[C@H](O)C[C@H]12</smiles>

45<smiles>O=C1N[C@H](Cc2ccccc2)C(=O)N2CCC[C@H]12</smiles>

48<smiles>CCC(C)[C@H]1NC(=O)[C@@H]2CCCN2C1=O</smiles>

51<smiles>O=C1N[C@@H](Cc2c[nH]c3ccccc23)C(=O)N2CCC[C@H]12</smiles>

54<smiles>O=C1[C@H](Cc2ccccc2)NC(=O)[C@]2(O)CCCN12</smiles>

46<smiles>CC(C)C[C@@H]1NC(=O)[C@@H]2CCCN2C1=O</smiles>

49<smiles>O=C1N[C@@H](Cc2ccccc2)C(=O)N2C[C@H](O)C[C@H]12</smiles>

52<smiles>CC(C)[C@H]1NC(=O)[C@H](Cc2c[nH]c3ccccc23)NC1=O</smiles>

55<smiles>O=C1[C@H](Cc2ccccc2)NC(=O)[C@]2(O)CCCN12</smiles>

47<smiles>CC(C)[C@@H]1NC(=O)[C@@H]2CCCN2C1=O</smiles>

50<smiles>O=C1N[C@@H](Cc2c[nH]c3ccccc23)C(=O)N2CCC[C@H]12</smiles>

53<smiles>C[C@@H]1NC(=O)[C@H](Cc2c[nH]c3ccccc23)NC1=O</smiles>

56

\section{Cytostatic DKPs}

There have been very few reports of cytotoxic and cytostatic activities from simple proline and tryptophan-containing DKPs. DKPs $\mathbf{2 4}, \mathbf{3 7}, \mathbf{3 8}, \mathbf{4 0}, \mathbf{4 4}$, cyclo(L-His-L-Pro) (57) and cyclo(L-Thr-L-Pro) (58) have been tested against HT-29 colon cancer, MCF-7 breast cancer and HeLa cervical cancer cell lines. ${ }^{120}$ DKP 38 only showed weak inhibition of MCF-7, whereas DKP 37 weakly inhibited the growth of all three cell lines with $\mathrm{IC}_{50}$ values of $4.04,6.53$ and $2.92 \mathrm{mM}$, respectively. No activity was reported for the other DKPs. DKP 37 also induced apoptotic cell death in the HT-29 cells, which was later found to be mediated by a caspase cascade. ${ }^{121}$ These results suggested that 37 could potentially inhibit the growth of tumours in vivo. DKP 44 has also been tested against K562, HL-60, and U937 leukemia cell lines, and at a concentration of $100 \mu \mathrm{g} / \mathrm{mL}$, it exerted significant growth inhibitory rates of 95,91 and $93 \%$, respectively. ${ }^{111}$ 


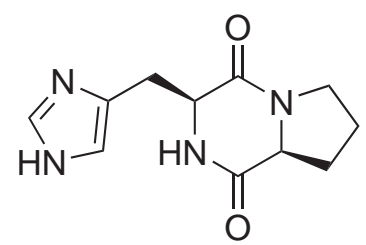

57

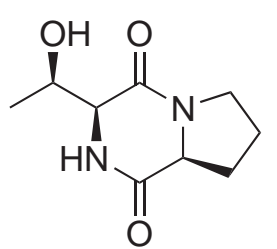

58

Cyclo(L-Trp-L-Pro) (53), cyclo(L-Trp-L-Val) (55) and cyclo(L-Trp-L-Ala) (56) are precursors to numerous modified and complex DKPs that have been isolated from microbes. However, it is mainly the modified versions of DKP 53 that have exhibited cytostatic activities and, therefore, some of these are discussed here. DKP 53 serves as a biosynthetic precursor to many DKPs including fumitremorgins, verruculogen, tryprostatins, spirotryprostatins and cyclotryprostatins. Fumitremorgins A (59) and B (60) are prenylated and annulated analogues of $\mathbf{5 3}$ that were initially isolated from A. fumigatus Fres. in 1971. ${ }^{122}$ Fumitremorgin $\mathrm{C}(\mathbf{6 1})$ is another analogue that was isolated from a different strain of A. fumigatus in 1977. ${ }^{123}$ Verruculogen (62), which is structurally similar to $\mathbf{5 9}$ with a hydroxyl group in place of a prenyl group, was isolated from Penicillium verruculosum in 1972. ${ }^{124}$ Compounds 59, 60 and $\mathbf{6 2}$ were all isolated as toxins that were capable of producing severe tremors in mice when administered orally. ${ }^{122-124}$ In 1990 , a dihydroxylated version (63) of $\mathbf{6 1}$ was isolated from A. fumigatus DSM 790 with no report on its biological acitvity. ${ }^{125}$ Compounds 60, 61, 62 and 63 were later re-isolated from A. fumigatus BM939 along with demethoxyfumitremorgin C (64) and tryprostatins A (65) and B (66), which are non-annulated versions of 61 and 64, respectively. ${ }^{126}$ All the isolated compounds were tested for their inhibitory activity on the cell cycle progression of mouse tsFT210 cells and each compound showed inhibition at the M phase of the cell cycle (Table 3.1), which makes these compounds useful as potential anticancer agents as they cause mitotic arrest. Subsequent studies showed that $\mathbf{6 5}$ specifically inhibits cell cycle progression at the $\mathrm{M}$ phase by disrupting microtubule assembly whereas 66 is a nonspecific inhibitor of the cell cycle. ${ }^{127}$ Compounds 65 and 61 have also showed potential as reversers of breast cancer resistance protein (BCRP)-mediated multidrug resistance by inhibiting the ATP-dependent drug transport activity of BCRP. ${ }^{128,129}$ Spirotryprostatins A (67) and B (68) are spiro-annulated and prenylated analogues of 53 that were also isolated from A. fumigatus BM939. ${ }^{130}$ The same production strain was screened again and led to the isolation of cyclotryprostatins A-D (69-72), which are mono-prenylated 
and annulated analogues. ${ }^{131}$ All six compounds showed inhibition of the cell cycle progression of mouse tsFT210 cells at the G2/M phase (Table 3.1). ${ }^{130,131}$

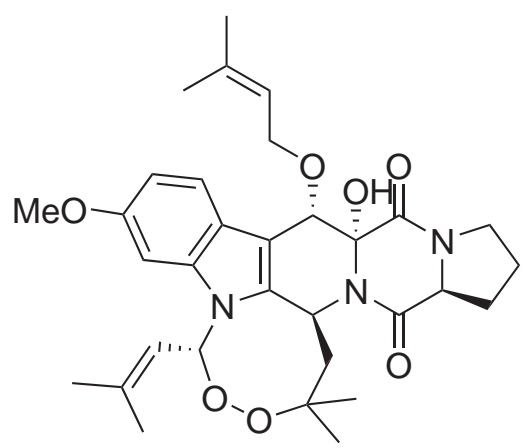

59

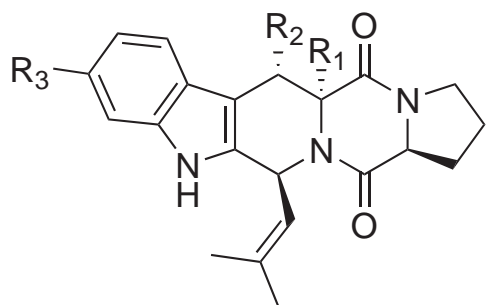

$61 \mathrm{R}_{1}=\mathrm{H}, \mathrm{R}_{2}=\mathrm{H}, \mathrm{R}_{3}=\mathrm{OMe}$

$63 \mathrm{R}_{1}=\mathrm{OH}, \mathrm{R}_{2}=\mathrm{OH}, \mathrm{R}_{3}=\mathrm{OMe}$

$64 \mathrm{R}_{1}=\mathrm{H}, \mathrm{R}_{2}=\mathrm{H}, \mathrm{R}_{3}=\mathrm{H}$

$71 \mathrm{R}_{1}=\mathrm{OH}, \mathrm{R}_{2}=\mathrm{OH}, \mathrm{R}_{3}=\mathrm{H}$

$72 \mathrm{R}_{1}=\mathrm{OH}, \mathrm{R}_{2}==\mathrm{O}, \mathrm{R}_{3}=\mathrm{H}$<smiles>[R]c1ccc2c(C[C@@H]3NC(=O)[C@@H]4CCCN4C3=O)c(CC=C(C)C)[nH]c2c1</smiles>

$65 \mathrm{R}=\mathrm{OMe}$

$66 \quad \mathrm{R}=\mathrm{H}$<smiles>CC(C)=CC1N2C(=O)C3CCCN3C(=O)C2=CC12C(=O)Nc1ccccc12</smiles>

68<smiles>COc1ccc2c3c(n(CC=C(C)C)c2c1)[C@@H](O)[C@]1(O)C(=O)N2CCC[C@H]2C(=O)N1C3C=C(C)C</smiles>

60

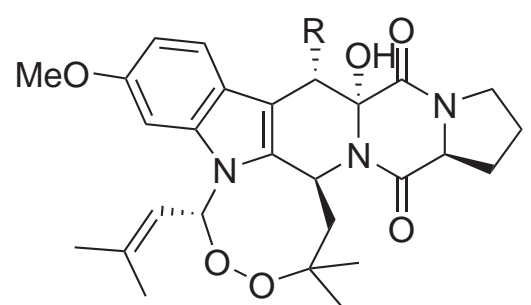

$62 \mathrm{R}=\mathrm{OH}$

$78 \quad \mathrm{R}==\mathrm{O}$

$67 \mathrm{R}=\mathrm{H}$

$79 \mathrm{R}=\mathrm{OH}$<smiles>COc1ccc2c3c([nH]c2c1)[C@H](C=C(C)C)N1C(=O)C2CCCN2C(=O)[C@]1(O)[C@H]3O</smiles>

$69 \mathrm{R}=\mathrm{OH}$

$70 \mathrm{R}=\mathrm{OMe}$ 
<smiles>COc1ccc2c(c1)N(CC=C(C)C)C(=O)C2C(O)C1C(=O)N2CCC[C@H]2C(=O)N1C=C(C)C</smiles>

$73 \mathrm{R}=\mathrm{H}$

$74 \mathrm{R}=\mathrm{OH}$<smiles>COc1ccc2c(c1)[C@]1(C(=O)N2/C=C/C(C)(C)O)C(O)C(=O)N2CCCC2C(=O)N1/C=C/C(C)=O</smiles>

75<smiles>C=C(C)[C@H](O)Cn1c2c(c3ccc(OC)cc31)[C@@H](O)[C@@H]1C(=O)N3CCC[C@H]3C(=O)N1C2C=C(C)C</smiles>

76, 77

Table 3.1. $\mathrm{IC}_{50}$ values of some complex DKPs against the cell cycle progression of mouse tsFT210 cells ${ }^{126,130,131}$

\begin{tabular}{l|l|l}
\hline Compound & $\mathbf{I C}_{50}(\mu \mathbf{M})$ & Cell Cycle Phase \\
\hline Fumitremorgin B (60) & $>209.0$ & $\mathrm{M}$ \\
\hline Fumitremorgin C (61) & 14.0 & $\mathrm{M}$ \\
\hline Verruculogen $(\mathbf{6 2})$ & $>196.0$ & $\mathrm{M}$ \\
\hline 12,13-Dihydroxyfumitremorgin C $(\mathbf{6 3})$ & $>243.0$ & $\mathrm{M}$ \\
\hline Demethoxyfumitremorgin C (64) & 1.78 & $\mathrm{M}$ \\
\hline Tryprostatin A (65) & 78.7 & $\mathrm{M}$ \\
\hline Tryprostatin B (66) & 18.8 & $\mathrm{M}$ \\
\hline Spirotryprostatin A (67) & 197.5 & $\mathrm{G} 2 / \mathrm{M}$ \\
\hline Spirotryprostatin B (68) & 14.0 & $\mathrm{G} 2 / \mathrm{M}$ \\
\hline Cyclotryprostatin A (69) & 5.6 & $\mathrm{G} 2 / \mathrm{M}$ \\
\hline Cyclotryprostatin B (70) & 19.5 & $\mathrm{G} 2 / \mathrm{M}$ \\
\hline Cyclotryprostatin C (71) & 23.4 & $\mathrm{G} 2 / \mathrm{M}$ \\
\hline Cyclotryprostatin D (72) & 25.3 & $\mathrm{G} 2 / \mathrm{M}$ \\
\hline
\end{tabular}

In 2008, spirotryprostatins C-E (73-75) were isolated from A. fumigatus Fres. along with two hydroxylated derivatives (76 and 77) of $\mathbf{6 0}$ and 13-oxoverruculogen (78). ${ }^{132}$ All compounds were evaluated for their cytotoxic activities against MOLT-4, A549, HL-60, and BEL-7420 cancer cell lines. Compounds $\mathbf{7 3}$ and $\mathbf{7 4}$ showed weak activities against all four cell lines with $\mathrm{IC}_{50}$ values ranging from $17.5-68.8 \mu \mathrm{M}$, whereas 75 showed moderate activity against MOLT-4, HL-60 and A-549 cells at 3.1, 2.3 and $3.1 \mu \mathrm{M}$, respectively. Compounds $\mathbf{7 6}$ and $\mathbf{7 7}$ showed moderate activities against all cell lines with $\mathrm{IC}_{50}$ values 
ranging from 3.4-11.6 $\mu \mathrm{M}$. Compound 78 also showed moderate activity against HL-60 cells at $\mathrm{IC}_{50} 1.9 \mu \mathrm{M}$, with weak activity against the other cell lines ( $\left.\mathrm{IC}_{50} 16.9-25.7 \mu \mathrm{M}\right)$. Spirotryprostatin F (79) was recently isolated from a marine isolate of A. fumigatus and showed phytoregulating activity, with no other biological activity reported. ${ }^{133}$

\section{DKPs with Quorum Sensing Activity}

Quorum sensing (QS) is the process by which bacteria communicate with each other using self-produced small diffusible signalling molecules known as autoinducers (AIs), which help mediate gene expression simultaneously in all members of the population. ${ }^{134}$ The concentration of secreted AI molecules in a particular environment correlates directly to the abundance of bacteria in the vicinity. Once a certain concentration threshold of AIs is reached, the communicating bacteria undertake a coordinated change in their gene expression profiles. These changes lead to phenotypes such as secondary metabolite production, bioluminescence, virulence factor production, motility, biolfilm formation and many others. ${ }^{134,135}$ The coordinated nature of these changes allows these prokaryotes to behave like multicellular organisms and exhibit complex intercellular interactions.

There are three main classes of AIs that are used by bacteria for QS and these differ depending on the type of bacteria. The first class comprises of acylated homoserine lactones (AHLs) (80), also termed AI-1, which are generally produced by Gram-negative bacteria and that diffuse through the cellular plasma membrane. ${ }^{134}$ This system consists of two regulatory genes, a luxI homologue that encodes the AHL synthase and a luxR homologue that encodes the AHL sensor peptide. Once a threshold concentration of AHLs is reached, it is sensed and bound by the cytoplasmic LuxR-type peptide and this complex either activates or inactivates target gene(s) in the operon, thereby producing phentoypic changes in the bacterial population. This system was initially discovered in 1970 in Vibrio fischeri and was found to play a role in the bioluminescence of these bacteria. ${ }^{136}$ This was also the first report of QS as a method of bacterial intercellular communication. The second class of AIs is seen primarily in Gram-positive bacteria and comprises of small modified peptides, which are usually produced from the 
cleavage of precursor oligopeptides and are then transported out of the cell via an ATP binding cassette transporter. ${ }^{135}$ In this system, once the secreted peptide concentration is sufficient, it is recognised by a membrane-bound sensor kinase protein, which causes phosphorylation of a response regulator protein and leads to transcription of the target gene(s). The sensor proteins in Gram-positive QS are usually highly specific to their peptide AIs. The third class of AIs, termed AI-2, consists of a furanosyl borate diester (81) and a non-borate diester (82), which are produced by an AI-2 LuxS-type synthase that is encoded by a luxS homologue. ${ }^{135}$ This homologue is present in almost half of all sequenced bacterial genomes, and thus, AI-2 production can be found in both Gramnegative and Gram-positive bacteria. The A1-2 signalling system can also be used in conjuction with other signalling systems. These characteristics of AI-2 have suggested that it could be a method of interspecies communication, whereas the more conserved AI-1 and peptide signalling systems serve as intraspecies communication.

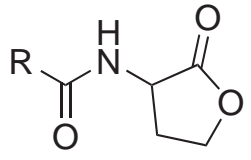

80

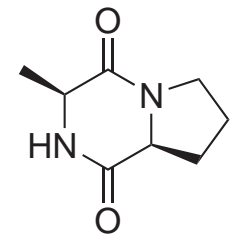

83<smiles>C[C@]12OC[C@@H](O)C1(O)OB(O)O2</smiles>

81<smiles>C=C1NC(=O)C(C(C)C)NC1=O</smiles>

84<smiles>C[C@]1(O)OC[C@@H](O)C1(O)O</smiles>

82

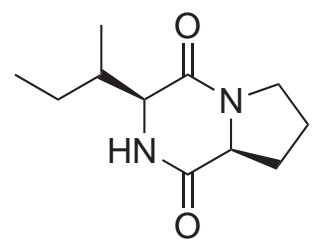

85

As mentioned above, QS is used by pathogenic bacteria to exert their virulence on hosts. Therefore, disruption of this communication, known as quorum quenching, is an attractive target for the development of an anti-infective compounds. Interestingly, some 2,5-DKPs have showed inhibition of QS in microbes, whereas others have been shown to activate QS. In 1999, Holden et al. evaluated the activity of DKPs 37, 38, 35, 41, 44, cyclo(LAla-L-Pro) (83), and cyclo( $\Delta$ Ala-L-Val) (84) against several LuxR-based AHL biosensor strains. ${ }^{137}$ All DKPs except 35 showed concentration-dependent activation of the AHL biosensor in E. coli (pSB401) but at much lower concentrations than the native AHL. Competition studies showed that these DKPs may be competing with the AHL for the same LuxR binding site as they were able to antagonise the AHL-mediated induction 
of bioluminescence, with $\mathbf{4 1}$ having the highest inhibitory activity. DKP 35, on the other hand, showed agonistic affects and was the most potent activator of the biosensor in E. coli (pSB401). DKP 41 was also able to induce pigment production in the Chromobacterium violaceum AHL reporter strain. In a bioassay against Serratia liquefaciens, it was found that DKPs 38 and $\mathbf{8 4}$ were able to reduce the swarming ability of these bacteria. DKP 44 isolated from Achromobacter xylosoxidans showed inhibition of aflatoxin production from Aspergillus parasiticus by repressing transcription of the genes involved. ${ }^{138}$ DKP 37 isolated from four Vibrio spp. showed induction of the ompU genes in all species and also induced the $c t x$ genes in Vibrio cholerae. ${ }^{139}$ These genes encode virulence factor production and thus play a role in the pathogenicity of these bacteria. Collectively, these studies showed that DKPs could not only modulate the activity of LuxR-based QS, but could also represent a new class of AIs as they are capable of mimicking the actions of AHLs in Gram-negative bacteria. Following these reports, Campbell et al. published an elaborate study in 2009 in which they designed a synthetic library of 23 DKPs, which included those previously reported as QS agonists and antagonists to confirm their activity and mode of action. ${ }^{140}$ In order to directly validate reported results, all biosensor strains used in assays were the same as previously reported. Surprisingly, the results conflicted with previous reports as it was found that none of the naturally occuring DKPs exhibited either agonistic or antagonistic activities in any tested strains. When tested in $V$. fischeri, several non-native DKPs were capable of inhibiting bioluminescence but did not do so through interaction with LuxR, which was another contradiction to previous reports. The study concluded that while DKPs can affect QS-related outcomes, they do not interact with LuxR-type proteins and that previous studies may have suffered contamination issues. Since this study, there have been more reports of QS-interfering DKPs. DKP 24 was recently shown to inhibit many QS-dependent phenotypes in P. aeruginosa by competing with the AHL for the LasR receptor protein, which is responsible for inducing many phenotypes when bound to the AHL. ${ }^{141}$ Abed et al. recently reported that DKPs 37, 44 and cyclo(L-Ile-L-Pro) (85) reduced QS-dependent bioluminescence in E. coli (pSB401) in the presence of AHL, and DKPs $\mathbf{3 7}$ and $\mathbf{8 5}$ also showed inhibition of QSdependent pigment production in C. violaceum. ${ }^{142}$ Although DKPs may not exhibit their actions via interaction with LuxR-type peptides, they remain interesting compounds for 
use in quorum quenching and it remains to be seen whether they do in fact represent a new class of signalling molecules.

\subsection{The Genus Shewanella}

Bacteria from the genus Shewanella, the sole genus in the Shewanellaceae family, are Gram-negative, facultatively anaerobic, rod-shaped microbes that possess polar flagella for motility. ${ }^{143}$ The majority of members of this genus are psychrotolerant, with many being true psychrophiles, while others can grow at higher temperatures. ${ }^{144}$ These bacteria are widely distributed throughout the world, especially in aquatic environments. ${ }^{144}$ The type of environments they are found in can range from freshwater lakes to deep cold-water marine environments to hydrothermal vents. ${ }^{145}$ They have been isolated from various sources including fish, algae, ground meat, oil emulsions, milk, cream and many more. ${ }^{146}$ They can be free-living or symbionts. ${ }^{147}$ Shewanella spp. produce trimethylamines and hydrogen sulfide and are thus associated with the rotting of fish. ${ }^{143}$ The first report of a Shewanella sp. was in 1931 by Derby and Hammer from putrefied butter, although the bacterium was tentatively named Achromobacter putrefaciens. ${ }^{148}$ It was only in 1985 that the genus was redesignated to Shewanella by MacDonell and Colwell. ${ }^{149}$ Since then, there have been over 50 different species described (Table 3.2). Multiple unidentified strains of Shewanella have also been researched.

Numerous species of Shewanella have been investigated for their enzymes over the past two decades. To date, various enzymes have been characterised from these bacteria including alkaline phosphatases, reductases, pepsin (Shewasin A), dehydrogenases, proteases, endonucleases and many more. ${ }^{150-155}$ In 2008, Bodor et al. reported the presence of the luxS gene that codes for the synthase enzyme of the AI-2 group of signalling molecules (discussed in Section 3.1.2), in all tested Shewanella strains. ${ }^{156}$ The production of AI-2 was confirmed by a Vibrio harveyi luminescence bioassay, as these bacteria can sense AI-2, which then causes luminescence. All tested Shewanella strains were able to induce luminescence in $V$. harveyi. The study confirmed the presence of luxS related signalling in Shewanella. Another important characteristic of bacteria 
Table 3.2. Taxonomic classification of species from the genus Shewanella from order Alteromonadales

\begin{tabular}{|c|c|c|c|c|}
\hline \multirow[t]{2}{*}{ Order } & \multirow{2}{*}{$\begin{array}{l}\text { Family } \\
\text { Alteromonadaceae }\end{array}$} & \multirow{2}{*}{$\begin{array}{l}\text { Genus } \\
\ldots\end{array}$} & \multicolumn{2}{|c|}{ Species } \\
\hline & & & $\ldots$ & $\ldots$ \\
\hline & Colwelliaceae & $\ldots$ & $\ldots$ & $\ldots$ \\
\hline & Ferrimonadaceae & $\ldots$ & $\ldots$ & $\ldots$ \\
\hline & Idiomarinaceae & $\ldots$ & $\ldots$ & $\ldots$ \\
\hline & Moritellaceae & $\ldots$ & $\ldots$ & $\ldots$ \\
\hline & Pseudoalteromonadaceae & $\ldots$ & $\ldots$ & $\ldots$ \\
\hline & Psychromonadaceae & $\ldots$ & $\ldots$ & $\ldots$ \\
\hline Alteromonadales & Shewanellaceae & Shewanella & $\begin{array}{l}\text { abyssi } \\
\text { algidipiscicola } \\
\text { algae } \\
\text { amazonensis } \\
\text { aquimarina } \\
\text { arctica } \\
\text { atlantica } \\
\text { baltica } \\
\text { basaltis } \\
\text { benthica } \\
\text { canadensis } \\
\text { chilikensis } \\
\text { colwelliana } \\
\text { corallii } \\
\text { decolorationis } \\
\text { denitrificans } \\
\text { dokdonensis } \\
\text { donghaensis } \\
\text { fidelis } \\
\text { fodinae } \\
\text { frigidimarina } \\
\text { gaetbuli } \\
\text { gelidimarina } \\
\text { glacialipiscicola } \\
\text { hafniensis } \\
\text { halifaxensis } \\
\text { haliotis } \\
\text { hanedai } \\
\text { indica } \\
\text { irciniae } \\
\text { japonica } \\
\text { kaireitica }\end{array}$ & $\begin{array}{l}\text { litorisediminis } \\
\text { livingstonensis } \\
\text { loihica } \\
\text { marina } \\
\text { marinintestina } \\
\text { marisflavi } \\
\text { massilia } \\
\text { morhuae } \\
\text { olleyana } \\
\text { oneidensis } \\
\text { pacifica } \\
\text { pealeana } \\
\text { piezotolerans } \\
\text { pneumatophori } \\
\text { profunda } \\
\text { psychrophila } \\
\text { putida } \\
\text { putrefaciens } \\
\text { saccharophilus } \\
\text { sairae } \\
\text { schlegeliana } \\
\text { sediminis } \\
\text { seohaensis } \\
\text { spongiae } \\
\text { surugensis } \\
\text { taiwanensis } \\
\text { upenei } \\
\text { vesiculosa } \\
\text { violacea } \\
\text { waksmanii } \\
\text { woodyi } \\
\text { xiamenensis }\end{array}$ \\
\hline
\end{tabular}

from this genus is that they are capable of dissimilatory reduction of various heavy metals and other toxic substances by using them as electron acceptors during respiration, thereby detoxifying these substances. ${ }^{147}$ Metals and compounds that can be reduced by Shewanella bacteria include elemental sulphur, nitrate, nitrite, thiosulphate, manganese and iron oxides, vanadium, chromium, neptunium and many more. ${ }^{147}$ These diverse metabolic capabilities make Shewanella bacteria important for carbon cycling and of potential use in the bioremediation of contaminated environments. ${ }^{147}$ 


\subsubsection{Pathogenicity of Shewanella spp.}

In 1990, Simidu et al. isolated a Shewanella sp. from a red alga and found that it produced tetrodotoxin (86), a potent neurotoxin that is lethal to many organisms, and called the isolate Shewanella algae. ${ }^{157}$ No other species of Shewanella has been reported to produce this toxin. Both $S$. algae and S. putrefaciens are known as opportunistic pathogens in humans and marine organisms. ${ }^{144}$ The occurrence of Shewanella infections in humans are rare and, in the past, were only reported in patients who lived in warm temperatures. However, reports of bacterial infections in humans from both warm and cool temperatures has been increasing over the last few decades. ${ }^{143}$ Shewanella infections that have been reported manifest symptoms such as bacteremia, septicemia, meningitis, ear infection, respiratory distress, pneumonia, and many more. ${ }^{146}$ However, both S. algae and $S$. putrefaciens are susceptible to common antibacterials. Although infections are caused by both species, S. algae is more pathogenic in humans. ${ }^{144}$ It has also been suggested that the production of $\mathbf{8 6}$ by this species could play a role in its higher pathogenicity. ${ }^{144}$

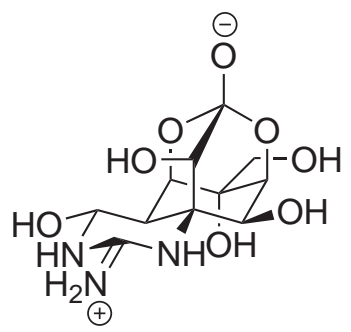

86

It was recently reported that at warm temperatures, a soybean protein concentrate diet caused intestinal disorders in farmed Atlantic salmon. ${ }^{158}$ The causal fish pathogens were later identified as V. harveyi and Yersinia ruckeri (NIWA - Unpublished), both of which pose a large threat to fish farming industries. An assay was recently carried out at Callaghan Innovation to assess the pathogenicity of several strains of Shewanella towards V. harveyi and Y. ruckeri. The results (Figure 3.2) showed that nine strains (Table 3.3) inhibited the growth of both pathogens. V. harveyi and $Y$. ruckeri are both known to use QS for pathogenicity. ${ }^{159}$ Therefore, it is possible that the Shewanella strains exhibit their inhibitory activity by disrupting the QS of these bacteria. Further studies into this project are being carried out at NIWA, Callaghan Innovation and VUW. These results may have important implications for the aquaculture industry in New Zealand. 


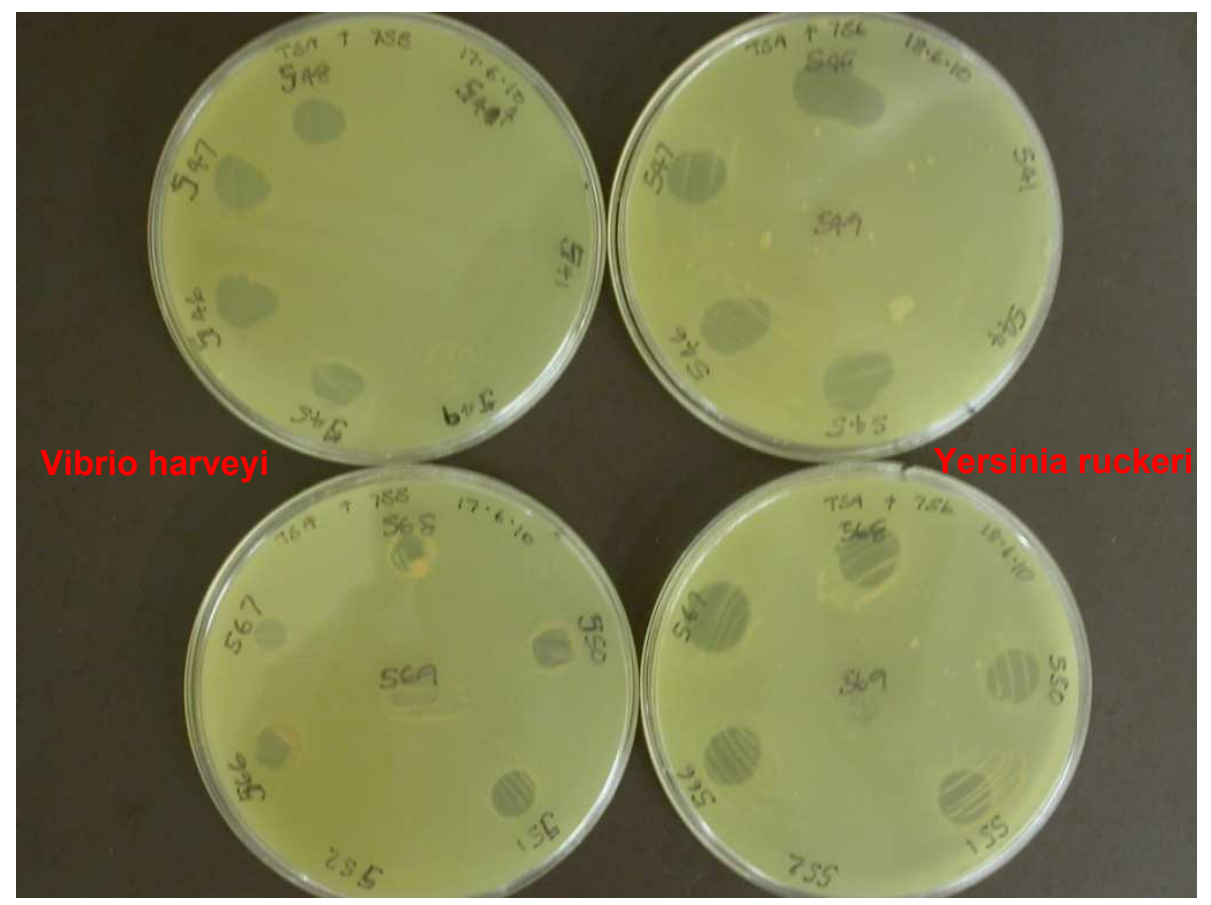

Figure 3.2. Shewanella assay against $V$. harveyi (left) and $Y$. ruckeri (right). Image courtesy of Jason Ryan, Callaghan Innovation.

Table 3.3. List of tested strains and their activity against $V$. harveyi and $Y$. ruckeri

\begin{tabular}{l|l|l|l|l}
\hline \multirow{2}{*}{ Isolate no. } & \multirow{2}{*}{ Species $(>\mathbf{9 9 \%}$ similarity) } & \multirow{2}{*}{ Source } & \multicolumn{2}{|c}{ Active against } \\
\cline { 4 - 5 } & S. fidelis & South China Sea & No & Norveyi \\
\hline 541 & Photobacterium sp. & Tarakihi & No & No \\
\hline 544 & S. marinitestina/S. sairae & Tarakihi & Yes & Yes \\
\hline 545 & S. marinitestina/S. sairae & Tarakihi & Yes & Yes \\
\hline 546 & S. baltica & Bluenose & Yes & Yes \\
\hline 547 & S. halifaxensis & Bluenose & Yes & Yes \\
\hline 548 & S. halifaxensis & Jack Mackerel & No & No \\
\hline 549 & S. baltica & Jack Mackerel & Yes & Yes \\
\hline 550 & S. baltica & Jack Mackerel & Yes & Yes \\
\hline 551 & Vibrio sp. & Scorpion Fish & No & No \\
\hline 552 & S. halifaxensis & Blue Warehou & Yes & Yes \\
\hline 566 & S. marinitestina/S. sairae & Blue Warehou & Yes & Yes \\
\hline 567 & S. marinitestina/S. sairae & Blue Warehou & Yes & Yes \\
\hline 568 & S. marinitestina/S. sairae & Blue Warehou & No & No \\
\hline 569 & & & &
\end{tabular}

\subsubsection{Reported Bioactive Metabolites from Shewanella spp.}

Since the isolation of the first species of Shewanella, there have been very few reports of bioactive metabolites from these bacteria. As mentioned above, the production of neurotoxin 86 by $S$. algae was one of the first reports of a bioactive metabolite from 
this genus. ${ }^{157}$ The fatty acids 2-hydroxymyristic acid (87) and cis-9-oleic acid (88) were isolated from S. oneidensis by Bhattari et al. in 2007. ${ }^{160}$ Both compounds showed potential for use as antifoulants. Many species of Shewanella produce various fatty acids including eicosapentaenoic acid (EPA) (89), an omega-3 fatty acid (essential fatty acid) that cannot be produced by humans and must be obtained nutritionally. In 2007, Nishida et al. showed that EPA may have an antioxidative function within its producer, $S$. marinintestina. ${ }^{161}$

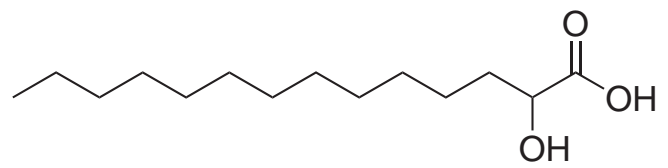

87

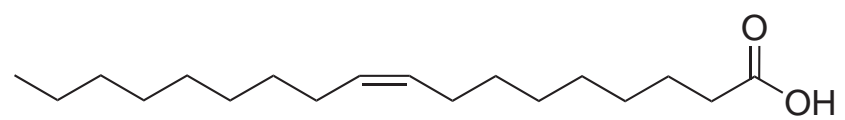

88

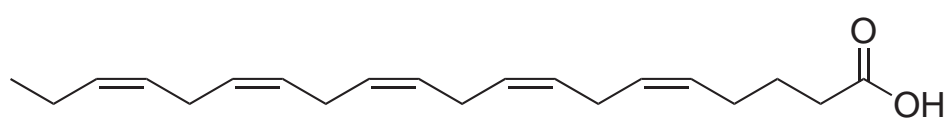

89

In 1997, putrebactin (90), which is a siderophore, was isolated from S. putrefaciens. ${ }^{162}$ Siderophores are metal-specific chelating compounds that are secreted by microbes to sequester iron, especially by those undergoing low iron stress such as in marine environments where iron solubility is poor but essential for almost all life processes. Another siderophore, avaroferrin (91), was isolated recently from S. algae and was found to inhibit the swarming ability of Vibrio alginolyticus by binding iron in a form that is inaccessible to these bacteria. ${ }^{163}$ In November 2013, Gu et al. published a study that focussed on the extracellular metabolite production of $S$. baltica, and its role in food spoilage. ${ }^{164}$ Four DKPs, cyclo(L-Gly-L-Pro) (24), cyclo(L-Phe-L-Pro) (37), cyclo(LLeu-L-Pro) (44) and cyclo(L-Leu-L-Leu) (92), were isolated from the supernatant of $S$. baltica strain 00C and were evaluated for their role in food spoilage using fish muscle juice. The study concluded that $\mathbf{3 7}$ had the highest spoilage capability after 24 hours. These results suggested that the DKPs could be acting as QS signalling molecules by increasing the spoilage capability of S. baltica. Since the members of this genus have relatively unexplored secondary metabolic profiles, they are attractive targets for natural product research. 
<smiles>O=C1CCC(=O)N(O)CCCCNC(=O)CCC(=O)N(O)CCCCN1</smiles>

90<smiles>O=C1CCCCCN(O)C(=O)CCC(=O)NCCCCN(O)C(=O)CC1</smiles>

91

\subsection{Isolation of Secondary Metabolites from Shewanella}

Sp.

Shewanella sp. strain 569 was isolated from the intestines of Blue Warehou (Seriolella brama) found in the Cook Strait (Table 3.3). A 16S sequence carried out at Callaghan Innovation revealed that the strain is $>99 \%$ phylogenetically similar to $S$. marinintestina and S. sairae. However, ongoing chemotaxonomic studies are being carried out to identify the species. During this research, two cultures (a total of 33 L) of Shewanella sp. strain 569 obtained from Callaghan Innovation were studied as described in Chapter 2.

\subsubsection{Compounds from the $75 \% \mathrm{Me}_{2} \mathrm{CO} / \mathrm{H}_{2} \mathrm{O}$ fraction}

The $75 \% \mathrm{Me}_{2} \mathrm{CO} / \mathrm{H}_{2} \mathrm{O}$ fraction from the culture filtrate showed proton NMR signals pertaining to secondary metabolites and was further separated on a reversed-phase column (HP20ss). Subsequent fractionation using size-exclusion (LH-20) and normal phase (DIOL) chromatography led to the isolation of one compound, CDB01_77C. Reversed-phase HPLC purification on another DIOL fraction resulted in the isolation of a second pure compound, CDB01_80C (Scheme 3.3). Both compounds, CDB01_77C and CDB01_80C, were then characterised mainly by MS and NMR.

\section{Indole-3-carboxaldehyde}

The molecular formula $\mathrm{C}_{9} \mathrm{H}_{7} \mathrm{NO}$ was determined for $\mathrm{CDB} 01 \_77 \mathrm{C}$ by positive ion HRESIMS from the $[\mathrm{M}+\mathrm{H}]^{+}$adduct at $\mathrm{m} / z .146 .0597(\mathrm{~m} / z, \Delta=-0.0003)$, requiring 


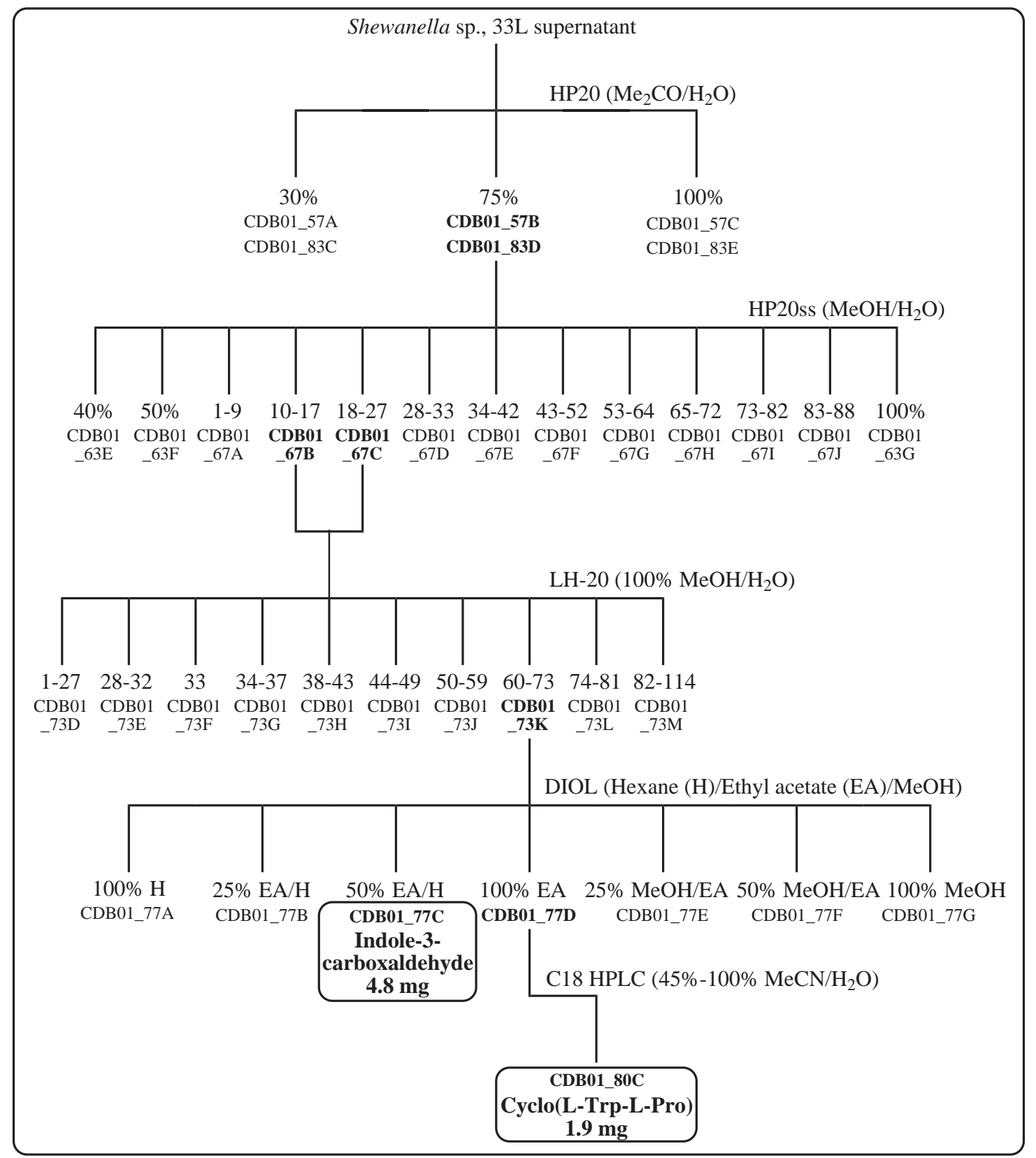

Scheme 3.3. Isolation of indole-3-carboxaldehyde and cyclo(L-Trp-L-Pro).

seven DBEs. The ${ }^{13} \mathrm{C}$ NMR spectrum contained five protonated $\left(\delta_{C} 187.4,125.0,123.6\right.$, $122.4,113.1)$ and four non-protonated carbon resonances $\left(\delta_{C} 139.7,138.9,125.6,120.0\right)$ assigned from HMBC correlations through neighbouring protons. One of the carbon resonances was highly deshielded and attached to a proton $\left(\delta_{H} 9.89 ; \delta_{C} 187.4\right)$, and was indicative of an aldehyde group in the compound.

The ${ }^{1} \mathrm{H}$ NMR spectrum $\left(\mathrm{CD}_{3} \mathrm{OD}\right)$ contained resonances that accounted for six of the seven protons in the molecule. An HSQC experiment confirmed the attachment of all six protons to carbons, indicating the presence of one exchangeable proton. Four aromatic proton 
signals $\left(\delta_{H} 8.16,7.48,7.28,7.24\right)$ with similar coupling constants were seen in the ${ }^{1} \mathrm{H}$ NMR spectrum. COSY correlations between aromatic protons $\mathrm{H}-4\left(\delta_{H} 8.16 ; \delta_{C} 122.4\right)$ and H-5 $\left(\delta_{H} 7.24 ; \delta_{C} 123.6\right), \mathrm{H}-5$ and H-6 $\left(\delta_{H} 7.28 ; \delta_{C} 125.0\right)$, and H-6 and H-7 $\left(\delta_{H}\right.$ 7.48, $\delta_{C}$ 113.1) established the connection between C-4 and C-7. HMBC correlations from $\mathrm{H}-4$ to C-6, H-5 to C-7 and H-6 to C-4 and H-7 to C-5 confirmed the presence of this connection. HMBC correlations were also seen from $\mathrm{H}-5$ and $\mathrm{H}-7$ to non-protonated C-3a $\left(\delta_{C}\right.$ 125.6) along with HMBC correlations from H-4 and H-6 to non-protonated C$7 \mathrm{a}\left(\delta_{C}\right.$ 138.9). These correlations confirmed the presence of a 1,2-disubstituted benzene substructure in the molecule (Figure 3.3).

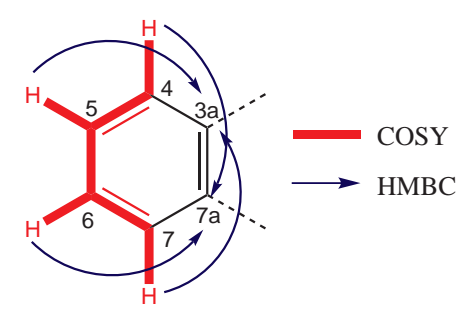

Figure 3.3. COSY and HMBC correlations establishing the 1,2-disubstituted benzene substructure in indole-3-carboxaldehyde.

Aromatic proton H-2 $\left(\delta_{H} 8.11 ; \delta_{C} 139.7\right)$ showed HMBC correlations to non-protonated C-3 $\left(\delta_{C}\right.$ 120.0), C-3a and C-7a. These correlations suggested that the 1,2-disubstituted ring was an indole moiety in the compound. This accounted for the one exchangeable proton in the compound. Furthermore, HMBC correlations were seen from aldehyde proton $\mathrm{H}-8\left(\delta_{H} 9.89 ; \delta_{C} 187.4\right)$ to $\mathrm{C}-3$ and $\mathrm{C}-3 \mathrm{a}$, suggesting that the aldehyde was substituted at C-3 of the indole (Figure 3.4). This structure fits with the molecular formula and also contained seven DBEs, confirming that the elucidated structure was correct.

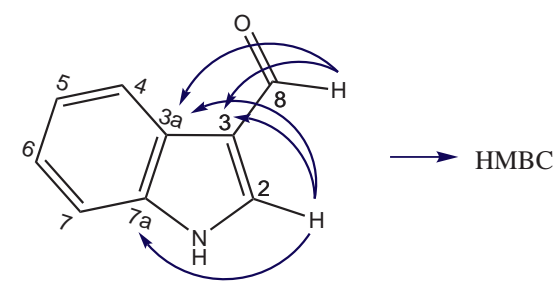

Figure 3.4. HMBC correlations establishing the indole moiety and the connection to the aldehyde group in indole-3-carboxaldehyde.

The structure showed that a known indole alkaloid, indole-3-carboxaldehyde (93), was isolated. The recorded NMR data (Table 3.4) were identical to those in the literature. ${ }^{165}$ 


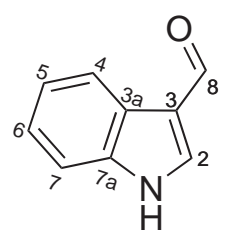

93

Table 3.4. ${ }^{1} \mathrm{H}(600 \mathrm{MHz})$ and ${ }^{13} \mathrm{C}(150 \mathrm{MHz}) \mathrm{NMR}$ data for indole-3-carboxaldehyde (93) $\left(\mathrm{CD}_{3} \mathrm{OD}\right)$

\begin{tabular}{|c|c|c|c|c|c|c|c|}
\hline \multirow[b]{2}{*}{ Position } & \multicolumn{2}{|c|}{${ }^{13} \mathrm{C}$} & \multicolumn{3}{|c|}{${ }^{1} \mathrm{H}$} & \multirow[b]{2}{*}{ COSY } & \multirow{2}{*}{$\begin{array}{c}\text { HMBC } \\
\left({ }^{1} \mathrm{H} \text { to }{ }^{13} \mathrm{C}\right)\end{array}$} \\
\hline & $\delta(\mathrm{ppm})$ & mult & $\delta(\mathrm{ppm})$ & mult & $J(\mathrm{~Hz})$ & & \\
\hline 2 & 139.7 & $\mathrm{CH}$ & 8.11 & $\mathrm{~S}$ & - & - & $3,3 a, 7 a$ \\
\hline 3 & 120.0 & $\mathrm{C}$ & - & - & - & - & - \\
\hline $3 a$ & 125.6 & $\mathrm{C}$ & - & - & - & - & - \\
\hline 4 & 122.4 & $\mathrm{CH}$ & 8.16 & d & 7.7 & 5 & $6,7 \mathrm{a}$ \\
\hline 5 & 123.6 & $\mathrm{CH}$ & 7.24 & $\mathrm{t}$ & 8 & 4,6 & $3 a, 7$ \\
\hline 6 & 125.0 & $\mathrm{CH}$ & 7.28 & $\mathrm{t}$ & 7.3 & 5,7 & $4,7 \mathrm{a}$ \\
\hline 7 & 113.1 & $\mathrm{CH}$ & 7.48 & d & 8.2 & 6 & $3 a, 5$ \\
\hline $7 \mathrm{a}$ & 138.9 & $\mathrm{C}$ & - & - & - & - & - \\
\hline 8 & 187.4 & $\mathrm{CH}$ & 9.89 & $\mathrm{~s}$ & - & - & $3,3 \mathrm{a}$ \\
\hline
\end{tabular}

\section{Cyclo(L-Trp-L-Pro)}

The positive ion HRESIMS for CDB01_80C showed an $[\mathrm{M}+\mathrm{H}]^{+}$adduct at $m / z, 284.1392$ $(m / z, \Delta=-0.0002)$, suitable for a molecular formula of $\mathrm{C}_{16} \mathrm{H}_{17} \mathrm{~N}_{3} \mathrm{O}_{2}$ and 10 DBEs. The ${ }^{13} \mathrm{C}$ NMR spectrum contained 11 protonated $\left(\delta_{C} 125.6,122.6,119.9,119.8,112.2,60.0\right.$, $57.2,45.9,29.2,29.1,22.5)$ and five non-protonated carbon resonances $\left(\delta_{C} 170.7,167.4\right.$, 138.0, 128.7, 109.4) that were assigned from HMBC correlations through neighbouring protons. Two of the carbon resonances were highly deshielded ( $\delta_{C} 170.7$ and $\left.\delta_{C} 167.4\right)$ and were indicative of two ester or amide groups in the compound.

The ${ }^{1} \mathrm{H}$ NMR spectrum $\left(\mathrm{CD}_{3} \mathrm{OD}\right)$ contained resonances that accounted for 15 of the 17 protons in the molecule. An HSQC experiment confirmed the attachment of all 15 protons to carbons, indicating the presence of two exchangeable protons. Four aromatic proton signals H-4 $\left(\delta_{H} 7.58 ; \delta_{C} 119.8\right), \mathrm{H}-5\left(\delta_{H} 7.01 ; \delta_{C} 119.9\right), \mathrm{H}-6\left(\delta_{H} 7.09 ; \delta_{C} 122.6\right)$ and H-7 $\left(\delta_{H} 7.33, \delta_{C} 112.2\right)$ with similar coupling constants, along with another aromatic proton $\mathrm{H}-2\left(\delta_{H} 7.10 ; \delta_{C}\right.$ 125.6) were seen in the ${ }^{1} \mathrm{H}$ NMR spectrum with the same COSY and HMBC correlations that were observed for indole-3-carboxaldehyde (93). These correlations suggested that there was an indole moiety in the compound (Figure 3.5). 
This also accounted for one of the two exchangeable protons in the compound.

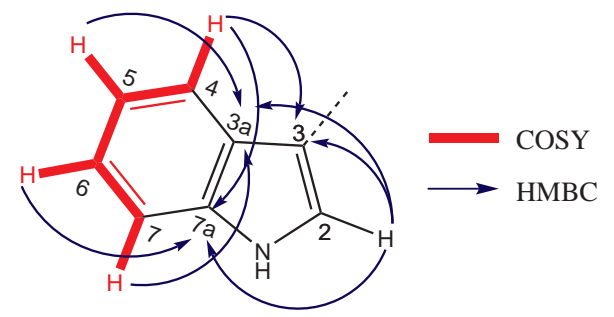

Figure 3.5. COSY and HMBC correlations establishing indole in cyclo(L-Trp-L-Pro).

Long range COSY correlations between methylene $\mathrm{H}_{2}-8\left(\delta_{H} 3.32 ; \delta_{C} 29.2\right)$ and $\mathrm{H}-2$ indicated that C-8 was directly attached to C-3 $\left(\delta_{C} 109.4\right)$ of the indole ring. HMBC correlations from $\mathrm{H}_{2}-8$ to $\mathrm{C}-2, \mathrm{C}-3$ and $\mathrm{C}-3 \mathrm{a}\left(\delta_{C}\right.$ 128.7) confirmed this substitution on the indole. Furthermore, $\mathrm{H}_{2}-8$ also showed HMBC correlations to two more carbon atoms, protonated C-9 $\left(\delta_{H} 4.42 ; \delta_{C} 57.2\right)$ and non-protonated, highly deshielded C-14 $\left(\delta_{C}\right.$ 167.4). A strong COSY correlation between $\mathrm{H}_{2}-8$ and $\mathrm{H}-9$ confirmed that $\mathrm{C}-9$ was directly connected to C-8, and a weak HMBC correlation from $\mathrm{H}-9$ to $\mathrm{C}-14$ confirmed that C-14 was connected to C-9 (Figure 3.6). The downfield chemical shift of C-14 suggested that it was part of either an ester or an amide group. However, the two oxygen atoms in the molecule were already accounted for as part of carbonyl groups, which meant that C-14 was part of an amide group.

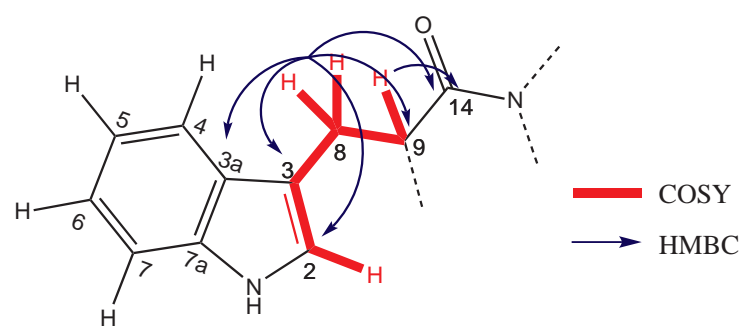

Figure 3.6. COSY and HMBC correlations establishing the connections between C-3 and $\mathrm{C}-14$ in cyclo(L-Trp-L-Pro).

A separate spin system was established from COSY correlations between deshielded methylene $\mathrm{H}_{2}-15\left(\delta_{H} 3.46(\mathrm{a}), 3.27(\mathrm{~b}) ; \delta_{C} 45.9\right)$ and $\mathrm{H}_{2}-16\left(\delta_{H} 1.69(\mathrm{a}), 1.47(\mathrm{~b}) ; \delta_{C}\right.$ 22.5), and $\mathrm{H}_{2}-16$ and $\mathrm{H}_{2}-17\left(\delta_{H} 1.97\right.$ (a), 0.93 (b); $\left.\delta_{C} 29.1\right)$ which indicated connections between $\mathrm{C}-15$ and $\mathrm{C}-17$. A strong HMBC correlation from $\mathrm{H}-17$ (a) to $\mathrm{C}-15$, and weak correlations from H-15(a) and H-17(b) to C-16 confirmed this connection. H-17(b) also showed a weak correlation to C-12 $\left(\delta_{H} 4.00 ; \delta_{C} 60.0\right)$ and H-12 showed strong COSY correlations to both H-17(a) and (b) confirming the presence of a bond between the two 
carbons. A weak HMBC correlation was also seen from H-12 to non-protonated, highly deshielded C-11 ( $\left.\delta_{C} 170.7\right)$, whose chemical shift was indicative of an amide group. This correlation suggested that C-11 was directly connected to C-12 (Figure 3.7).

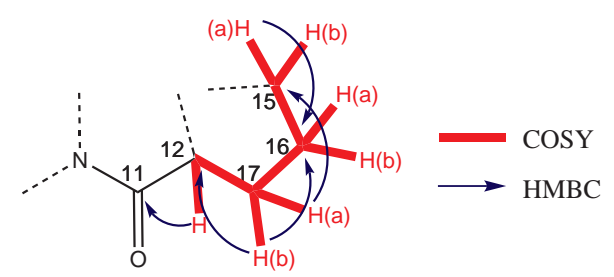

Figure 3.7. COSY and HMBC correlations establishing the connections between C-15 and C-11 in cyclo(L-Trp-L-Pro).

Thus far, all the carbon, nitrogen and non-exchangeable proton atoms in the molecule had been accounted for, with one exchangeable proton unaccounted for. Eight of the 10 DBEs had also been established in the compound. Since the NMR spectra showed no evidence of more double bonds, the remaining two DBEs required two more rings in the molecule. Methylene $\mathrm{CH}_{2}-15$ should be connected to one of the two amide nitrogen atoms, as it was deshielded. It could only be connected to the amide containing C-14, as a connection to the other amide would result in an isolated structure. Similarly, C-12 should also be connected to the same amide group. This resulted in a five-membered ring in the molecule (Figure 3.8), accounting for one more DBE.

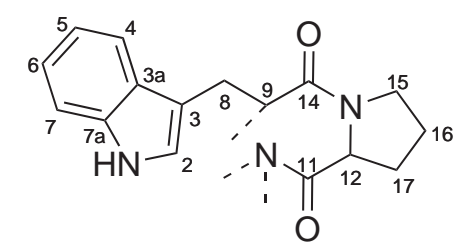

Figure 3.8. Connection between the two established substructures for cyclo(L-Trp-L-Pro).

The last remaining connection was that from C-9 to the amide containing C-11, which formed a six-membered ring accounting for the tenth DBE. A weak HMBC correlation from $\mathrm{H}-9$ to $\mathrm{C}-11$ confirmed this connection. This means that the exchangeable proton was also connected to the nitrogen atom in this amide group. $\mathrm{CH}-12$ and $\mathrm{CH}-9$ were both in $\alpha$-positions to a nitrogen atom and a carbonyl group, which explained their downfield chemical shifts.

The elucidated structure showed that a known 2,5-DKP consisting of amino acids 
tryptophan and proline had been isolated. The NMR data for the D-D and L-L isomers of DKPs are identical but differ from their D-L and L-D counterparts. The specific rotations of all four stereoisomers also differ from each other and this property can be used to determine which one is present. Thus, the configuration of centres C-9 and C-12 were determined by comparison of specific rotation measurements and NMR data (Table 3.5) with published data. The NMR, MS and MS/MS data, along with an $[\alpha]_{\mathrm{D}}^{25}$ of $-70(\mathrm{c}=0.1$, $\mathrm{MeOH})\left(\right.$ lit. $\left.[\alpha]_{\mathrm{D}}^{25}=-48, \mathrm{c}=0.06, \mathrm{MeOH}\right)$ confirmed that cyclo(L-Trp-L-Pro) (53) was isolated. ${ }^{166,167}$

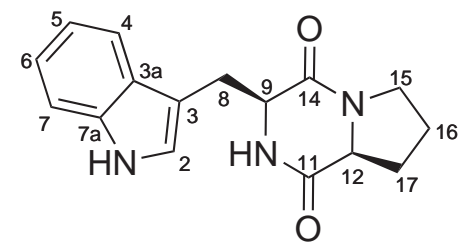

53

Table 3.5. ${ }^{1} \mathrm{H}(600 \mathrm{MHz})$ and ${ }^{13} \mathrm{C}(150 \mathrm{MHz})$ NMR data for cyclo(L-Trp-L-Pro) (53) $\left(\mathrm{CD}_{3} \mathrm{OD}\right)$

\begin{tabular}{cccccccc}
\hline & \multicolumn{9}{c}{${ }^{13} \mathrm{C}$} & \multicolumn{1}{c}{$\mathrm{H}$} & & HMBC \\
\cline { 2 - 6 } Position & $\delta(\mathrm{ppm})$ & mult & $\delta(\mathrm{ppm})$ & mult & $J(\mathrm{~Hz})$ & COSY & $\left({ }^{1} \mathrm{H}_{\text {to }}{ }^{13} \mathrm{C}\right)$ \\
\hline 2 & 125.6 & $\mathrm{CH}$ & 7.10 & $\mathrm{~s}$ & - & 8 & $3,3 \mathrm{a}, 7 \mathrm{a}$ \\
3 & 109.4 & $\mathrm{C}$ & - & - & - & - & - \\
$3 \mathrm{a}$ & 128.7 & $\mathrm{C}$ & - & - & - & - & - \\
4 & 119.8 & $\mathrm{CH}$ & 7.58 & $\mathrm{~d}$ & 8 & 5 & $6,7 \mathrm{a}$ \\
5 & 119.9 & $\mathrm{CH}$ & 7.01 & $\mathrm{t}$ & 7 & 4,6 & $3 \mathrm{a}, 7$ \\
6 & 122.6 & $\mathrm{CH}$ & 7.09 & $\mathrm{t}$ & 7 & 5,7 & $4,7 \mathrm{a}$ \\
7 & 112.2 & $\mathrm{CH}$ & 7.33 & $\mathrm{~d}$ & 8.2 & 6 & $3 \mathrm{a}, 5$ \\
$7 \mathrm{a}$ & 138.0 & $\mathrm{C}$ & - & - & - & - & - \\
8 & 29.2 & $\mathrm{CH}_{2}$ & 3.32 & $\mathrm{~m}$ & - & 2,9 & $2,3,3 \mathrm{a}, 9,14$ \\
9 & 57.2 & $\mathrm{CH}$ & 4.42 & $\mathrm{~m}$ & - & 8 & $3,8,11,14$ \\
11 & 170.7 & $\mathrm{C}$ & - & - & - & - & - \\
12 & 60.0 & $\mathrm{CH}$ & 4.00 & $\mathrm{ddd}$ & $10.9,6.3,1.8$ & $17(\mathrm{a}),(\mathrm{b})$ & 11,17 \\
14 & 167.4 & $\mathrm{C}$ & - & - & - & - & - \\
15 & 45.9 & $\mathrm{CH}_{2}$ & $3.46(\mathrm{a})$ & $\mathrm{m}$ & - & $15(\mathrm{~b}), 16(\mathrm{a}),(\mathrm{b})$ & 16 \\
& & & $3.27(\mathrm{~b})$ & $\mathrm{m}$ & - & $15(\mathrm{a}), 16(\mathrm{a}),(\mathrm{b})$ & - \\
16 & 22.5 & $\mathrm{CH}_{2}$ & $1.69(\mathrm{a})$ & $\mathrm{m}$ & - & $15(\mathrm{a}), 15(\mathrm{~b}), 16(\mathrm{~b}), 17(\mathrm{a})$ & - \\
& & & $1.47(\mathrm{~b})$ & $\mathrm{m}$ & - & $15(\mathrm{a}), 15(\mathrm{~b}), 16(\mathrm{a}), 17(\mathrm{~b})$ & - \\
17 & 29.1 & $\mathrm{CH}_{2}$ & $1.97(\mathrm{a})$ & $\mathrm{m}$ & - & $12,16(\mathrm{a}), 16(\mathrm{~b}), 17(\mathrm{~b})$ & 15 \\
& & & $0.93(\mathrm{~b})$ & $\mathrm{m}$ & - & $12,16(\mathrm{~b}), 17(\mathrm{a})$ & 12,16 \\
\hline
\end{tabular}

\subsubsection{Compounds from the $30 \% \mathrm{Me}_{2} \mathrm{CO} / \mathrm{H}_{2} \mathrm{O}$ fraction}

The $30 \% \mathrm{Me}_{2} \mathrm{CO} / \mathrm{H}_{2} \mathrm{O}$ fraction from the culture filtrate showed proton NMR signals that were indicative of secondary metabolites along with those pertaining to the cul- 
ture medium. To separate the compounds from the medium, size-exclusion (LH-20) chromatography was carried out on this fraction. The resulting fractions contained mixtures of similar compounds and were further separated by reversed-phase (HP20ss) chromatography, followed by HPLC purification. MS and NMR analysis on all fractions revealed that 13 more known 2,5-DKPs were isolated (Scheme 3.4).

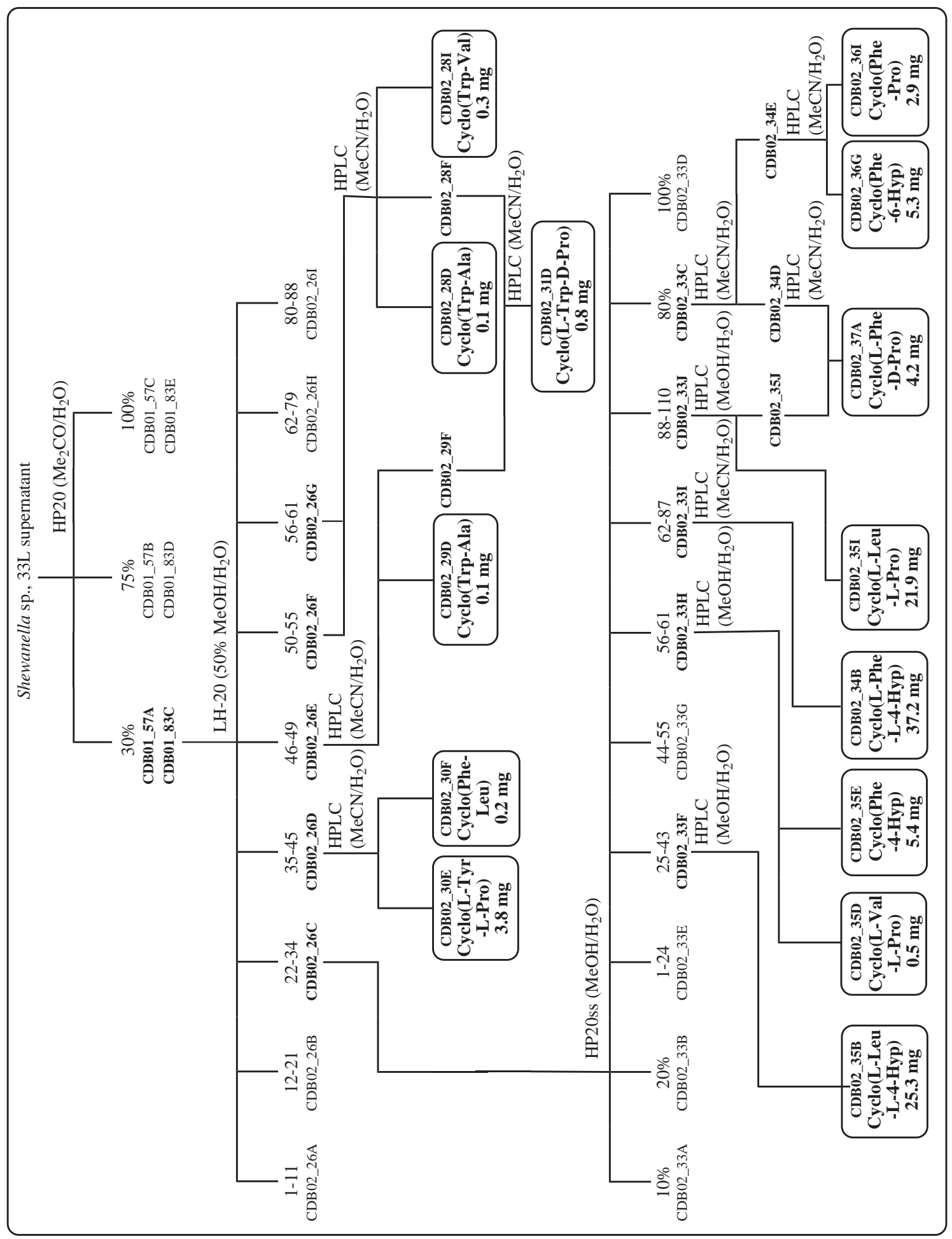

Scheme 3.4. Isolation of more 2,5-DKPs from the $30 \%$ fraction of Shewanella sp.. 


\section{Cyclo(L-Phe-L-4-Hyp)}

The molecular formula $\mathrm{C}_{14} \mathrm{H}_{16} \mathrm{~N}_{2} \mathrm{O}_{3}$ was confirmed for CDB02_34B by the presence of an HRESIMS $[\mathrm{M}+\mathrm{H}]^{+}$adduct at $\mathrm{m} / z 261.1237(\mathrm{~m} / \mathrm{z}, \Delta=0.0003)$, requiring eight DBEs. The ${ }^{13} \mathrm{C}$ NMR spectrum contained 12 distinct resonances $\left(\delta_{C} 171.3,167.0,137.4,131\right.$, $129.4,128.1,68.4,58.3,57.6,55.2,38.8,38.0)$. Two of the carbon resonances $\left(\delta_{C} 171.3\right.$ and $\delta_{C}$ 167.0) had chemical shifts similar to those seen for the two carbonyl groups in cyclo(L-Trp-L-Pro) (53), which suggested that this compound was another 2,5-DKP. This accounted for two nitrogen and two oxygen atoms in the molecule.

The ${ }^{1} \mathrm{H}$ NMR spectrum $\left(\mathrm{CD}_{3} \mathrm{OD}\right)$ contained resonances that accounted for 14 protons in the molecule. An HSQC experiment confirmed the attachment of all 14 protons to carbons, indicating the presence of two exchangeable protons. A deshielded methylene, $\mathrm{CH}_{2}-3\left(\delta_{H} 3.70(\mathrm{a}), 3.29(\mathrm{~b}) ; \delta_{C}\right.$ 55.2) and a highly deshielded methine group $\mathrm{CH}-4\left(\delta_{H}\right.$ 4.28; $\delta_{C}$ 68.4) along with another methylene $\mathrm{CH}_{2}-5\left(\delta_{H} 2.06(\mathrm{a}), 1.36(\mathrm{~b}) ; \delta_{C} 38.8\right)$, all belonging to the same spin system were observed in the ${ }^{1} \mathrm{H}$ NMR spectrum. COSY correlations between $\mathrm{H}-3$ (a) and $\mathrm{H}-4$, and $\mathrm{H}-4$ and $\mathrm{H}-5$ (b) established the connection between C-3 and C-5. Furthermore, HMBC correlations from H-5(a) to C-3 and C4, H-3(a) to C-5, and H-4 to C-3 confirmed this connectivity. No other COSY or HMBC correlations were evident for a carbon atom connected to C-3 and C-4. The deshielded nature of methylene $\mathrm{CH}_{2}-3$ suggested that it was connected to an amide nitrogen. Similarly, the highly deshielded nature of the methine suggested that C-4 was directly connected to a hydroxyl group (Figure 3.9). This accounted for the final oxygen atom and one exchangeable proton in the molecule.

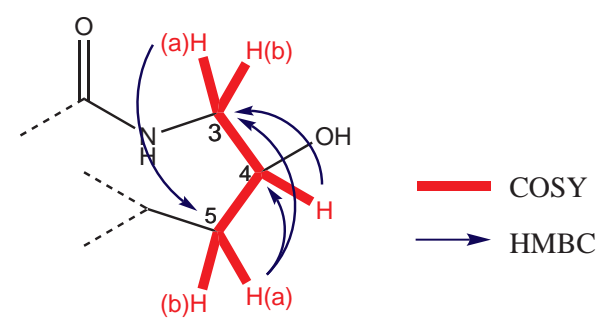

Figure 3.9. COSY and HMBC correlations establishing the connections between C-3 and C-5 in cyclo(L-Phe-L-4-Hyp). 
HMBC correlations were observed from $\mathrm{H}-3(\mathrm{a}), \mathrm{H}-5(\mathrm{~b})$ and $\mathrm{H}-4$ to methine $\mathrm{CH}-6$ $\left(\delta_{H} 4.37 ; \delta_{C} 58.3\right)$, along with COSY correlations between methylene $\mathrm{H}_{2}-5$ and $\mathrm{H}-6$, confirming that C-6 was directly connected to C-5. The presence of HMBC correlations from H-5(b) and H-6 to amide C-7 $\left(\delta_{C}\right.$ 171.3) extended the substructure to a 4hydroxyproline moiety in the molecule. This substructure also accounted for the final exchangeable proton. Furthermore, HMBC correlations were seen from methine H-9 $\left(\delta_{H}\right.$ $\left.4.48 ; \delta_{C} 57.6\right)$ to $\mathrm{C}-1, \mathrm{C}-6$ and C-7, confirming that C-9 was directly attached to amide C-1 $\left(\delta_{C} 167.0\right)$ and to the nitrogen atom of amide C-7 (Figure 3.10). This substructure accounted for four DBEs in the molecule.

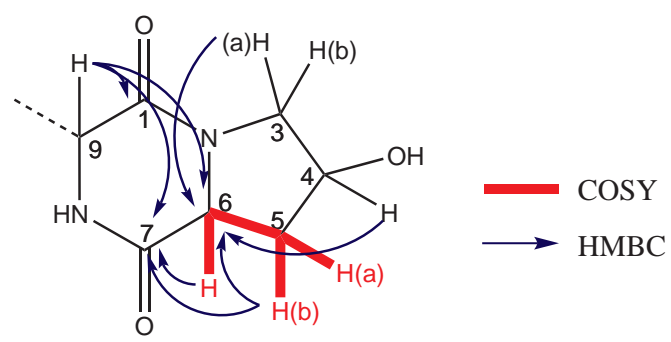

Figure 3.10. COSY and HMBC correlations establishing amino acid 4-hydroxyproline in cyclo(L-Phe-L-4-Hyp).

The substructure above confirmed that another 2,5-DKP had been isolated. A multiplet that integrated for five protons was seen in the aromatic region $\left(\delta_{H} 7.27,7.24,7.22\right)$, which was characteristic for a monosubstituted benzene ring. This also accounted for the four remaining DBEs. Monosubstituted benzene ring protons H-12/16 $\left(\delta_{H} 7.24 ; \delta_{C}\right.$ 131.0) showed HMBC correlations to methylene $\mathrm{C}-10\left(\delta_{H} 3.17 ; \delta_{C} 38.0\right)$ suggesting that C-10 was directly connected to C-11 $\left(\delta_{C}\right.$ 137.4) of the ring. HMBC correlations from methylene $\mathrm{H}_{2}-10$ to $\mathrm{C}-11$ and $\mathrm{C}-12 / 16$ confirmed this connection. A COSY correlation from $\mathrm{H}_{2}-10$ to $\mathrm{H}-9$ and $\mathrm{HMBC}$ correlations from $\mathrm{H}_{2}-10$ to C-9 and C-1 established the connection to the DKP ring (Figure 3.11).

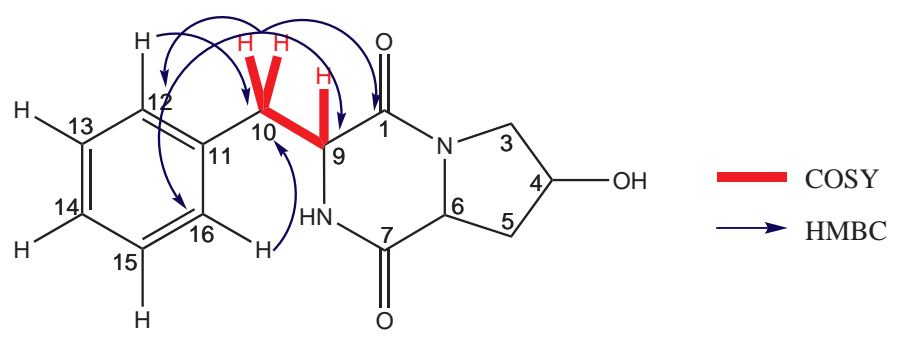

Figure 3.11. COSY and HMBC correlations establishing the connections between the monosubstituted benzene ring and 4-hydroxyproline in cyclo(L-Phe-L-4-Hyp). 
The elucidated structure showed that a known 2,5-DKP consisting of phenylalanine and 4-hydroxyproline had been isolated. The configurations of centres C-4, C-6 and C-9 were established based on comparisons of obtained NMR (Table 3.6) and specific rotation data with those in the literature. An $[\alpha]_{\mathrm{D}}^{25}$ of $-98(\mathrm{c}=1.77, \mathrm{MeOH})\left(\right.$ lit. $[\alpha]_{\mathrm{D}}^{20}=-90, \mathrm{c}=$ 1.0, EtOH) confirmed that cyclo(L-Phe-L-4-Hyp) (43) was isolated. ${ }^{106,168}$ MS/MS data obtained for this compound were also consistent with those in the literature. ${ }^{169}$<smiles>O=C1N[C@H](Cc2ccccc2)C(=O)N2C[C@H](O)C[C@H]12</smiles>

43

Table 3.6. ${ }^{1} \mathrm{H}(600 \mathrm{MHz})$ and ${ }^{13} \mathrm{C}(150 \mathrm{MHz})$ NMR data for cyclo(L-Phe-L-4-Hyp) (43) $\left(\mathrm{CD}_{3} \mathrm{OD}\right)$

\begin{tabular}{cccccccc}
\hline & \multicolumn{9}{c}{${ }^{13} \mathrm{C}$} & \multicolumn{3}{c}{$\mathrm{H}$} & & HMBC \\
\cline { 2 - 5 } Position & $\delta(\mathrm{ppm})$ & mult & $\delta(\mathrm{ppm})$ & mult & $J(\mathrm{~Hz})$ & COSY & $\left({ }^{1} \mathrm{H}\right.$ to $\left.{ }^{13} \mathrm{C}\right)$ \\
\hline 1 & 167.0 & $\mathrm{C}$ & - & - & - & - & - \\
3 & 55.2 & $\mathrm{CH}_{2}$ & $3.70(\mathrm{a})$ & $\mathrm{dd}$ & $13,5.1$ & $3(\mathrm{~b}), 4$ & $1,5,6$ \\
& & & $3.29(\mathrm{~b})$ & $\mathrm{d}$ & 13 & $3(\mathrm{a})$ & $4,5,6$ \\
4 & 68.4 & $\mathrm{CH}$ & 4.28 & $\mathrm{t}$ & 4.7 & $3(\mathrm{a}), 5(\mathrm{~b})$ & 3,6 \\
5 & 38.8 & $\mathrm{CH}_{2}$ & 2.06 & $\mathrm{dd}$ & $13,5.9$ & $5(\mathrm{~b}), 6$ & 3,4 \\
& & & $1.36(\mathrm{~b})$ & $\mathrm{ddd}$ & $24.7,12.6,4.7$ & $4,5(\mathrm{a}), 6$ & 6,7 \\
6 & 58.3 & $\mathrm{CH}$ & 4.37 & $\mathrm{ddd}$ & $12,5.9,1.6$ & $5(\mathrm{a}), 5(\mathrm{~b})$ & 5,7 \\
7 & 171.3 & $\mathrm{C}$ & - & - & - & - & - \\
9 & 57.6 & $\mathrm{CH}$ & 4.48 & $\mathrm{td}$ & $5.4,1.9$ & 10 & $1,6,7,10,11$ \\
10 & 38.0 & $\mathrm{CH}$ & 3.17 & $\mathrm{~m}$ & - & 9 & $1,9,11,12,16$ \\
11 & 137.4 & $\mathrm{C}$ & - & - & - & - & - \\
12 & 131.0 & $\mathrm{CH}$ & 7.24 & $\mathrm{~m}$ & - & - & 10,14 \\
13 & 129.4 & $\mathrm{CH}$ & 7.27 & $\mathrm{~m}$ & - & - & 11 \\
14 & 128.1 & $\mathrm{CH}$ & 7.22 & $\mathrm{~m}$ & - & $-\dagger$ & 12,16 \\
15 & 129.4 & $\mathrm{CH}$ & 7.27 & $\mathrm{~m}$ & - & $-\dagger$ & 11 \\
16 & 131.0 & $\mathrm{CH}$ & 7.24 & $\mathrm{~m}$ & - & $-\dagger$ & 10,14 \\
\hline
\end{tabular}

$\nmid \mathrm{COSY}$ correlations could not be resolved due to overlapping of peaks.

\section{Cyclo(L-Leu-L-4-Hyp)}

Positive ion HRESIMS analysis of CDB02_35B revealed an $[\mathbf{M}+\mathbf{H}]^{+}$adduct at $m / z$ $227.1392(\mathrm{~m} / \mathrm{z}, \Delta=0.0002)$, which corresponded to the molecular formula $\mathrm{C}_{11} \mathrm{H}_{18} \mathrm{~N}_{2} \mathrm{O}_{3}$ and four DBEs. The ${ }^{13} \mathrm{C}$ NMR spectrum contained 11 distinct resonances $\left(\delta_{C} 173.1\right.$, 169.0, 69.1, 58.7, 55.1, 54.6, 39.3, 38.1, 25.8, 23.3, 22.2). The ${ }^{1} \mathrm{H}$ NMR spectrum $\left(\mathrm{CD}_{3} \mathrm{OD}\right)$ contained resonances that accounted for 16 protons in the molecule. An HSQC experiment confirmed the attachment of all 16 protons to carbons, indicating the presence 
of two exchangeable protons. The presence of two highly deshielded carbon atoms, C-1 $\left(\delta_{C} 169.0\right)$ and C-7 $\left(\delta_{C}\right.$ 173.1), which were indicative of amides, along with two characteristic deshielded methines, $\mathrm{CH}-6\left(\delta_{H} 4.53 ; \delta_{C} 58.7\right)$ and $\mathrm{CH}-9\left(\delta_{H} 4.18 ; \delta_{C}\right.$ 54.6), suggested that this compound was another 2,5-DKP. A deshielded methylene $\mathrm{CH}_{2}$ $3\left(\delta_{H} 3.65(\mathrm{a}), 3.43(\mathrm{~b}) ; \delta_{C} 55.1\right)$, a highly deshielded methine $\mathrm{CH}-4\left(\delta_{H} 4.47 ; \delta_{C} 69.1\right)$ and another methylene $\mathrm{CH}_{2}-5\left(\delta_{H} 2.28(\mathrm{a}), 2.08(\mathrm{~b}) ; \delta_{C} 38.1\right)$ were seen belonging to the same spin system and were indicative of 4-hydroxyproline as one of the amino acids. This accounted for all four DBEs in the molecule.

Two methyl doublets, $\mathrm{CH}_{3}-12\left(\delta_{H} 0.96 ; \delta_{C} 23.3\right)$ and $\mathrm{CH}_{3}-13\left(\delta_{H} 0.95 ; \delta_{C} 22.2\right)$, were seen in the ${ }^{1} \mathrm{H}$ NMR spectrum. HMBC correlations from both methyl groups to methine $\mathrm{CH}-11\left(\delta_{H} 1.90 ; \delta_{C} 25.8\right)$ established a gem-dimethyl group in the second amino acid. COSY correlations from $\mathrm{H}-11$ to methylene $\mathrm{CH}_{2}-10\left(\delta_{H} 1.91\right.$ (a), 1.51 (b); $\left.\delta_{C} 39.3\right)$ established a connection from C-11 to C-10. COSY correlations between $\mathrm{H}_{2}-10$ and methine H-9 established the connection to the DKP ring, which was confirmed by HMBC correlations from $\mathrm{H}-11$ and $\mathrm{H}_{2}-10$ to $\mathrm{C}-9$ (Figure 3.12).

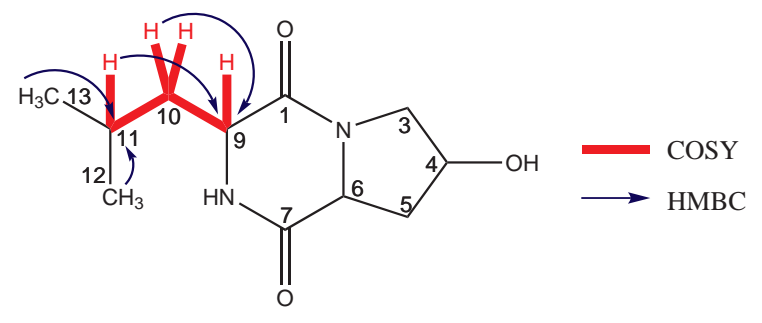

Figure 3.12. COSY and HMBC correlations establishing leucine in cyclo(L-Leu-L-4-Hyp).

The established structure showed that a 2,5-DKP containing leucine and 4-hydroxyproline had been isolated. The NMR (Table 3.7), MS and MS/MS data, along with an $[\alpha]_{D}^{25}$ of $-123(\mathrm{c}=1.15, \mathrm{MeOH})\left(\right.$ lit. $\left.[\alpha]_{\mathrm{D}}^{20}=-108, \mathrm{c}=1.0, \mathrm{EtOH}\right)$ confirmed that cyclo(L-Leu-L4-Hyp) (42) was isolated. ${ }^{100,168,169}$<smiles>CC(C)C[C@H]1NC(=O)[C@@H]2C[C@@H](O)CN2C1=O</smiles> 
Table 3.7. ${ }^{1} \mathrm{H}(600 \mathrm{MHz})$ and ${ }^{13} \mathrm{C}(150 \mathrm{MHz})$ NMR data for cyclo(L-Leu-L-4-Hyp) (42) $\left(\mathrm{CD}_{3} \mathrm{OD}\right)$

\begin{tabular}{|c|c|c|c|c|c|c|c|}
\hline \multirow[b]{2}{*}{ Position } & \multicolumn{2}{|c|}{${ }^{13} \mathrm{C}$} & \multicolumn{3}{|c|}{${ }^{1} \mathrm{H}$} & \multirow[b]{2}{*}{ COSY } & \multirow{2}{*}{$\begin{array}{c}\text { HMBC } \\
\left({ }^{1} \mathrm{H} \text { to }{ }^{13} \mathrm{C}\right)\end{array}$} \\
\hline & $\delta(\mathrm{ppm})$ & mult & $\delta(\mathrm{ppm})$ & mult & $J(\mathrm{~Hz})$ & & \\
\hline 1 & 169.0 & $\mathrm{C}$ & - & - & - & - & - \\
\hline \multirow[t]{2}{*}{3} & 55.1 & $\mathrm{CH}_{2}$ & $3.65(\mathrm{a})$ & $\mathrm{dd}$ & $13,4.5$ & $3(\mathrm{~b}), 4$ & 6 \\
\hline & & & $3.43(\mathrm{~b})$ & $\mathrm{d}$ & 13 & 3(a) & $4,5,6$ \\
\hline 4 & 69.1 & $\mathrm{CH}$ & 4.47 & $\mathrm{t}$ & 4.2 & $3(a), 5(b)$ & 3,6 \\
\hline \multirow[t]{2}{*}{5} & 38.1 & $\mathrm{CH}_{2}$ & 2.28 & $\mathrm{dd}$ & $13.3,6.5$ & $5(b), 6$ & 3,4 \\
\hline & & & $2.08(\mathrm{~b})$ & $\mathrm{m}$ & - & $4,5(a), 6$ & 6,7 \\
\hline 6 & 58.7 & $\mathrm{CH}$ & 4.53 & $\mathrm{dd}$ & $11.2,6.5$ & $5(a), 5(b)$ & 5,7 \\
\hline 7 & 173.1 & $\mathrm{C}$ & - & - & - & - & - \\
\hline 9 & 54.6 & $\mathrm{CH}$ & 4.18 & $\mathrm{~m}$ & - & $10(a), 10(b)$ & $1,10,11$ \\
\hline \multirow[t]{2}{*}{10} & 39.3 & $\mathrm{CH}_{2}$ & 1.91(a) & $\mathrm{m}$ & - & $9,10(b), 11$ & $1,9,11,12,13$ \\
\hline & & & $1.51(\mathrm{a})$ & $\mathrm{m}$ & - & $9,10(\mathrm{a}), 11$ & $1,9,11,12,13$ \\
\hline 11 & 25.8 & $\mathrm{CH}$ & 1.90 & $\mathrm{~m}$ & - & $10(\mathrm{a}), 10(\mathrm{~b}), 12,13$ & 9,10 \\
\hline 12 & 23.3 & $\mathrm{CH}_{3}$ & 0.96 & $\mathrm{~d}$ & 6.4 & 11 & $10,11,13$ \\
\hline 13 & 22.2 & $\mathrm{CH}_{3}$ & 0.95 & $\mathrm{~d}$ & 6.4 & 11 & $10,11,12$ \\
\hline
\end{tabular}

\section{Cyclo(Phe-4-Hyp)}

Detection of an $[\mathrm{M}+\mathrm{H}]^{+}$adduct at $\mathrm{m} / \mathrm{z} 261.1237(\mathrm{~m} / \mathrm{z} \Delta=0.0003)$ indicated a molecular formula of $\mathrm{C}_{14} \mathrm{H}_{16} \mathrm{~N}_{2} \mathrm{O}_{3}$ for CDB02_35E. The ${ }^{13} \mathrm{C}$ and ${ }^{1} \mathrm{H}$ NMR spectra showed aromatic peaks pertaining to a monosubstituted benzene ring, which was indicative of phenylalanine. The other amino acid was identified as 4-hydroxyproline due to the presence of two methylene groups and a highly deshielded methine group in the same spin system. These data suggested that the compound isolated was a stereoisomer of 43. The MS/MS data for this compound were also similar to those obtained for $\mathbf{4 3}$. The configuration of the amino acids was not established due to the presence of an impurity in the fraction, which meant that specific rotation measurements would be inconclusive. However, comparison of the recorded NMR data with those in the literature revealed that either the L-D or the D-L stereoisomer of cyclo(Phe-4-Hyp) (94) had been isolated. ${ }^{107}$<smiles>O=C1NC(Cc2ccccc2)C(=O)N2CC(O)CC12</smiles>

94 


\section{Cyclo(Phe-6-Hyp)}

An $[\mathrm{M}+\mathrm{H}]^{+}$adduct was observed for CDB02_36G at $\mathrm{m} / \mathrm{z} 261.1241(\mathrm{~m} / \mathrm{z}, \Delta=0.0007)$ that was suitable for a molecular formula of $\mathrm{C}_{14} \mathrm{H}_{16} \mathrm{~N}_{2} \mathrm{O}_{3}$, which was the same as DKP 43. The NMR spectra showed evidence that phenylalanine was one of the amino acids. Three methylene groups $\left(\delta_{H} 1.94 ; \delta_{C} 19.2\right.$ and $\left.\delta_{H} 1.98-2.24 ; \delta_{C} 36.8\right)$, one of which was deshielded $\left(\delta_{H} 3.66 ; \delta_{C} 45.8\right)$, were observed in the same spin system, suggesting that the other amino acid was a derivative of proline. COSY correlations between all three methylene groups, along with an HMBC correlation from one methylene $\left(\delta_{H} 1.98\right.$ $\left.2.24 ; \delta_{C} 36.8\right)$ to the DKP ring carbon $\left(\delta_{C} 86.6\right)$ confirmed this substructure. The DKP ring carbon belonging to the proline moiety was highly deshielded and also nonprotonated, which confirmed that a hydroxyl group was directly connected to it. Hence, a regioisomer of 43, cyclo(Phe-6-Hyp) (95) that contains 6-hydroxyproline instead of 4hydroxyproline was isolated. The fraction was a mixture of compounds and therefore its specific rotation could not be measured, and hence the configuration of the amino acids was not established. The obtained NMR data was compared with published data, and it was concluded that either the L-L or the D-D enantiomer had been isolated. ${ }^{104} \mathrm{MS} / \mathrm{MS}$ analysis on this compound showed five product ions, which are presented below.

Table 3.8. MS/MS data for cyclo(Phe-6-Hyp)

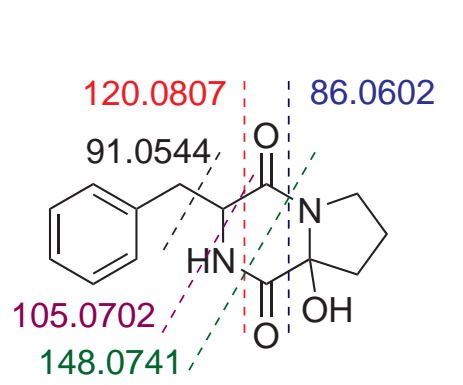

\begin{tabular}{|l|l|l|l|}
\hline $\boldsymbol{m} / \boldsymbol{z}$ & Calc. $\boldsymbol{m} / \boldsymbol{z}$ & Fragment & $\boldsymbol{m} / \boldsymbol{z} \Delta$ \\
\hline 148.0741 & 148.0757 & $\mathrm{C}_{9} \mathrm{H}_{10} \mathrm{NO}$ & -0.0016 \\
\hline 120.0807 & 120.0808 & $\mathrm{C}_{8} \mathrm{H}_{10} \mathrm{~N}$ & -0.0001 \\
\hline 105.0702 & 105.0699 & $\mathrm{C}_{8} \mathrm{H}_{9}$ & 0.0003 \\
\hline 91.0544 & 91.0542 & $\mathrm{C}_{7} \mathrm{H}_{7}$ & 0.0002 \\
\hline 86.0602 & 86.0600 & $\mathrm{C}_{4} \mathrm{H}_{8} \mathrm{NO}$ & 0.0002 \\
\hline
\end{tabular}

95

\section{Cyclo(Phe-Pro)}

Analysis of the $[\mathrm{M}+\mathrm{H}]^{+}$adduct observed at $\mathrm{m} / \mathrm{z} 245.1289(\mathrm{~m} / \mathrm{z} \Delta=0.0004)$ for CDB02_36I established a molecular formula of $\mathrm{C}_{14} \mathrm{H}_{16} \mathrm{~N}_{2} \mathrm{O}_{2}$. The ${ }^{1} \mathrm{H}$ NMR spectrum showed peaks that were similar to those seen for DKP 43. The three major differences were the loss of one oxygen atom, the presence of a methylene group instead of a 
methine and an upfield shift of the DKP ring methine in the proline moiety. These differences suggested that this compound contained proline instead of 4-hydroxyproline. The recorded spectroscopic data confirmed that the compound isolated was cyclo(PhePro) (96). ${ }^{169}$ Owing to an impurity of the fraction, its specific rotation could not be measured, and hence the configuration of the amino acids was not established. However, comparison of the obtained NMR data to the literature indicated that either the L-L or the D-D enantiomer had been isolated. ${ }^{106}$ Unfortunately, a majority of the compound degraded before a ${ }^{13} \mathrm{C}$ NMR spectrum could be obtained, and as a result, the presented ${ }^{13} \mathrm{C}$ NMR spectrum appears more crowded than the ${ }^{1} \mathrm{H}$ NMR spectrum (see Appendix D).

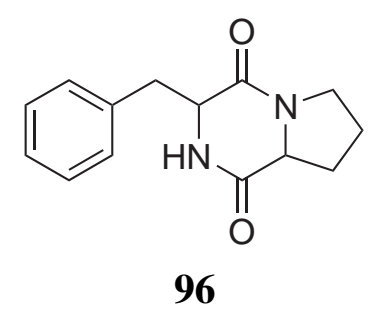

\section{Cyclo(L-Phe-D-Pro)}

The HRESIMS $[\mathrm{M}+\mathrm{H}]^{+}$adduct at $\mathrm{m} / \mathrm{z} 245.1283(\mathrm{~m} / \mathrm{z}, \Delta=-0.0002)$ afforded the molecular formula $\mathrm{C}_{14} \mathrm{H}_{16} \mathrm{~N}_{2} \mathrm{O}_{2}$ for CDB02_37A. The ${ }^{13} \mathrm{C}$ and ${ }^{1} \mathrm{H}$ NMR spectra showed aromatic peaks pertaining to a monosubstituted benzene ring that were characteristic for phenylalanine. The other amino acid was identified as proline due to the presence of three methylene groups in the same spin system. The recorded spectroscopic data, along with an $[\alpha]_{\mathrm{D}}^{25}$ of $+61(\mathrm{c}=0.28, \mathrm{MeOH})\left(\right.$ lit. $[\alpha]_{\mathrm{D}}^{20}=+67, \mathrm{c}=$ not reported, $\left.\mathrm{MeOH}\right)$, were in agreement with published data and confirmed that the compound isolated was another known 2,5-DKP, cyclo(L-Phe-D-Pro) (36). ${ }^{169,170}$<smiles>O=C1N[C@@H](Cc2ccccc2)C(=O)N2CCC[C@H]12</smiles>

36

\section{Cyclo(Phe-Leu)}

The observation of an $[\mathrm{M}+\mathrm{H}]^{+}$adduct at $\mathrm{m} / \mathrm{z} 261.1596(\mathrm{~m} / \mathrm{z}, \Delta=-0.0002)$ indicated a molecular formula of $\mathrm{C}_{15} \mathrm{H}_{20} \mathrm{~N}_{2} \mathrm{O}_{2}$ for CDB02_30F. The NMR spectra showed evidence 
that phenylalanine was one of the amino acids. The other amino acid was identified as leucine due to the presence of two methyl doublets, a methine and a methylene group in the same spin system. The NMR, MS and MS/MS data confirmed that the compound isolated was another known 2,5-DKP, cyclo(Phe-Leu) (97). ${ }^{167}$ Due to insufficient mass of the compound, specific rotation measurements were not obtained. Although the configuration of the amino acids was not known, spectroscopic data of the compound suggested that it was either the L-L or the D-D enantiomer. ${ }^{171}$

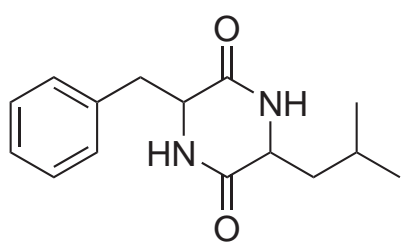

97

\section{Cyclo(L-Leu-L-Pro)}

HRESIMS data for CDB02_35I showed an $[\mathrm{M}+\mathrm{H}]^{+}$adduct at $\mathrm{m} / \mathrm{z} 211.1445(\mathrm{~m} / \mathrm{z} \Delta=$ 0.0004) that was consistent with a molecular formula of $\mathrm{C}_{11} \mathrm{H}_{18} \mathrm{~N}_{2} \mathrm{O}_{2}$. The NMR spectra showed peaks that were very similar to those seen for DKP 42, with the three major differences being the loss of one oxygen atom, the presence of a methylene group instead of a methine and an upfield shift of the DKP ring methine in the proline moiety. These differences suggested that this compound contained proline instead of 4-hydroxyproline. The specific rotation of $-127(\mathrm{c}=0.89, \mathrm{MeOH})\left(\right.$ lit. $\left.[\alpha]_{\mathrm{D}}^{20}=-136, \mathrm{c}=0.12, \mathrm{EtOH}\right)$ and spectroscopic data were all consistent with published data and confirmed that cyclo(LLeu-L-Pro) (44) was isolated. ${ }^{100,169,172}$

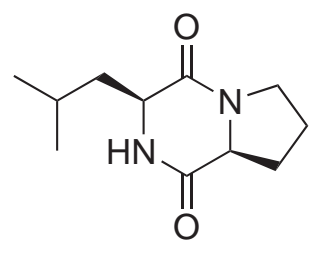

44

\section{Cyclo(L-Val-L-Pro)}

The presence of an $[\mathrm{M}+\mathrm{H}]^{+}$adduct at $\mathrm{m} / \mathrm{z} 197.1290(\mathrm{~m} / \mathrm{z} \Delta=0.0005)$ suggested a molecular formula of $\mathrm{C}_{10} \mathrm{H}_{16} \mathrm{~N}_{2} \mathrm{O}_{2}$ for CDB02_35D. The ${ }^{13} \mathrm{C}$ and ${ }^{1} \mathrm{H}$ NMR spectra showed three methylene groups that were indicative of proline. Two methyl doublets 
$\left(\delta_{H} 0.94 ; \delta_{C} 16.7\right.$ and $\left.\delta_{H} 1.09 ; \delta_{C} 18.8\right)$ and a methine septet $\left(\delta_{H} 2.49 ; \delta_{C} 30.0\right)$ were also observed in the same spin system. COSY and HMBC correlations between these groups established an isopropyl group in the second amino acid. The methine proton of the isopropyl group showed a COSY correlation to a DKP ring methine proton $\left(\delta_{H}\right.$ $\left.4.03 ; \delta_{C} 61.4\right)$ and also showed HMBC correlations to carbon atoms within the DKP ring, establishing a direct connection between the two. Altogether, these correlations confirmed that the second amino acid was valine. The NMR, MS and MS/MS data, along with an $[\alpha]_{\mathrm{D}}^{25}$ of $-150(\mathrm{c}=0.04, \mathrm{MeOH})\left(\right.$ lit. $\left.[\alpha]_{\mathrm{D}}^{22}=-143, \mathrm{c}=0.2, \mathrm{EtOH}\right)$, were in agreement with those in the literature and confirmed that the compound isolated was another known 2,5-DKP, cyclo(L-Val-L-Pro) (41). ${ }^{100,101,173}$

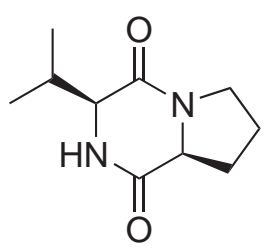

41

\section{Cyclo(L-Tyr-L-Pro)}

An $[\mathrm{M}+\mathrm{H}]^{+}$adduct that was observed at $\mathrm{m} / \mathrm{z} 261.1233(\mathrm{~m} / \mathrm{z} \Delta=-0.0001)$ for CDB02_30E revealed a molecular formula of $\mathrm{C}_{14} \mathrm{H}_{16} \mathrm{~N}_{2} \mathrm{O}_{3}$, which was isomeric with DKP 43. The NMR spectra showed evidence that proline was one of the amino acids. However, there was no indication of a monosubstituted benzene ring in the molecule, which suggested that this compound was a regioisomer of 43. Two proton doublets $\left(\delta_{H}\right.$ 7.04; $\delta_{C} 131.8$ and $\left.\delta_{H} 6.70 ; \delta_{C} 115.9\right)$ that integrated for two protons each were observed in the aromatic region of the ${ }^{1} \mathrm{H}$ NMR spectrum. COSY correlations between the two sets of methines and HMBC correlations to the surrounding non-protonated aromatic carbons $\left(\delta_{C} 157.8,127.8\right)$ established a 1,4-disubstituted benzene ring in the molecule. One of the carbon atoms in the 1,4-disubstituted benzene ring was highly deshielded $\left(\delta_{C} 157.8\right)$, which suggested that it was substituted with a hydroxyl group. An HMBC correlation from the aromatic protons $\left(\delta_{H} 7.04\right)$ to a methylene group $\left(\delta_{H} 3.09\right.$ (a), 3.02 (b); $\delta_{C}$ 37.5), along with COSY correlations between the methylene and a DKP ring methine proton $\left(\delta_{H} 4.37 ; \delta_{C} 57.9\right)$ established a connection between the two. Collectively, these correlations confirmed that the other amino acid was tyrosine. All recorded data including 
an $[\alpha]_{\mathrm{D}}^{25}$ of $-59(\mathrm{c}=0.25, \mathrm{MeOH})\left(\right.$ lit. $\left.[\alpha]_{\mathrm{D}}^{24}=-58, \mathrm{c}=0.50, \mathrm{MeOH}\right)$ were consistent with published data and confirmed that cyclo(L-Tyr-L-Pro) (38) had been isolated. ${ }^{173-175}$

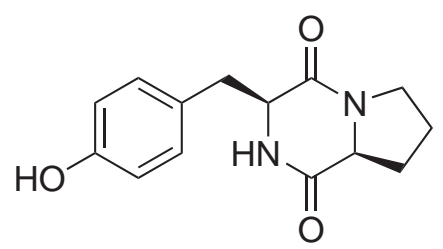

38

\section{Cyclo(L-Trp-D-Pro)}

HRESIMS analysis of CDB02_31D showed an $[\mathrm{M}+\mathrm{H}]^{+}$adduct at $\mathrm{m} / \mathrm{z} 284.1388(\mathrm{~m} / \mathrm{z}$ $\Delta=-0.0006)$ that corresponded to the molecular formula $\mathrm{C}_{16} \mathrm{H}_{17} \mathrm{~N}_{3} \mathrm{O}_{2}$, which was the same as DKP 53. The MS/MS and NMR data for this compound were also very similar to those obtained for $\mathbf{5 3}$, with major differences visible in the chemical shifts of the DKP ring methines, which suggested that it was a stereoisomer of 53. The MS, NMR and specific rotation data $\left([\alpha]_{\mathrm{D}}^{25}\right.$ of $\left.+94(\mathrm{c}=0.05, \mathrm{MeOH})\right)\left(\right.$ lit. $\left.[\alpha]_{\mathrm{D}}^{20}=+68, \mathrm{c}=0.1, \mathrm{MeOH}\right)$ suggested that the cyclo(L-Trp-D-Pro) (54) stereoisomer had been isolated. ${ }^{117}$

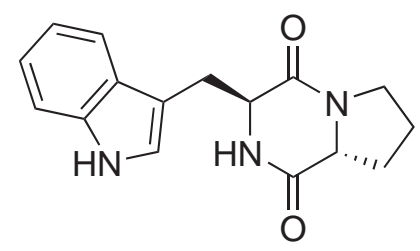

54

\section{$\underline{\text { Cyclo(Trp-Ala) }}$}

The molecular formula $\mathrm{C}_{14} \mathrm{H}_{15} \mathrm{~N}_{3} \mathrm{O}_{2}$ was determined for CDB02 28D from the HRESIMS $[\mathrm{M}+\mathrm{H}]^{+}$adduct at $\mathrm{m} / z$ 258.1242 $(\mathrm{m} / z, \Delta=0.0005)$. The ${ }^{13} \mathrm{C}$ and ${ }^{1} \mathrm{H}$ NMR spectra showed aromatic peaks pertaining to an indole moiety, which was indicative of tryptophan. Additionally, one methyl doublet $\left(\delta_{H} 0.40 ; \delta_{C} 19.5\right)$ that showed a COSY correlation to one of the 2,5-DKP ring methine protons $\left(\delta_{H} 3.58 ; \delta_{C} 49.7\right)$ was observed in the NMR spectra, which was indicative of alanine as the second amino acid. The MS and NMR data confirmed that the compound isolated was another known 2,5-DKP, cyclo(Trp-Ala) (98). MS/MS analysis on this compound only showed one product ion, which is presented below. Owing to an insufficient amount of the compound, specific rotation measurements could not be carried out. Despite the unknown configuration of 
the amino acids, recorded spectroscopic data indicated that either the L-L or the D-D enantiomer had been isolated. ${ }^{176}$

Table 3.9. MS/MS data for cyclo(Trp-Ala)

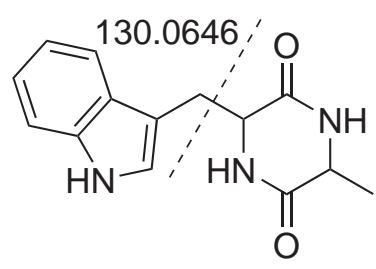

\begin{tabular}{|l|l|l|l|}
\hline $\boldsymbol{m} / \boldsymbol{z}$ & Calc. $\boldsymbol{m} / \boldsymbol{z}$ & Fragment & $\boldsymbol{m} / \boldsymbol{z} \Delta$ \\
\hline 130.0646 & 130.0651 & $\mathrm{C}_{9} \mathrm{H}_{8} \mathrm{~N}$ & -0.0005 \\
\hline
\end{tabular}

98

\section{Cyclo(Trp-Val)}

The $[\mathrm{M}+\mathrm{Na}]^{+}$adduct at $\mathrm{m} / z 308.1369(\mathrm{~m} / \mathrm{z} \Delta=0.0000)$ was observed by HRESIMS for CDB02_28I and afforded a molecular formula of $\mathrm{C}_{16} \mathrm{H}_{19} \mathrm{~N}_{3} \mathrm{O}_{2}$. The NMR spectra showed evidence that tryptophan was one of the amino acids. The other amino acid was identified as valine due to the presence of two methyl doublets and a methine group in the same spin system. The MS and NMR data were in agreement with those published for cyclo(Trp-Val) (99). MS/MS analysis on this compound only showed one product ion, which is presented below. The configuration of the amino acids could not be established due to the small amount of compound isolated. However, comparison of the obtained NMR data to those in the literature suggested that either the L-L or the D-D enantiomer had been isolated. ${ }^{177}$

Table 3.10. MS/MS data for cyclo(Trp-Val)<smiles>CC(C)C1CC(C)(C)C(Cc2c[nH]c3ccccc23)C(=O)N1</smiles>

\begin{tabular}{|l|l|l|l|}
\hline $\boldsymbol{m} / \boldsymbol{z}$ & Calc. $\boldsymbol{m} / \boldsymbol{z}$ & Fragment & $\boldsymbol{m} / \boldsymbol{z} \Delta$ \\
\hline 130.0634 & 130.0651 & $\mathrm{C}_{9} \mathrm{H}_{8} \mathrm{~N}$ & -0.0017 \\
\hline
\end{tabular}




\subsection{Biological Testing at VUW}

As discussed in Section 3.1.2, simple DKPs have shown inhibition against a variety of fungi, with activities ranging from moderate to potent. The mechanism of action for this activity has not fully been elucidated, but some research has been done in the past using the yeast Saccharomyces cerevisiae. In 1996, cyclo(L-Arg-D-Pro) (100) was isolated from Pseudomonas sp. IZ208 as a chitinase inhibitor. ${ }^{178}$ Chitinase is an enzyme that hydrolyses chitin, which is a linear polymer of $\mathrm{N}$-acetylglucosamine and is an essential component in the cell walls of fungi. S. cerevisiae are known to use chitinases during cell separation, whereas $C$. albicans have been suggested to utilise these enzymes when undergoing morphological changes from the non-pathogenic yeast form to the pathogenic filamentous form. ${ }^{179}$ Shortly after its isolation, in vivo tests on DKP 100 showed, as expected, that it inhibited the separation of daughter cells in cultures of S. cerevisiae and prevented the progression of $C$. albicans from yeast to the infective form. ${ }^{180}$ It was also found that while cell separation was inhibited, no effect was observed on the growth of both yeasts. Following these results, Houston et al. investigated the crystal structure of DKP 100 in complex with the enzyme and found that it exerts its activity by mimicking a reaction intermediate (101). ${ }^{179}$ The group went on to explore the activities of similar DKPs 24, 38, 57, and cyclo(L-Arg-L-Pro) (102) in cultures of S. cerevisiae and when in complex with chitinase. ${ }^{181}$ The study concluded that DKP 57 had the highest cell separation inhibitory activity in $S$. cerevisiae, albeit with a low $\mathrm{IC}_{50}$ of $1.1 \mathrm{mM}$ for chitinase inhibition (calculated through a fluorescence-based assay for chitinase), and that the cyclo(Gly-L-Pro) residue alone is sufficient for binding family 18 chitinases and exerting this inhibitory activity, which can be altered by changing the non-proline residue.<smiles>N=C(N)NCCC[C@@H]1NC(=O)[C@@H]2CCCN2C1=O</smiles>

100<smiles>[R]OC1C(CO)O[C@H]2OC(C)N[C@H]2[C@H]1O</smiles>

101<smiles>N=C(N)NCCC[C@H]1NC(=O)[C@@H]2CCCN2C1=O</smiles>

102

The studies described above focussed only on simple proline DKPs and their inhibition of cell separation in S. cerevisiae, with no proper results reported on growth inhibition. 
As a result, DKPs 42, 43 and 44 were submitted for yeast chemical genetic profiling using wild-type $S$. cerevisiae to establish their activities, in addition to a mutant deletion strain library to identify any other modes of action. These three DKPs differ from those previously tested not only in the non-proline residue but two also contain a 4hydroxyproline residue, which could potentially affect their antifungal activity. Due to unforeseen circumstances such as machine malfunction and inavailability, only preliminary results were available for inclusion in this thesis. For the initial growth assay, all three DKPs were tested against wild-type S. cerevisiae (BY4741) at concentrations of $30,45,60,75,90,120,150$ and $180 \mu \mathrm{M}$. The results (Figure 3.13, 3.14, 3.15) showed that at the highest concentration of $180 \mu \mathrm{M}$, all three compounds failed to exhibit significant acitvity ( $\mathrm{p}>0.05$ ). The growth curve for DKP 43 (Figure 3.14) shows that at $30 \mu \mathrm{M}$, inhibition was observed after 17 hours of incubation. However, this observation was attributed to an anomaly of the plate reader and should not be considered accurate.

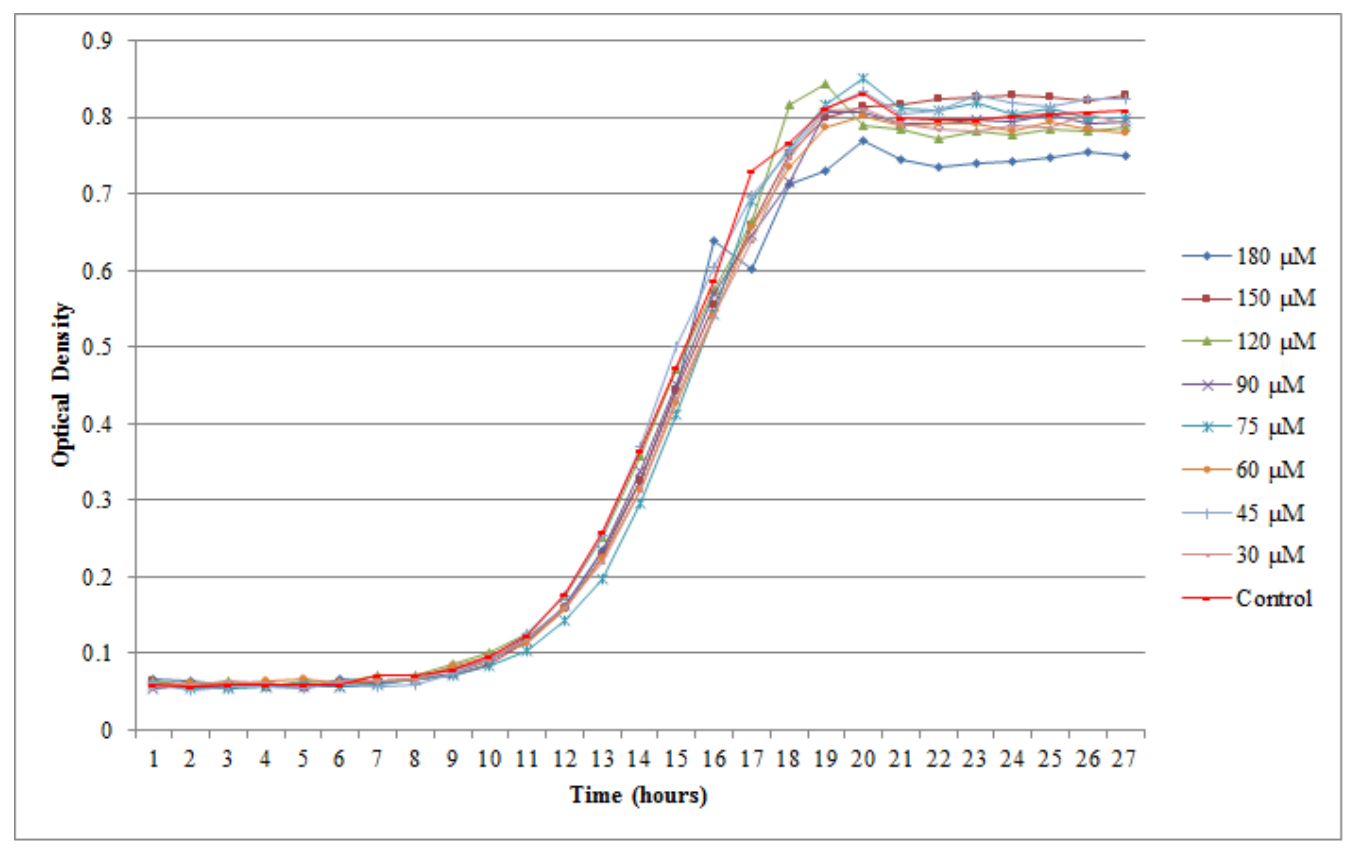

Figure 3.13. Growth curve for cyclo(L-Leu-L-4-Hyp) (42) against wild-type $S$. cerevisiae.

S. cerevisiae are known to contain an extensive network of membrane-bound pumps, known as the pleiotropic drug resistance network, whose function is to eject drugs out of the cell as a defense mechanism. ${ }^{54}$ Thus, these efflux pumps may prevent some compounds from reaching concentrations that affect growth. It is possible that the three DKPs did not exhibit activity in the wild-type strain due to the presence of these pumps 


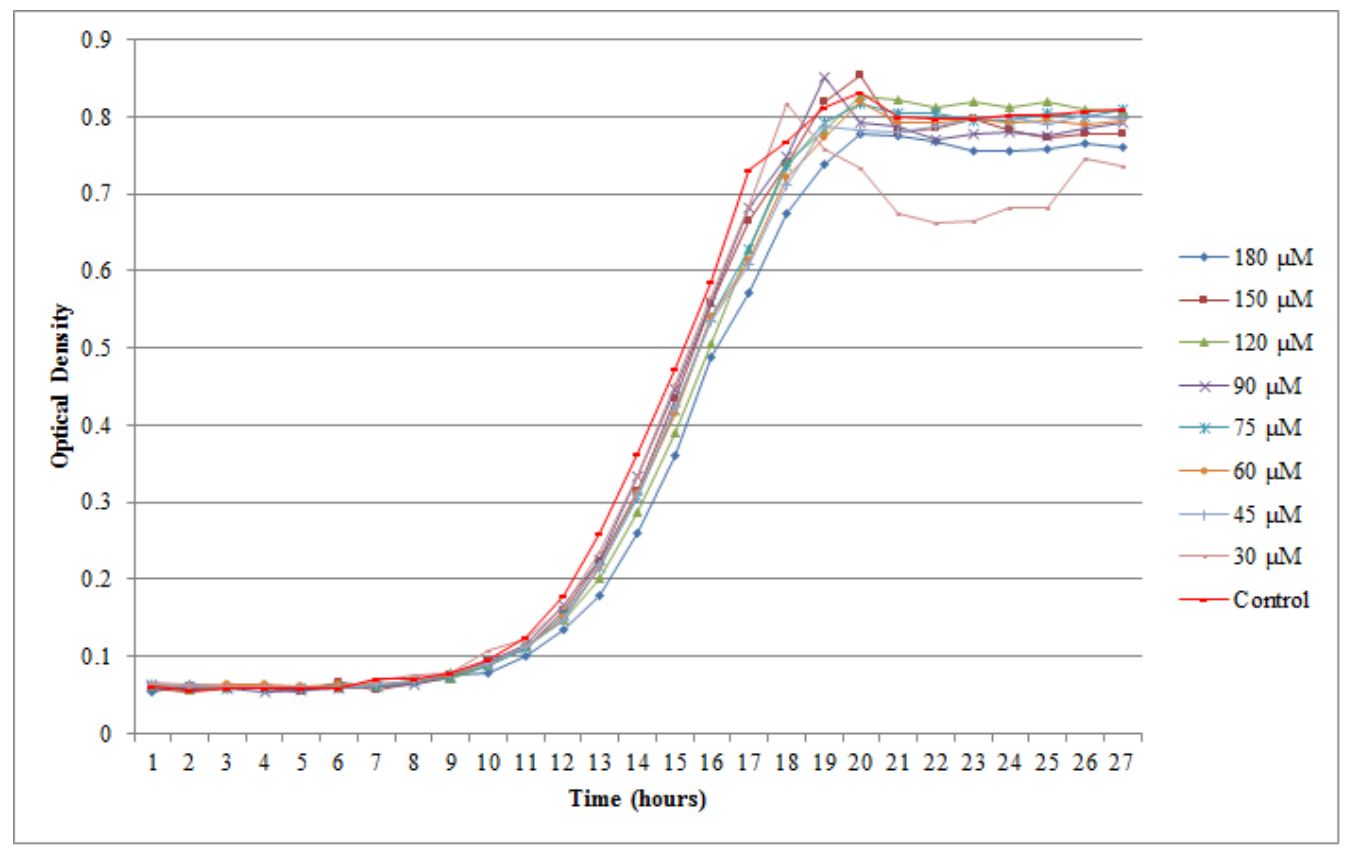

Figure 3.14. Growth curve for cyclo(L-Phe-L-4-Hyp) (43) against wild-type $S$. cerevisiae.

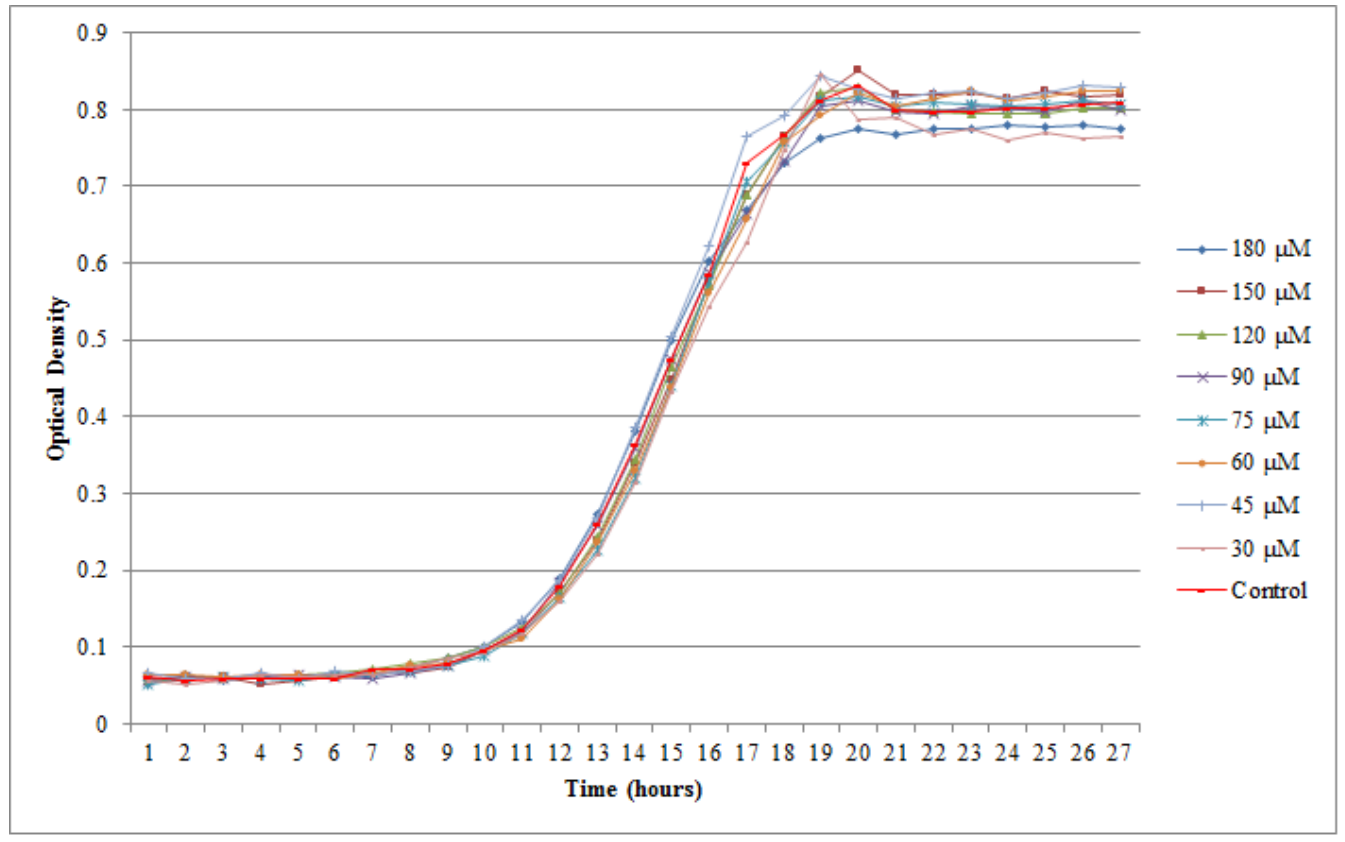

Figure 3.15. Growth curve for cyclo(L-Leu-L-Pro) (44) against wild-type $S$. cerevisiae.

and as a result, they will be tested in a drug efflux pump knockout strain $(\Delta p d r)$, which could potentially result in inhibitory activity. Another possibility is that the DKPs are only active at millimolar concentrations similar to those reported in studies carried out by Houston et al. on other DKP compounds. ${ }^{181}$ Consequently, the three DKPs will also be tested at higher concentrations in order to establish their activities, if any, and will then be subjected to screening against the mutant deletion library. These results could potentially contribute to the understanding of SAR for this class of compounds as antifungals. 


\section{Chapter 4}

\section{Concluding Remarks}

The marine and extremophilic environments continue to host various unique microbes that are yet to be investigated for their secondary metabolite production. As a result, they represent attractive targets for natural product research. During the course of this study, 10 extremophilic microbes were screened using an adapted version of the existing screening protocol at VUW. The protocol was adapted to screen liquid microbial cultures instead of organic extracts. Seven extremophilic microbes yielded very low amounts of biomass, which was primarily made up of culture media components. Moreover, the NMR signals of potentially important compounds were masked by these components, a problem that is not encountered when dealing with marine invertebrates and macroalgae. These two limitations made it difficult to identify secondary metabolites in any fractions. The addition of antifoam to one of the bulk cultures proved to be another issue. The antifoam used in the culturing process was of mid-polar nature, which caused it to elute along with secondary metabolites of interest and also masked their NMR signals. In the future, to overcome these limitations, only bulk cultures without added antifoam should be screened so as to minimise the masking of secondary metabolites.

Investigation of the thermophilic bacteria Anoxybacillus flavithermus resulted in the isolation of 1 -acetyl- $\beta$-carboline (25) from the $75 \%$ fraction of the culture filtrate. This compound was tested for its antimicrobial, anticancer and MAO activity but did not show any activity at the highest tested concentrations. A detailed investigation of the marine extremophile Shewanella sp. led to the isolation of a known indole alkaloid, indole-3carboxaldehyde (93), and 14 known 2,5-DKPs (36, 38, 41-44, 53, 54, 94-99). This class of compounds has previously been reported to have significant antifungal activity, however, the mechanism has not fully been elucidated. Consequently, DKPs $\mathbf{4 2}, \mathbf{4 3}$ and 44 were submitted for yeast chemical genetic profiling using Saccharomyces cerevisiae to establish their modes of action. However, all three compounds failed to show significant inhibitory activity at concentations up to $180 \mu \mathrm{M}$ in the preliminary assay. This research 
also concluded that 2,5-DKPs do not play a role in attenuating the growth of $V$. harveyi as this strain was inactive in an assay carried out at Callaghan Innovation (discussed in Section 3.2.1). It is important to note that the majority of compounds were isolated from the $30 \%$ fraction of the Shewanella sp. culture filtrate. This result illustrated that all three crude fractions from a screen should be investigated further, as in this case, only two compounds were isolated from the $75 \%$ fraction. Altogether, the outcomes of this study demonstrated the successful use of the adapted screening method for isolating secondary metabolites from microbial cultures.

The compounds isolated during this research are all known and in order to prevent this from recurring, an important direction to consider in terms of future work towards this project would be to develop a 2D-NMR screening tool similar to the one developed by Dr. Northcote's group at VUW for screening sponge extracts. ${ }^{52,53,56}$ The screening tool consists of a COSY, HSQC or HMBC mask that is generated by the addition of several screens and is then overlaid on the screen fraction from the organism of interest. This allows the user to distinguish between correlations pertaining to primary metabolites or known compounds and those belonging to novel secondary metabolites. The screening tool would ideally also include suitable blank cultures and antifoams to allow for elimination of these signals. Another avenue would be to investigate extremophiles that have been co-cultured with other microbes to see if this evokes novel/different secondary metabolite production. Finally, a proper investigation on higher amounts of cell mass of the microbes used in this research would be interesting as it could lead to the isolation of novel compounds that were masked and therefore overlooked during this study. 


\section{Chapter 5}

\section{Experimental}

\subsection{General Experimental}

NMR spectra were obtained using a Varian DirectDrive spectrometer equipped with a triple resonance $\mathrm{HCN}$ cryogenic probe operating at $600 \mathrm{MHz}$ for ${ }^{1} \mathrm{H}$ and $150 \mathrm{MHz}$ for ${ }^{13} \mathrm{C}$ nuclei. The chemical shifts of ${ }^{13} \mathrm{C}$ and ${ }^{1} \mathrm{H}$ spectra were referenced to the residual solvent peaks $\left(\mathrm{D}_{2} \mathrm{O}: \delta_{H} 4.79 ; \mathrm{CD}_{3} \mathrm{OD}: \delta_{C} 49.0, \delta_{H} 3.31 ; \mathrm{CDCl}_{3}: \delta_{C} 77.0, \delta_{H}\right.$ 7.26; DMSO-d $\mathrm{d}_{6}: \delta_{C} 39.5, \delta_{H}$ 2.50). All NMR solvents were purchased from Aldrich with the exception of deuterated methanol, which was purchased from Cambridge Isotope Laboratories Inc. HRESIMS results were obtained from an Agilent 6530 Q-TOF mass spectrometer equipped with an Agilent 1260 HPLC for solvent delivery utilising a JetStream $^{\mathrm{TM}}$ electrospray ionisation source in positive mode. Water and MeCN solvents were both made up as $5 \mathrm{mM}$ solutions with ammonium formate. CID was performed using nitrogen as collision gas at various energies (10-40, arbitrary units). Optical rotations were measured at $25^{\circ} \mathrm{C}$ using a Rudolph Research Analytical Autopol II polarimeter operating at the emission wavelength of a sodium lamp $(589 \mathrm{~nm})$, with concentrations given in $\mathrm{g} / 100 \mathrm{~mL}$.

Normal-phase column chromatography was performed using Supelco Discovery ${ }^{\circledR}$ DSCDIOL functionalised silica: 3-(2,3-Dihydroxy-propoxy)-propyl-silica (Diol). Reversedphase column chromatography was performed using Supelco Diaion ${ }^{\circledR}$ HP20 and HP20ss poly(styrene-divinylbenzene) (PSDVB) resins. Size-exclusion chromatography was performed using Sephadex ${ }^{\circledR}$ LH-20 media. Two separate HPLC systems were used, the first using a Rainin Dynamax SD-200 solvent delivery system with $25 \mathrm{~mL}$ pump heads and a Varian Prostar 335 photodiode array detector for UV/Vis detection. The second HPLC system was an Agilent Technologies 1260 Infinity HPLC equipped with a quaternary pump, a thermostatted column compartment and diode array detector (DAD). Following the DAD, a Quicksplit ${ }^{\mathrm{TM}}$ flow splitter directs $5 \%$ of the flow to an Agilent 
380-evaporative light scattering detector (ELSD) with 95\% of the flow directed towards collection. For HPLC purification, reversed-phase C18 analytical (Phenomenex Prodigy, 4.6 x $250 \mathrm{~mm}, 5 \mu \mathrm{m}$ particle size) or semi-preparative (Phenomenex Prodigy, 10.0 x 250 $\mathrm{mm}, 10 \mu \mathrm{m}$ particle size) columns were used. For all HPLC runs, the UV/Vis detector was set to monitor at wavelengths of 210 and $280 \mathrm{~nm}$.

All solvents used were HPLC-grade (purchased from Fisher Scientific) with the exception of hexanes and dichloromethane, which were Optima ${ }^{\circledR}$ grade. Water was distilled prior to use and in the case of HPLC the water was further filtered through a membrane with a pore size of $0.45 \mu \mathrm{m}$ before use. Solvent compositions used are all reported as \% vol/vol. TLC analyses were performed using Machery-Nagel Polygram ${ }^{\circledR}$ Sil G/UV 254 plates and developed in $10 \% \mathrm{MeOH}$ in dichloromethane. TLC plates were then visualised under UV light $(\lambda=254 \mathrm{~nm}$ and $350 \mathrm{~nm})$ and then by dipping in $5 \%$ conc. $\mathrm{H}_{2} \mathrm{SO}_{4}$ in methanol $(\mathrm{v} / \mathrm{v} \%)$ followed by $0.1 \%$ vanillin in ethanol $(\mathrm{w} / \mathrm{v} \%)$ and heated for analysis.

\subsection{Screening Protocol for Microbial Cultures}

The following protocol was used for screening cultures of NGM11.1 (3 L), NGM22.9 (1 L), WAP10.3.2 (1 L), WC14 (2 L), K22 (1 L), P373 (3 L) and WKT50.2 (3 L), which were obtained from GNS Science, as well as T49 (20 L), which was obtained from Callaghan Innovation.

The liquid culture was filtered using celite and filter paper to separate the supernatant from any existing cell mass. The filtered supernatant was then passed through a $50 \mathrm{~mL} \mathrm{HP} 20$ column that had been washed with $150 \mathrm{~mL}$ of $\mathrm{Me}_{2} \mathrm{CO}$ and $\mathrm{MeOH}$ and pre-equilibrated in $150 \mathrm{~mL} \mathrm{H}_{2} \mathrm{O}$. The column was then eluted with $150 \mathrm{~mL}$ portions of i) $\mathrm{H}_{2} \mathrm{O}$, ii) $30 \%$ $\mathrm{Me}_{2} \mathrm{CO} / \mathrm{H}_{2} \mathrm{O}$, iii) $75 \% \mathrm{Me}_{2} \mathrm{CO} / \mathrm{H}_{2} \mathrm{O}$ and iv) $100 \% \mathrm{Me}_{2} \mathrm{CO}$. The $100 \% \mathrm{Me}_{2} \mathrm{CO}$ fraction was concentrated in vacuo. The $30 \%$ and $75 \%$ fractions were backloaded onto $30 \mathrm{~mL}$ and $15 \mathrm{~mL}$ HP20 columns, respectively. The columns were then eluted with $90 \mathrm{~mL}$ and 45 $\mathrm{mL} 100 \% \mathrm{Me}_{2} \mathrm{CO}$, respectively. The fractions were then concentrated in vacuo. The cell mass and celite were extracted overnight twice, first in $80 \% \mathrm{MeOH}$ and second in $100 \%$ 
$\mathrm{MeOH}$. The second extract was passed through a pre-equilibrated $25 \mathrm{~mL}$ HP20 column, followed by the first extract. The extracts were then collected together and cyclic loaded onto the same column. The column was then eluted with $75 \mathrm{~mL}$ portions of i) $\mathrm{H}_{2} \mathrm{O}$, ii) $30 \% \mathrm{Me}_{2} \mathrm{CO} / \mathrm{H}_{2} \mathrm{O}$, iii) $75 \% \mathrm{Me}_{2} \mathrm{CO} / \mathrm{H}_{2} \mathrm{O}$ and iv) $100 \% \mathrm{Me}_{2} \mathrm{CO}$. The $100 \% \mathrm{Me}_{2} \mathrm{CO}$ fraction was concentrated in vacuo. The $30 \%$ and $75 \%$ fractions were backloaded onto 15 $\mathrm{mL}$ and $10 \mathrm{~mL}$ HP20 columns, respectively. The columns were then eluted with $45 \mathrm{~mL}$ and $30 \mathrm{~mL} 100 \% \mathrm{Me}_{2} \mathrm{CO}$, respectively. The fractions were then concentrated in vacuo. The $\mathrm{H}_{2} \mathrm{O}$ fractions were also concentrated in vacuo but showed no compounds of interest. Hence, each screen resulted in six fractions: i) $30 \% \mathrm{Me}_{2} \mathrm{CO} / \mathrm{H}_{2} \mathrm{O}$, ii) $75 \% \mathrm{Me}_{2} \mathrm{CO} / \mathrm{H}_{2} \mathrm{O}$, iii) $100 \% \mathrm{Me}_{2} \mathrm{CO}$ fractions from the culture filtrate and iv) $30 \% \mathrm{Me}_{2} \mathrm{CO} / \mathrm{H}_{2} \mathrm{O}$, v) $75 \%$ $\mathrm{Me}_{2} \mathrm{CO} / \mathrm{H}_{2} \mathrm{O}$, vi) $100 \% \mathrm{Me}_{2} \mathrm{CO}$ fractions from the cell mass extract.

\subsection{Isolation of 1-acetyl- $\beta$-carboline from $A$. flavithermus}

A 2 L liquid culture of A. flavithermus, obtained from GNS Science, was filtered using celite and filter paper to separate the supernatant from any existing cell mass. The filtered supernatant was then passed through a $50 \mathrm{~mL}$ HP20 column that had been washed with $\mathrm{Me}_{2} \mathrm{CO}$ and $\mathrm{MeOH}$ and pre-equilibrated in $\mathrm{H}_{2} \mathrm{O}$. The column was then eluted with 150 mL portions of i) $\mathrm{H}_{2} \mathrm{O}$, ii) $30 \% \mathrm{Me}_{2} \mathrm{CO} / \mathrm{H}_{2} \mathrm{O}$, iii) $75 \% \mathrm{Me}_{2} \mathrm{CO} / \mathrm{H}_{2} \mathrm{O}$ and iv) $100 \% \mathrm{Me}_{2} \mathrm{CO}$. The $100 \% \mathrm{Me}_{2} \mathrm{CO}$ fraction was concentrated in vacuo to give CDB01_61C (2.3 mg). The $30 \%$ and $75 \%$ fractions were backloaded onto $30 \mathrm{~mL}$ and $15 \mathrm{~mL}$ HP20 columns, respectively. The columns were then eluted with $90 \mathrm{~mL}$ and $45 \mathrm{~mL} 100 \% \mathrm{Me}_{2} \mathrm{CO}$, respectively. The fractions were then concentrated in vacuo to give CDB01_61A (995.7 mg) and CDB01_61B (207 mg). The cell mass and celite were extracted overnight twice, first in $80 \% \mathrm{MeOH}$ and second in $100 \% \mathrm{MeOH}$. The second extract was passed through a pre-equilibrated $50 \mathrm{~mL}$ HP20 column, followed by the first extract. The extracts were then collected together and cyclic loaded onto the same column. The column was then eluted with $150 \mathrm{~mL}$ portions of i) $\mathrm{H}_{2} \mathrm{O}$, ii) $30 \% \mathrm{Me}_{2} \mathrm{CO} / \mathrm{H}_{2} \mathrm{O}$, iii) $75 \% \mathrm{Me}_{2} \mathrm{CO} / \mathrm{H}_{2} \mathrm{O}$ and iv) $100 \% \mathrm{Me}_{2} \mathrm{CO}$. The $100 \% \mathrm{Me}_{2} \mathrm{CO}$ fraction was concentrated in vacuo to give CDB01_62F (3.2 mg). The 30\% and $75 \%$ fractions were backloaded onto $40 \mathrm{~mL}$ and 
$20 \mathrm{~mL}$ HP20 columns, respectively. The columns were then eluted with $120 \mathrm{~mL}$ and 60 $\mathrm{mL} 100 \% \mathrm{Me}_{2} \mathrm{CO}$, respectively. The fractions were then concentrated in vacuo to give CDB01_62D (9.5 mg) and CDB01_62E (5.9 mg).

CDB01_61B (207 mg) was cyclic loaded onto $10 \mathrm{~mL}$ HP20ss, which was then transferred as a slurry onto a $40 \mathrm{~mL}$ pre-equilibrated HP20ss column. The column was eluted with $150 \mathrm{~mL}$ portions of $40 \%, 50 \%, 60 \%, 70 \%, 80 \%, 90 \% \mathrm{MeOH} / \mathrm{H}_{2} \mathrm{O}$ and finally $100 \%$ $\mathrm{MeOH}$. The 40\%, 50\% and 100\% (CDB01_68E, $1.6 \mathrm{mg}$ ) fractions were collected in bulk while the others were collected across 96 test tubes. The test tube fractions were analysed by TLC and combined. NMR and MS analysis of CDB01_68E showed that it contained impure 1-acetyl- $\beta$-carboline (1.6 mg).

1-acetyl- $\beta$-carboline (25). Pale yellow film, $1.6 \mathrm{mg}$; NMR data see Table 2.1; ${ }^{73}$ HRESIMS $[\mathrm{M}+\mathrm{H}]^{+} \mathrm{m} / \mathrm{z} 211.0868$ for $\mathrm{C}_{13} \mathrm{H}_{11} \mathrm{~N}_{2} \mathrm{O}$ (calculated 211.0866, $\mathrm{m} / \mathrm{z} \Delta=$ $0.0002)$.

\subsection{Isolation of Compounds from Shewanella sp.}

A 20 L liquid culture of Shewanella sp., obtained from Callaghan Innovation, was filtered using celite and filter paper to separate the supernatant from any existing cell mass. The filtered supernatant was then passed through a $50 \mathrm{~mL}$ HP20 column that had been washed with $\mathrm{Me}_{2} \mathrm{CO}$ and $\mathrm{MeOH}$ and pre-equilibrated in $\mathrm{H}_{2} \mathrm{O}$. The column was then eluted with $150 \mathrm{~mL}$ portions of i) $\mathrm{H}_{2} \mathrm{O}$, ii) $30 \% \mathrm{Me}_{2} \mathrm{CO} / \mathrm{H}_{2} \mathrm{O}$, iii) $75 \% \mathrm{Me}_{2} \mathrm{CO} / \mathrm{H}_{2} \mathrm{O}$ and iv) $100 \% \mathrm{Me}_{2} \mathrm{CO}$. The $100 \% \mathrm{Me}_{2} \mathrm{CO}$ fraction was concentrated in vacuo to give CDB01 57C (837.4 mg). The 30\% and 75\% fractions were backloaded onto $30 \mathrm{~mL}$ and $15 \mathrm{~mL}$ HP20 columns, respectively. The columns were then eluted with $90 \mathrm{~mL}$ and 45 $\mathrm{mL} 100 \% \mathrm{Me}_{2} \mathrm{CO}$, respectively. The fractions were then concentrated in vacuo to give CDB01_57A (552.3 mg) and CDB01_57B (204.7 mg). The cell mass and celite were extracted overnight twice, first in $80 \% \mathrm{MeOH}$ and second in $100 \% \mathrm{MeOH}$. The second extract was passed through a pre-equilibrated $100 \mathrm{~mL} \mathrm{HP} 20$ column, followed by the first extract. The extracts were then collected together and cyclic loaded onto the same column. 
The column was then eluted with $300 \mathrm{~mL}$ portions of i) $\mathrm{H}_{2} \mathrm{O}$, ii) $30 \% \mathrm{Me}_{2} \mathrm{CO} / \mathrm{H}_{2} \mathrm{O}$, iii) $75 \% \mathrm{Me}_{2} \mathrm{CO} / \mathrm{H}_{2} \mathrm{O}$ and iv) $100 \% \mathrm{Me}_{2} \mathrm{CO}$. The $100 \% \mathrm{Me}_{2} \mathrm{CO}$ fraction was concentrated in vacuo to give CDB01_62C (184.6 mg). The 30\% and 75\% fractions were backloaded onto $50 \mathrm{~mL}$ and $25 \mathrm{~mL}$ HP20 columns, respectively. The columns were then eluted with 150 $\mathrm{mL}$ and $75 \mathrm{~mL} 100 \% \mathrm{Me}_{2} \mathrm{CO}$, respectively. The fractions were then concentrated in vacuo to give CDB01_62A (30.9 mg) and CDB01_62B (101.8 mg). A second 13 L liquid culture of Shewanella sp. was obtained from Callaghan Innovation and was treated the same way as described above to give fractions CDB01_83C (30\%) (987.1 mg), CDB01_83D (75\%) (767 mg) and CDB01_83E (100\%) (2.27 g). NMR analysis of the fractions from the second culture showed that they were identical to the first culture.

\subsubsection{Isolation of Indole-3-carboxaldehyde and Cyclo(L-Trp-L-Pro)}

CDB01_57B (204.7 mg) was cyclic loaded onto $10 \mathrm{~mL}$ HP20ss, which was then transferred as a slurry onto a $40 \mathrm{~mL}$ pre-equilibrated HP20ss column and eluted with $150 \mathrm{~mL}$ portions of $40 \%, 50 \%, 60 \%, 70 \%, 80 \%, 90 \% \mathrm{MeOH} / \mathrm{H}_{2} \mathrm{O}$ and finally $100 \%$ $\mathrm{MeOH}$. The $40 \%, 50 \%$ and $100 \%$ fractions were collected in bulk while the others were collected across 88 test tubes. The test tube fractions were analysed by TLC and combined to give ten fractions (CDB01_67A-J). ${ }^{1} \mathrm{H}$ NMR analysis of CDB01_67B (2.7 mg) and CDB01_67C (3.4 mg) revealed that they were similar. The two fractions were combined and dissolved in $100 \% \mathrm{MeOH}$, and were then loaded onto a $100 \mathrm{~g} \mathrm{LH}-20$ column, which had been pre-equilibrated in 100\% $\mathrm{MeOH}$. The column was eluted with $\sim 300 \mathrm{~mL} 100 \%$ $\mathrm{MeOH}$ and collected across 114 tubes. The test tube fractions were analysed by TLC and combined to give ten fractions (CDB01_73D-M). CDB01_73K (3.7 mg) was adsorbed onto $0.1 \mathrm{~mL}$ of DIOL, which was then transferred as a slurry in hexane onto a $0.9 \mathrm{~mL}$ DIOL column that had been pre-equilibrated in hexane. The column was eluted with 3 $\mathrm{mL}$ portions of i) $100 \%$ hexane, ii) $25 \%$ ethyl acetate (EA) in hexane, iii) $50 \%$ EA in hexane (CDB01_77C, $1.1 \mathrm{mg})$, iv) 100\% EA (CDB01_77D, $2 \mathrm{mg}$ ), v) 25\% $\mathrm{MeOH}$ in EA, vi) $50 \% \mathrm{MeOH}$ in EA and vii) $100 \% \mathrm{MeOH}$. NMR and MS analysis revealed that CDB01_77C contained indole-3-carboxaldehyde (1.1 mg). 
CDB01_77D (2 mg) was separated further using reversed-phase (C18) analytical HPLC on the Rainin HPLC system, eluting with $\mathrm{MeCN} / \mathrm{H}_{2} \mathrm{O}$ at a flow rate of $1 \mathrm{~mL} / \mathrm{min}$. The method held the solvent mixture at $45 \% \mathrm{MeCN}$ for eight minutes followed by a two minute ramp to $100 \% \mathrm{MeCN}$, holding at $100 \%$ for five minutes, there was then a two minute ramp back to $45 \% \mathrm{MeCN}$ and finally the solvent mixture was held at $45 \% \mathrm{MeCN}$ for five minutes (22 minutes total), and fractions CDB01_80A $(0.4 \mathrm{mg}), \mathrm{B}(0.1 \mathrm{mg}), \mathrm{C}$ $\left(t_{\mathrm{R}}=3.5 \mathrm{~min}\right)$ containing pure cyclo(L-Trp-L-Pro) $(0.5 \mathrm{mg})$, and $\mathrm{D}-\mathrm{N}(0.7 \mathrm{mg})$ were collected. The same protocol was followed for CDB01_83D (767 mg) and identical fractions were combined together.

Indole-3-carboxaldehyde (93). Colourless film, $4.8 \mathrm{mg}$; NMR data see Table 3.4; ${ }^{165}$ HRESIMS $[\mathrm{M}+\mathrm{H}]^{+} \mathrm{m} / z 146.0597$ for $\mathrm{C}_{9} \mathrm{H}_{8} \mathrm{NO}$ (calculated 146.0600, $\mathrm{m} / z, \Delta=-0.0003$ ).

Cyclo(L-Trp-L-Pro) (53). Pale yellow film, $1.9 \mathrm{mg} ;[\alpha]_{\mathrm{D}}^{25}=-70(\mathrm{c}=0.1, \mathrm{MeOH}) ;{ }^{166}$ NMR data see Table 3.5; ${ }^{166}$ HRESIMS $[\mathrm{M}+\mathrm{H}]^{+} m / z 284.1392$ for $\mathrm{C}_{16} \mathrm{H}_{18} \mathrm{~N}_{3} \mathrm{O}_{2}$ (calculated 284.1394, $m / z \Delta=-0.0002$ ); MS/MS fragments $m / z 170.0571$ for $\mathrm{C}_{11} \mathrm{H}_{8} \mathrm{NO}$ (calculated 170.0600, $\mathrm{m} / \mathrm{z}, \Delta=-0.0029$ ), $\mathrm{m} / \mathrm{z} 130.0638$ for $\mathrm{C}_{9} \mathrm{H}_{8} \mathrm{~N}$ (calculated 130.0651, $m / z \Delta=-0.0013) .{ }^{167}$

\subsubsection{Isolation of 2,5-DKPs from the $30 \%$ Fraction}

The two $30 \% \mathrm{Me}_{2} \mathrm{CO} / \mathrm{H}_{2} \mathrm{O}$ fractions, CDB01_57A (552.3 mg) and CDB01_83C (987.1 $\mathrm{mg}$ ), from both the culture filtrates were combined together. A $300 \mathrm{mg}$ sub-sample of the mixture was dissolved in $50 \% \mathrm{MeOH} / \mathrm{H}_{2} \mathrm{O}$ and loaded onto a $100 \mathrm{~g} \mathrm{LH}-20$ column, which had been pre-equilibrated in $50 \% \mathrm{MeOH} / \mathrm{H}_{2} \mathrm{O}$. The column was eluted with $\sim 300$ $\mathrm{mL} 50 \% \mathrm{MeOH} / \mathrm{H}_{2} \mathrm{O}$ and collected across 88 tubes. The test tube fractions were analysed by TLC and combined to give nine fractions (CDB02_26A-I). NMR analysis of these fractions revealed that fractions $\mathrm{CDB} 0226 \mathrm{C}-\mathrm{G}$ contained mixtures of 2,5-DKPs. The remainder of the combined $30 \%$ fraction was subjected to LH-20 chromatography over four more runs ( $\sim 300 \mathrm{mg}$ per run), and using TLC analysis, fractions were combined with those from the first LH-20 run. Fractions CDB02 26D-G were separated further by reversed-phase (C18) HPLC as described below. 
CDB02 26C (419.5 mg) was cyclic loaded onto $17 \mathrm{~mL}$ HP20ss, which was then transferred as a slurry onto a $53 \mathrm{~mL}$ pre-equilibrated HP20ss column and eluted with $210 \mathrm{~mL}$ portions of $10 \%, 20 \%, 30 \%, 40 \%, 50 \%, 80 \% \mathrm{MeOH} / \mathrm{H}_{2} \mathrm{O}$ and finally $100 \%$ $\mathrm{MeOH}$. The 10\%, 20\%, 80\% (CDB02_33C, $70.7 \mathrm{mg}$ ) and 100\% fractions were collected in bulk while the others were collected across 110 test tubes. The test tube fractions were analysed by TLC and combined to give six fractions (CDB02_33E-J).

\section{Cyclo(L-Phe-L-4-Hyp)}

A $50 \mathrm{mg}$ sub-sample of HP20ss fraction CDB02_33I (134.7 mg) was dissolved in 20\% $\mathrm{MeCN} / \mathrm{H}_{2} \mathrm{O}$ and purified using semi-preparative HPLC on the Agilent HPLC system, eluting with $\mathrm{MeCN} / \mathrm{H}_{2} \mathrm{O}$ (both with $0.1 \%$ formic acid) at a flow rate of $4 \mathrm{~mL} / \mathrm{min}$. The method started with a ten mintue ramp from $15 \% \mathrm{MeCN}$ to $20 \% \mathrm{MeCN}$, holding at $20 \%$ for three minutes, there was then a one minute ramp back to $15 \% \mathrm{MeCN}$ and finally the solvent mixture was held at 15\% MeCN for five minutes (19 minutes total), and fractions CDB02_34A $(7.5 \mathrm{mg})$ and $\mathrm{B}\left(t_{\mathrm{R}}=11 \mathrm{~min}\right)$ were collected, the latter of which contained pure cyclo(L-Phe-L-4-Hyp) (37.2 mg).

Cyclo(L-Phe-L-4-Hyp) (43). Viscous colourless film, $37.2 \mathrm{mg} ;[\alpha]_{\mathrm{D}}^{25}=-98(\mathrm{c}=$ 1.77, $\mathrm{MeOH}) ;{ }^{168}$ NMR data see Table 3.6; ${ }^{106}$ HRESIMS $[\mathrm{M}+\mathrm{H}]^{+} m / z 261.1237$ for $\mathrm{C}_{14} \mathrm{H}_{17} \mathrm{~N}_{2} \mathrm{O}_{3}$ (calculated 261.1234, $m / z, \Delta=0.0003$ ); MS/MS fragments $m / z$ 170.0695 for $\mathrm{C}_{7} \mathrm{H}_{10} \mathrm{~N}_{2} \mathrm{O}_{3}$ (calculated 170.0691, $m / z \Delta=0.0004$ ), $m / z, 120.0798$ for $\mathrm{C}_{8} \mathrm{H}_{10} \mathrm{~N}$ (calculated 120.0808, $m / z \Delta=-0.0010$ ), $m / z 114.0539$ for $\mathrm{C}_{5} \mathrm{H}_{8} \mathrm{NO}_{2}$ (calculated 114.0550, $\mathrm{m} / \mathrm{z} \Delta=$ $0.0011), m / z, 103.0538$ for $\mathrm{C}_{8} \mathrm{H}_{7}$ (calculated 103.0542, $\left.\mathrm{m} / z \Delta=-0.0004\right) .{ }^{169}$

\section{Cyclo(L-Leu-L-4-Hyp)}

HP20ss fraction CDB02_33F (35.9 mg) was dissolved in 20\% $\mathrm{MeOH} / \mathrm{H}_{2} \mathrm{O}$ and purified using semi-preparative HPLC (Agilent), eluting with $\mathrm{MeOH} / \mathrm{H}_{2} \mathrm{O}$ (both with $0.1 \%$ formic acid) at a flow rate of $4 \mathrm{~mL} / \mathrm{min}$. The method started with a five minute ramp from $20 \%$ $\mathrm{MeOH}$ to $30 \% \mathrm{MeOH}$, holding at $30 \%$ for five minutes, there was then a two minute ramp back to $20 \% \mathrm{MeOH}$ and finally the solvent mixture was held at $20 \% \mathrm{MeOH}$ for five minutes (17 minutes total), and fractions CDB02_35A $(2.3 \mathrm{mg})$ and $\mathrm{B}\left(t_{\mathrm{R}}=12 \mathrm{~min}\right)$ were 
collected, the latter of which contained pure cyclo(L-Leu-L-4-Hyp) (25.3 mg).

Cyclo(L-Leu-L-4-Hyp) (42). Amorphous white solid, $25.3 \mathrm{mg} ;[\alpha]_{\mathrm{D}}^{25}=-123$ (c = 1.15, MeOH); ${ }^{168}$ NMR data see Table 3.7; ${ }^{100}$ HRESIMS $[\mathrm{M}+\mathrm{H}]^{+} m / z, 227.1392$ for $\mathrm{C}_{11} \mathrm{H}_{19} \mathrm{~N}_{2} \mathrm{O}_{3}$ (calculated 227.1390, $m / z \Delta=0.0002$ ); MS/MS fragments $m / z$ 199.1437 for $\mathrm{C}_{10} \mathrm{H}_{19} \mathrm{~N}_{2} \mathrm{O}_{2}$ (calculated 199.1441, $m / z, \Delta=-0.0004$ ), $m / z, 170.0678$ for $\mathrm{C}_{7} \mathrm{H}_{10} \mathrm{~N}_{2} \mathrm{O}_{3}$ (calculated 170.0686, $\mathrm{m} / z, \Delta=-0.0008$ ), $\mathrm{m} / \mathrm{z} 136.1124$ for $\mathrm{C}_{9} \mathrm{H}_{14} \mathrm{~N}$ (calculated 136.1121, $m / z \Delta=0.0003$ ), $m / z, 114.0916$ for $\mathrm{C}_{6} \mathrm{H}_{12} \mathrm{NO}$ (calculated 114.0913, $m / z, \Delta=0.0003$ ), $\mathrm{m} / \mathrm{z}$ 86.0963 for $\mathrm{C}_{5} \mathrm{H}_{12} \mathrm{~N}$ (calculated 86.0964, $m / z, \Delta=-0.0001$ ), $m / z 86.0608$ for $\mathrm{C}_{4} \mathrm{H}_{8} \mathrm{NO}$ (calculated 86.0600, $\mathrm{m} / \mathrm{z} \Delta=0.0008$ ), $\mathrm{m} / \mathrm{z} 68.0500$ for $\mathrm{C}_{4} \mathrm{H}_{6} \mathrm{~N}$ (calculated 68.0495, $\mathrm{m} / \mathrm{z}$ $\Delta=0.0005) .{ }^{169}$

\section{Cyclo(L-Leu-L-Pro)}

HP20ss fraction CDB02_33J (52.6 mg) was dissolved in 50\% $\mathrm{MeOH} / \mathrm{H}_{2} \mathrm{O}$ and purified using semi-preparative HPLC (Agilent), eluting with $\mathrm{MeOH} / \mathrm{H}_{2} \mathrm{O}$ (both with $0.1 \%$ formic acid) at a flow rate of $4 \mathrm{~mL} / \mathrm{min}$. The method started with a ten minute ramp from $40 \%$ $\mathrm{MeOH}$ to $50 \% \mathrm{MeOH}$, holding at $50 \%$ for five minutes, there was then a one minute ramp back to $40 \% \mathrm{MeOH}$ and finally the solvent mixture was held at $40 \% \mathrm{MeOH}$ for five minutes (21 minutes total), and fractions CDB02_35G-H $(10.4 \mathrm{mg}), \mathrm{I}\left(t_{\mathrm{R}}=8.5 \mathrm{~min}\right)$ containing pure cyclo(L-Leu-L-Pro) $(21.9 \mathrm{mg}), \mathrm{J}\left(t_{\mathrm{R}}=9.5 \mathrm{~min}, 2.4 \mathrm{mg}\right)$, and $\mathrm{K}(5.3 \mathrm{mg})$ were collected. CDB02_35J contained another impure 2,5-DKP that was purified later (described below).

Cyclo(L-Leu-L-Pro) (44). Amorphous white solid, $21.9 \mathrm{mg} ;[\alpha]_{\mathrm{D}}^{25}=-127(\mathrm{c}=0.89$, $\mathrm{MeOH}) ;{ }^{172} \mathrm{NMR}$ data as previously reported; ${ }^{100} \mathrm{HRESIMS}[\mathrm{M}+\mathrm{H}]^{+} \mathrm{m} / \mathrm{z} 211.1445$ for $\mathrm{C}_{11} \mathrm{H}_{19} \mathrm{~N}_{2} \mathrm{O}_{2}$ (calculated 211.1441, $m / z, \Delta=0.0004$ ); MS/MS fragments $m / z 183.1498$ for $\mathrm{C}_{10} \mathrm{H}_{19} \mathrm{~N}_{2} \mathrm{O}$ (calculated 183.1492, $m / z, \Delta=0.0006$ ), $m / z$ 138.1273 for $\mathrm{C}_{9} \mathrm{H}_{16} \mathrm{~N}$ (calculated 138.1277, $m / z \Delta=-0.0004$ ), $m / z 114.0906$ for $\mathrm{C}_{6} \mathrm{H}_{12} \mathrm{NO}$ (calculated 114.0913, $\mathrm{m} / \mathrm{z} \Delta=$ -0.0007), $m / z, 98.0599$ for $\mathrm{C}_{5} \mathrm{H}_{8} \mathrm{NO}$ (calculated 98.0600, $\mathrm{m} / \mathrm{z}, \Delta=-0.0001$ ), $\mathrm{m} / \mathrm{z} 86.0974$ for $\mathrm{C}_{5} \mathrm{H}_{12} \mathrm{~N}$ (calculated 86.0964, $\mathrm{m} / z, \Delta=0.0010$ ), $\mathrm{m} / \mathrm{z} 70.0655$ for $\mathrm{C}_{4} \mathrm{H}_{8} \mathrm{~N}$ (calculated 70.0651, $m / z, \Delta=0.0004) .{ }^{169}$ 


\section{Cyclo(L-Val-L-Pro) and Cyclo(Phe-4-Hyp)}

HP20ss fraction CDB02_33H (27.5 mg) was dissolved in $20 \% \mathrm{MeOH} / \mathrm{H}_{2} \mathrm{O}$ and purified using semi-preparative HPLC (Agilent), eluting with $\mathrm{MeOH} / \mathrm{H}_{2} \mathrm{O}$ (both with $0.1 \%$ formic acid) at a flow rate of $4 \mathrm{~mL} / \mathrm{min}$. The method started with a ten minute ramp from $20 \%$ $\mathrm{MeOH}$ to $30 \% \mathrm{MeOH}$, holding at $30 \%$ for five minutes, there was then a one minute ramp back to $20 \% \mathrm{MeOH}$ and finally the solvent mixture was held at $20 \% \mathrm{MeOH}$ for five minutes (21 minutes total), and fractions CDB02_35C (1.7 mg), D $\left(t_{\mathrm{R}}=8 \mathrm{~min}\right)$ containing pure cyclo(L-Val-L-Pro) $(0.5 \mathrm{mg}), \mathrm{E}\left(t_{\mathrm{R}}=10.5 \mathrm{~min}\right)$ containing impure cyclo(Phe-4-Hyp) (5.4 mg), and F (12.2 mg) were collected.

Cyclo(L-Val-L-Pro) (41). Amorphous white solid, $0.5 \mathrm{mg} ;[\alpha]_{\mathrm{D}}^{25}=-150(\mathrm{c}=0.04$, $\mathrm{MeOH}) ;{ }^{101} \mathrm{NMR}$ data as previously reported; ${ }^{100}$ HRESIMS $[\mathrm{M}+\mathrm{H}]^{+} \mathrm{m} / z 197.1290$ for $\mathrm{C}_{10} \mathrm{H}_{17} \mathrm{~N}_{2} \mathrm{O}_{2}$ (calculated 197.1285, $\mathrm{m} / z, \Delta=0.0005$ ); MS/MS fragments $\mathrm{m} / \mathrm{z} 154.0746$ for $\mathrm{C}_{7} \mathrm{H}_{10} \mathrm{~N}_{2} \mathrm{O}_{2}$ (calculated 154.0737, $\mathrm{m} / \mathrm{z} \Delta=0.0009$ ), $\mathrm{m} / \mathrm{z} 100.0766$ for $\mathrm{C}_{5} \mathrm{H}_{10} \mathrm{NO}$ (calculated 100.0757, $\mathrm{m} / \mathrm{z} \Delta=0.0009$ ), $\mathrm{m} / \mathrm{z} 98.0608$ for $\mathrm{C}_{5} \mathrm{H}_{8} \mathrm{NO}$ (calculated 98.0600, $m / z \Delta=0.0008$ ), $m / z, 72.0816$ for $\mathrm{C}_{4} \mathrm{H}_{10} \mathrm{~N}$ (calculated 72.0808, $\mathrm{m} / \mathrm{z} \Delta=0.0008$ ), $\mathrm{m} / \mathrm{z}$ 70.0662 for $\mathrm{C}_{4} \mathrm{H}_{8} \mathrm{~N}$ (calculated 70.0651, $\mathrm{m} / z \Delta=0.0011$ ). ${ }^{173}$

Cyclo(Phe-4-Hyp) (94). Colourless film, 5.4 mg; NMR data as previously reported; ${ }^{107}$ HRESIMS $[\mathrm{M}+\mathrm{H}]^{+} m / z, 261.1237$ for $\mathrm{C}_{14} \mathrm{H}_{17} \mathrm{~N}_{2} \mathrm{O}_{3}$ (calculated 261.1234, $m / z, \Delta=$ 0.0003); MS/MS fragments $m / z 233.1212$ for $\mathrm{C}_{13} \mathrm{H}_{16} \mathrm{~N}_{2} \mathrm{O}_{2}$ (calculated 233.1172, $\mathrm{m} / \mathrm{z} \Delta$ $=0.0040$ ), $m / z 215.1104$ for $\mathrm{C}_{13} \mathrm{H}_{14} \mathrm{~N}_{2} \mathrm{O}$ (calculated 215.1067, $\mathrm{m} / \mathrm{z} \Delta=0.0037$ ), $\mathrm{m} / \mathrm{z}$ 170.0830 for $\mathrm{C}_{7} \mathrm{H}_{10} \mathrm{~N}_{2} \mathrm{O}_{3}$ (calculated 170.0838, $\mathrm{m} / \mathrm{z}, \Delta=-0.0008$ ), $\mathrm{m} / \mathrm{z} 120.0807$ for $\mathrm{C}_{8} \mathrm{H}_{10} \mathrm{~N}$ (calculated 120.0808, $\mathrm{m} / \mathrm{z}, \Delta=-0.0001$ ), $\mathrm{m} / \mathrm{z} 103.0543$ for $\mathrm{C}_{8} \mathrm{H}_{7}$ (calculated 103.0542, $\mathrm{m} / \mathrm{z} \Delta=0.0001$ ), $\mathrm{m} / \mathrm{z} 91.0545$ for $\mathrm{C}_{7} \mathrm{H}_{7}$ (calculated 91.0542, $\mathrm{m} / \mathrm{z} \Delta=0.0003$ ), $m / z 86.0603$ for $\mathrm{C}_{4} \mathrm{H}_{8} \mathrm{NO}$ (calculated 86.0600, $m / z \Delta=0.0003$ ), $m / z 68.0499$ for $\mathrm{C}_{4} \mathrm{H}_{6} \mathrm{~N}$ (calculated 68.0495, $\mathrm{m} / \mathrm{z} \Delta=0.0004){ }^{169}$

\section{Cyclo(Trp-Val), Cyclo(Trp-Ala) and Cyclo(L-Trp-D-Pro)}

LH-20 fractions CDB02_26F (3.6 mg) and G (9 mg) were combined together, dissolved in $20 \% \mathrm{MeCN} / \mathrm{H}_{2} \mathrm{O}$, and subjected to semi-preparative HPLC (Agilent), eluting with 
$\mathrm{MeCN} / \mathrm{H}_{2} \mathrm{O}$ (both with $0.1 \%$ formic acid) at a flow rate of $4 \mathrm{~mL} / \mathrm{min}$. The method started with a 23 minute ramp from $20 \% \mathrm{MeCN}$ to $27.7 \% \mathrm{MeCN}$, followed by a two minute ramp back to $20 \% \mathrm{MeCN}$ and finally the solvent mixture was held at $20 \% \mathrm{MeCN}$ for five minutes (30 minutes total), and fractions CDB02_28A-C (2.6 mg), D ( $\left.t_{\mathrm{R}}=6.5 \mathrm{~min}\right)$ containing impure cyclo(Trp-Ala) $(0.1 \mathrm{mg}), \mathrm{E}(0.6 \mathrm{mg}), \mathrm{F}\left(t_{\mathrm{R}}=12.5 \mathrm{~min}\right)$ containing impure cyclo(Trp-Pro) $(0.8 \mathrm{mg}), \mathrm{G}-\mathrm{H}$, and I ( $\left.t_{\mathrm{R}}=16 \mathrm{~min}\right)$ containing impure cyclo(TrpVal) $(0.3 \mathrm{mg})$ were collected.

LH-20 fraction CDB02_26E (3.5 mg) was dissolved in 20\% $\mathrm{MeCN} / \mathrm{H}_{2} \mathrm{O}$ and purified using semi-preparative HPLC (Agilent), eluting with $\mathrm{MeCN} / \mathrm{H}_{2} \mathrm{O}$ (both with $0.1 \%$ formic acid) at a flow rate of $4 \mathrm{~mL} / \mathrm{min}$. The method held the solvent mixture at $20 \% \mathrm{MeCN}$ for five minutes followed by a twenty minute ramp to $28.3 \% \mathrm{MeCN}$, there was then a two minute ramp back to $20 \% \mathrm{MeCN}$ and finally the solvent mixture was held at $20 \%$ $\mathrm{MeCN}$ for five minutes (32 minutes total), and fractions CDB02_29A-C (1.3 mg), D $\left(t_{\mathrm{R}}\right.$ $=9.5 \mathrm{~min})$ containing impure cyclo(Trp-Ala) $(0.1 \mathrm{mg}), \mathrm{E}(0.1 \mathrm{mg})$ and $\mathrm{F}\left(t_{\mathrm{R}}=13 \mathrm{~min}\right)$ containing impure cyclo(Trp-Pro) $(1.1 \mathrm{mg})$ were collected. Fractions CDB02_28D and 29D were combined together (into sample CDB02_28D) as they were identical.

HPLC fractions CDB02_28F (0.8 mg) and 29F (1.1 mg) were combined together, dissolved in $20 \% \mathrm{MeCN} / \mathrm{H}_{2} \mathrm{O}$, and subjected to semi-preparative HPLC (Agilent), eluting with $\mathrm{MeCN} / \mathrm{H}_{2} \mathrm{O}$ (both with $0.1 \%$ formic acid) at a flow rate of $4 \mathrm{~mL} / \mathrm{min}$. The method started with a eight minute ramp from $20 \% \mathrm{MeCN}$ to $25.3 \% \mathrm{MeCN}$, followed by a one minute ramp back to $20 \% \mathrm{MeCN}$ and finally the solvent mixture was held at $20 \%$ $\mathrm{MeCN}$ for five minutes (14 minutes total), and one fraction, CDB02_31D ( $\left.t_{\mathrm{R}}=10.5 \mathrm{~min}\right)$ containing pure cyclo(L-Trp-D-Pro) $(0.8 \mathrm{mg})$ was collected.

Cyclo(Trp-Val) (99). Colourless film, $0.3 \mathrm{mg}$; NMR data as previously reported; ${ }^{177}$ HRESIMS $[\mathrm{M}+\mathrm{Na}]^{+} \mathrm{m} / z \quad 308.1369$ for $\mathrm{C}_{16} \mathrm{H}_{19} \mathrm{~N}_{3} \mathrm{O}_{2} \mathrm{Na}$ (calculated $308.1369, \mathrm{~m} / z \Delta$ = 0.0000); MS/MS data see Table 3.10.

Cyclo(Trp-Ala) (98). Colourless film, $0.2 \mathrm{mg}$; NMR data as previously reported; ${ }^{176}$ HRESIMS $[\mathrm{M}+\mathrm{H}]^{+} m / z 258.1242$ for $\mathrm{C}_{14} \mathrm{H}_{16} \mathrm{~N}_{3} \mathrm{O}_{2}$ (calculated 258.1237, $m / z \Delta=$ 0.0005); MS/MS data see Table 3.9. 
Cyclo(L-Trp-D-Pro) (54). Colourless film, $0.8 \mathrm{mg} ;[\alpha]_{\mathrm{D}}^{25}=+94(\mathrm{c}=0.05, \mathrm{MeOH}){ }^{117}$ NMR data as previously reported; ${ }^{117} \mathrm{HRESIMS}[\mathrm{M}+\mathrm{H}]^{+} m / z 284.1388$ for $\mathrm{C}_{16} \mathrm{H}_{18} \mathrm{~N}_{3} \mathrm{O}_{2}$ (calculated 284.1394, $m / z \Delta=-0.0006$ ); MS/MS fragments $m / z 153.0636$ for $\mathrm{C}_{7} \mathrm{H}_{9} \mathrm{~N}_{2} \mathrm{O}_{2}$ (calculated 153.0659, $\mathrm{m} / \mathrm{z}, \Delta=-0.0023$ ), $\mathrm{m} / \mathrm{z} 130.0645$ for $\mathrm{C}_{9} \mathrm{H}_{8} \mathrm{~N}$ (calculated 130.0651, $m / z \Delta=-0.0006){ }^{167}$

\section{Cyclo(L-Tyr-L-Pro) and Cyclo(Phe-Leu)}

LH-20 fraction CDB02_26D (12.5 mg) was dissolved in 20\% $\mathrm{MeCN} / \mathrm{H}_{2} \mathrm{O}$ and purified using semi-preparative HPLC (Agilent), eluting with $\mathrm{MeCN} / \mathrm{H}_{2} \mathrm{O}$ (both with $0.1 \%$ formic acid) at a flow rate of $4 \mathrm{~mL} / \mathrm{min}$. The method held the solvent mixture at $20 \% \mathrm{MeCN}$ for five minutes followed by a ten minute ramp to $24.2 \% \mathrm{MeCN}$, there was then a two minute ramp back to $20 \% \mathrm{MeCN}$ and finally the solvent mixture was held at $20 \% \mathrm{MeCN}$ for five minutes (22 minutes total), and fractions CDB02_30A-D (2.3 mg), E ( $\left.t_{\mathrm{R}}=5 \mathrm{~min}\right)$ containing pure cyclo(L-Tyr-L-Pro) $(3.8 \mathrm{mg}), \mathrm{F}\left(t_{\mathrm{R}}=8 \mathrm{~min}\right)$ containing impure cyclo(PheLeu) (0.2 mg), and G-L (4.9 mg) were collected.

Cyclo(L-Tyr-L-Pro) (38). Colourless film, $3.8 \mathrm{mg} ;[\alpha]_{\mathrm{D}}^{25}=-59(\mathrm{c}=0.25, \mathrm{MeOH}){ }^{174}$ NMR data as previously reported; ${ }^{175} \mathrm{HRESIMS}[\mathrm{M}+\mathrm{H}]^{+} m / z 261.1233$ for $\mathrm{C}_{14} \mathrm{H}_{17} \mathrm{~N}_{2} \mathrm{O}_{3}$ (calculated 261.1234, $m / z, \Delta=-0.0001$ ); MS/MS fragments $m / z 154.0721$ for $\mathrm{C}_{7} \mathrm{H}_{10} \mathrm{~N}_{2} \mathrm{O}_{2}$ (calculated 154.0742, $\mathrm{m} / \mathrm{z} \Delta=-0.0021$ ), $\mathrm{m} / \mathrm{z} 136.0747$ for $\mathrm{C}_{8} \mathrm{H}_{10} \mathrm{NO}$ (calculated 136.0757, $m / z \Delta=-0.0010), m / z 119.0476$ for $\mathrm{C}_{8} \mathrm{H}_{7} \mathrm{O}$ (calculated 119.0491, $\left.\mathrm{m} / \mathrm{z} \Delta=-0.0015\right), \mathrm{m} / \mathrm{z}$ 107.0489 for $\mathrm{C}_{7} \mathrm{H}_{7} \mathrm{O}$ (calculated 107.0491, $\mathrm{m} / z \Delta=-0.0002$ ). ${ }^{173}$

Cyclo(Phe-Leu) (97). Colourless film, $0.2 \mathrm{mg}$; NMR data as previously reported; ${ }^{171}$ HRESIMS $[\mathrm{M}+\mathrm{H}]^{+} \mathrm{m} / \mathrm{z} 261.1596$ for $\mathrm{C}_{15} \mathrm{H}_{21} \mathrm{~N}_{2} \mathrm{O}_{2}$ (calculated 261.1598, $\mathrm{m} / \mathrm{z} \Delta=-$ 0.0002); MS/MS fragments $m / z 170.1069$ for $\mathrm{C}_{8} \mathrm{H}_{14} \mathrm{~N}_{2} \mathrm{O}_{2}$ (calculated 170.1055, $\mathrm{m} / \mathrm{z}, \Delta=$ 0.0014), $m / z 120.0808$ for $\mathrm{C}_{8} \mathrm{H}_{10} \mathrm{~N}$ (calculated 120.0808, $\mathrm{m} / \mathrm{z} \Delta=0.0000$ ), $\mathrm{m} / \mathrm{z} 114.0916$ for $\mathrm{C}_{6} \mathrm{H}_{12} \mathrm{NO}$ (calculated 114.0913, $m / z \Delta=0.0003$ ), $m / z 105.0698$ for $\mathrm{C}_{8} \mathrm{H}_{9}$ (calculated 105.0699, $\mathrm{m} / \mathrm{z} \Delta=-0.0001), \mathrm{m} / \mathrm{z} 103.0543$ for $\mathrm{C}_{8} \mathrm{H}_{7}$ (calculated 103.0542, $\mathrm{m} / \mathrm{z} \Delta=$ 0.0001 ), $m / z, 91.0546$ for $\mathrm{C}_{7} \mathrm{H}_{7}$ (calculated 91.0542, $\mathrm{m} / \mathrm{z}, \Delta=0.0004$ ), $\mathrm{m} / \mathrm{z} 86.0967$ for $\mathrm{C}_{5} \mathrm{H}_{12} \mathrm{~N}$ (calculated 86.0964, $m / z \Delta=0.0003$ ). ${ }^{167}$ 


\section{Cyclo(L-Phe-D-Pro), Cyclo(Phe-6-Hyp) and Cyclo(Phe-Pro)}

HP20ss fraction CDB02_33C (70.7 mg) was dissolved in 20\% $\mathrm{MeCN} / \mathrm{H}_{2} \mathrm{O}$ and purified using semi-preparative HPLC (Agilent), eluting with $\mathrm{MeCN} / \mathrm{H}_{2} \mathrm{O}$ (both with $0.1 \%$ formic acid) at a flow rate of $4 \mathrm{~mL} / \mathrm{min}$. The method started with a ten minute ramp from $15 \%$ $\mathrm{MeCN}$ to $20 \% \mathrm{MeCN}$, holding at $20 \%$ for five minutes, followed by a one minute ramp back to $15 \% \mathrm{MeCN}$ and finally the solvent mixture was held at $15 \% \mathrm{MeCN}$ for five minutes (21 minutes total), and fractions CDB02_34C (6.5 mg), D ( $\left.t_{\mathrm{R}}=14 \mathrm{~min}, 4.3 \mathrm{mg}\right)$, and $\mathrm{E}\left(t_{\mathrm{R}}=16.5 \mathrm{~min}, 31.2 \mathrm{mg}\right)$ were collected. Fraction CDB02_34D was identical to CDB02_35J, and CDB02_34E contained a mixture of more 2,5-DKPs.

HPLC fractions CDB02_34D (4.3 mg) and 35J (2.4 mg) were combined together, dissolved in 50\% $\mathrm{MeCN} / \mathrm{H}_{2} \mathrm{O}$, and subjected to semi-preparative HPLC (Agilent), eluting with $\mathrm{MeCN} / \mathrm{H}_{2} \mathrm{O}$ (both with $0.1 \%$ formic acid) at a flow rate of $4 \mathrm{~mL} / \mathrm{min}$. The method held the solvent mixture at $40 \% \mathrm{MeCN}$ for ten minutes, and one fraction, CDB02_37A $\left(t_{\mathrm{R}}=4.5 \mathrm{~min}\right)$ containing cyclo(L-Phe-D-Pro) $(4.2 \mathrm{mg})$ was collected.

HPLC fraction CDB02_34E (31.2 mg) was dissolved in 20\% $\mathrm{MeCN} / \mathrm{H}_{2} \mathrm{O}$, and subjected to semi-preparative HPLC (Agilent), eluting with $\mathrm{MeCN} / \mathrm{H}_{2} \mathrm{O}$ (both with $0.1 \%$ formic acid) at a flow rate of $4 \mathrm{~mL} / \mathrm{min}$. The method started with a five minute ramp from $15 \%$ $\mathrm{MeCN}$ to $20 \% \mathrm{MeCN}$, followed by another thirteen minute ramp to $20.8 \%$, there was then a two minute ramp back to $15 \% \mathrm{MeCN}$ and finally the solvent mixture was held at $15 \%$ MeCN for five minutes (25 minutes total), and fractions CDB02_36D-F (9.3 mg), G $\left(t_{\mathrm{R}}\right.$ $=11 \mathrm{~min})$ containing impure cyclo(Phe-6-Hyp) $(5.3 \mathrm{mg}), \mathrm{H}(4.4 \mathrm{mg}), \mathrm{I}\left(t_{\mathrm{R}}=14.5 \mathrm{~min}\right)$ containing impure cyclo(Phe-Pro) $(2.9 \mathrm{mg})$, and $\mathrm{J}(3.2 \mathrm{mg}$ ) were collected.

Cyclo(L-Phe-D-Pro) (36). Colourless film, $4.2 \mathrm{mg} ;[\alpha]_{\mathrm{D}}^{25}=+61(\mathrm{c}=0.28, \mathrm{MeOH})$; NMR data as previously reported; ${ }^{170} \mathrm{HRESIMS}[\mathrm{M}+\mathrm{H}]^{+} m / z 245.1283$ for $\mathrm{C}_{14} \mathrm{H}_{17} \mathrm{~N}_{2} \mathrm{O}_{2}$ (calculated 245.1285, $m / z \Delta=-0.0002$ ); MS/MS fragments $m / z 217.1319$ for $\mathrm{C}_{13} \mathrm{H}_{16} \mathrm{~N}_{2} \mathrm{O}$ (calculated 217.1335, $\mathrm{m} / \mathrm{z} \Delta=-0.0016$ ), $\mathrm{m} / \mathrm{z} 172.1115$ for $\mathrm{C}_{12} \mathrm{H}_{14} \mathrm{~N}$ (calculated 172.1121, $m / z \Delta=-0.0006$ ), $m / z 120.0804$ for $\mathrm{C}_{8} \mathrm{H}_{10} \mathrm{~N}$ (calculated 120.0808, $m / z, \Delta=-0.0004$ ), $\mathrm{m} / \mathrm{z}$ 103.0538 for $\mathrm{C}_{8} \mathrm{H}_{7}$ (calculated 103.0542, $m / z, \Delta=-0.0004$ ), $m / z, 98.0595$ for $\mathrm{C}_{5} \mathrm{H}_{8} \mathrm{NO}$ (calculated 98.0600, $\mathrm{m} / \mathrm{z} \Delta=-0.0005$ ), $\mathrm{m} / \mathrm{z} 70.0652$ for $\mathrm{C}_{4} \mathrm{H}_{8} \mathrm{~N}$ (calculated 70.0651, $\mathrm{m} / \mathrm{z}$ 
$\Delta=0.0001) .{ }^{169}$

Cyclo(Phe-6-Hyp) (95). Colourless film, $5.3 \mathrm{mg}$; NMR data as previously reported; ${ }^{104}$ HRESIMS $[\mathrm{M}+\mathrm{H}]^{+} m / z 261.1241$ for $\mathrm{C}_{14} \mathrm{H}_{17} \mathrm{~N}_{2} \mathrm{O}_{3}$ (calculated 261.1234, $\mathrm{m} / \mathrm{z}, \Delta=$ 0.0007); MS/MS data see Table 3.8.

Cyclo(Phe-Pro) (96). Colourless film, 2.9 mg; NMR data as previously reported; ${ }^{106}$ HRESIMS $[\mathrm{M}+\mathrm{H}]^{+} m / z, 245.1289$ for $\mathrm{C}_{14} \mathrm{H}_{17} \mathrm{~N}_{2} \mathrm{O}_{2}$ (calculated 245.1285, $\mathrm{m} / \mathrm{z}, \Delta=$ 0.0004); MS/MS fragments $m / z 217.1300$ for $\mathrm{C}_{13} \mathrm{H}_{16} \mathrm{~N}_{2} \mathrm{O}$ (calculated 217.1335, $m / z, \Delta=-$ 0.0035), $\mathrm{m} / z$ 172.1109 for $\mathrm{C}_{12} \mathrm{H}_{14} \mathrm{~N}$ (calculated 172.1121, $\left.\mathrm{m} / z \Delta=-0.0002\right), \mathrm{m} / z 120.0806$ for $\mathrm{C}_{8} \mathrm{H}_{10} \mathrm{~N}$ (calculated 120.0808, $\mathrm{m} / \mathrm{z} \Delta=-0.0002$ ), $\mathrm{m} / \mathrm{z} 103.0539$ for $\mathrm{C}_{8} \mathrm{H}_{7}$ (calculated 103.0542, $m / z \Delta=-0.0003$ ),$m / z 98.0599$ for $\mathrm{C}_{5} \mathrm{H}_{8} \mathrm{NO}$ (calculated $98.0600, \mathrm{~m} / z \Delta=-$ 0.0001 ), $\mathrm{m} / \mathrm{z} 91.0536$ for $\mathrm{C}_{7} \mathrm{H}_{7}$ (calculated 91.0542, $\mathrm{m} / \mathrm{z} \Delta=-0.0006$ ), $\mathrm{m} / \mathrm{z} 70.0655$ for $\mathrm{C}_{4} \mathrm{H}_{8} \mathrm{~N}$ (calculated 70.0651, $\left.\mathrm{m} / \mathrm{z} \Delta=0.0004\right) .{ }^{169}$ 


\section{Appendix A}

\section{Microbial Culture Conditions}

Table A.1. Aerobic culture conditions for the extremophilic microbes

\begin{tabular}{l|l|l|l}
\hline Microbe & Medium & Temp. $\left({ }^{\circ} \mathbf{C}\right)$ & pH \\
\hline NGM11.1 & R2AG & 69 & 7.2 \\
\hline NGM22.9 & R2AG & 60 & 7.2 \\
\hline WAP10.3.2 & R2AG & 60 & 7.2 \\
\hline WC14 & PDB & 60 & 5.6 \\
\hline WK1 & TSB & 60 & 7.3 \\
\hline T49 & 4.5NZS10.2A & 60 & 5.1 \\
\hline K22 & R2AG & 60 & 6.5 \\
\hline P373 & R2AG & 60 & 7.2 \\
\hline WKT50.2 & 10xCPS & 69 & 7.5 \\
\hline Shewanella sp. & PYM & 15 & - \\
\hline & & &
\end{tabular}

\section{A.1 Culture Media Components}

All culture media were water-based.

R2AG Medium - 1 L

R2A - 9 g

$\mathrm{MgCl}_{2} \cdot 6 \mathrm{H}_{2} \mathrm{O}-1 \mathrm{~g}$

Distilled $\mathrm{H}_{2} \mathrm{O}-1 \mathrm{~L}$

Potato Dextrose Broth (PDB) Medium - 1 L

Pre-prepared PDB media (Difco) - 24 g made up of:

Potato starch - $4 \mathrm{~g}$

Dextrose - $20 \mathrm{~g}$

Distilled $\mathrm{H}_{2} \mathrm{O}-1 \mathrm{~L}$

Tryptic Soy Broth (TSB) Medium - 1 L

Pre-prepared TSB media (Difco) - $30 \mathrm{~g}$ made up of:

Pancreatic digest of casein - $17 \mathrm{~g}$ 
Papaic digest of soybean - $3 \mathrm{~g}$

Dextrose $-2.5 \mathrm{~g}$

$\mathrm{NaCl}-5 \mathrm{~g}$

$\mathrm{K}_{2} \mathrm{HPO} 4-2.5 \mathrm{~g}$

Distilled $\mathrm{H}_{2} \mathrm{O}-1 \mathrm{~L}$

4.5NZS10.2A Medium - 1 L

$\mathrm{NH}_{4} \mathrm{Cl}-4 \mathrm{~g}$

$\mathrm{KH}_{2} \mathrm{PO}_{4}-0.5 \mathrm{~g}$

$\mathrm{MgSO}_{4}-0.2 \mathrm{~g}$

$\mathrm{CaCl}_{2}-0.1 \mathrm{~g}$

Yeast extract $-0.5 \mathrm{~g}$

FeEDTA solution - $3 \mathrm{~mL}$

Trace metal solution (Methanotrophs) - $3 \mathrm{~mL}$

Methanogen trace metal solution (Wolin) - $1 \mathrm{~mL}$

Starch - 6 g

Distilled $\mathrm{H}_{2} \mathrm{O}-1 \mathrm{~L}$

\section{0xCPS Medium - $1 \mathrm{~L}$}

Salt solution:

Nitrilotriacetic acid - $0.1 \mathrm{~g}$

$\mathrm{MgSO}_{4} \cdot 7 \mathrm{H}_{2} \mathrm{O}-0.1 \mathrm{~g}$

$\mathrm{CaCl}_{2} \cdot 2 \mathrm{H}_{2} \mathrm{O}-0.06 \mathrm{~g}$

$\mathrm{NaCl}-0.008 \mathrm{~g}$

$\mathrm{NaNO}_{3}-0.689 \mathrm{~g}$

$\mathrm{KNO}_{3}-0.103 \mathrm{~g}$

$\mathrm{Na}_{2} \mathrm{HPO}_{4} \cdot 12 \mathrm{H}_{2} \mathrm{O}-0.111 \mathrm{~g}$

$\mathrm{FeCL}_{2}$ solution (see below) - $1 \mathrm{~mL}$

Nitsch element solution (see below) - $1 \mathrm{~mL}$

Peptone $-5 \mathrm{~g}$

Sucrose $-2.5 \mathrm{~g}$

Distilled $\mathrm{H}_{2} \mathrm{O}-1 \mathrm{~L}$ 
Adjust $\mathrm{pH}$ to 8.2

$\mathrm{FeCl}_{2}$ solution:

$\mathrm{FeCl}_{2} \cdot 4 \mathrm{H}_{2} \mathrm{O}-0.44 \mathrm{~g}$

Distilled $\mathrm{H}_{2} \mathrm{O}-1 \mathrm{~L}$

Nitsch element solution:

$\mathrm{H}_{2} \mathrm{SO}_{4}-50 \mu \mathrm{l}$

$\mathrm{MnCl}_{2} 2.4 \mathrm{H}_{2} \mathrm{O}-0.28 \mathrm{~g}$

$\mathrm{ZnSO}_{4} .7 \mathrm{H}_{2} \mathrm{O}-0.05 \mathrm{~g}$

$\mathrm{H}_{3} \mathrm{BO}_{3}-0.05 \mathrm{~g}$

$\mathrm{CuSO}_{4} .5 \mathrm{H}_{2} \mathrm{O}-0.016 \mathrm{~g}$

$\mathrm{Na}_{2} \mathrm{MoO}_{4} .2 \mathrm{H}_{2} \mathrm{O}-0.0030 \mathrm{~g}$

$\mathrm{CoCl}_{2} \cdot 6 \mathrm{H}_{2} \mathrm{O}-0.0046 \mathrm{~g}$

Distilled $\mathrm{H}_{2} \mathrm{O}-100 \mathrm{~mL}$

Peptone-Yeast extract-Malt extract (PYM) Medium - 1L

Bactopeptone - $10 \mathrm{~g}$

Yeast extract $-2.5 \mathrm{~g}$

Meat extract - $2 \mathrm{~g}$

Instant Ocean ${ }^{\mathrm{R}}$ - $15 \mathrm{~g}$

Reverse Osmosis $\mathrm{H}_{2} \mathrm{O}-1 \mathrm{~L}$ 
NMR Spectra of 1-Acetyl- $\beta$-carboline

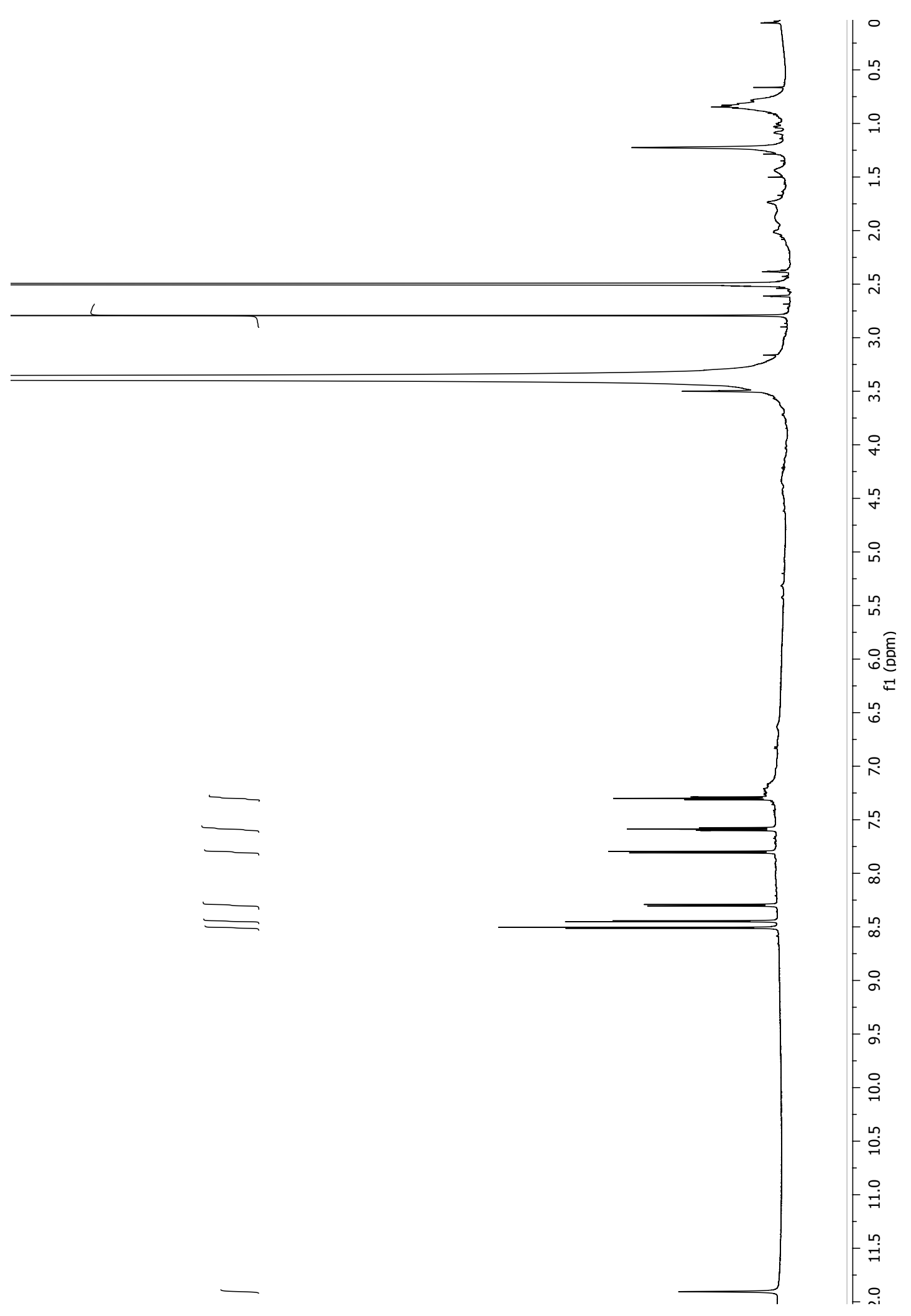

${ }^{1} \mathrm{H}$ NMR spectrum of 1 -acetyl- $\beta$-carboline (25) (600 MHz, DMSO- $\mathrm{d}_{6}$ ) 


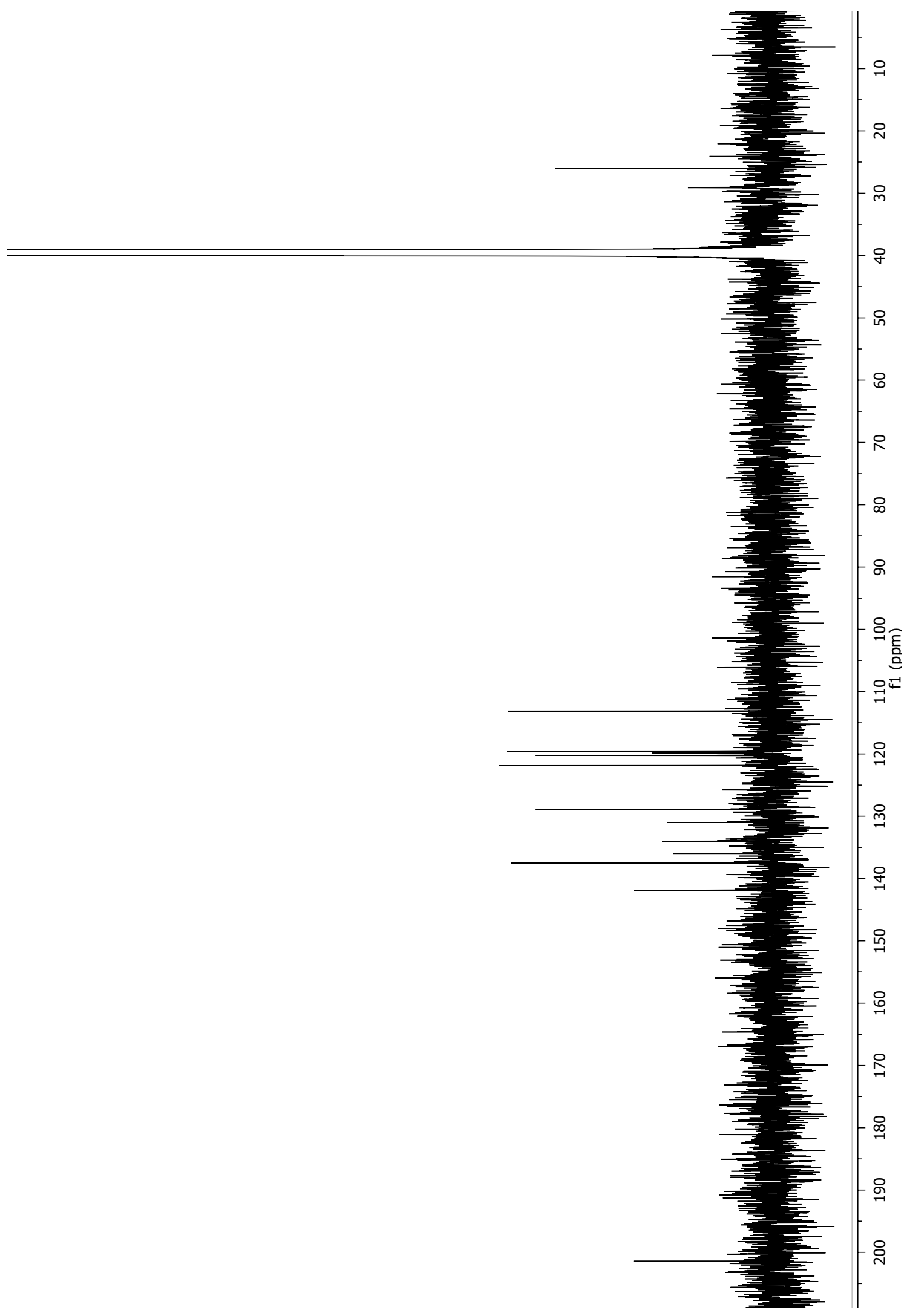

${ }^{13} \mathrm{C}$ NMR spectrum of 1 -acetyl- $\beta$-carboline (25) (150 MHz, DMSO- $\left.\mathrm{d}_{6}\right)$ 
(mua) if

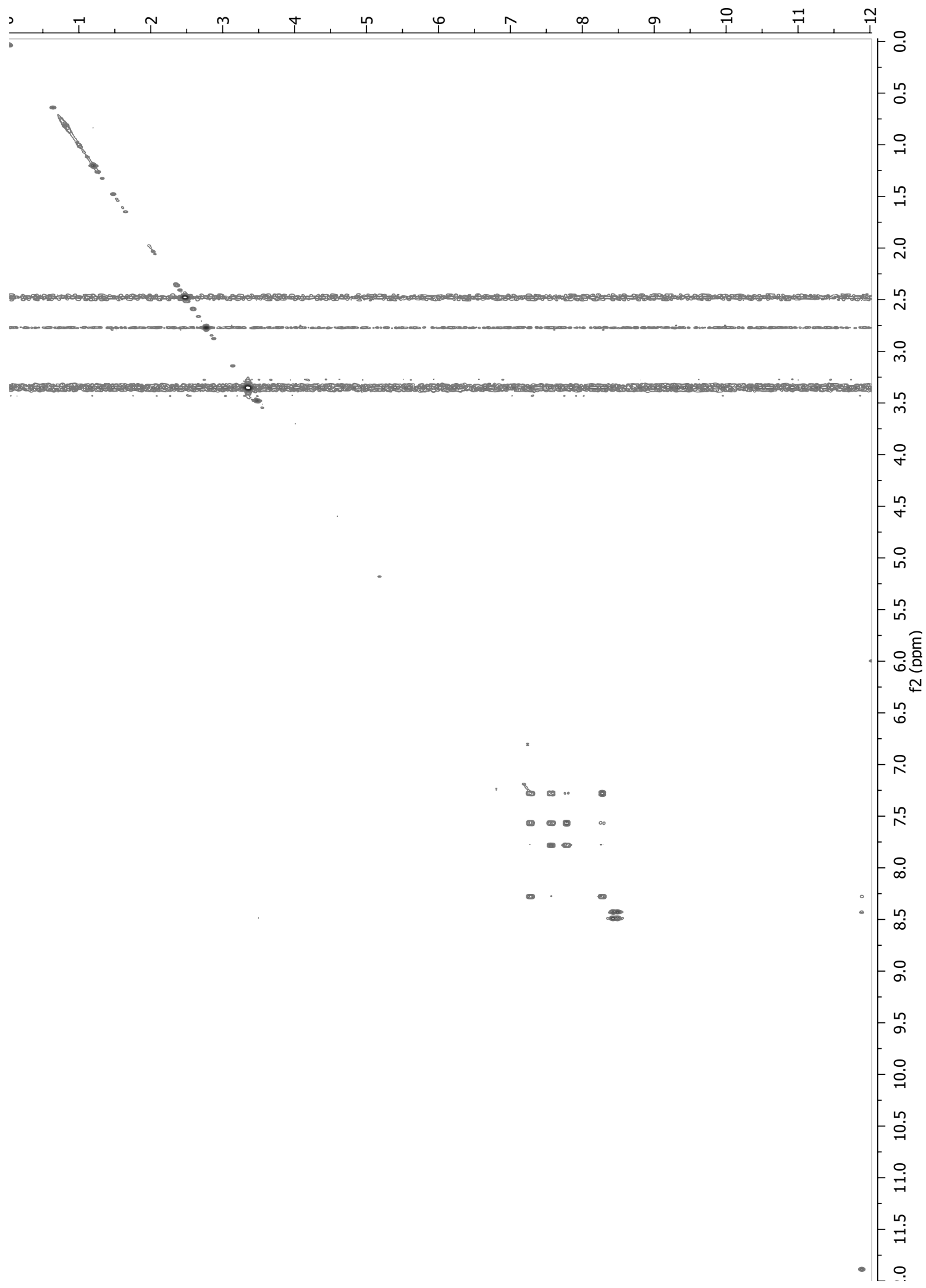

COSY spectrum of 1-acetyl- $\beta$-carboline (25) (600 MHz, DMSO- $\mathrm{d}_{6}$ ) 
(mou) if

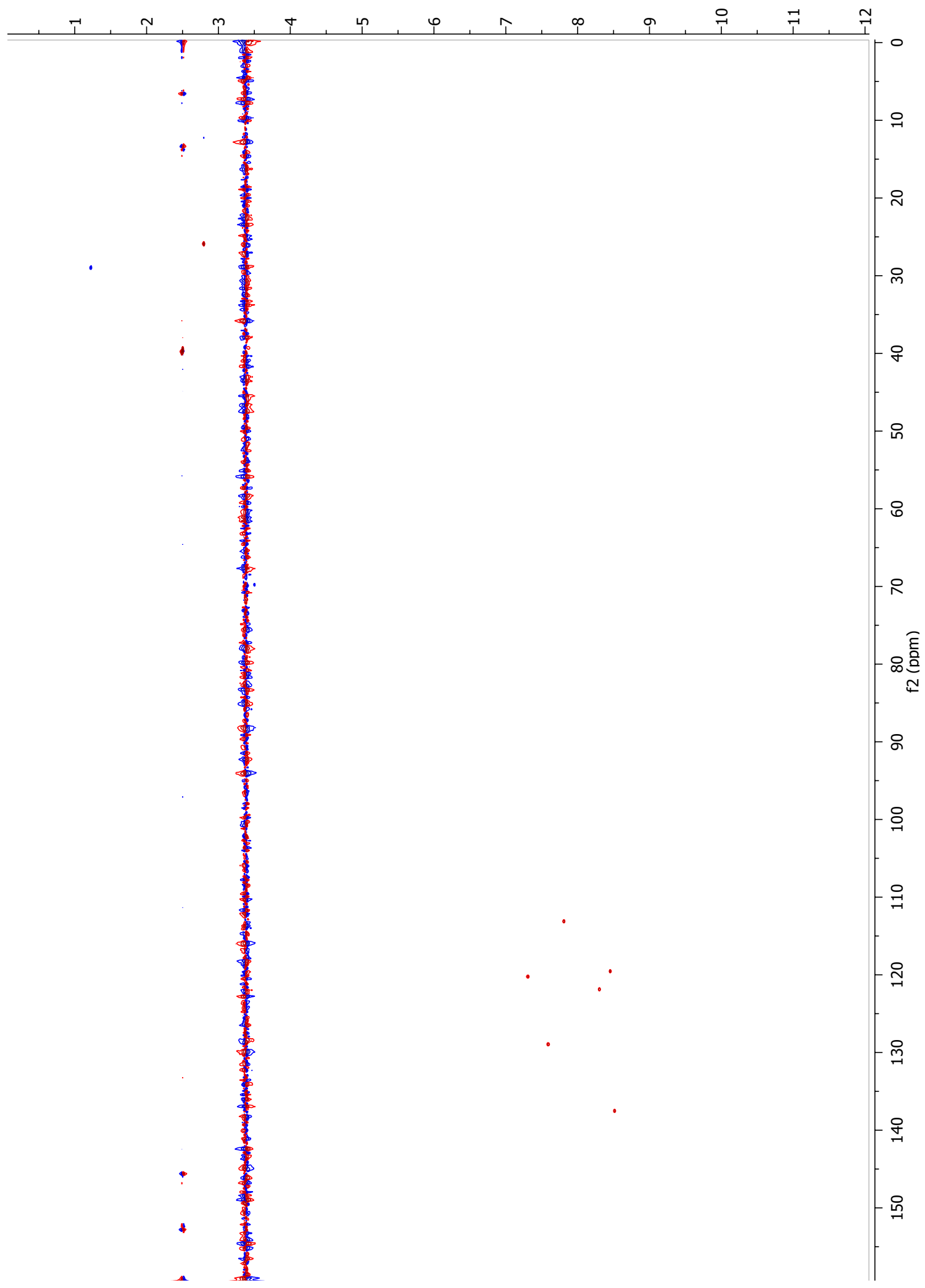

Mutliplicity-edited HSQC spectrum of 1-acetyl- $\beta$-carboline (25) showing methylenes in blue and methyls and methines in red $\left(600 \mathrm{MHz}, \mathrm{DMSO}-\mathrm{d}_{6}\right)$ 
(mau) if

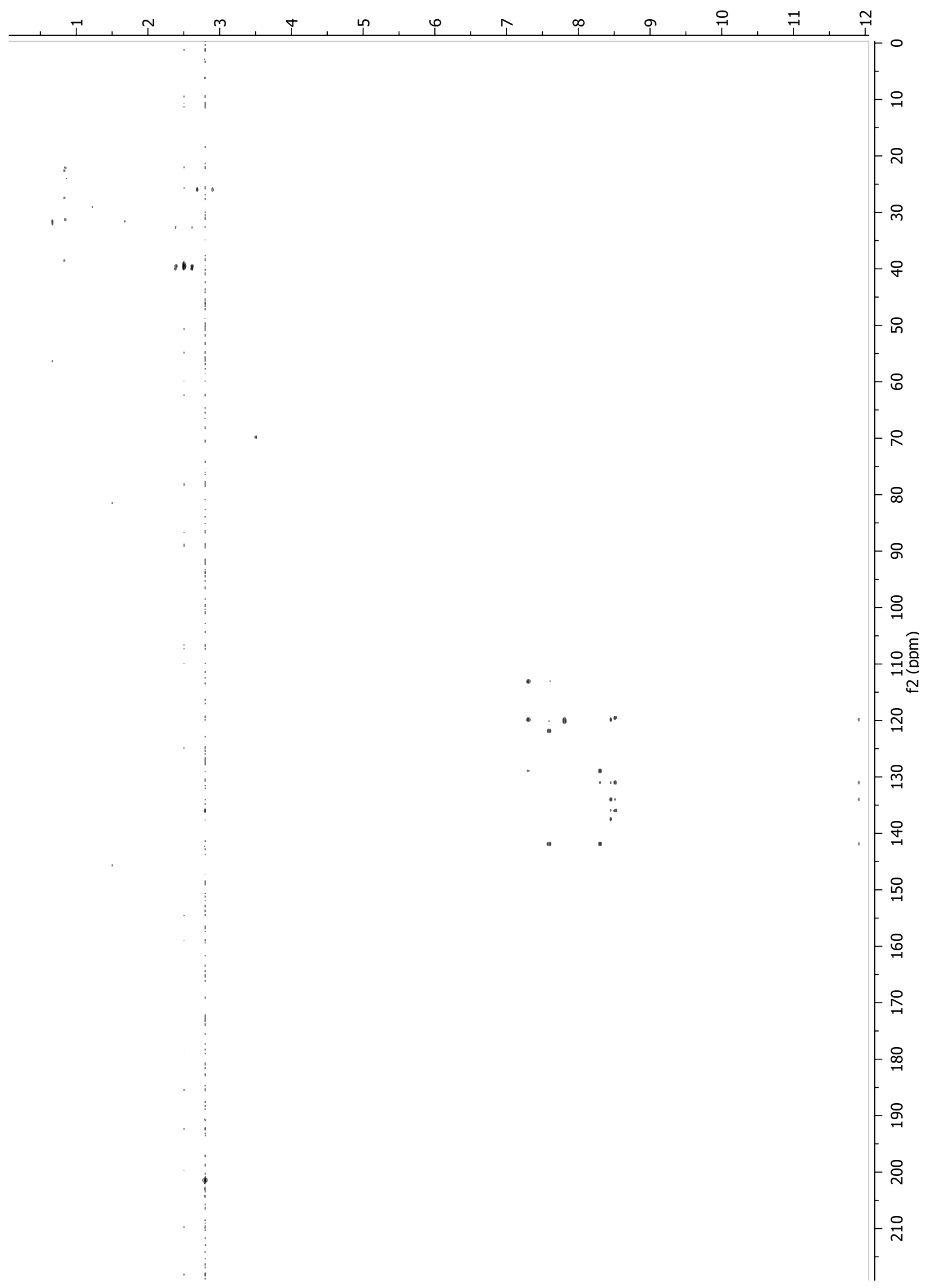

HMBC spectrum of 1 -acetyl- $\beta$-carboline (25) $\left(600 \mathrm{MHz}, \mathrm{DMSO}-\mathrm{d}_{6}\right)$ 


\section{Appendix C}

NMR Spectra of Indole-3-carboxaldehyde

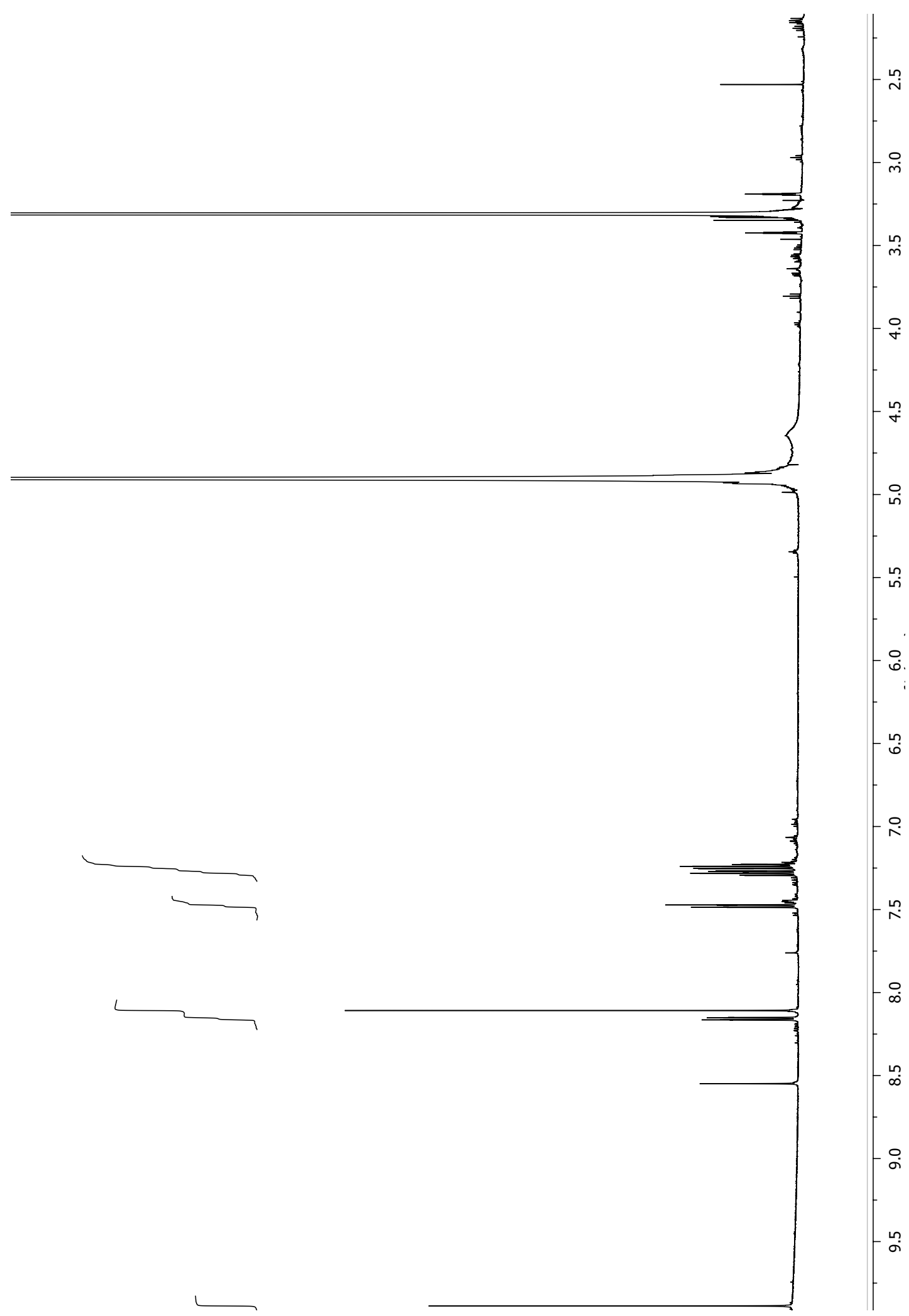

${ }^{1} \mathrm{H}$ NMR spectrum of indole-3-carboxaldehyde (93) (600 MHz, $\left.\mathrm{CD}_{3} \mathrm{OD}\right)$ 


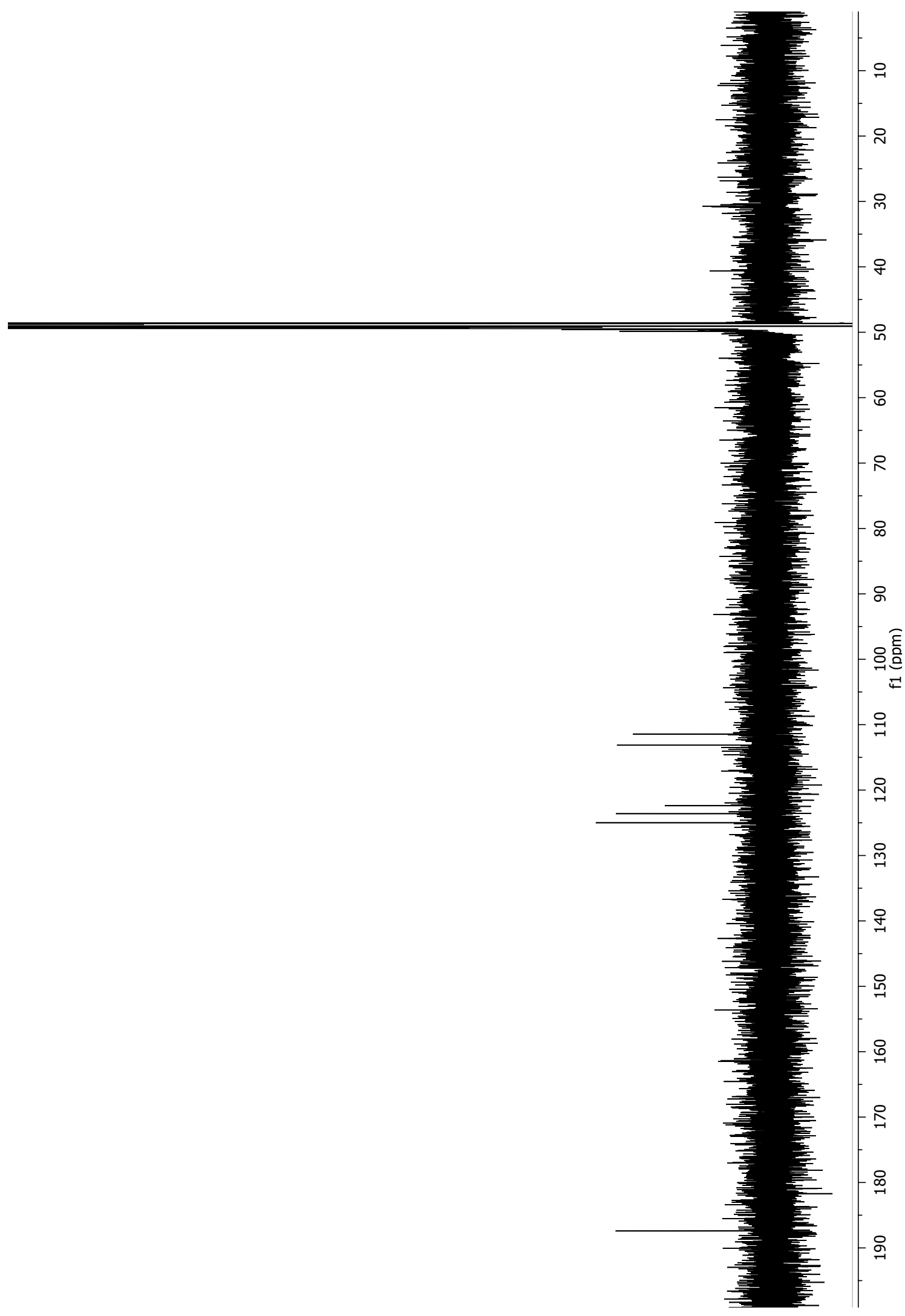

${ }^{13} \mathrm{C}$ NMR spectrum of indole-3-carboxaldehyde (93) (150 MHz, $\left.\mathrm{CD}_{3} \mathrm{OD}\right)$ 


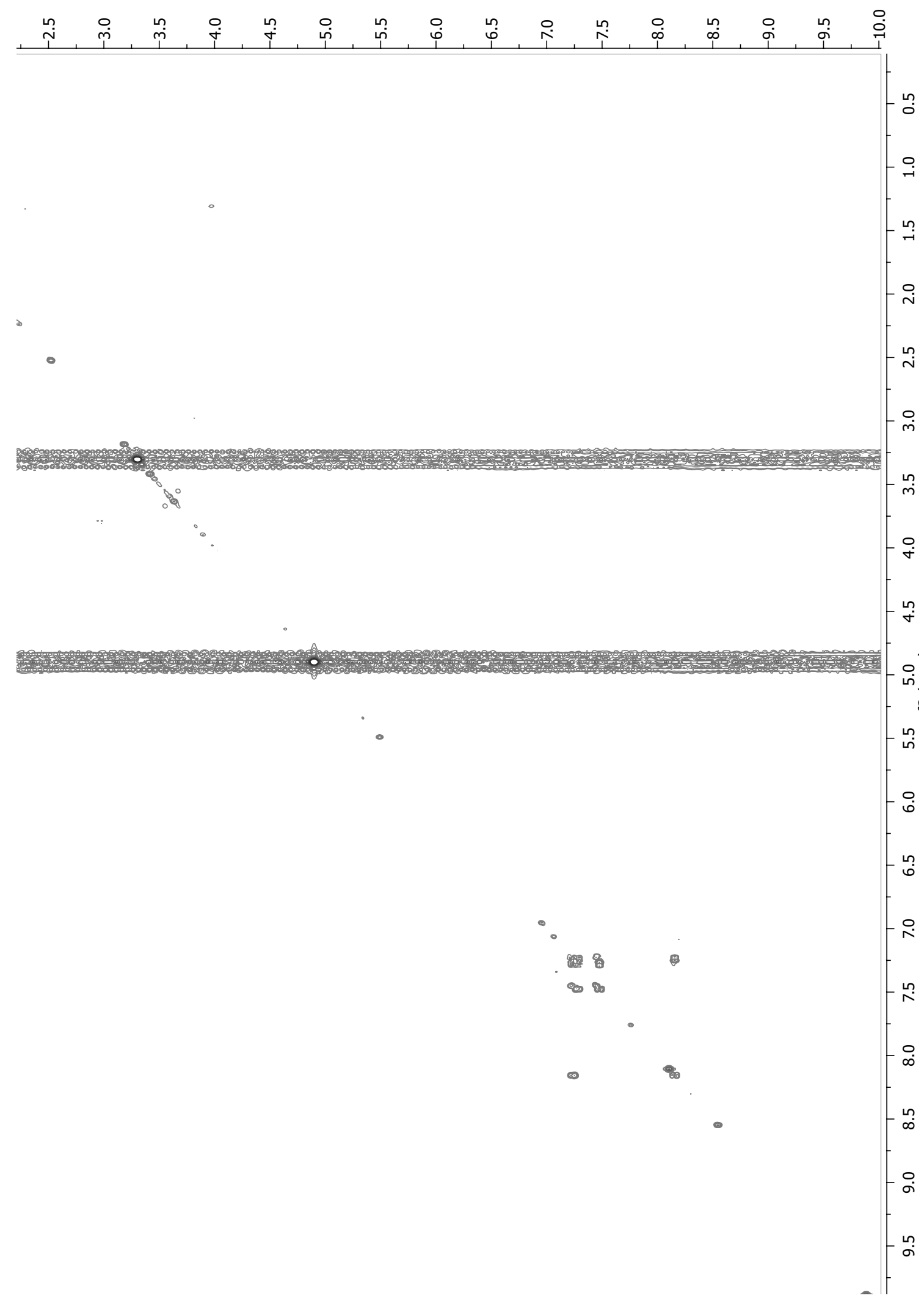

COSY spectrum of indole-3-carboxaldehyde (93) (600 MHz, $\left.\mathrm{CD}_{3} \mathrm{OD}\right)$ 
(mau) if

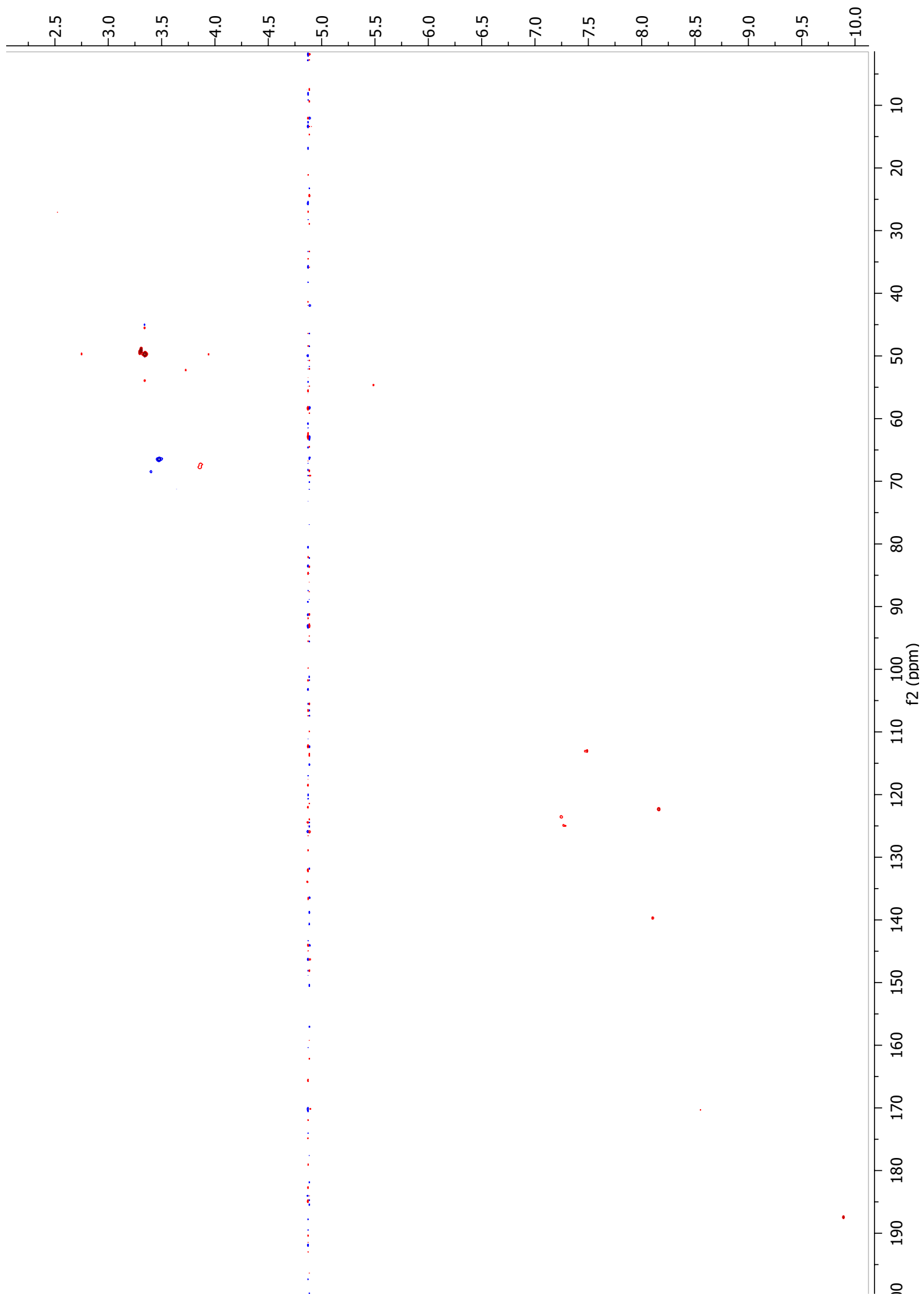

Mutliplicity-edited HSQC spectrum of indole-3-carboxaldehyde (93) showing methylenes in blue and methyls and methines in red (600 $\left.\mathrm{MHz}, \mathrm{CD}_{3} \mathrm{OD}\right)$ 


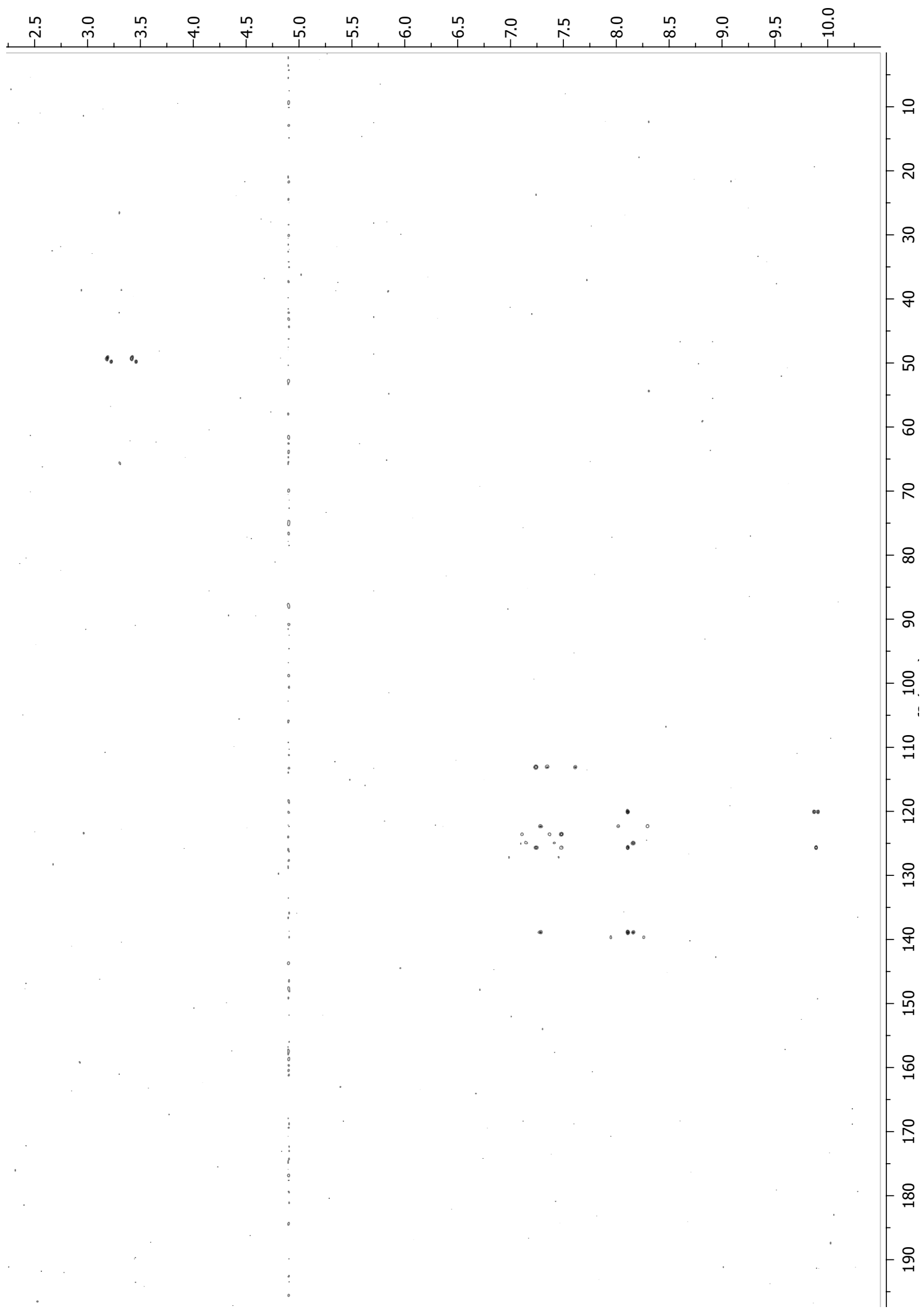

HMBC spectrum of indole-3-carboxaldehyde (93) $\left(600 \mathrm{MHz}, \mathrm{CD}_{3} \mathrm{OD}\right)$ 
Appendix D

\section{NMR Spectra of 2,5-DKPs}

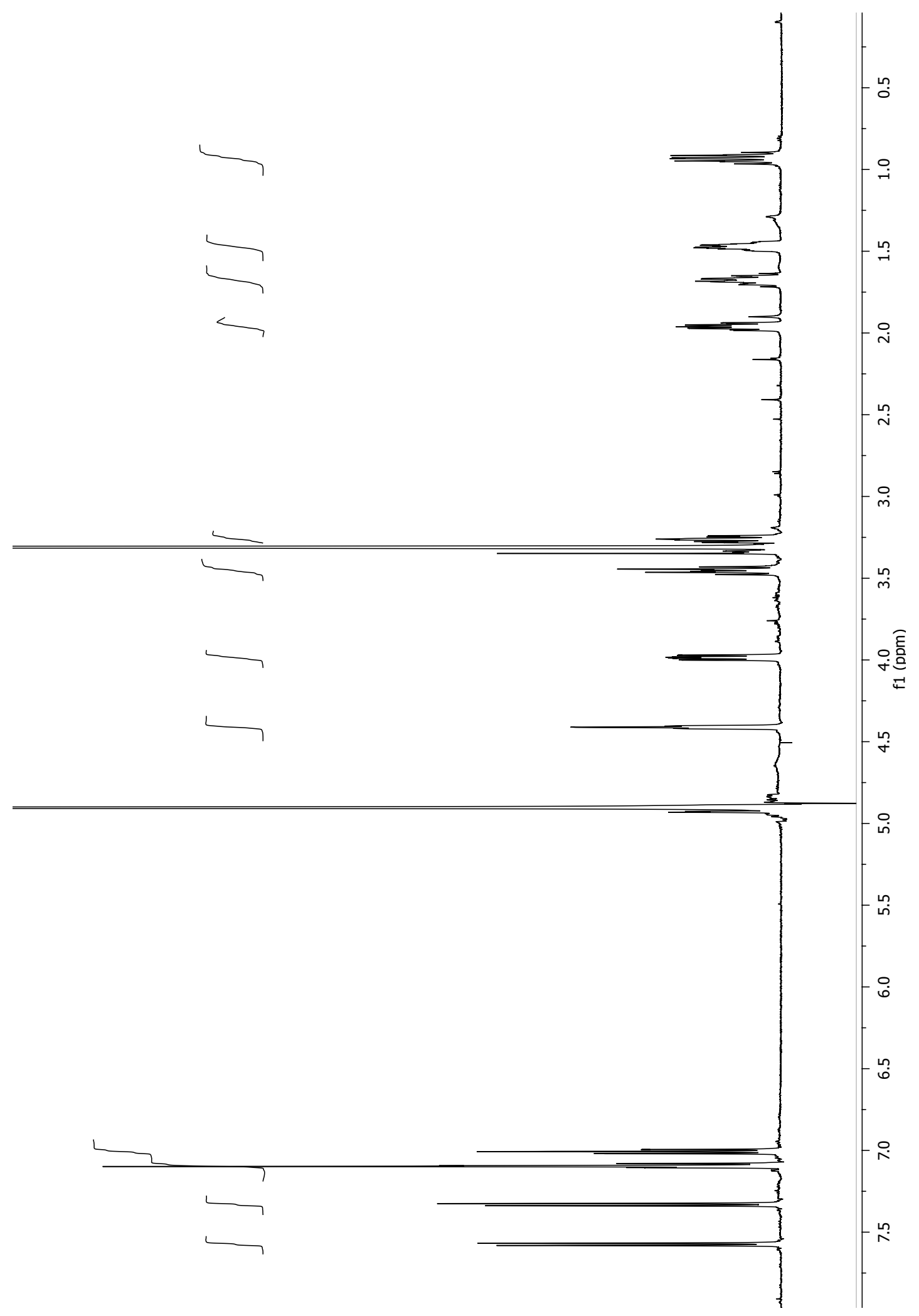

${ }^{1} \mathrm{H}$ NMR spectrum of cyclo(L-Trp-L-Pro) (53) (600 MHz, $\left.\mathrm{CD}_{3} \mathrm{OD}\right)$ 


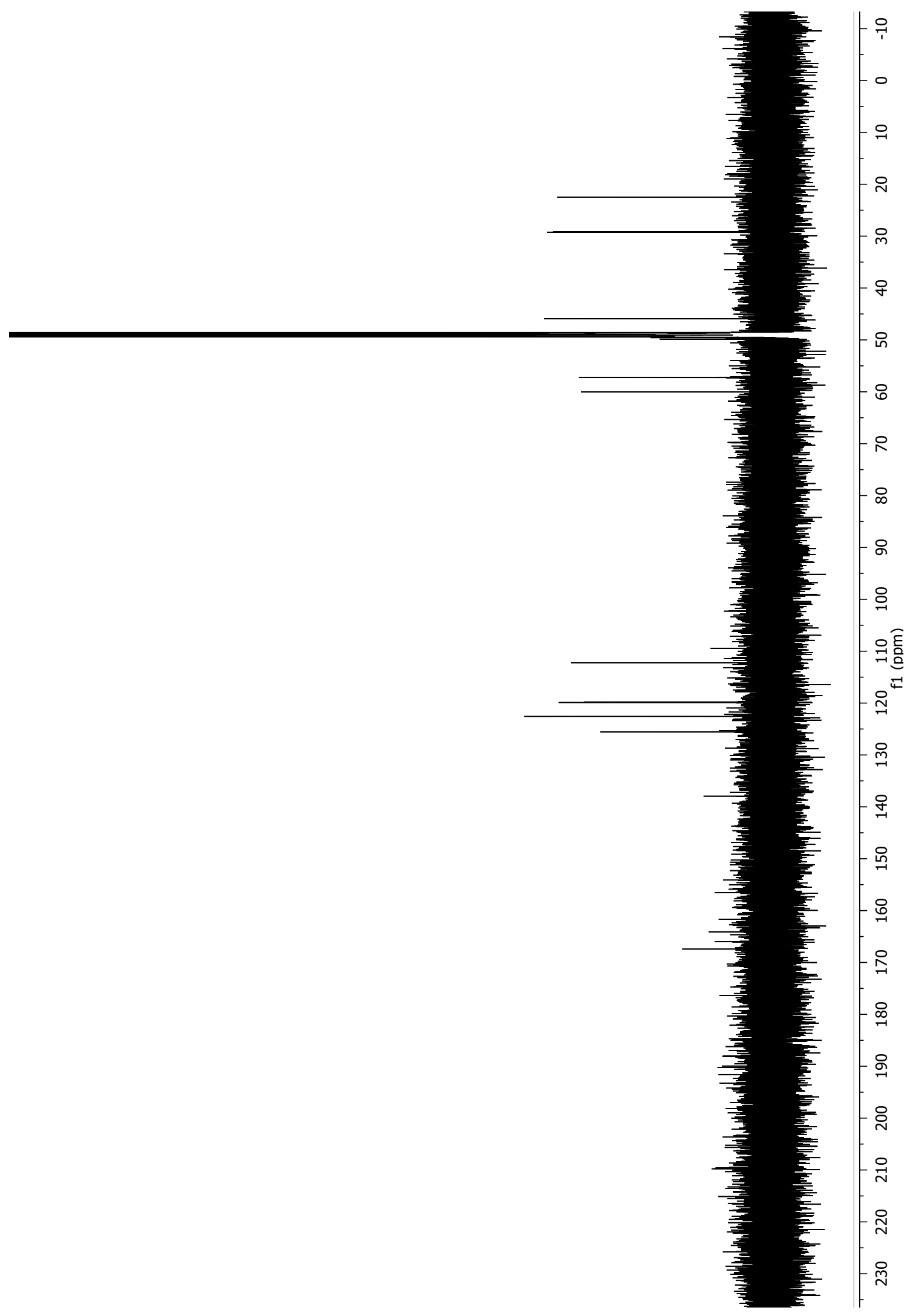

${ }^{13} \mathrm{C}$ NMR spectrum of cyclo(L-Trp-L-Pro) (53) (150 MHz, $\left.\mathrm{CD}_{3} \mathrm{OD}\right)$ 
(mua) if

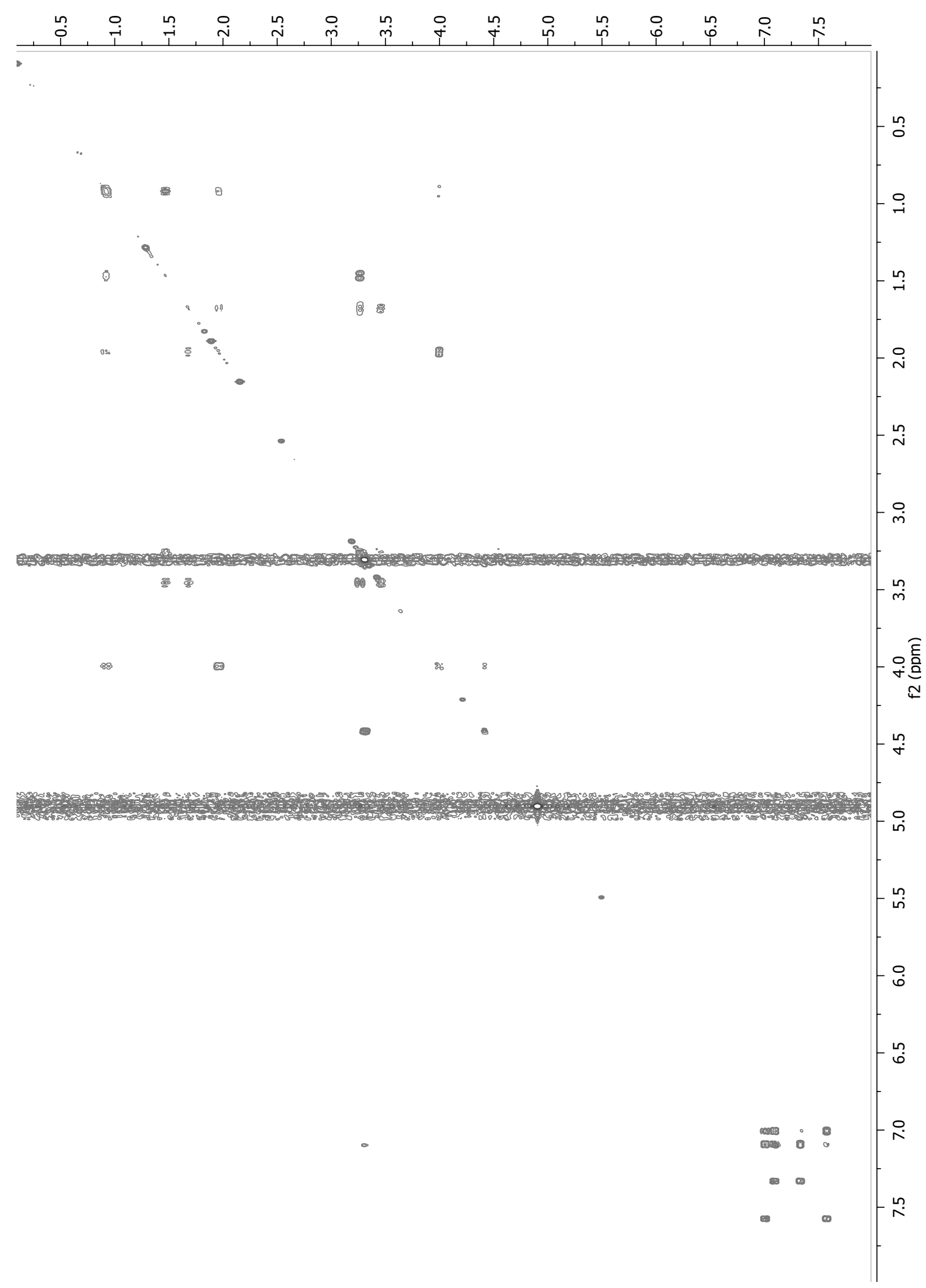

COSY spectrum of cyclo(L-Trp-L-Pro) (53) (600 MHz, $\left.\mathrm{CD}_{3} \mathrm{OD}\right)$ 


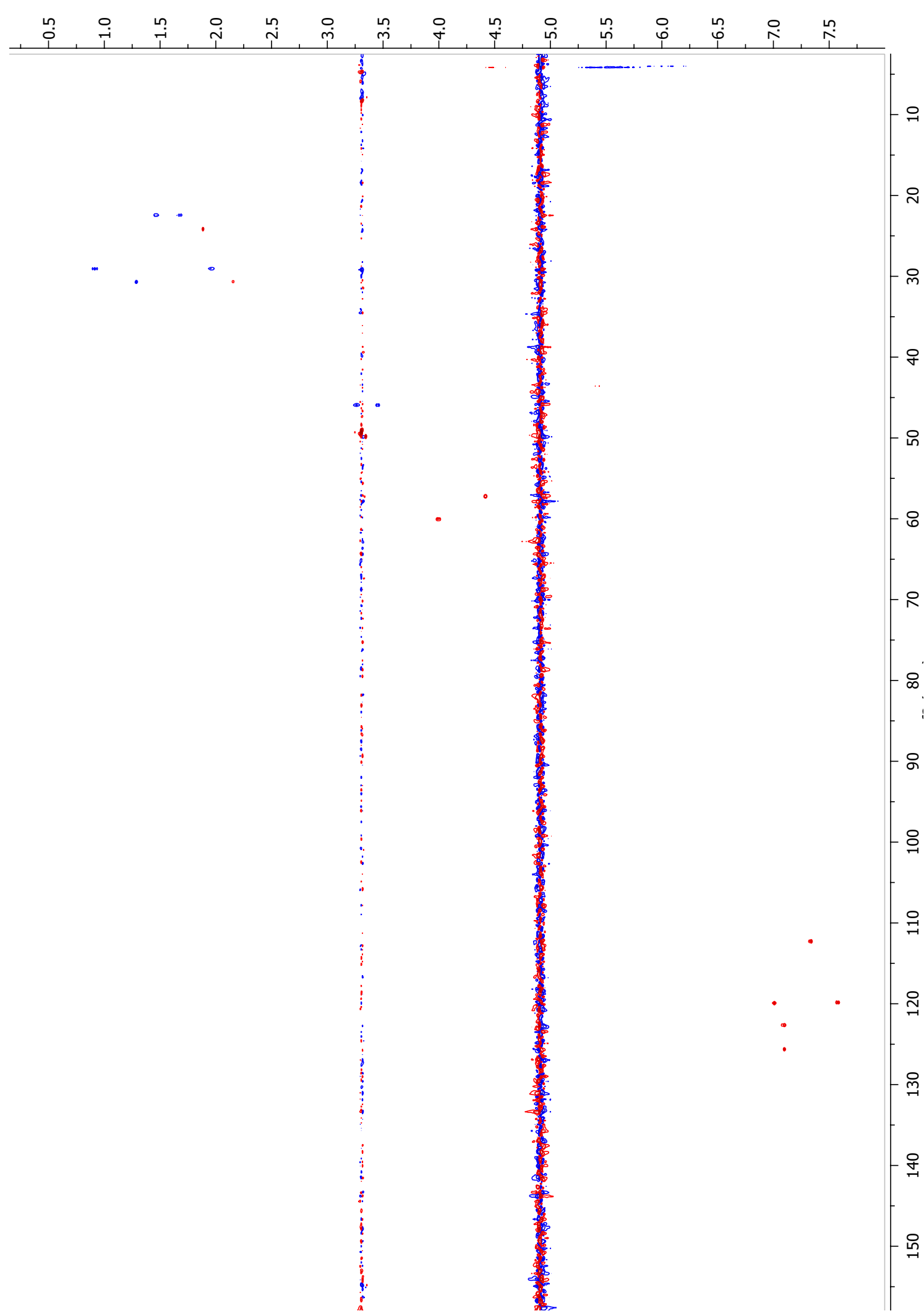

Mutliplicity-edited HSQC spectrum of cyclo(L-Trp-L-Pro) (53) showing methylenes in blue and methyls and methines in red $\left(600 \mathrm{MHz}, \mathrm{CD}_{3} \mathrm{OD}\right)$ 


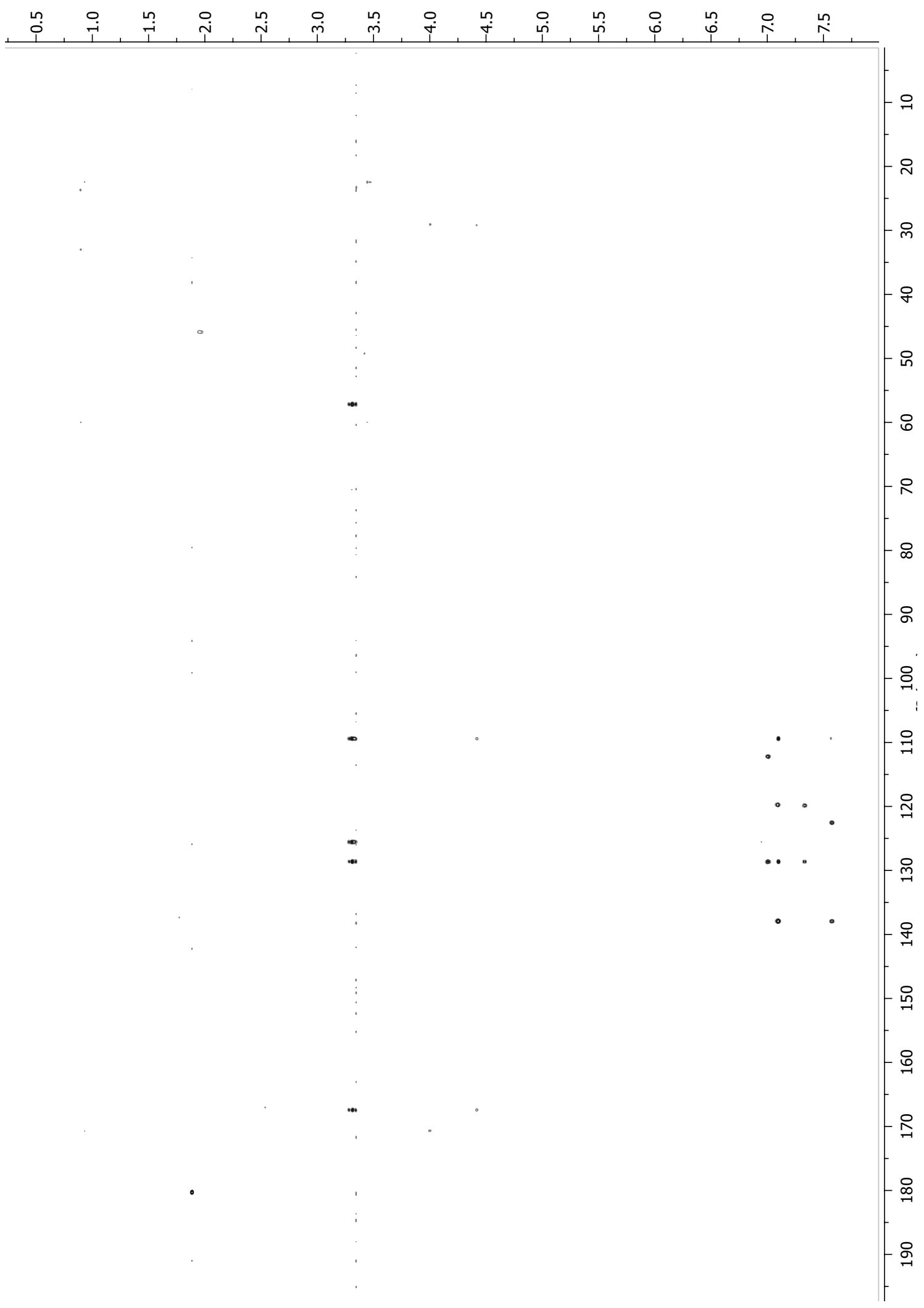

HMBC spectrum of cyclo(L-Trp-L-Pro) (53) (600 MHz, $\left.\mathrm{CD}_{3} \mathrm{OD}\right)$ 


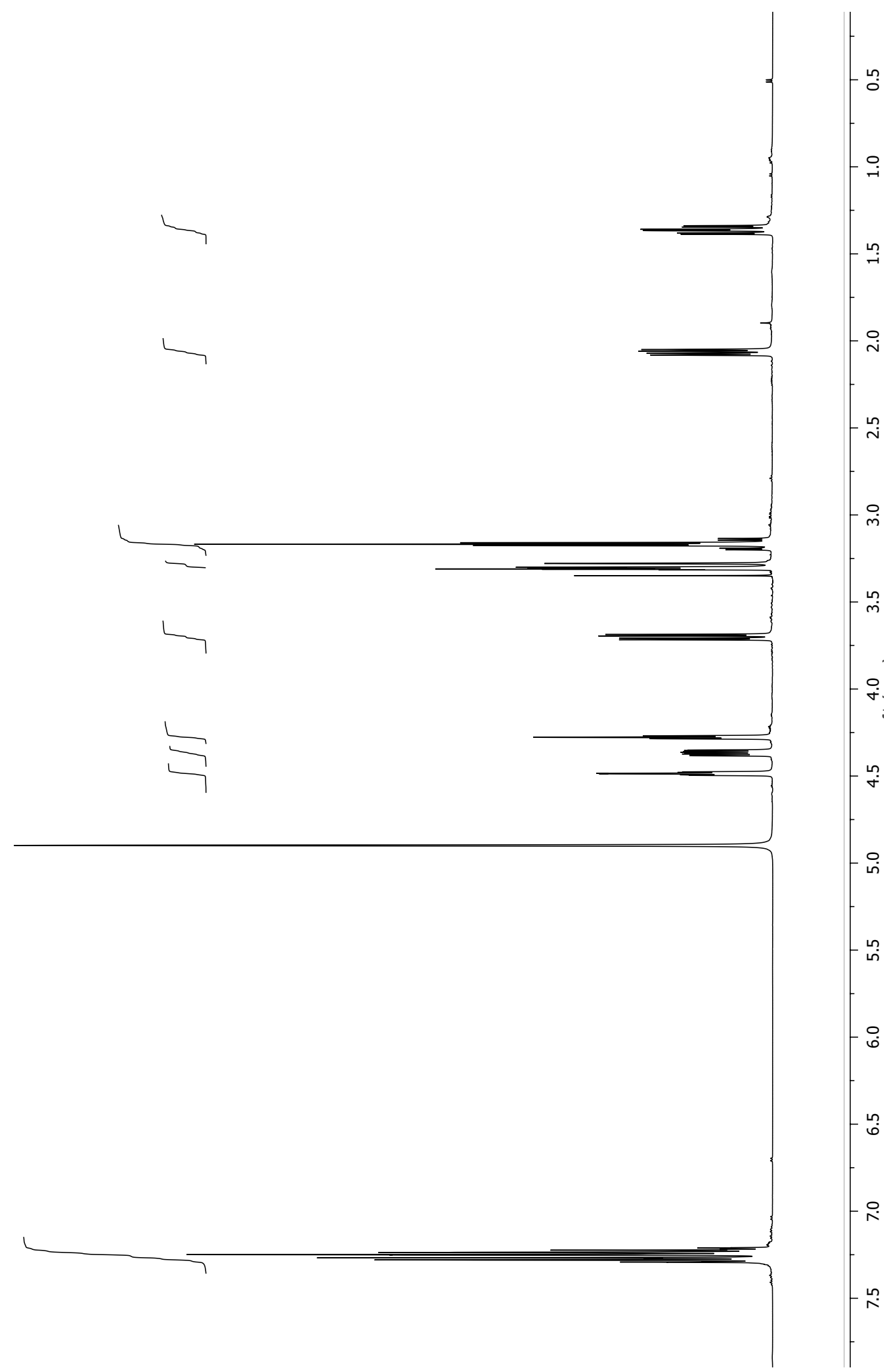

${ }^{1} \mathrm{H}$ NMR spectrum of cyclo(L-Phe-L-4-Hyp) (43) (600 MHz, CD 3 OD) 


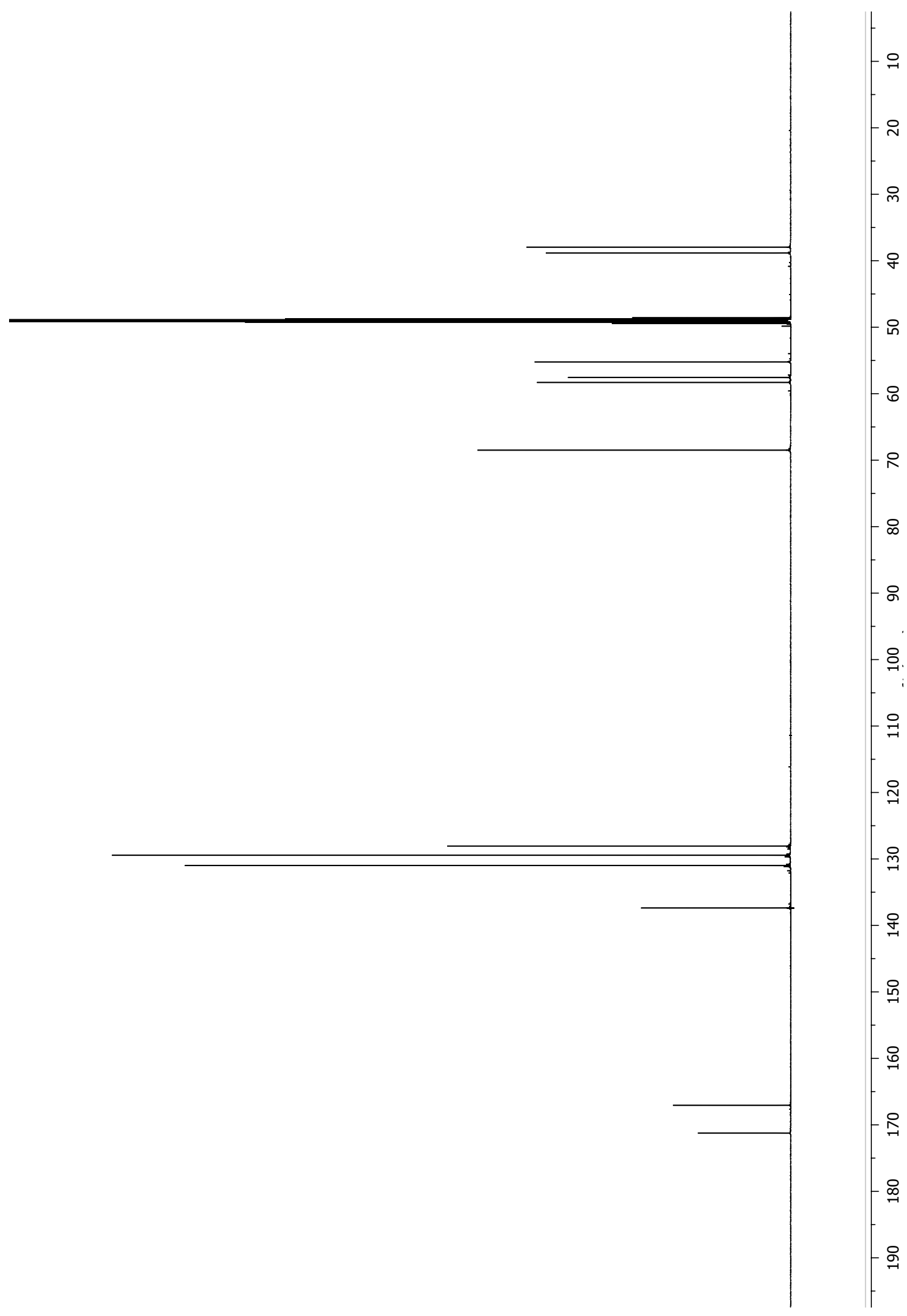

${ }^{13} \mathrm{C}$ NMR spectrum of cyclo(L-Phe-L-4-Hyp) (43) (150 MHz, $\left.\mathrm{CD}_{3} \mathrm{OD}\right)$ 


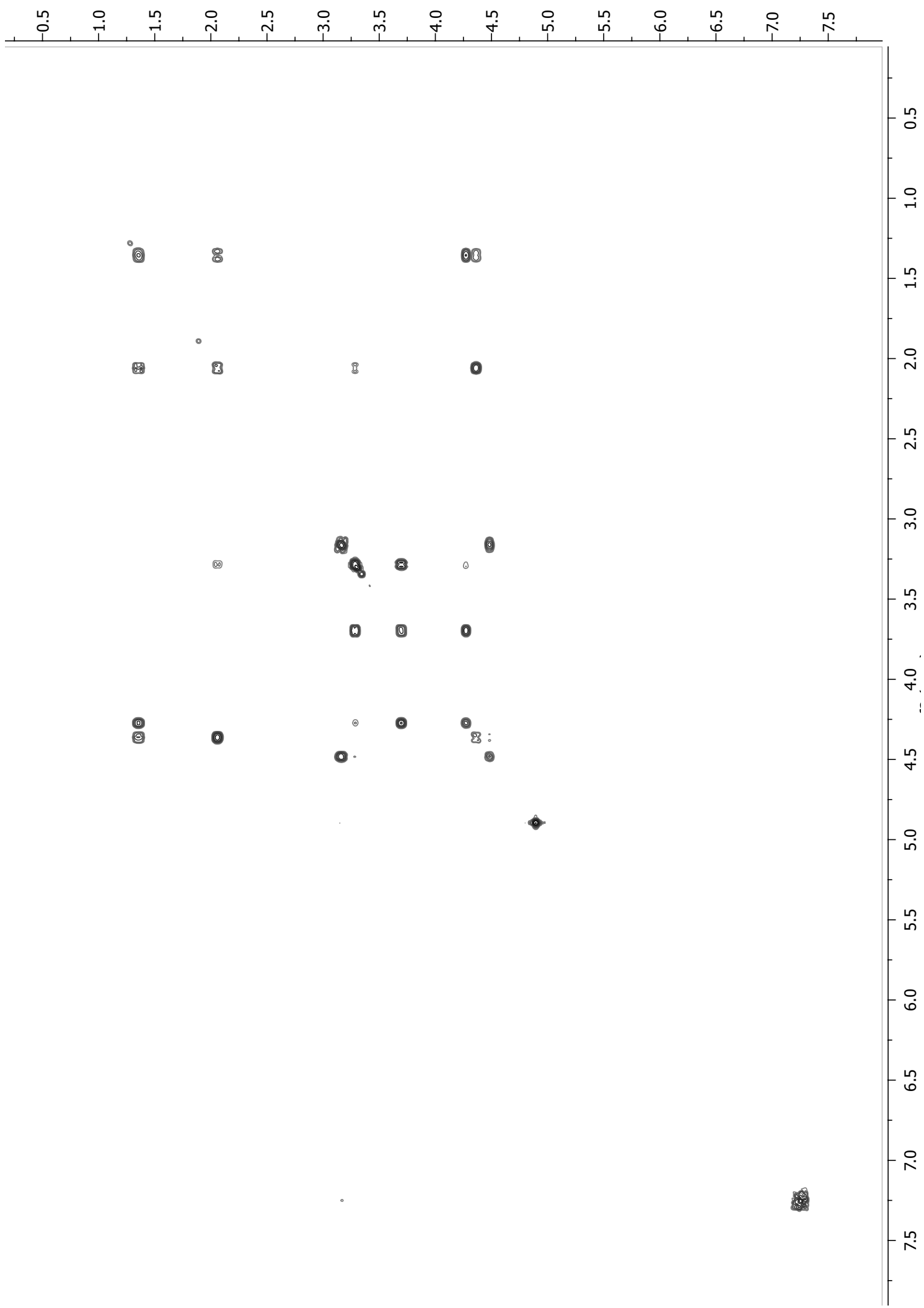

COSY spectrum of cyclo(L-Phe-L-4-Hyp) (43) (600 MHz, CD $\left.{ }_{3} \mathrm{OD}\right)$ 
(mua) it

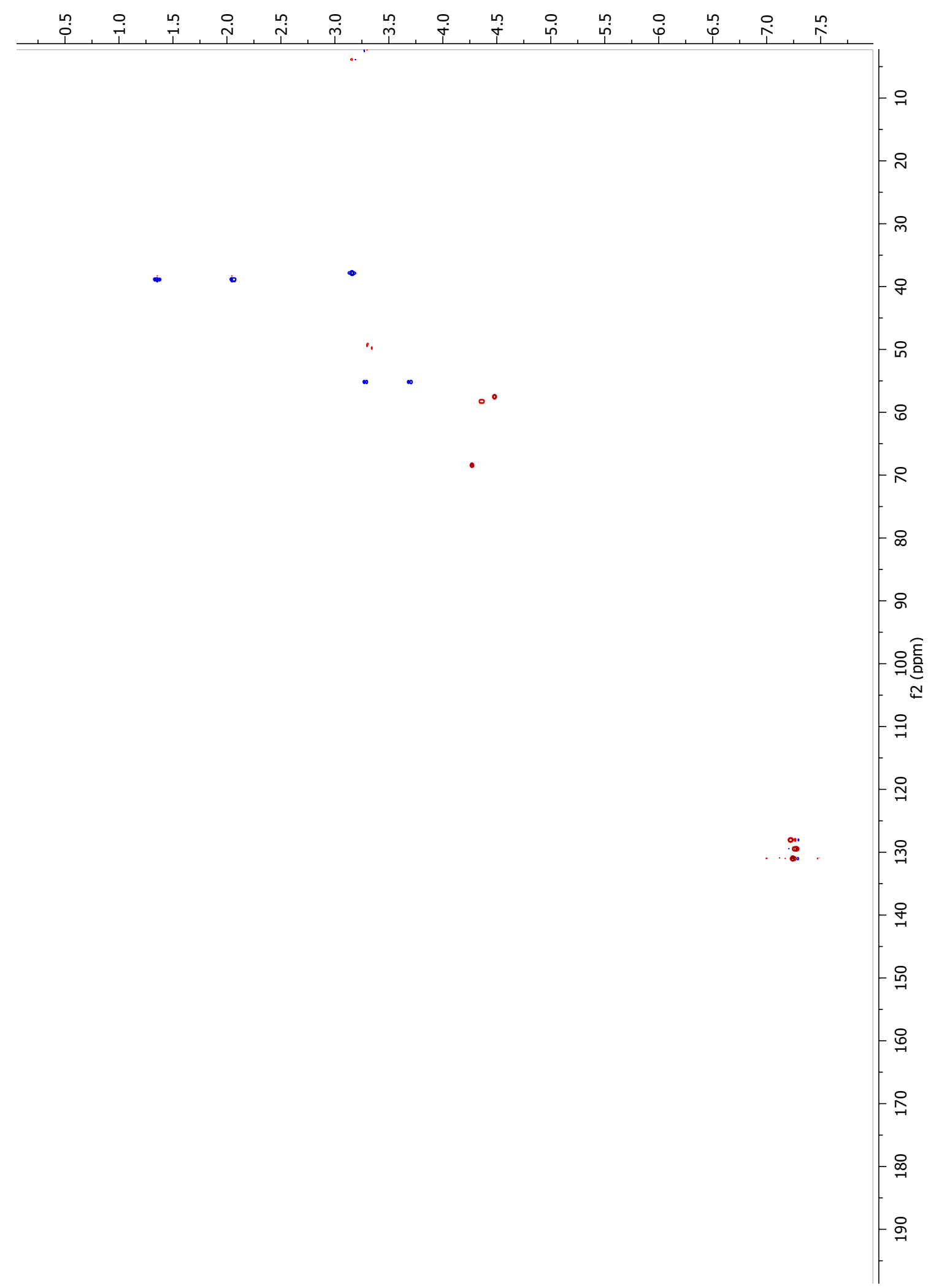

Mutliplicity-edited HSQC spectrum of cyclo(L-Phe-L-4-Hyp) (43) showing methylenes in blue and methyls and methines in red (600 MHz, $\left.\mathrm{CD}_{3} \mathrm{OD}\right)$ 


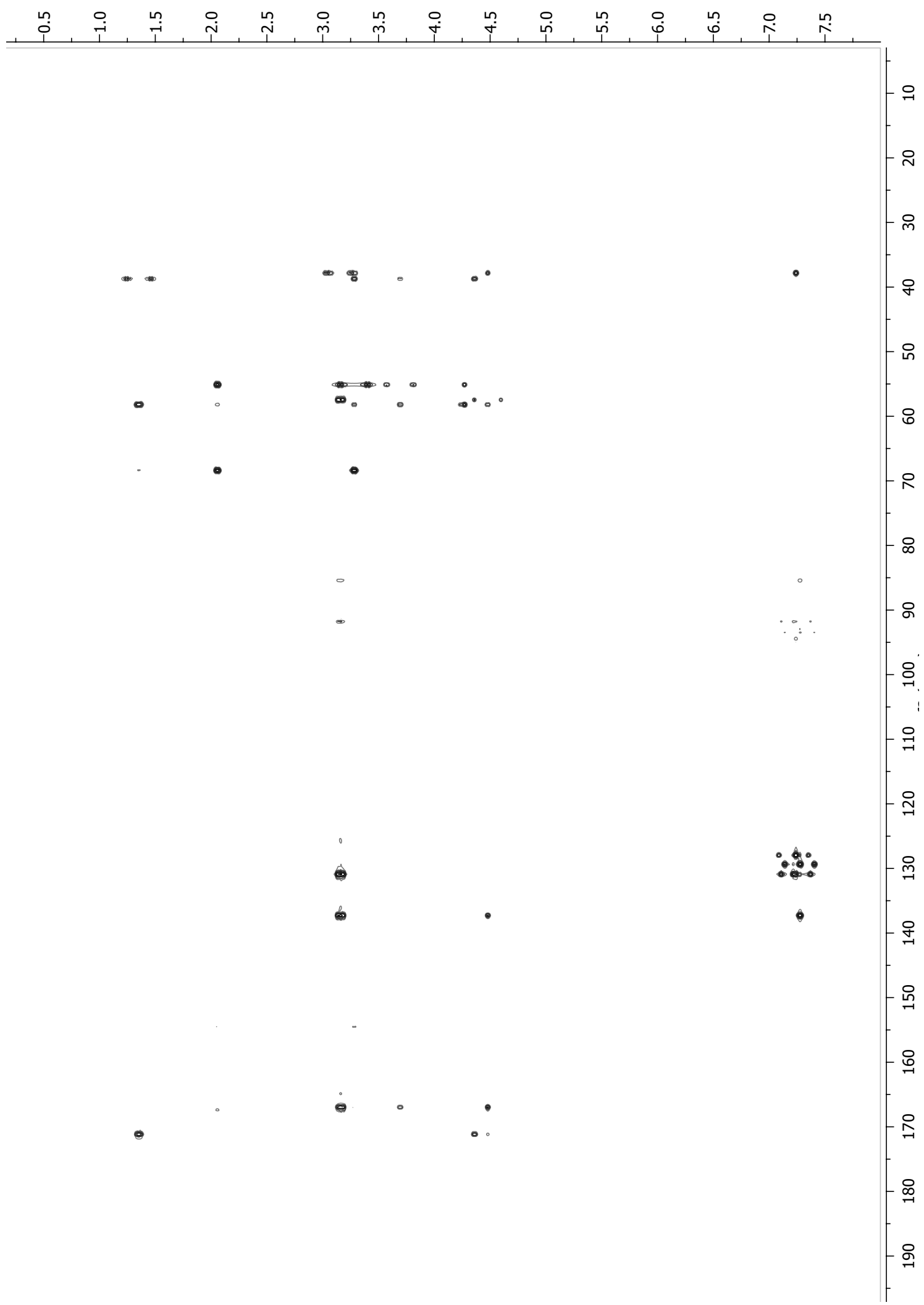

HMBC spectrum of cyclo(L-Phe-L-4-Hyp) (43) (600 MHz, $\left.\mathrm{CD}_{3} \mathrm{OD}\right)$ 


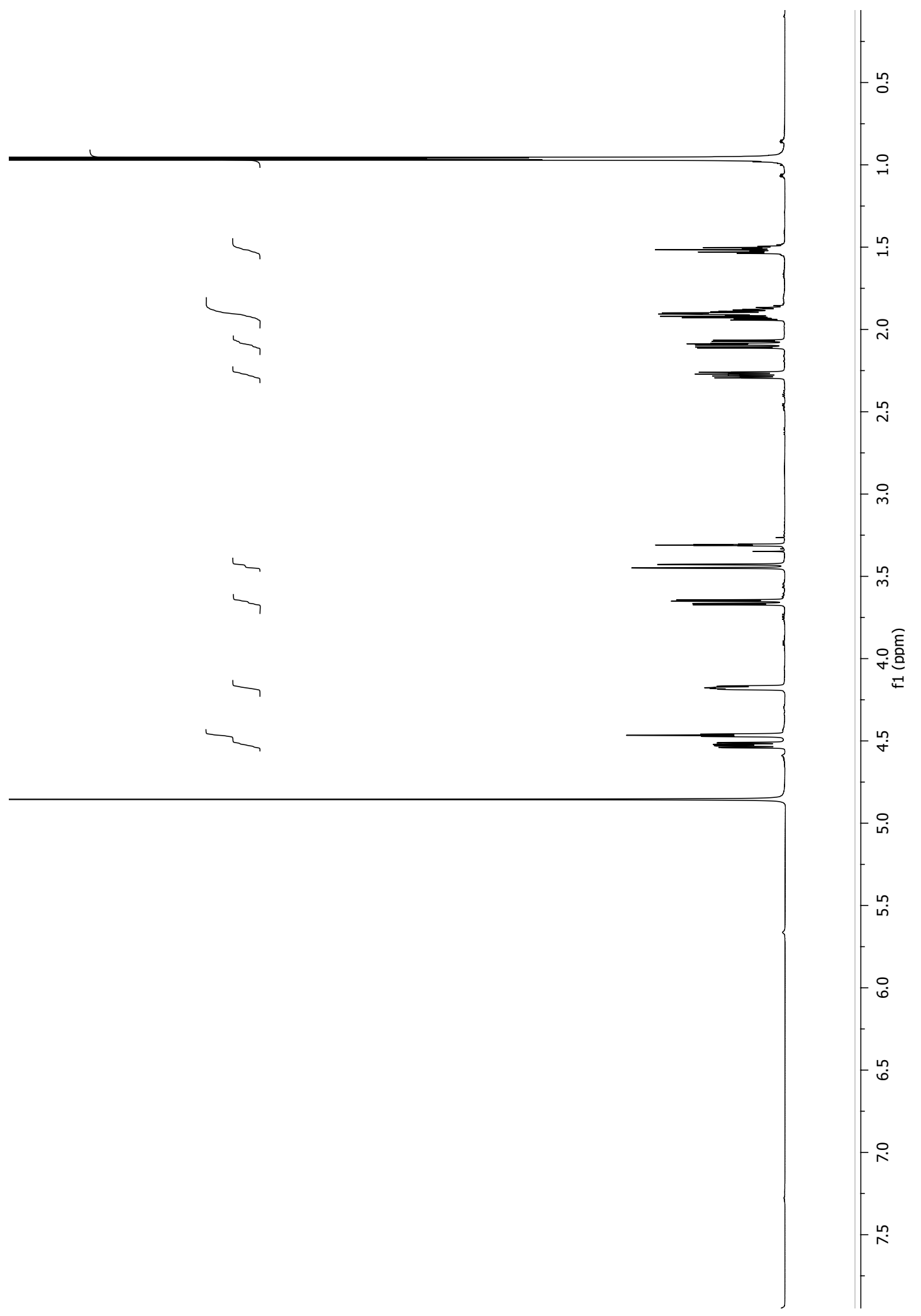

${ }^{1} \mathrm{H}$ NMR spectrum of cyclo(L-Leu-L-4-Hyp) (42) (600 MHz, $\left.\mathrm{CD}_{3} \mathrm{OD}\right)$ 


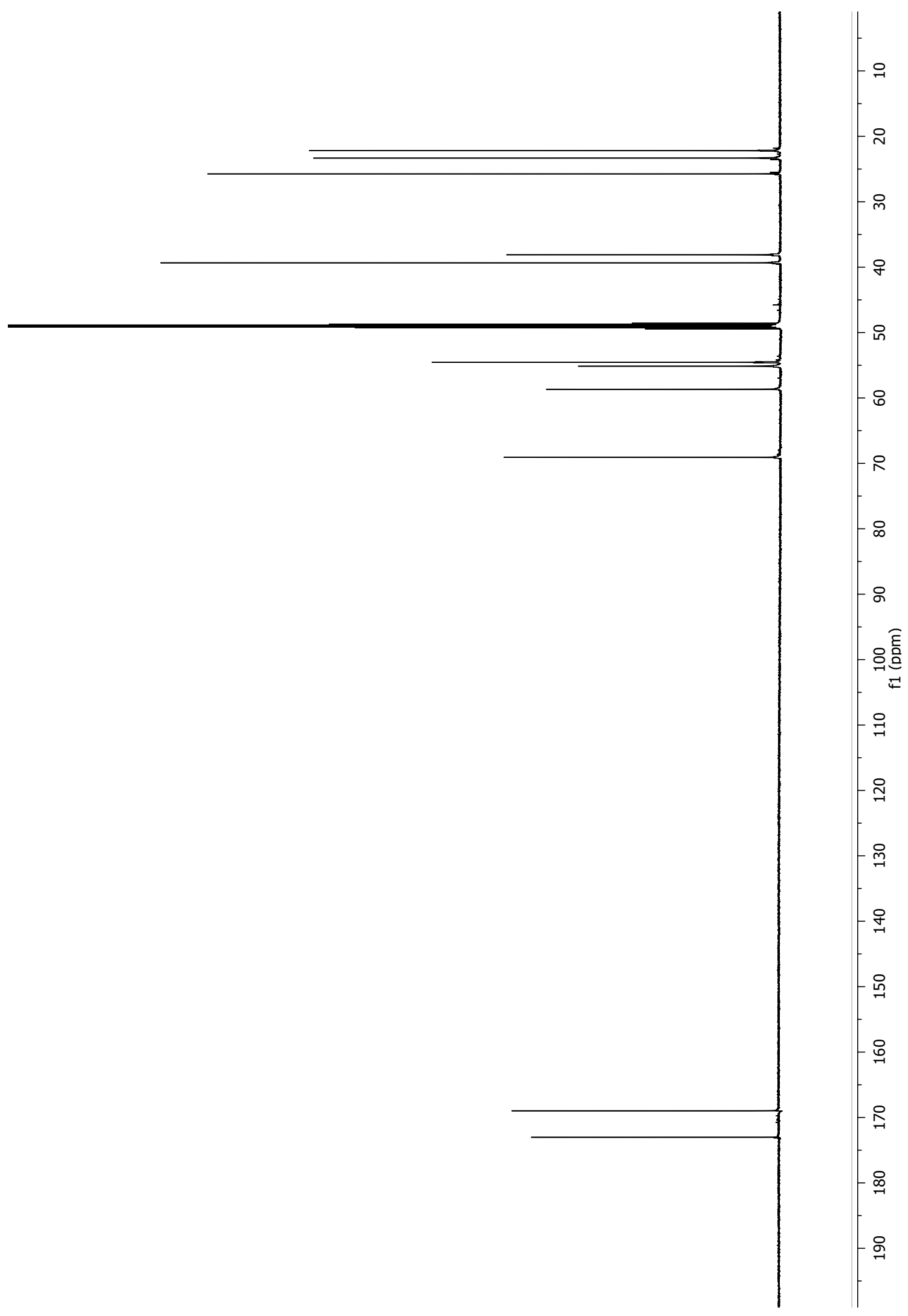

${ }^{13} \mathrm{C}$ NMR spectrum of cyclo(L-Leu-L-4-Hyp) (42) (150 MHz, $\left.\mathrm{CD}_{3} \mathrm{OD}\right)$ 
(mau) if

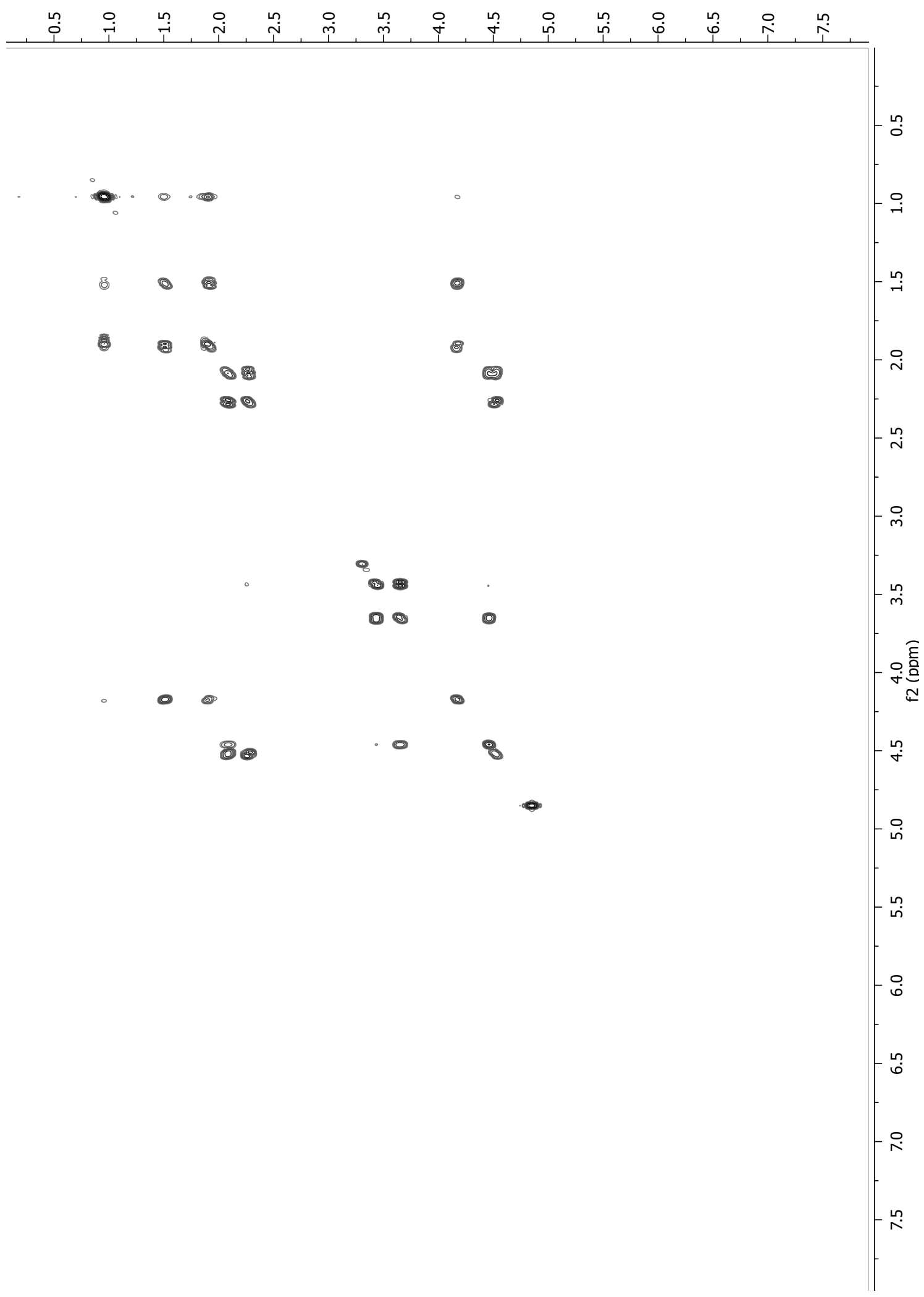

COSY spectrum of cyclo(L-Leu-L-4-Hyp) (42) (600 MHz, $\left.\mathrm{CD}_{3} \mathrm{OD}\right)$ 
(mau) if

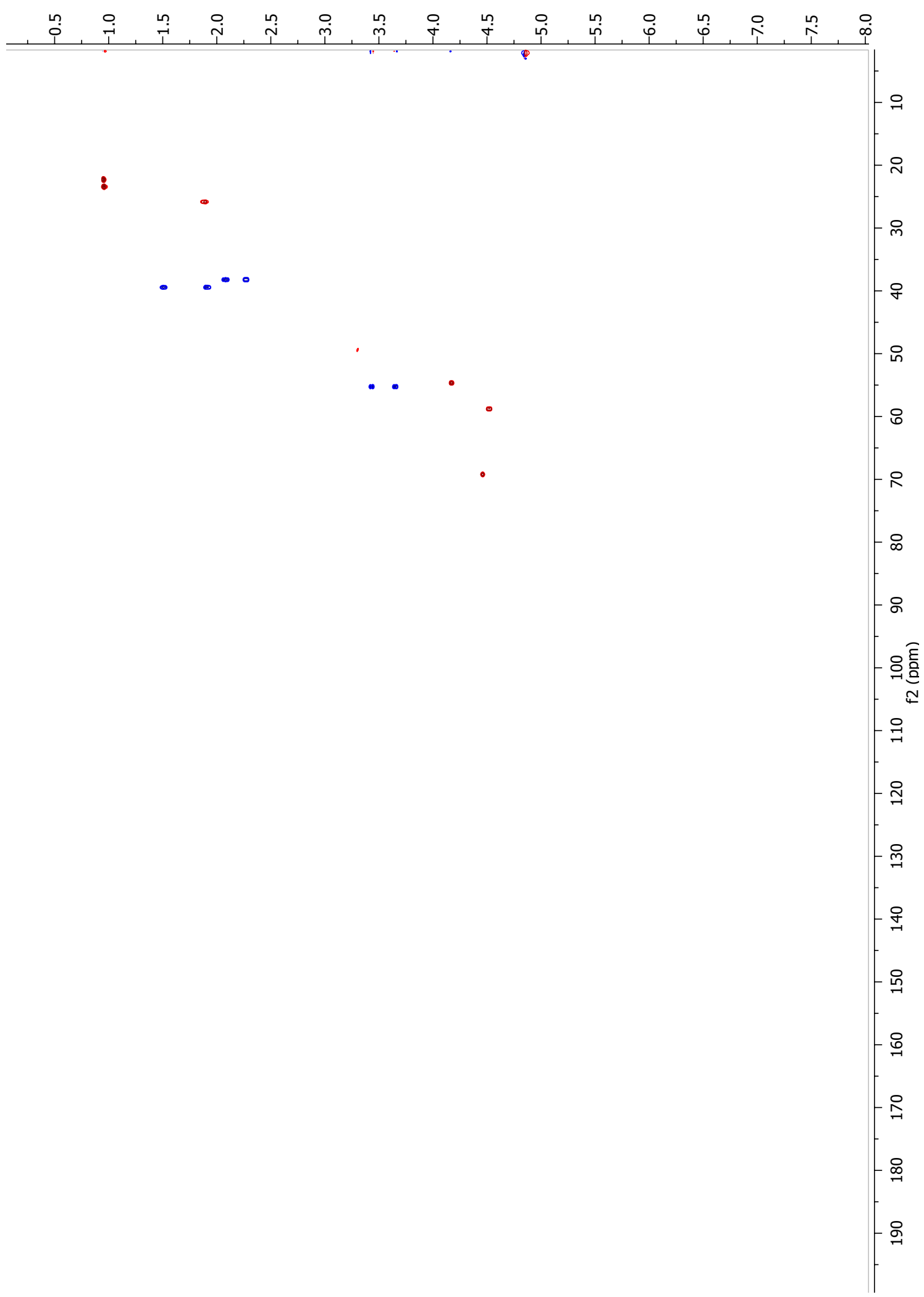

Mutliplicity-edited HSQC spectrum of cyclo(L-Leu-L-4-Hyp) (42) showing methylenes in blue and methyls and methines in red $\left(600 \mathrm{MHz}, \mathrm{CD}_{3} \mathrm{OD}\right)$ 
(mua) if

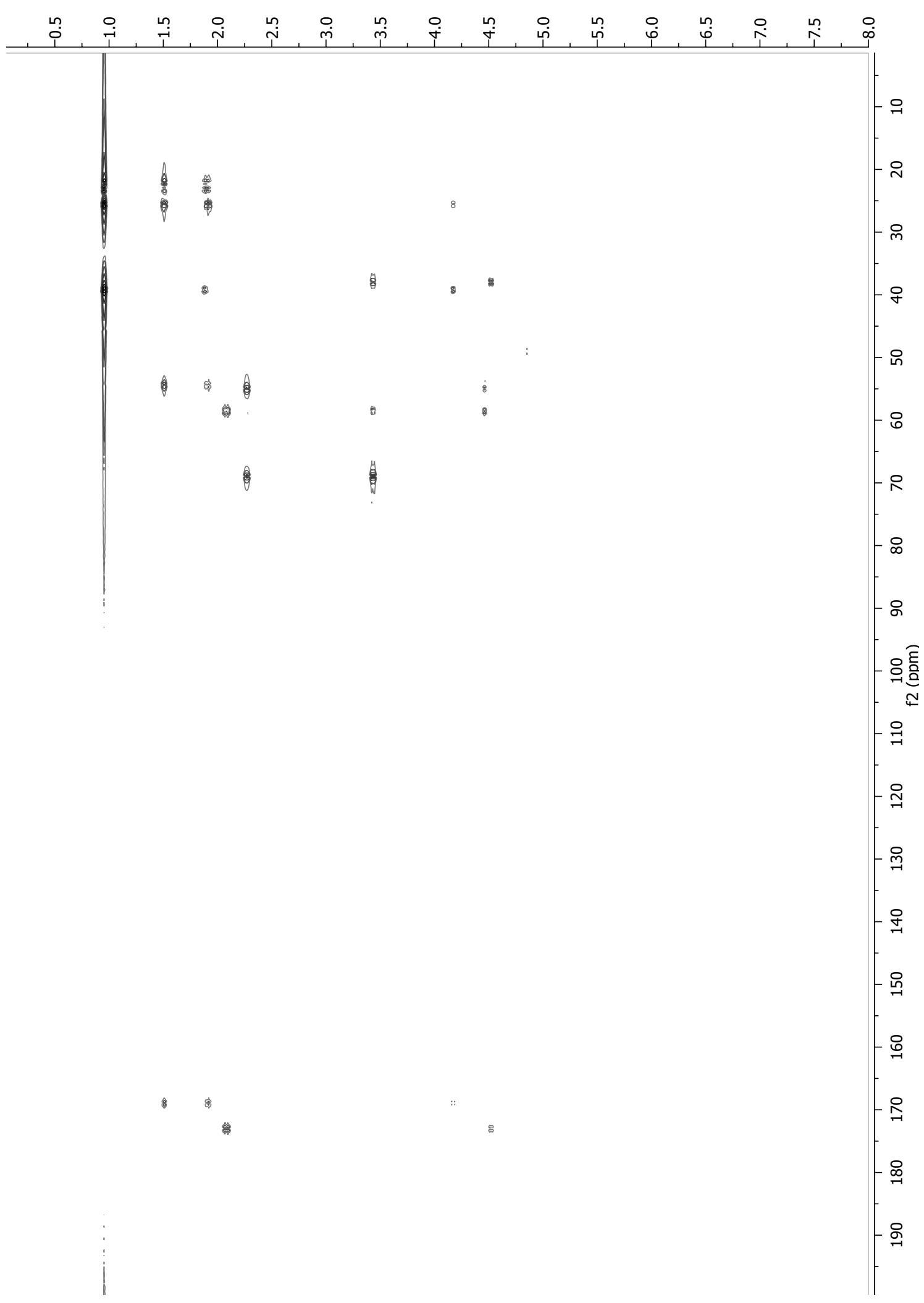

HMBC spectrum of cyclo(L-Leu-L-4-Hyp) (42) (600 MHz, $\left.\mathrm{CD}_{3} \mathrm{OD}\right)$ 


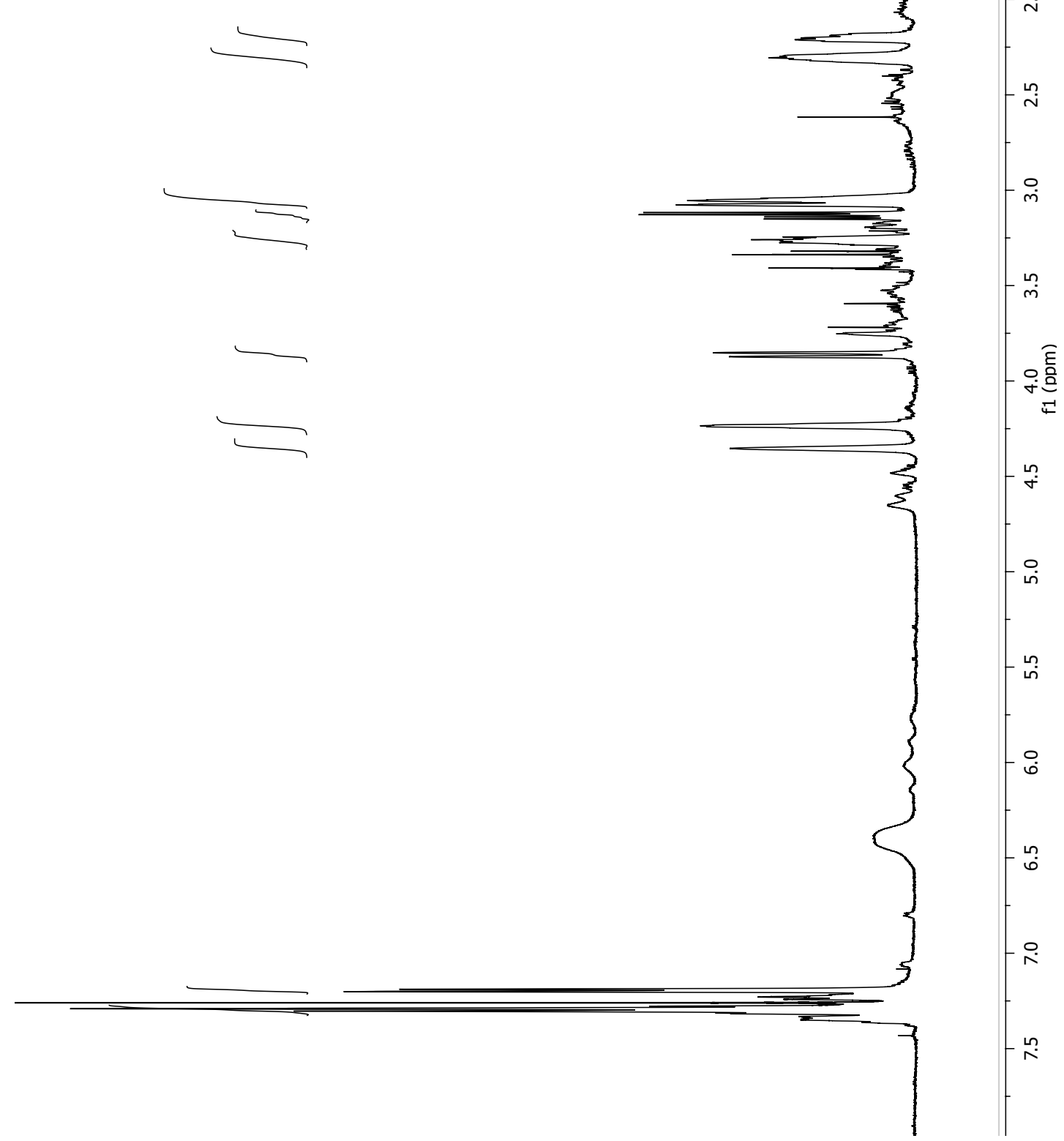

${ }^{1} \mathrm{H}$ NMR spectrum of cyclo(Phe-4-Hyp) (L-D/D-L) (94) $\left(600 \mathrm{MHz}, \mathrm{CDCl}_{3}\right.$ ) 


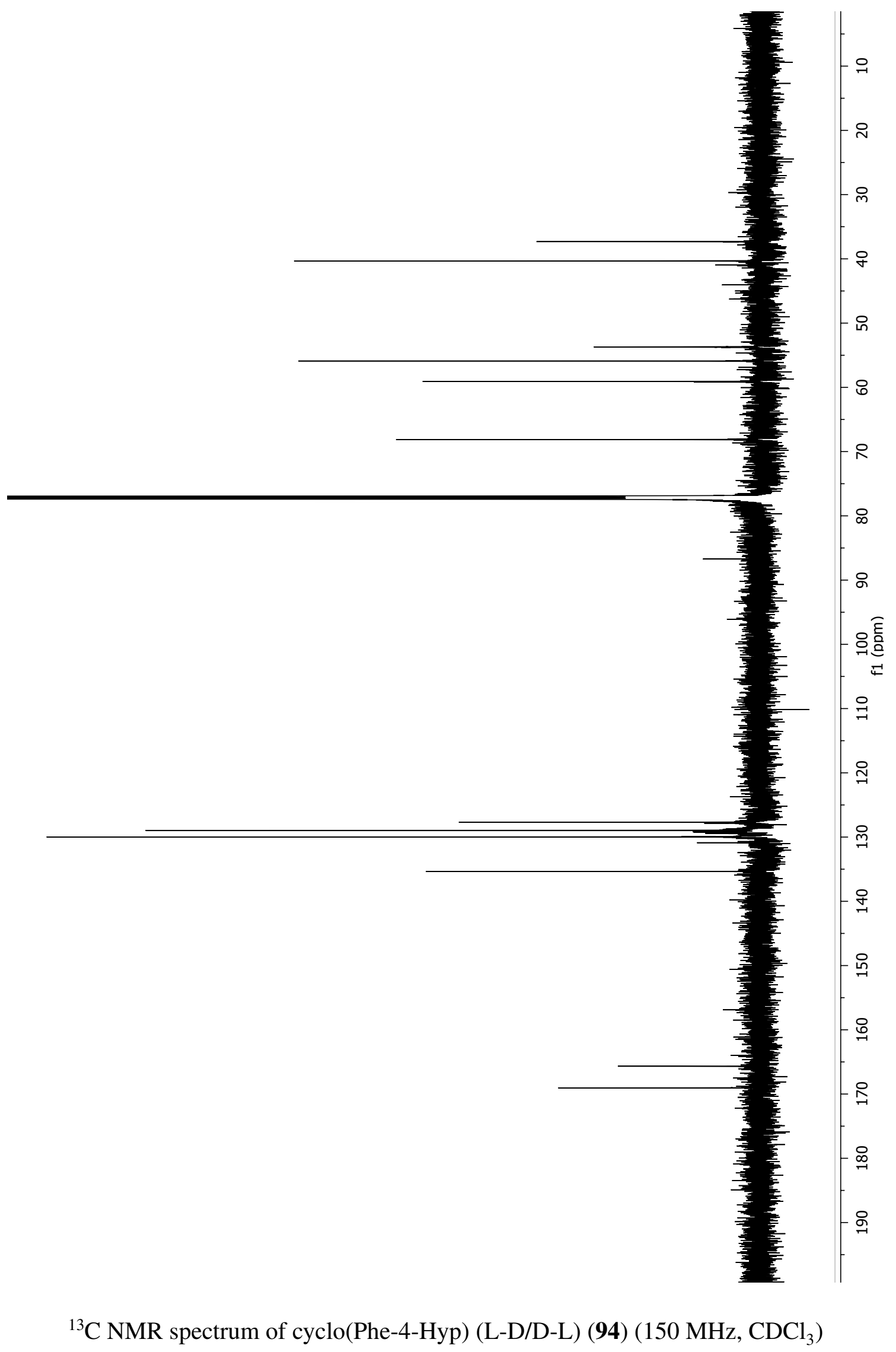




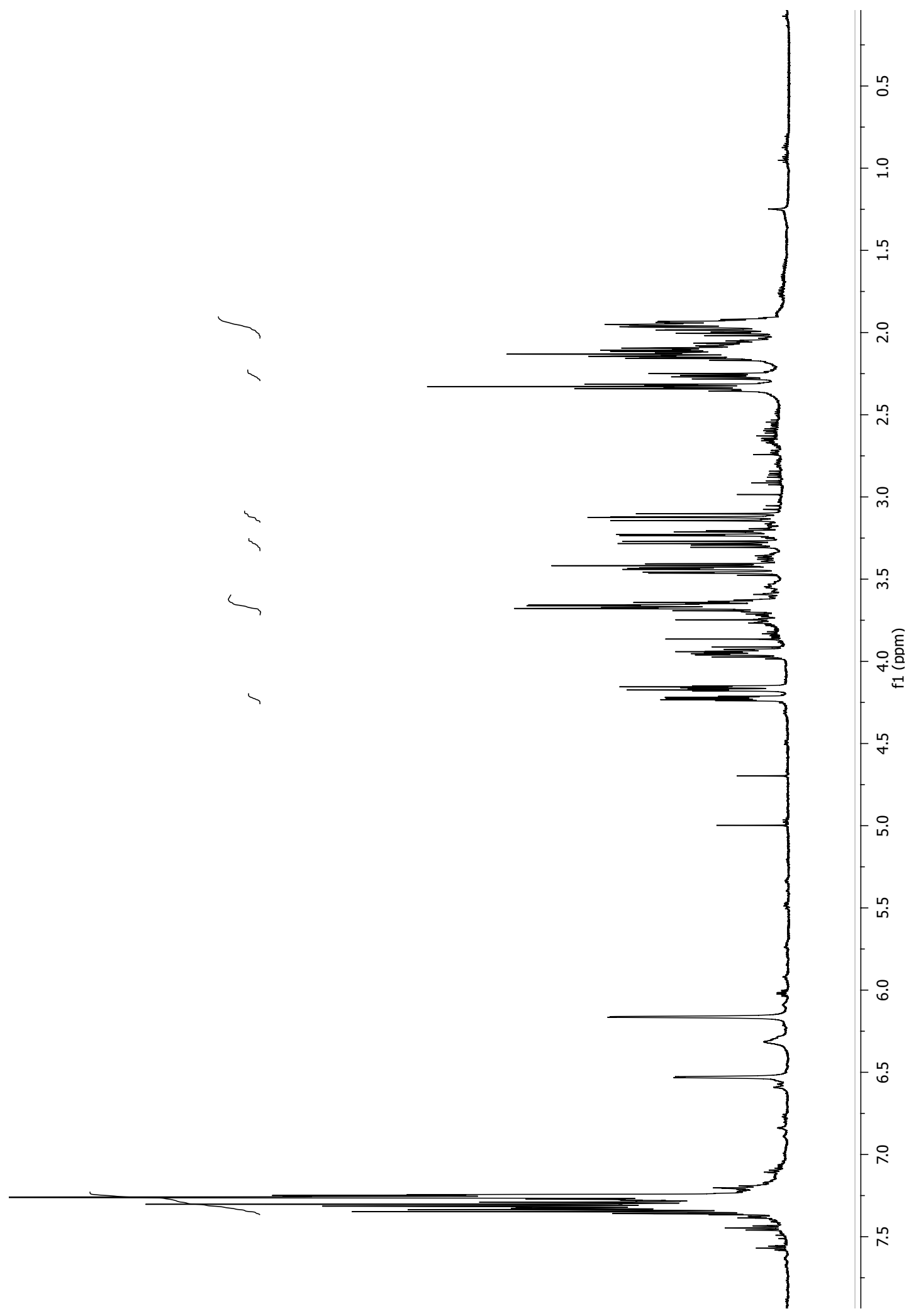

${ }^{1} \mathrm{H}$ NMR spectrum of cyclo(Phe-6-Hyp) (L-L/D-D) (95) (600 MHz, CDCl 3 ) 
${ }^{13} \mathrm{C}$ NMR spectrum of cyclo(Phe-6-Hyp) (L-L/D-D) (95) (150 MHz, $\mathrm{CDCl}_{3}$ ) 


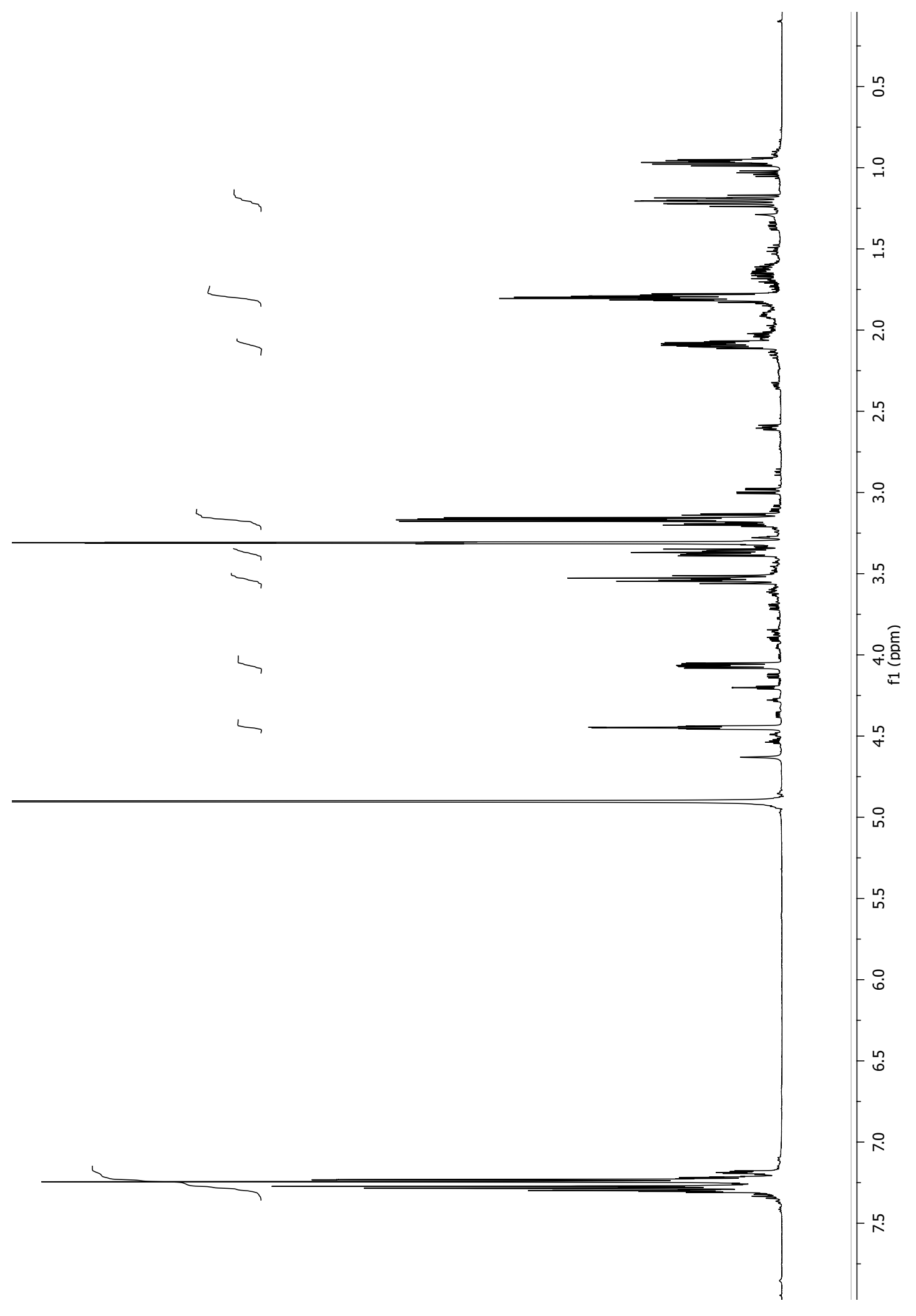

${ }^{1} \mathrm{H}$ NMR spectrum of cyclo(Phe-Pro) (L-L/D-D) (96) (600 MHz, CD 3 OD) 


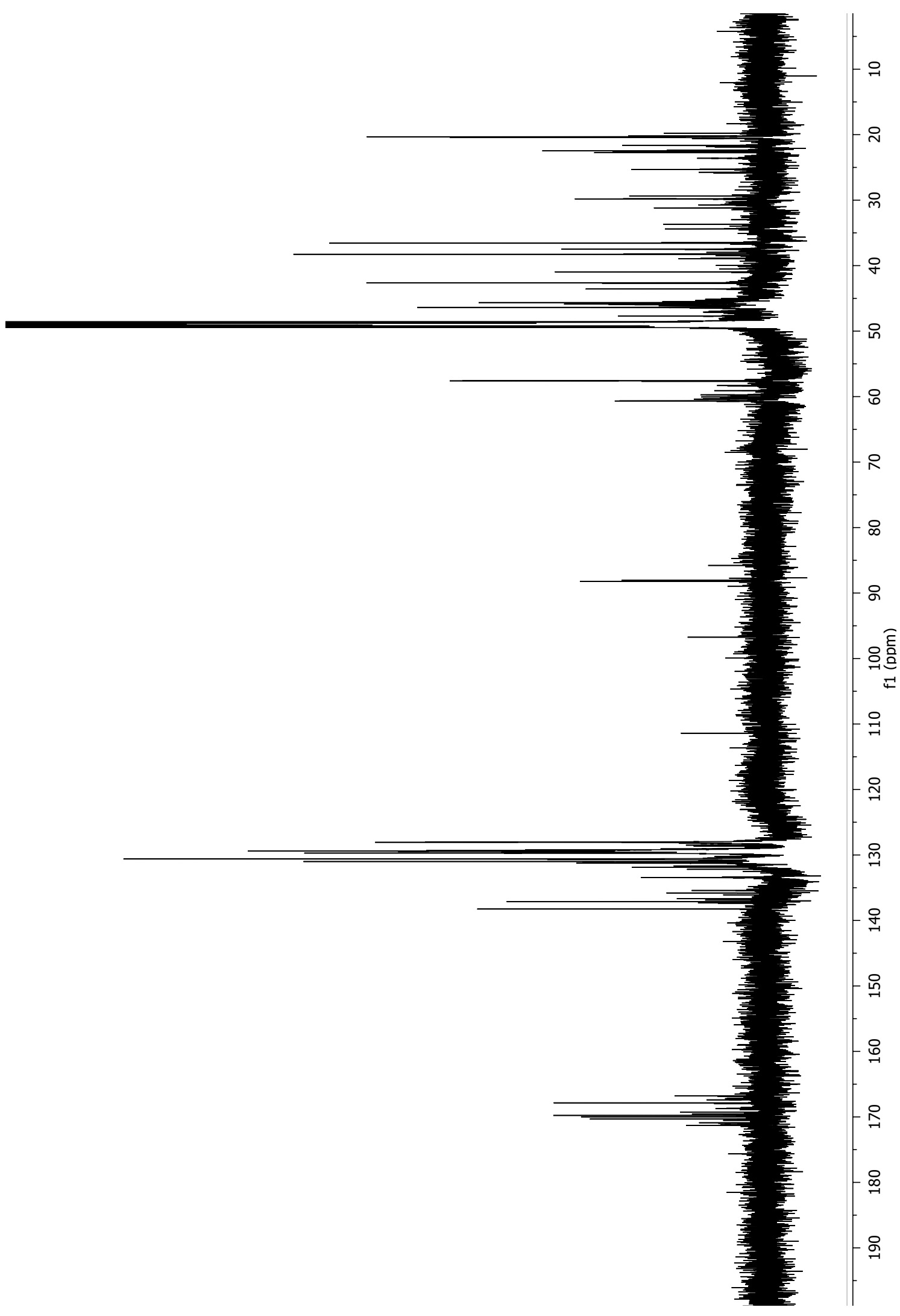

${ }^{13} \mathrm{C}$ NMR spectrum of cyclo(Phe-Pro) (L-L/D-D) (96) (150 MHz, $\left.\mathrm{CD}_{3} \mathrm{OD}\right)$ 


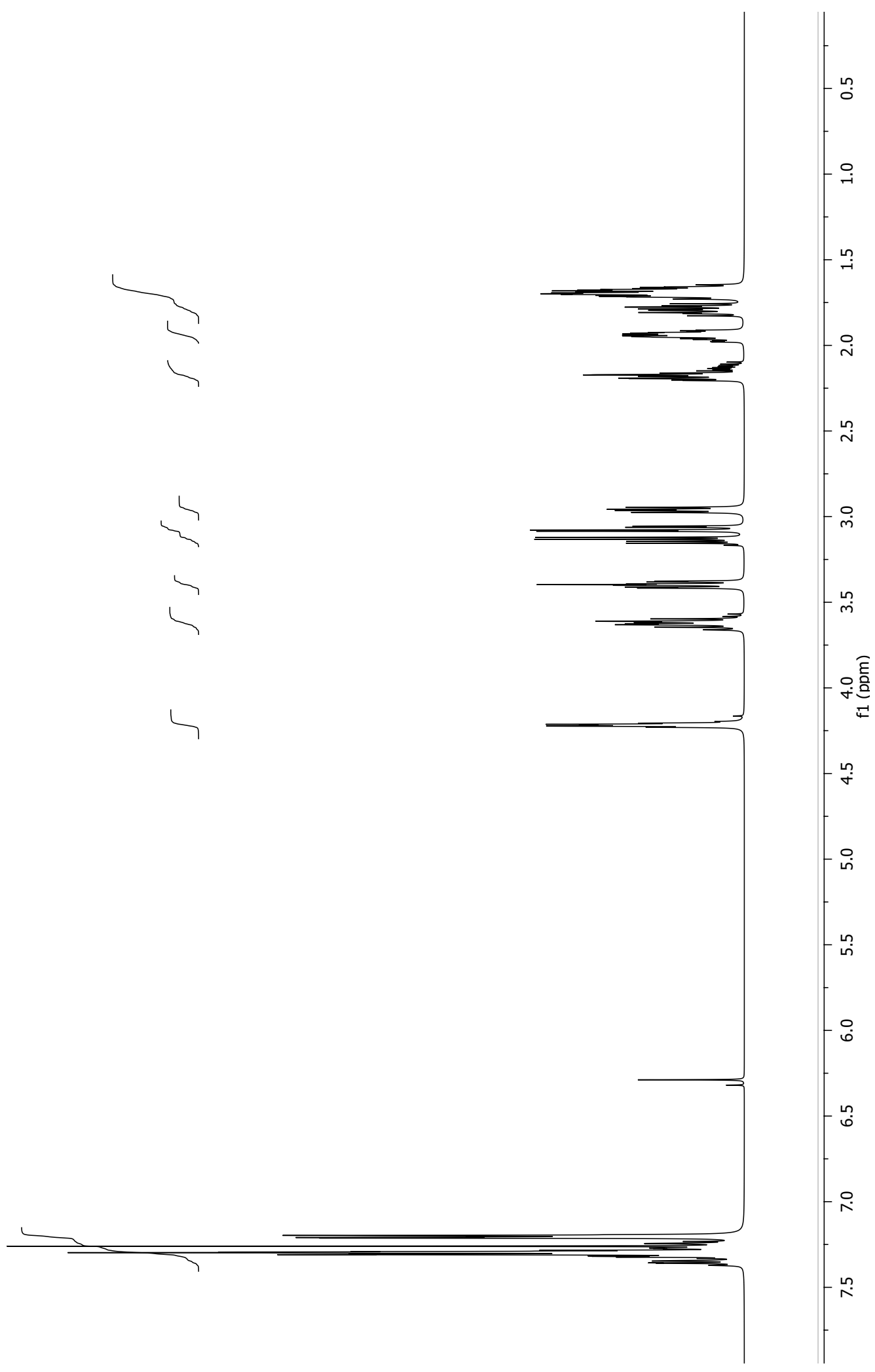

${ }^{1} \mathrm{H}$ NMR spectrum of cyclo(L-Phe-D-Pro) (36) (600 MHz, $\mathrm{CDCl}_{3}$ ) 


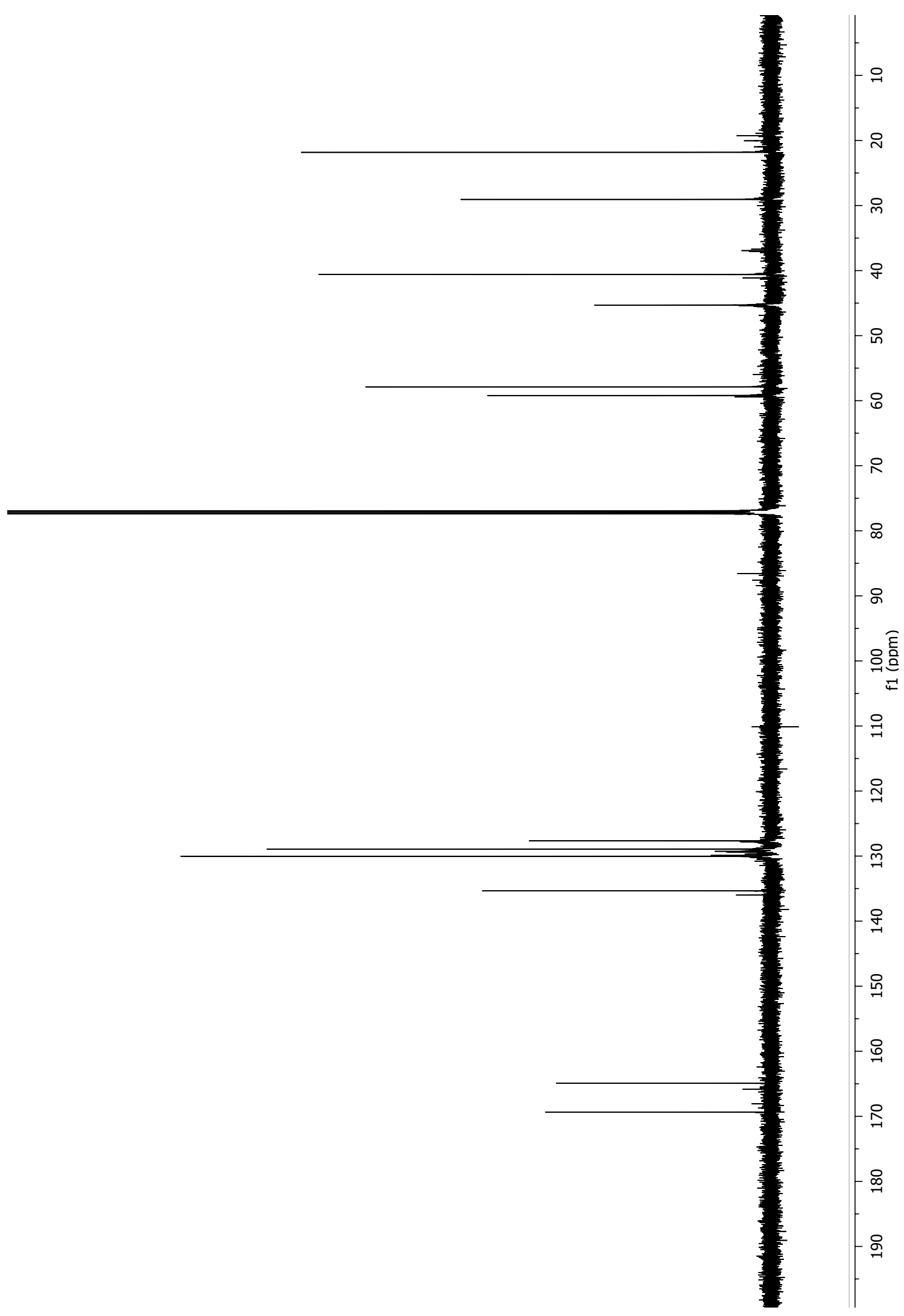

${ }^{13} \mathrm{C}$ NMR spectrum of cyclo(L-Phe-D-Pro) (36) (150 MHz, $\mathrm{CDCl}_{3}$ ) 


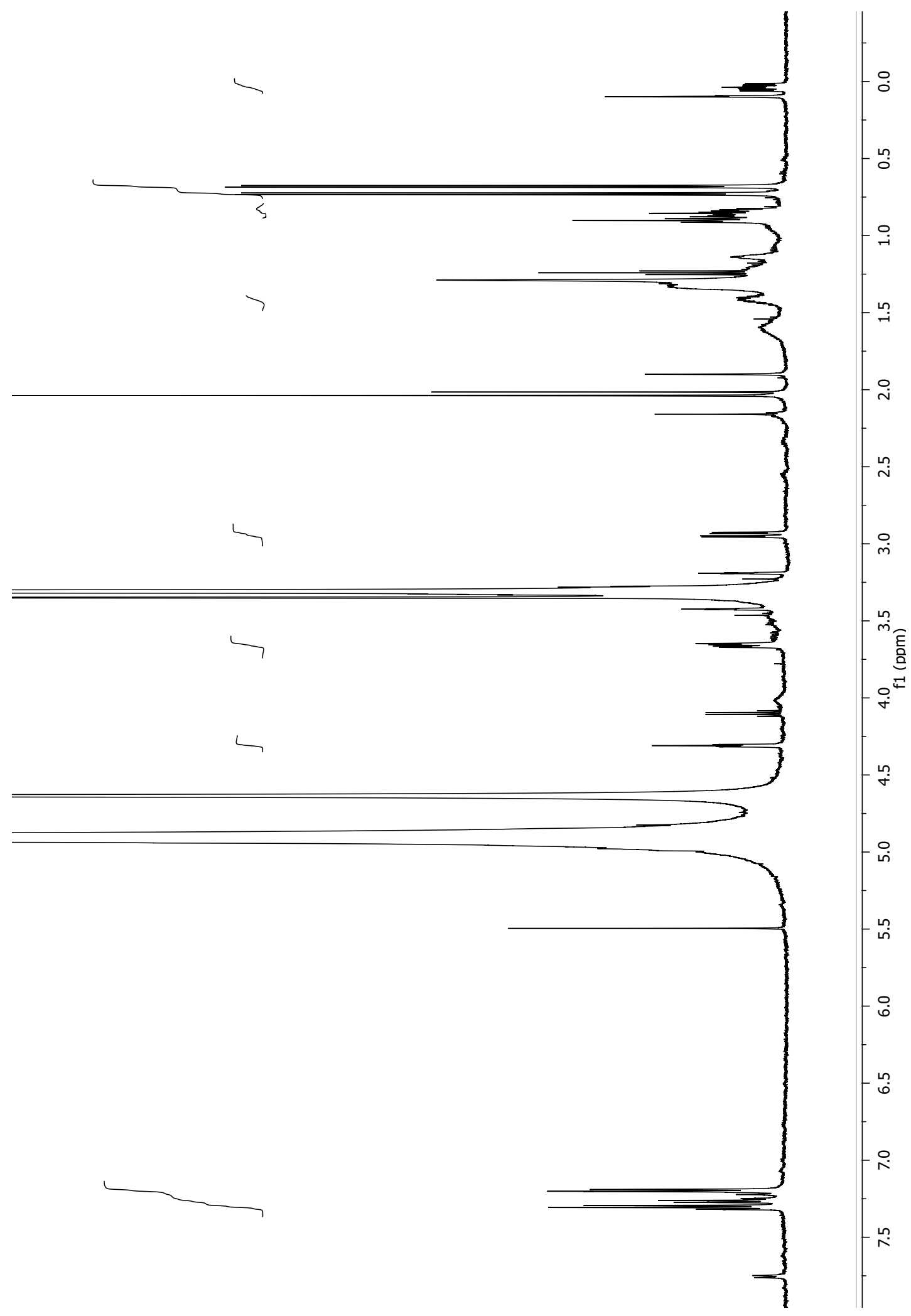

${ }^{1} \mathrm{H}$ NMR spectrum of cyclo(Phe-Leu) (L-L/D-D) (97) (600 MHz, $\left.\mathrm{CD}_{3} \mathrm{OD}\right)$ 


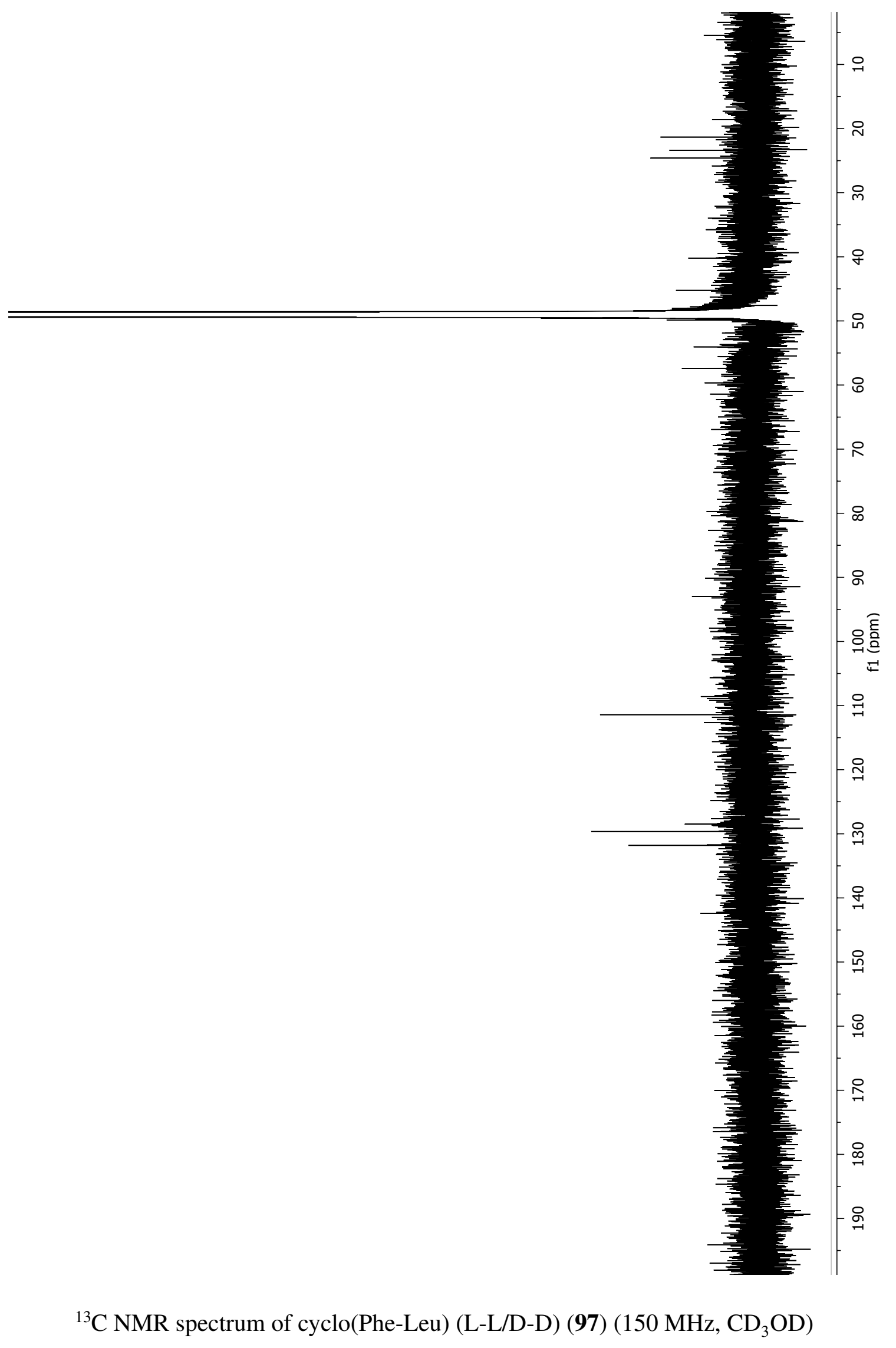




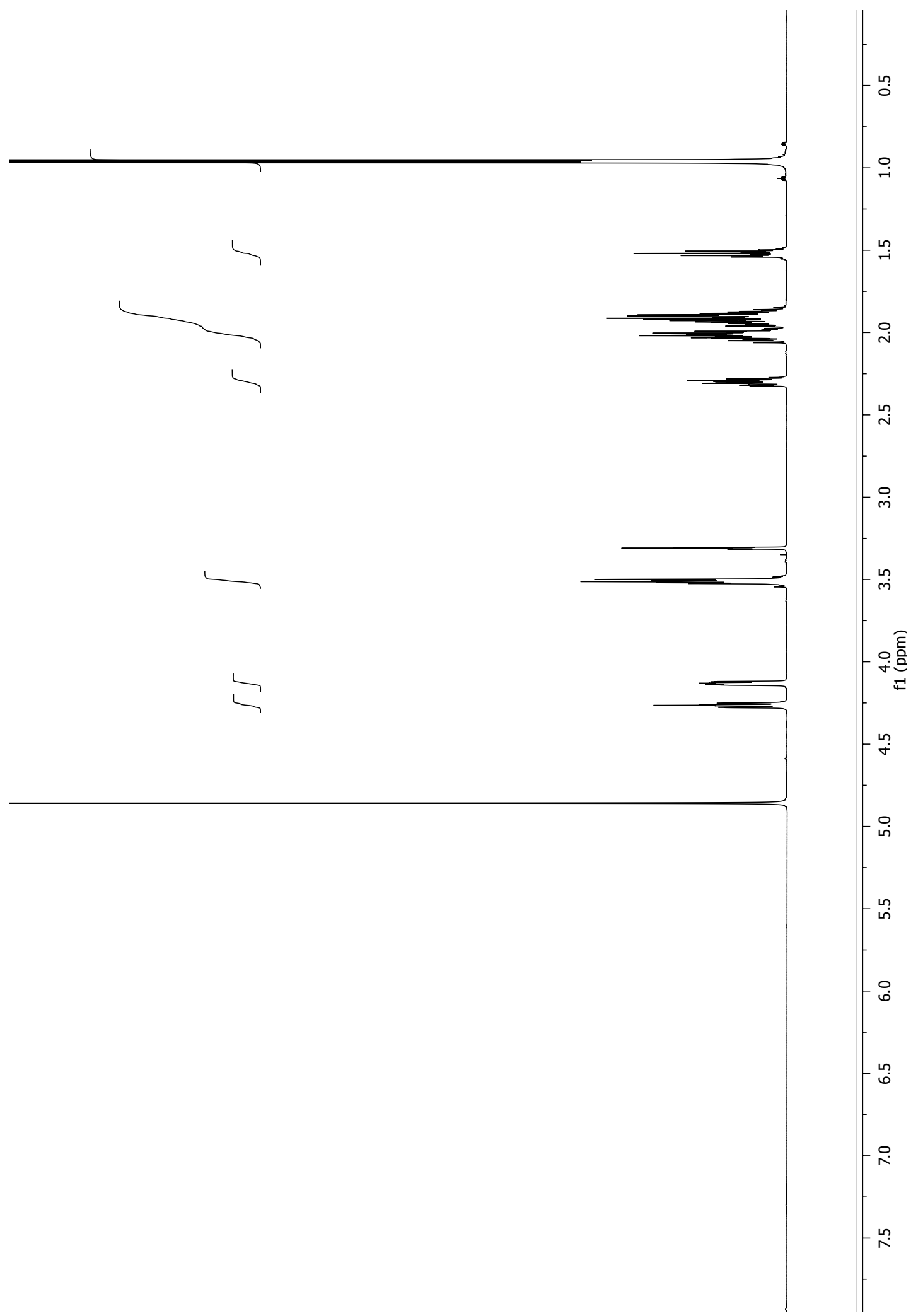

${ }^{1} \mathrm{H}$ NMR spectrum of cyclo(L-Leu-L-Pro) (44) (600 MHz, $\left.\mathrm{CD}_{3} \mathrm{OD}\right)$ 


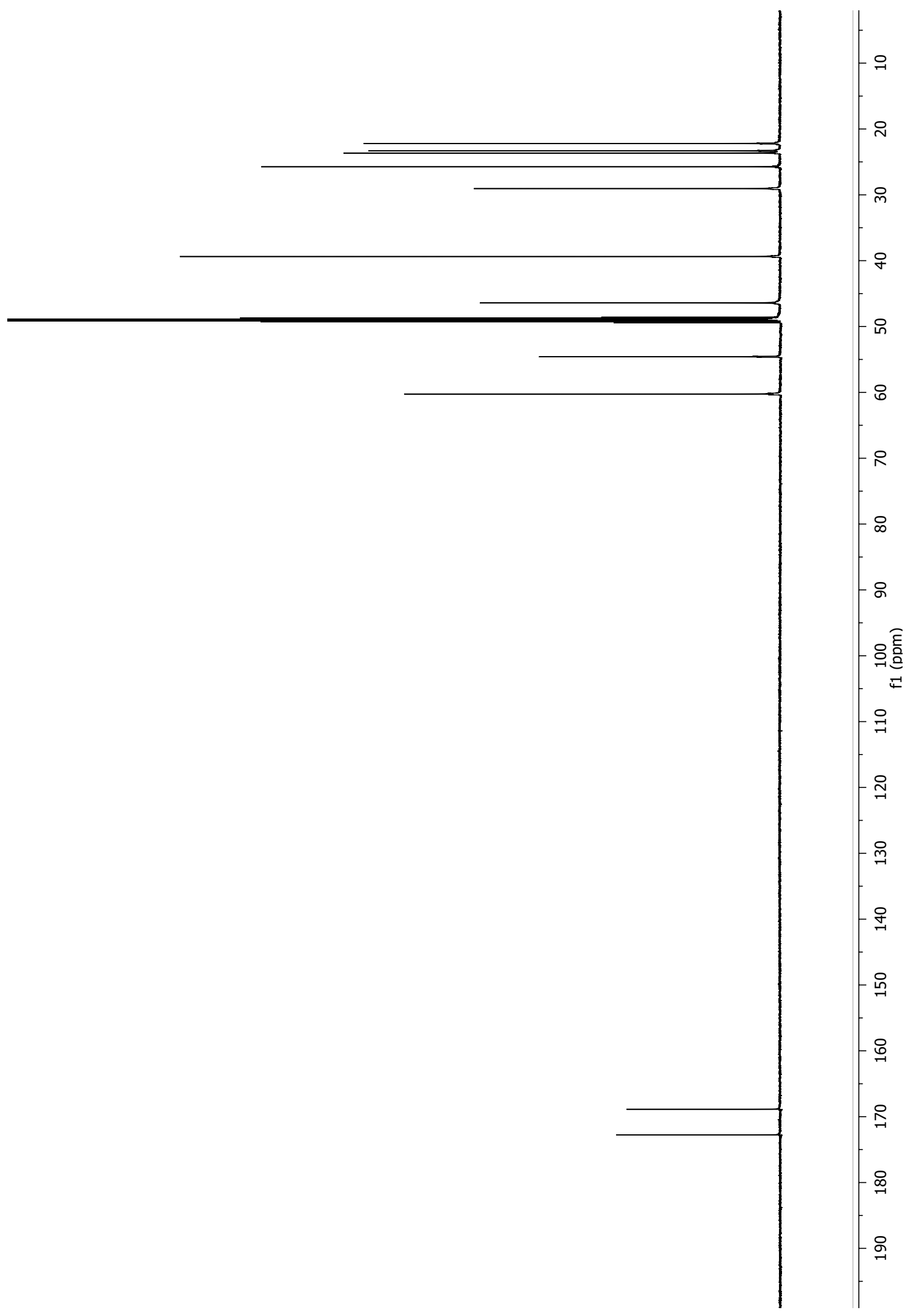

${ }^{13} \mathrm{C}$ NMR spectrum of cyclo(L-Leu-L-Pro) (44) (150 MHz, $\left.\mathrm{CD}_{3} \mathrm{OD}\right)$ 


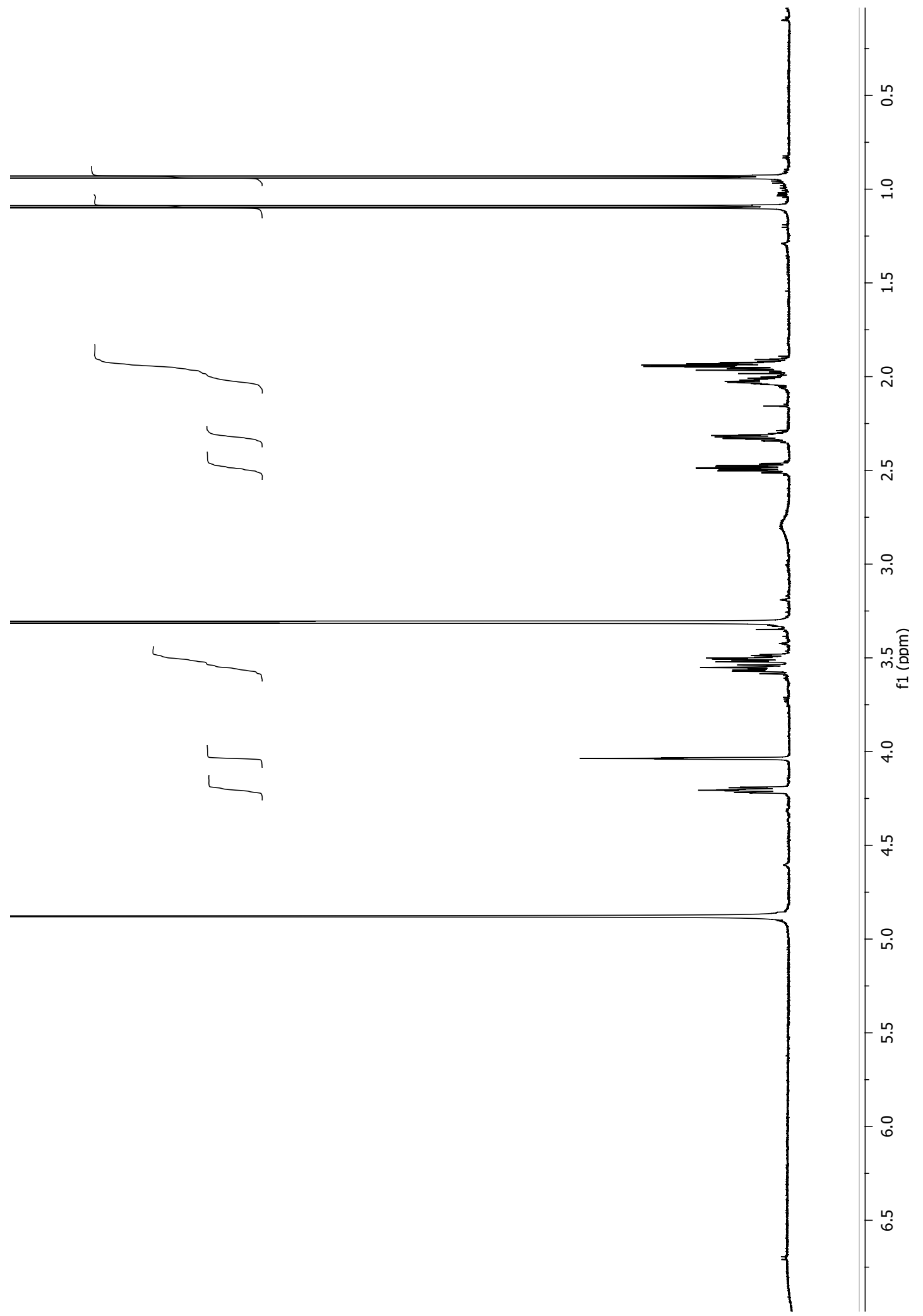

${ }^{1} \mathrm{H}$ NMR spectrum of cyclo(L-Val-L-Pro) (41) (600 MHz, $\left.\mathrm{CD}_{3} \mathrm{OD}\right)$ 


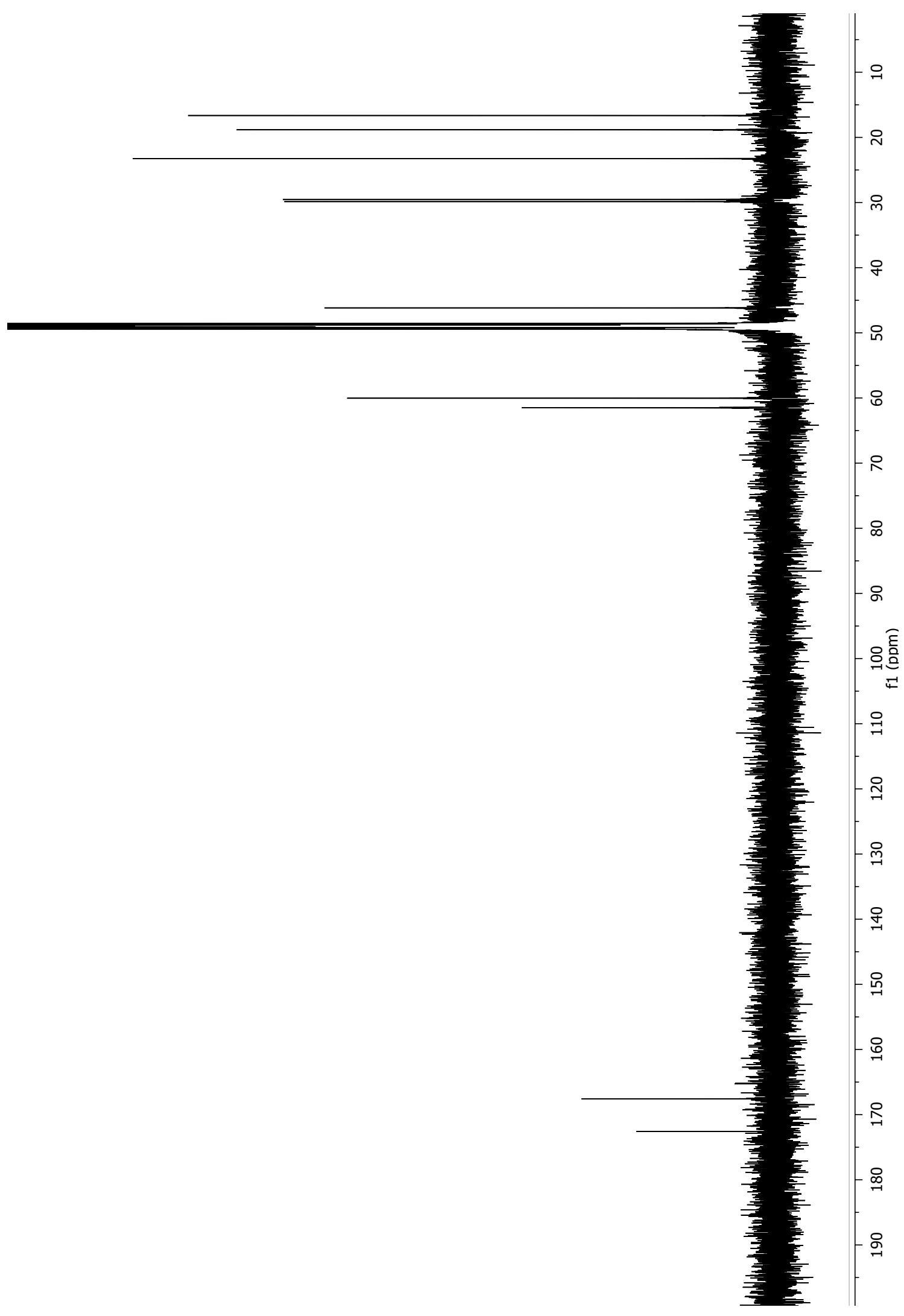

${ }^{13} \mathrm{C}$ NMR spectrum of cyclo(L-Val-L-Pro) (41) (150 MHz, $\left.\mathrm{CD}_{3} \mathrm{OD}\right)$ 


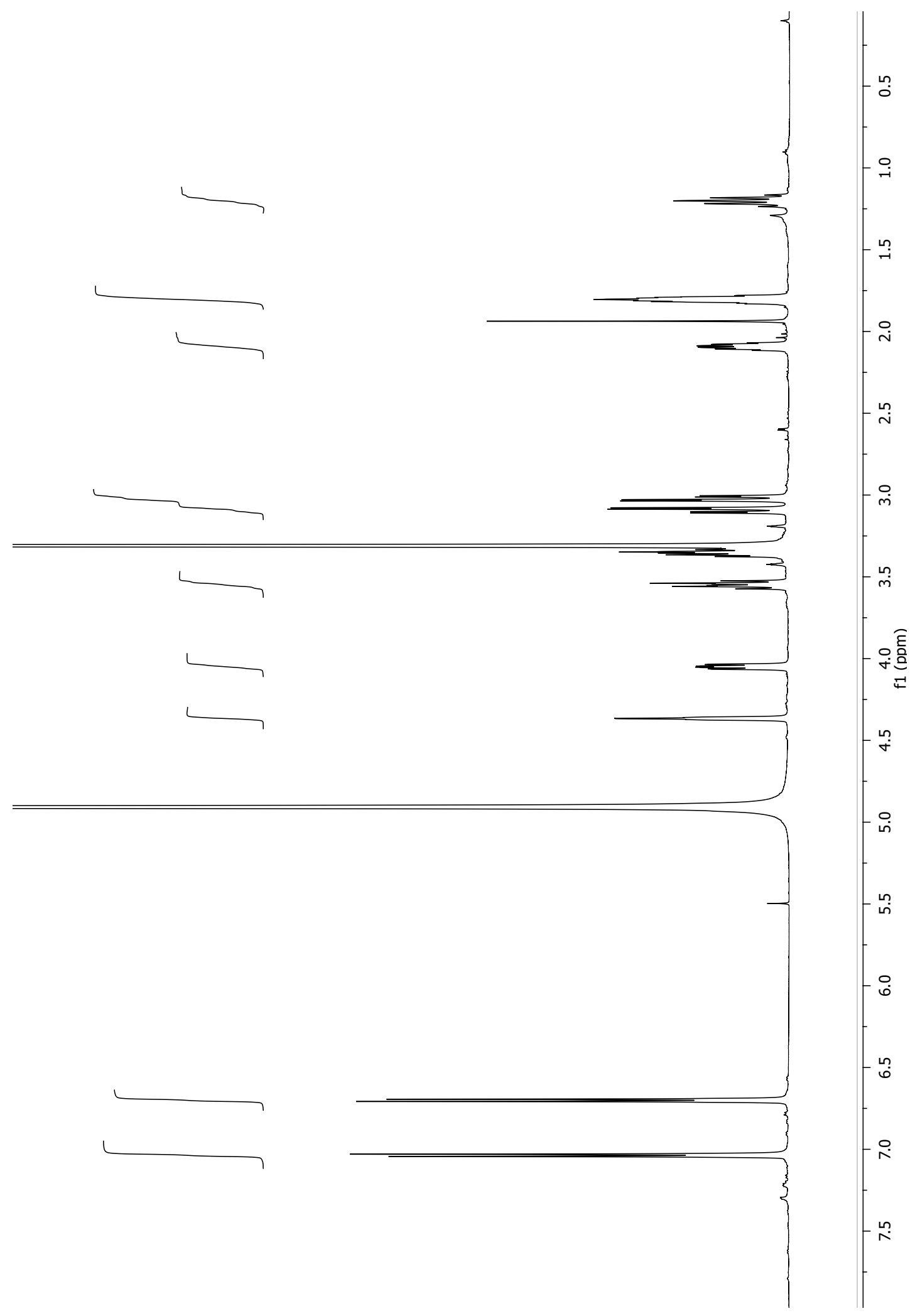

${ }^{1} \mathrm{H}$ NMR spectrum of cyclo(L-Tyr-L-Pro) (38) (600 MHz, $\left.\mathrm{CD}_{3} \mathrm{OD}\right)$ 


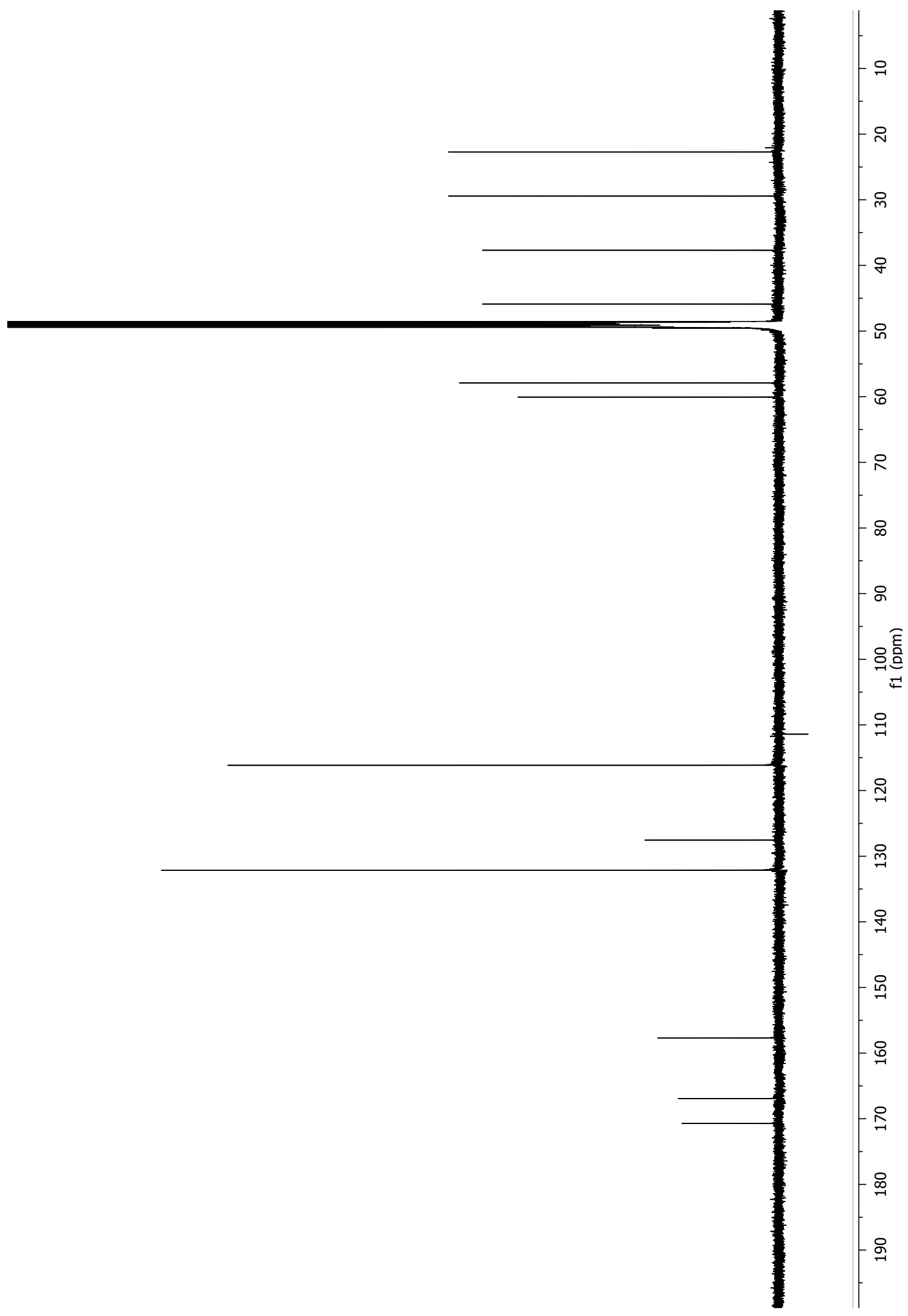

${ }^{13} \mathrm{C}$ NMR spectrum of cyclo(L-Tyr-L-Pro) (38) (150 MHz, $\left.\mathrm{CD}_{3} \mathrm{OD}\right)$ 


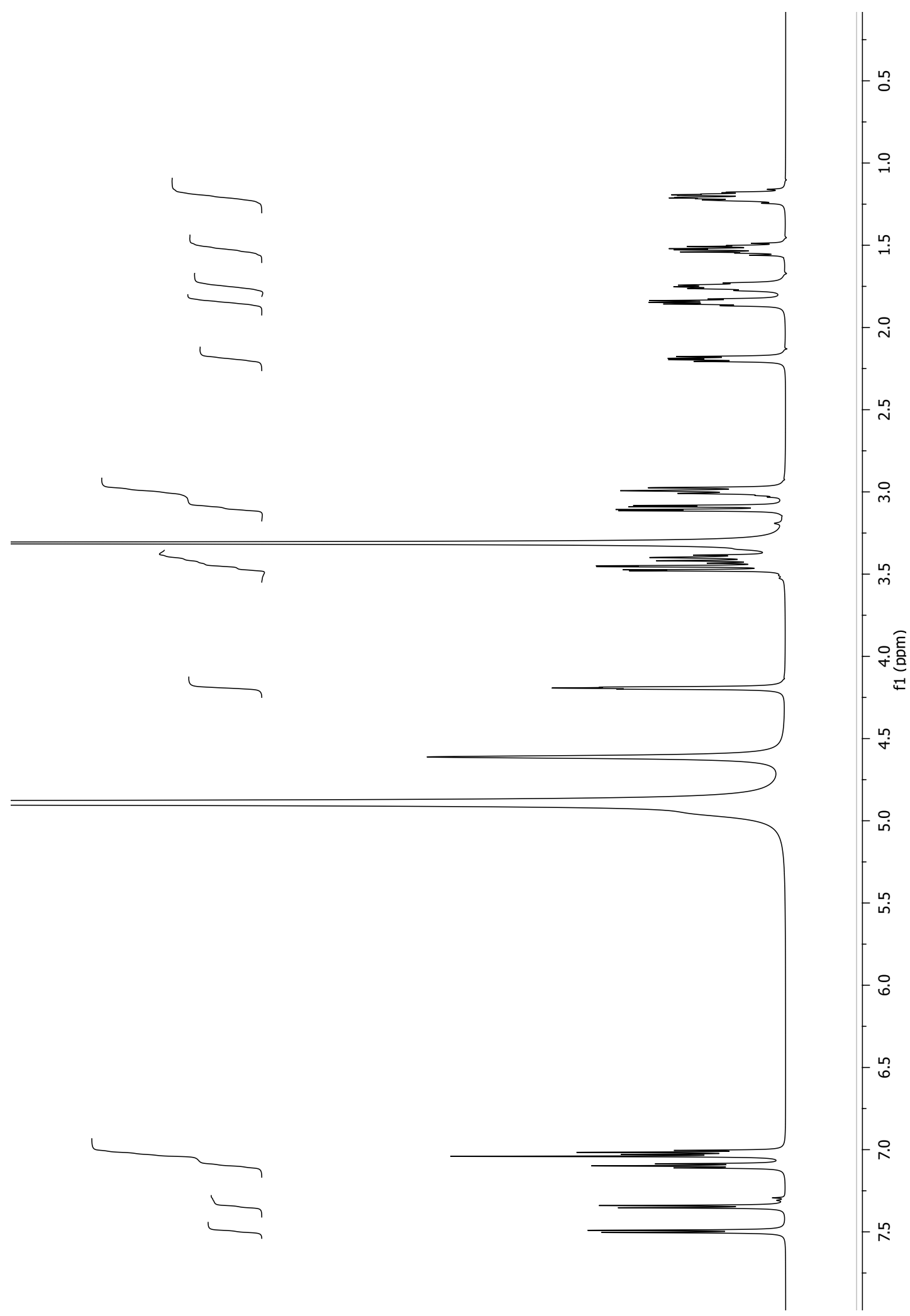

${ }^{1} \mathrm{H}$ NMR spectrum of cyclo(L-Trp-D-Pro) (54) (600 MHz, $\left.\mathrm{CD}_{3} \mathrm{OD}\right)$ 


$$
1
$$




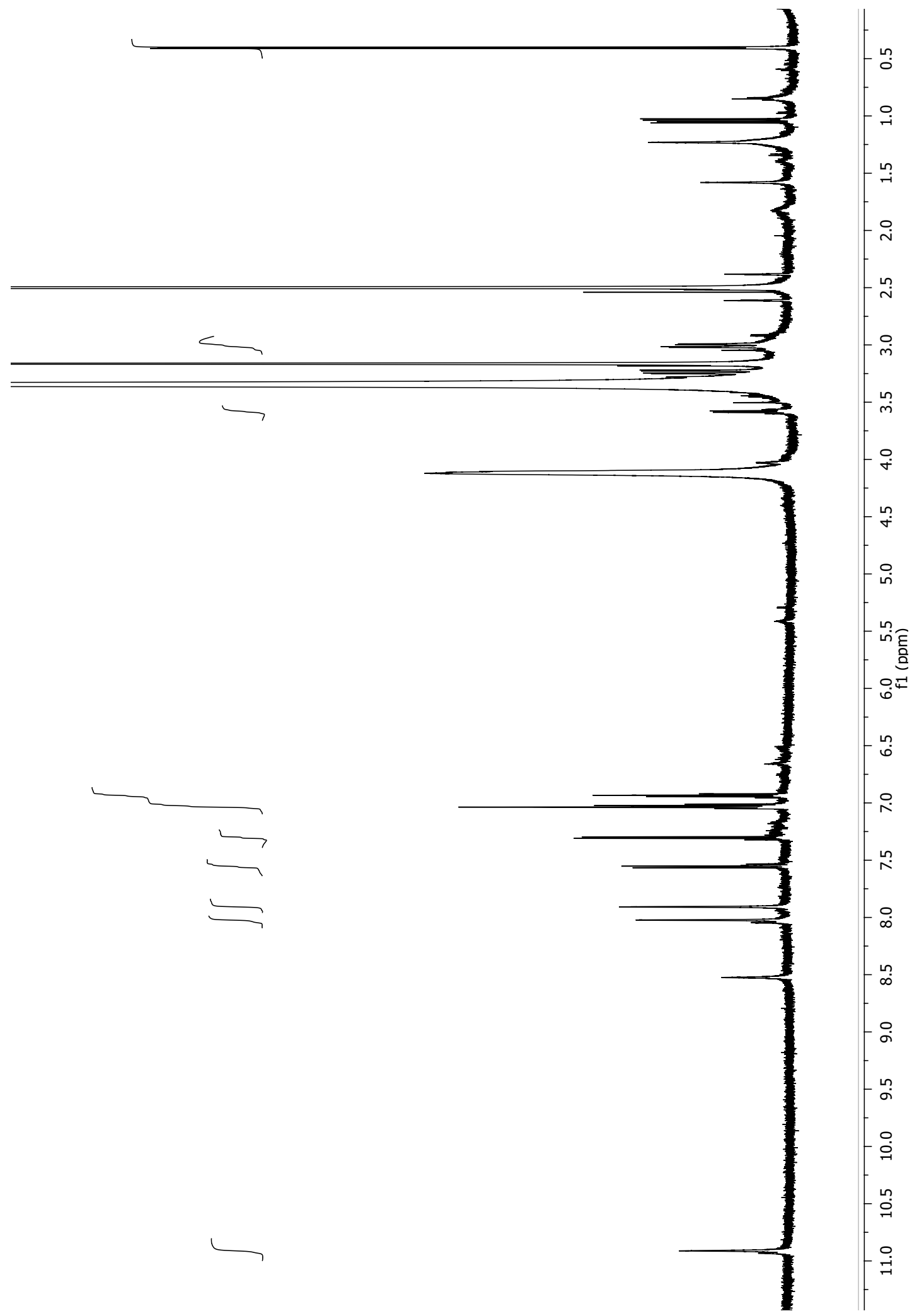

${ }^{1} \mathrm{H}$ NMR spectrum of cyclo(Trp-Ala) (L-L/D-D) (98) (600 MHz, DMSO- $\mathrm{d}_{6}$ ) 


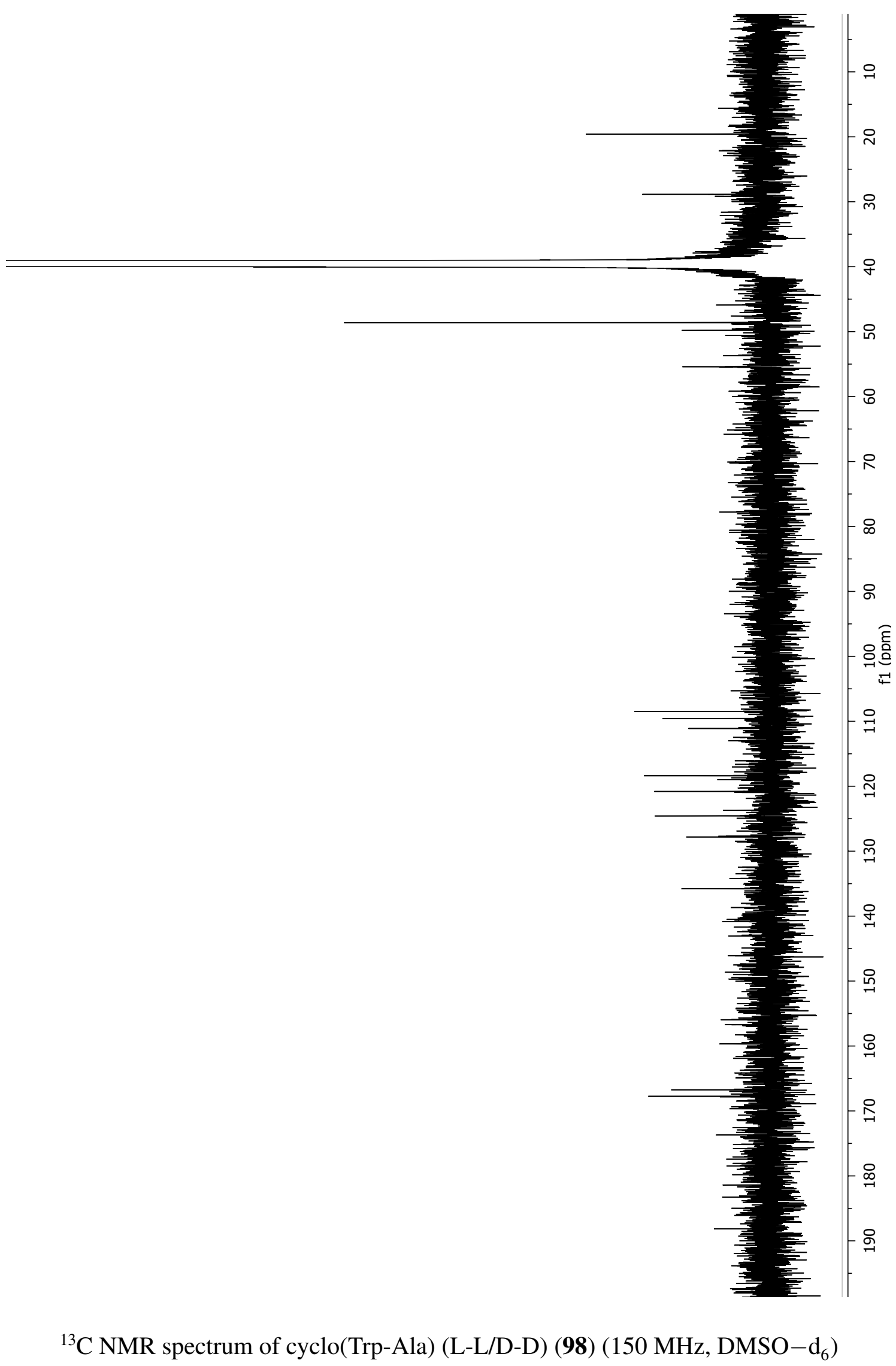




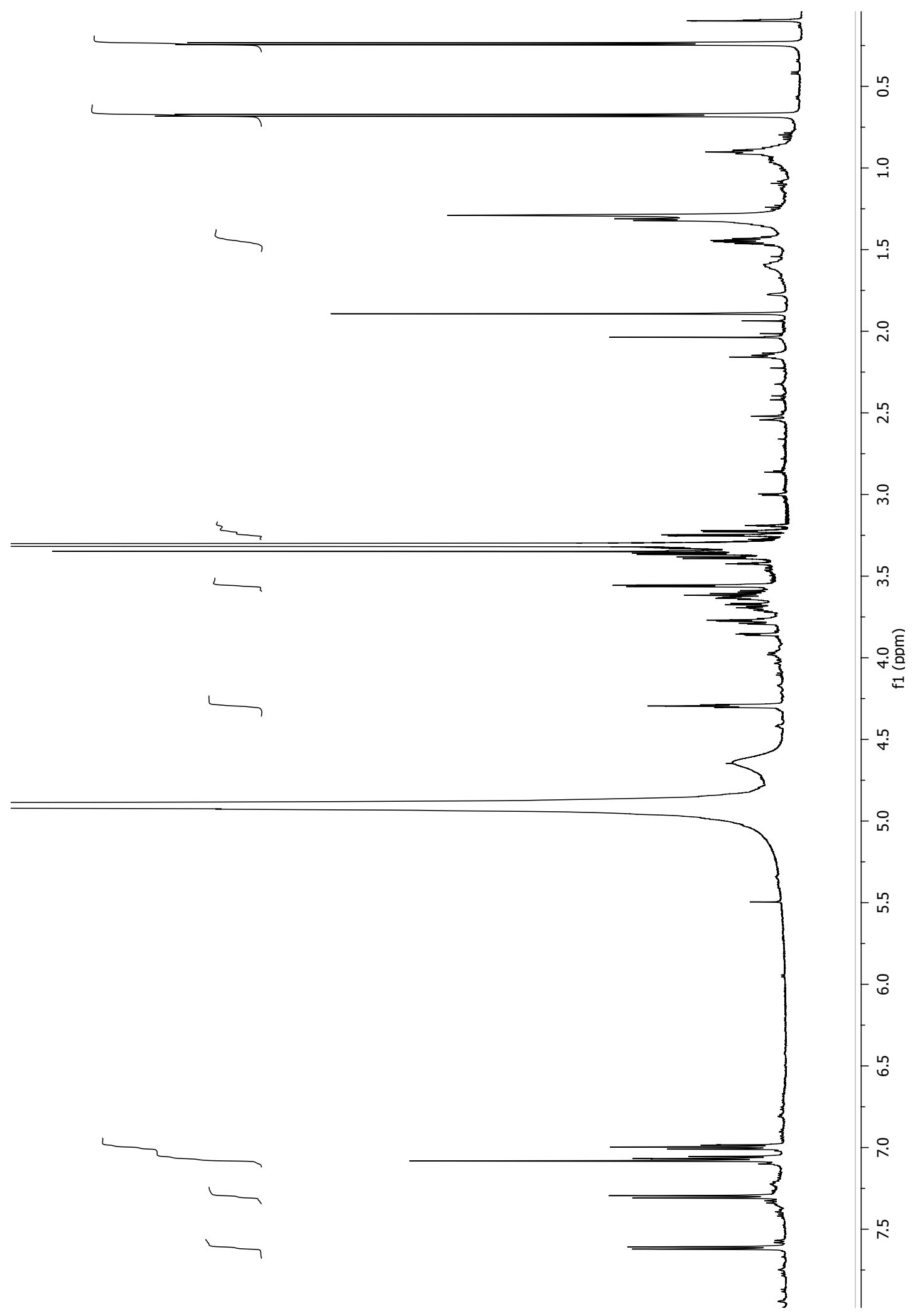

${ }^{1} \mathrm{H}$ NMR spectrum of cyclo(Trp-Val) (L-L/D-D) (99) (600 MHz, $\mathrm{CD}_{3} \mathrm{OD}$ ) 


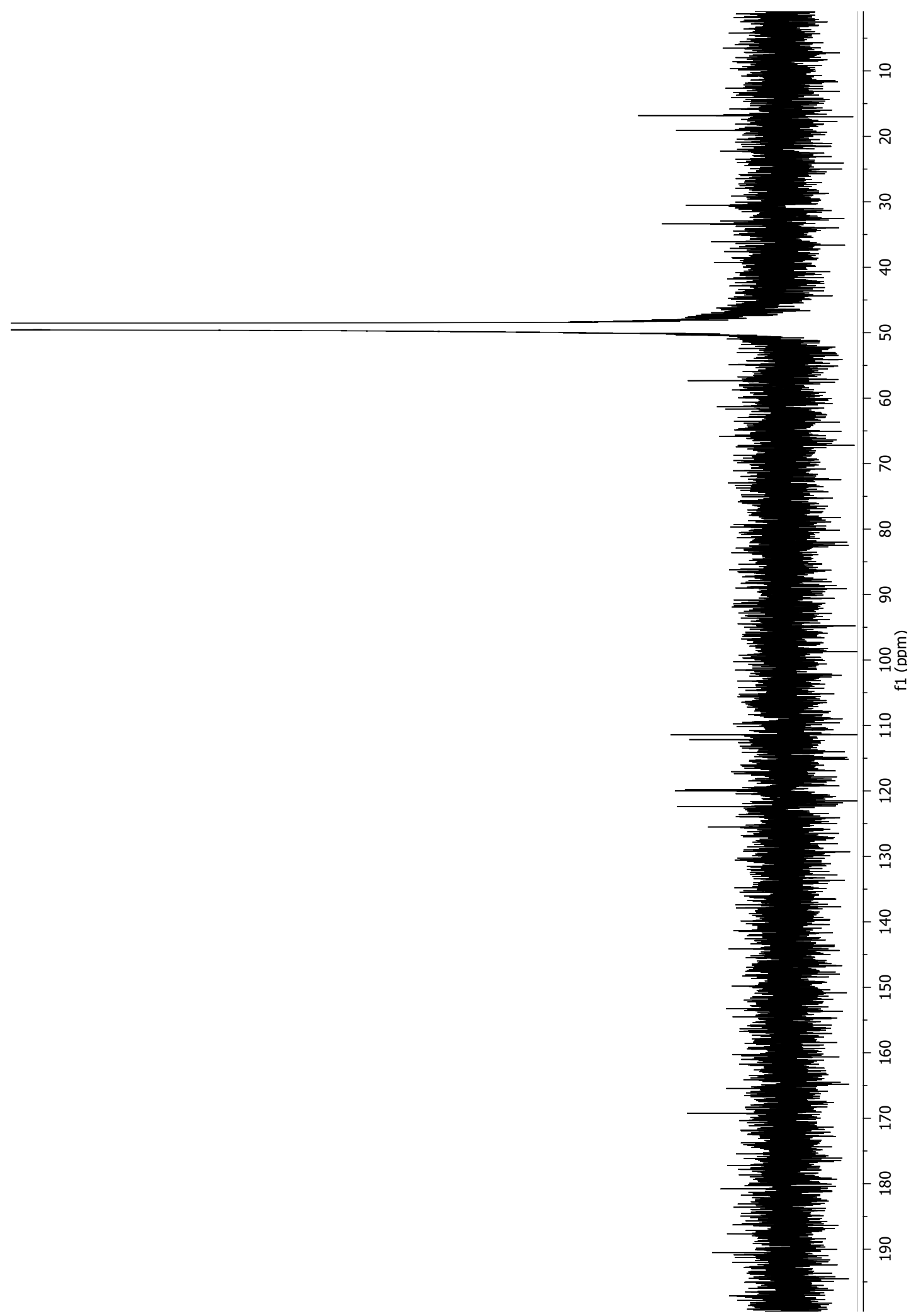

${ }^{13} \mathrm{C}$ NMR spectrum of cyclo(Trp-Val) (L-L/D-D) (99) (150 MHz, $\left.\mathrm{CD}_{3} \mathrm{OD}\right)$ 


\section{References}

1. Ji, H.-F.; Li, X.-J.; Zhang, H.-Y. EMBO Reports 2009, 10, 194-200.

2. Rishton, G. M. American Journal of Cardiology 2008, 101, 43D-49D.

3. Beutler, J. A. Current Protocols in Pharmacology 2009, 46, 9.11.1-9.11.21.

4. Wright, G. D. Nature Reviews Microbiology 2007, 5, 175-186.

5. Mishra, B. B.; Tiwari, V. K. European Journal of Medicinal Chemistry 2011, 46, 4769-4807.

6. Harvey, A. L. Drug Discovery Today 2008, 13, 894-901.

7. Newman, D. J.; Cragg, G. M. Journal of Natural Products 2012, 75, 311-335.

8. Lam, K. S. Trends in Microbiology 2007, 15, 279-289.

9. Miyadoh, S. Actinomycetologica 1993, 7, 100-106.

10. Demain, A. L.; Sanchez, S. The Journal of Antibiotics 2009, 62, 5-16.

11. Tan, C.; Tasaka, H.; Yu, K.-P.; Murphy, M. L.; Karnofsky, D. A. Cancer 1967, 20, 333-353.

12. Singh, S.; Kate, B. N.; Banerjee, U. C. Critical Reviews in Biotechnology 2005, 25, 73-95.

13. Jaiswal, P.; Singh, P. K.; Prasanna, R. Canadian Journal of Microbiology 2008, 54, 701-717.

14. Gademann, K.; Portmann, C. Current Organic Chemistry 2008, 12, 326-341.

15. Larsen, L. K.; Moore, R. E.; Patterson, G. M. L. Journal of Natural Products 1994, $57,419-421$.

16. Boyd, M. R. et al. Antimicrobial Agents and Chemotherapy 1997, 41, 1521-1530.

17. Schwartz, R. E.; Hirsch, C. F.; Sesin, D. F.; Flor, J. E.; Chartrain, M.; Fromtling, R. E.; Harris, G. H.; Salvatore, M. J.; Liesch, J. M.; Yudin, K. Journal of Industrial Microbiology and Biotechnology 1990, 5, 113-123.

18. Harvey, A. Drug Discovery Today 2000, 5, 294-300.

19. Ringel, S. M.; Greenough, R. C.; Roemer, S.; Connor, D.; Gutt, A. L.; Blair, B.; Kanter, G. The Journal of Antibiotics 1977, 30, 371-375.

20. Schneiker, S. et al. Nature Biotechnology 2007, 25, 1281-1289.

21. Cheng, K. L.; Bradley, T.; Budman, D. R. Biologics 2008, 2, 789-811.

22. Imhoff, J. F.; Labes, A.; Wiese, J. Biotechnology Advances 2011, 29, 468-482.

23. Joint, I.; Muhling, M.; Querellou, J. Microbial Biotechnology 2010, 3, 564-575.

24. Zhang, L.; An, R.; Wang, J.; Sun, N.; Zhang, S.; Hu, J.; Kuai, J. Current Opinion in Microbiology 2005, 8, 276-281. 
25. Romero, F.; Espliego, F.; Prez Baz, J.; Garca de Quesada, T.; Grvalos, D.; de la Calle, F.; Fernndez-Puentes, J. L. The Journal of Antibiotics 1997, 50, 734-737.

26. Feling, R. H.; Buchanan, G. O.; Mincer, T. J.; Kauffman, C. A.; Jensen, P. R.; Fenical, W. Angewandte Chemie International Edition 2003, 42, 355-357.

27. Solanki, R.; Khanna, M.; Lal, R. Indian Journal of Microbiology 2008, 48, 410-431.

28. Biswas, T.; Zolova, O. E.; Lomb, F.; de la Calle, F.; Salas, J. A.; Tsodikov, O. V.; Garneau-Tsodikova, S. Journal of Molecular Biology 2010, 397, 495-507.

29. Gerwick, W.; Moore, B. Chemistry and Biology 2012, 19, 85-98.

30. Belarbi, E. H.; Contreras Gmez, A.; Chisti, Y.; Garcia Camacho, F.; Molina Grima, E. Biotechnology Advances 2003, 21, 585-598.

31. Stierle, A. C.; Cardellina, J. H.; Singleton, F. L. Cellular and Molecular Life Sciences 1988, 44, 1021.

32. Elyakov, G. B.; Kuznetsova, T.; Mikhailov, V. V.; Maltsev, I. I.; Voinov, V. G.; Fedoreyev, S. A. Cellular and Molecular Life Sciences 1991, 47, 632-633.

33. Brock, T. D.; Freeze, H. Journal of Bacteriology 1969, 98, 289-297.

34. Brock, T. D.; Brock, K. M.; Belly, R. T.; Weiss, R. L. Archives of Microbiology 1972, 84, 54-68.

35. Wilson, Z. E.; Brimble, M. A. Natural Product Reports 2009, 26, 44-71.

36. Horikoshi, K.; Antranikian, G.; Bull, A.; Robb, F.; Stetter, K. Extremophiles Handbook; Springer, 2011.

37. Fujiwara, S. Journal of Bioscience and Bioengineering 2002, 94, 518-525.

38. Rothschild, L. J.; Mancinelli, R. L. Nature 2001, 409, 1092-1101.

39. Stierle, A. A.; Stierle, D. B.; Goldstein, E.; Parker, K.; Bugni, T.; Baarson, C.; Gress, J.; Blake, D. Journal of Natural Products 2003, 66, 1097-1100.

40. Stierle, D. B.; Stierle, A. A.; Hobbs, J. D.; Stokken, J.; Clardy, J. Organic Letters 2004, 6, 1049-1052.

41. Stierle, A. A.; Stierle, D. B.; Kelly, K. The Journal of Organic Chemistry 2006, 71, 5357-5360.

42. Stierle, D. B.; Stierle, A. A.; Patacini, B. Journal of Natural Products 2007, 70, 1820-1823.

43. Stierle, A. A.; Stierle, D. B.; Patacini, B. Journal of Natural Products 2008, 71, 856-860.

44. Sarker, S. D.; Latif, Z.; Gray, A. I. Natural Products Isolation; Humana Press, 2005; Vol. 20.

45. Houghton, P. J. Phytotherapy Research 2000, 14, 419-423.

46. Rahman, A.-u.; Choudhary, M. I.; Thomsen, W. J. Bioassay Techniques for Drug Development; Harwood Academic Publishers, 2001. 
47. Guza, R. C. Isolation of Natural Products from Casearia nigrescens, MSc Thesis, 2004.

48. Bohlin, L.; Bruhn, J. G. Bioassay Methods in Natural Product Research and Drug Development; Springer Netherlands, 1999; Vol. 43.

49. MarinLit, Department of Chemistry, University of Canterbury, http://www.chem.canterbury.ac.nz/marinlit/marinlit.shtml, 2013.

50. Laatsch, H. Antibase, A Database for Rapid Dereplication and Structure Determination of Microbial Natural Products, Wiley-VCH:Weinheim, Germany, 2013.

51. Scifinder, American Chemical Society, http://www.cas.org/products/scifinder, 2014.

52. Keyzers, R. A. The Isolation of Biologically Active Secondary Metabolites from New Zealand Marine Organisms, PhD Thesis, 2003.

53. Singh, A. J. The Structure-Directed Isolation of New Secondary Metabolites from South Pacific Marine Sponges, PhD Thesis, 2012.

54. Barber, J. M. E. K. Chemical and Biological Aspects of Secondary Metabolites from Tongan Marine Sponges, PhD Thesis, 2012.

55. Lipinski, C. A.; Lombardo, F.; Dominy, B. W.; Feeney, P. J. Advanced Drug Delivery Reviews 1997, 23, 3-25.

56. West, L. M. The Isolation of Secondary Metabolites from New Zealand Marine Sponges, PhD Thesis, 2001.

57. Hudson, J. A.; Morgan, H. W.; Daniel, R. M. International Journal of Systematic Bacteriology 1987, 37, 431-436.

58. Fomenkov, A.; Xu, S. Gene 1995, 163, 109-113.

59. Choi, J. J.; Jung, S. E.; Kim, H.; Kwon, S. Biotechnology and Applied Biochemistry 1999, 30, 19-25.

60. Egas, M. C. V.; da Costa, M. S.; Cowan, D. A.; Pires, E. M. V. Extremophiles 1998, $2,23-32$.

61. Donk, P. J. Journal of Bacteriology 1920, 5, 373-374.

62. Watanabe, T.; Furukawa, S.; Hirata, J.; Koyama, T.; Ogihara, H.; Yamasaki, M. Applied and Environmental Microbiology 2003, 69, 7124-7129.

63. Poli, A.; Esposito, E.; Lama, L.; Orlando, P.; Nicolaus, G.; de Appolonia, F.; Gambacorta, A.; Nicolaus, B. Systematic and Applied Microbiology 2006, 29, 300307.

64. Poli, A.; Salerno, A.; Laezza, G.; di Donato, P.; Dumontet, S.; Nicolaus, B. Research in Microbiology 2009, 160, 99-106.

65. Singh, S.; Madlala, A. M.; Prior, B. A. FEMS Microbiology Reviews 2003, 27, 3-16.

66. Mishra, R. S.; Maheshwari, R. Journal of Bioscience 1996, 21, 653672. 
67. Puchart, V.; Katapodis, P.; Biely, P.; Kremnicky, L.; Christakopoulos, P.; Vrsanska, M.; Kekos, D.; Macris, B. J.; Bhat, M. K. Enzyme and Microbial Technology 1999, 24, 355-361.

68. Fernandez-Lafuente, R. Journal of Molecular Catalysis B: Enzymatic 2010, 62, 197-212.

69. Pikuta, E.; Lysenko, A.; Chuvilskaya, N.; Mendrock, U.; Hippe, H.; Suzina, N.; Nikitin, D.; Osipov, G.; Laurinavichius, K. International Journal of Systematic and Evolutionary Microbiology 2000, 6, 2109-2117.

70. Saw, J. H. et al. Genome Biology 2008, 9, 17-33.

71. Ellis, J. T.; Magnuson, T. S. ISRN Microbiology 2012, 517-524.

72. Liu, J.; Lei, Y.; Wang, F.; Yi, Y.; Liu, Y.; Wang, G. Journal of Applied Microbiology 2011, 5, 1365-2672.

73. Proksa, B.; Uhrn, D.; Surdkova, M.; Fuska, J. Acta Biotechnologica 1990, 10, 337340.

74. Bratchkova, A.; Ivanova, V.; Gousterova, A.; Laatsch, H. Biotechnology and Biotechnological Equipment 2010, 26, 3005-3009.

75. Dillman, R. L.; Cardellina, J. H. Journal of Natural Products 1991, 54, 1056-1061.

76. Shaaban, M.; Schroder, D.; Shaaban, K. A.; Helmke, E.; Grun-Wollny, I.; WagnerDobler, I.; Laatsch, H. Revista Latinoamericana de Qumica 2007, 35, 58-67.

77. Elleuch, L.; Shaaban, M.; Smaoui, S.; Mellouli, L.; Karray-Rebai, I.; FouratiBen Fguira, L.; Shaaban, K. A.; Laatsch, H. Applied Biochemistry and Biotechnology 2010, 162, 579-593.

78. Huang, H.; Yao, Y.; He, Z.; Yang, T.; Ma, J.; Tian, X.; Li, Y.; Huang, C.; Chen, X.; Li, W.; Zhang, S.; Zhang, C.; Ju, J. Journal of Natural Products 2011, 74, 21222127.

79. Shin, H. J.; Lee, H. S.; Lee, D. S. Journal of Microbiology and Biotechnology 2010, 20, 501-505.

80. Herraiz, T.; Chaparro, C. Biochemical and Biophysical Research Communications 2005, 326, 378-386.

81. Lee, K. C.; Dunfield, P. F.; Morgan, X. C.; Crowe, M. A.; Houghton, K. M.; Vyssotski, M.; Ryan, J. L. J.; Lagutin, K.; McDonald, I. R.; Stott, M. B. International Journal of Systematic and Evolutionary Microbiology 2011, 61, 24822490.

82. Vyssotski, M.; Lee, K. C.; Lagutin, K.; Ryan, J.; Morgan, X. C.; Stott, M. B. Lipids 2011, 46, 1155-1161.

83. Crowe, M.; Power, J. F.; Morgan, X. C.; Dunfield, P. F.; Lagutin, K.; Rijpstra, W. I.; Rijpstra, I. C.; Sinninghe Damste, J. S.; Houghton, K. M.; Ryan, J. L.; Stott, M. B. International Journal of Systematic and Evolutionary Microbiology 2014, 64, 220 227. 
84. Ferrer, M.; Golyshina, O.; Beloqui, A.; Golyshin, P. N. Current Opinion in Microbiology 2007, 10, 207-14.

85. Borthwick, A. D. Chemical Reviews 2012, 112, 3641-3716.

86. Martins, M. B.; Carvalho, I. Tetrahedron 2007, 63, 9923-9932.

87. Dinsmore, C. J.; Beshore, D. C. Tetrahedron 2002, 58, 3297-3312.

88. Cava, F.; de Pedro, M. A.; Lam, H.; Davis, B. M.; Waldor, M. K. The EMBO Journal 2011, 30, 3442-3453.

89. Gondry, M. et al. Nature Chemical Biology 2009, 5, 414-420.

90. Gu, B.; He, S.; Yan, X.; Zhang, L. Applied Microbiology and Biotechnology 2013, 97, 8439-8453.

91. Belin, P.; Moutiez, M.; Lautru, S.; Seguin, J.; Pernodet, J.-L.; Gondry, M. Natural Product Reports 2012, 29, 961-979.

92. Schultz, A. W.; Oh, D.-C.; Carney, J. R.; Williamson, R. T.; Udwary, D. W.; Jensen, P. R.; Gould, S. J.; Fenical, W.; Moore, B. S. Journal of the American Chemical Society 2008, 130, 4507-4516.

93. Lautru, S.; Gondry, M.; Genet, R.; Pernodet, J.-L. Chemistry and Biology 2002, 9, 1355-1364.

94. Tang, M. R.; Sternberg, D.; Behr, R. K.; Sloma, A.; Berka, R. M. Industrial Biotechnology 2006, 2, 66-74.

95. Giessen, T. W.; von Tesmar, A. M.; Marahiel, M. A. Biochemistry 2013, 52, 42744283.

96. Huang, R.; Zhou, X.; Xu, T.; Yang, X.; Liu, Y. Chemistry and Biodiversity 2010, 7, 2809-2829.

97. Cornacchia, C.; Cacciatore, I.; Baldassarre, L.; Mollica, A.; Feliciani, F.; Pinnen, F. Mini Reviews in Medicinal Chemistry 2012, 12, 2-12.

98. Kumar, N.; Mohandas, C.; Nambisan, B.; Soban Kumar, D. R.; Lankalapalli, R. S. World Journal of Microbiology and Biotechnology 2013, 29, 355-364.

99. Cain, C. C.; Lee, D.; Waldo, R. H.; Henry, A. T.; Casida, E. J.; Wani, M. C.; Wall, M. E.; Oberlies, N. H.; Falkinham, J. O. Antimicrobial Agents and Chemotherapy 2003, 47, 2113-2117.

100. Furtado, N. A. J. C.; Pupo, M. T.; Carvalho, I.; Campo, V. L.; Duarte, M. C. T.; Bastos, J. K. Journal of the Brazilian Chemical Society 2005, 16, 1448-1453.

101. Mehnaz, S.; Saleem, R. S. Z.; Yameen, B.; Pianet, I.; Schnakenburg, G.; Pietraszkiewicz, H.; Valeriote, F.; Josten, M.; Sahl, H.-G.; Franzblau, S. G.; Gross, H. Journal of Natural Products 2013, 76, 135-141.

102. Cheenpracha, S.; Borris, R. P.; Tran, T. T.; Jee, J. M.; Seow, H. F.; Cheah, H.-Y.; Ho, C. C.; Chang, L. C. Journal of the Brazilian Chemical Society 2011, 22, 223229. 
103. Li, H.; Lee, B. C.; Kim, T. S.; Bae, K. S.; Hong, J.; Choi, S. H.; Bao, B.; Jung, J. H. Biomolecules and Therapeutics 2008, 16, 356-363.

104. Park, Y. C.; Gunasekera, S. P.; Lopez, J. V.; McCarthy, P. J.; Wright, A. E. Journal of Natural Products 2006, 69, 580-584.

105. Qi, S.-H.; Xu, Y.; Gao, J.; Qian, P.-Y.; Zhang, S. Annals of Microbiology 2009, 59, 229-233.

106. Strom, K.; Sjogren, J.; Broberg, A.; Schnrer, J. Applied and Environmental Microbiology 2002, 68, 4322-4327.

107. Shigemori, H.; Tenma, M.; Shimazaki, K.; Kobayashi, J. Journal of Natural Products 1998, 61, 696-698.

108. Li, X.-J.; Zhang, Q.; Zhang, A.-L.; Gao, J.-M. Journal of Agricultural and Food Chemistry 2012, 60, 3424-3431.

109. Rhee, K.-H. Journal of Microbiology and Biotechnology 2003, 13, 984-988.

110. Rhee, K.-H.; Choi, K.-H.; Kim, C.-J.; Kim, C.-H. Journal of Microbiology and Biotechnology 2001, 11, 469-474.

111. Rhee, K.-H. Journal of General and Applied Microbiology 2002, 48, 321-327.

112. Rhee, K.-H. International Journal of Antimicrobial Agents 2004, 24, 423-427.

113. Fdhila, F.; Vazquez, V.; Snchez, J. L.; Riguera, R. Journal of Natural Products 2003, 66, 1299-1301.

114. Birch, A. J.; Wright, J. J. Tetrahedron 1970, 26, 2329-44.

115. Li, X.; Dobretsov, S.; Xu, Y.; Xiao, X.; Hung, O. S.; Qian, P.-Y. Biofouling 2006, 22, 187-194.

116. Mehdi, R. B. A.; Shaaban, K. A.; Rebai, I. K.; Smaoui, S.; Bejar, S.; Mellouli, L. Natural Product Research 2009, 23, 1095-1107.

117. Ying, Y.-M.; Shan, W.-G.; Liu, W.-H.; Zhan, Z.-J. Chemistry of Natural Compounds 2013, 49, 184-186.

118. Meng, X.; Tian, L.; Lin, W.; Li, Q. Chinese Journal of Marine Drugs 2009, 28, 6-10.

119. Sun, K.; Wang, Y.; Fu, P.; Liu, P.; Zhu, W. Chinese Journal of Marine Drugs 2013, $32,37-45$.

120. Brauns, S. C.; Milne, P.; Naud, R.; Venter, M. V. D. Anticancer Research 2004, 24, 1713-1720.

121. Brauns, S. C.; Dealtry, G.; Milne, P.; Naud, R.; Venter, M. V. D. Anticancer Research 2005, 25, 4197-4202.

122. Yamazaki, M.; Suzuki, S.; Miyaki, K. Chemical and Pharmaceutical Bulletin 1971, 19, 1739-1740. 
123. Cole, R. J.; Kirksey, J. W.; Dorner, J. W.; Wilson, D. M.; Johnson Jr., J. C.; Johnson, A. N.; Bedell, D. M.; Springer, J. P.; Chexal, K. K.; Clardy, J. C.; Cox, R. H. Journal of Agricultural and Food Chemistry 1977, 25, 826-830.

124. Cole, R. J.; Kirksey, J. W.; Moore, J. H.; Blankenship, B. R.; Diener, U. L.; Davis, N. D. Applied and Environmental Microbiology 1972, 24, 248-256.

125. Abraham, W.-R.; Arfmann, H.-A. Phytochemistry 1990, 29, 1025-1026.

126. Cui, C.-B.; Kakeya, H.; Okada, G.; Onose, R.; Osada, H. The Journal of Antibiotics 1996, 49, 527-533.

127. Usui, T.; Kondoh, M.; Cui, C.-B.; Mayumi, T.; Sada, H. Biochemical Journal 1998, $333,543-548$.

128. Woehlecke, H.; Osada, H.; Herrmann, A.; Lage, H. International Journal of Cancer 2003, 107, 721-728.

129. Rabindran, S. K.; Ross, D. D.; Doyle, L. A.; Yang, W.; Greenberger, L. M. Cancer Research 2000, 60, 47-50.

130. Cui, C.-B.; Kakeya, H.; Osada, H. Tetrahedron 1996, 52, 12651-12666.

131. Cui, C.-B.; Kakeya, H.; Osada, H. Tetrahedron 1997, 53, 59-72.

132. Fazuo Wang, Y. F.; Zhu, T.; Zhang, M.; Lin, A.; Gu, Q.; Zhu, W. Tetrahedron 2008, 64, 7986-7991.

133. Afiyatullov, S. S.; Zhuravleva, O. I.; Chaikina, E. L.; Anisimov, M. M. Chemistry of Natural Compounds 2012, 48, 95-98.

134. Garg, N.; Manchanda, G.; Kumar, A. Antonie van Leeuwenhoek 2014, 105, 289305.

135. Nazzaro, F.; Fratianni, F.; Coppola, R. International Journal of Molecular Sciences 2013, 14, 12607-12619.

136. Nealson, K. H.; Platt, T.; Hastings, J. W. Journal of Bacteriology 1970, 104, 313322.

137. Holden, M. T. G. et al. Molecular Microbiology 1999, 33, 1254-1266.

138. Yan, P.-S.; Song, Y.; Sakuno, E.; Nakajima, H.; Nakagawa, H.; Yabe, K. Applied and Environmental Microbiology 2004, 70, 7466-7473.

139. Park, D.-K.; Lee, K.-E.; Baek, C.-H.; Kim, I. H.; Kwon, J.-H.; Lee, W. K.; Lee, K.H.; Kim, B.-S.; Choi, S.-H.; Kim, K.-S. Journal of Bacteriology 2006, 188, 22142221.

140. Campbell, J.; Lin, Q.; Geske, G. D.; Blackwell, H. E. ACS Chemical Biology 2009, 4, 1051-1059.

141. Musthafa, K. S.; Balamurugan, K.; Pandian, S. K.; Ravi, A. V. Journal of Basic Microbiology 2012, 52, 679-686.

142. Abed, R. M. M.; Dobretsov, S.; Al-Fori, M.; Gunasekera, S. P.; Sudesh, K.; Paul, V. J. Journal of Industrial Microbiology and Biotechnology 2013, 40, 759772. 
143. Holt, H. M.; Gahrn-Hansen, B.; Bruun, B. Clinical Microbiology and Infection 2005, 11, 347-352.

144. Hau, H. H.; Gralnick, J. A. Annual Review of Microbiology 2007, 61, 237-258.

145. Dikow, R. B. BMC Genomics 2011, 12, 237-250.

146. Chen, Y.; Liu, Y.; Yen, M.; Wang, J.; Wang, J.; Wann, S.; Cheng, D. Clinical Infectious Diseases 1997, 25, 225-229.

147. Fredrickson, J. K. et al. Nature Reviews Microbiology 2008, 6, 592-603.

148. Derby, H.; Hammer, B. Iowa Agricultural Experiment Station Research Bulletin 1931, 145, 387-416.

149. MacDonell, M.; Colwell, R. Systematic and Applied Microbiology 1985, 6, 171182.

150. Murakawa, T.; Yamagata, H.; Tsuruta, H.; Aizono, Y. Bioscience, Biotechnology, and Biochemistry 2002, 66, 754-761.

151. Malasarn, D.; Keeffe, J. R.; Newman, D. K. Journal of Bacteriology 2008, 190, $135-142$.

152. Simoes, I.; Faro, R.; Bur, D.; Kay, J.; Faro, C. FEBS Journal 2011, 278, 3177-3186.

153. Kasahara, R.; Sato, T.; Tamegai, H.; Kato, C. Bioscience, Biotechnology, and Biochemistry 2009, 73, 2541-2543.

154. Morita, J.; Suzuki, S. Journal of Marine Biotechnology 1994, 1, 197-202.

155. Godeke, J.; Heun, M.; Bubendorfer, S.; Paul, K.; Thormann, K. M. Applied and Environmental Microbiology 2011, 77, 5342-5351.

156. Bodor, A.; Elxnat, B.; Thiel, V.; Schulz, S.; Wagner-Dobler, I. BMC Microbiology 2008, 8, 13-21.

157. Simidu, U.; Kita-Tsukamoto, K.; Yasumoto, T.; Yotsu, M. International Journal of Systematic Bacteriology 1990, 40, 331-336.

158. Green, T. J.; Smullen, R.; Barnes, A. C. Veterinary Microbiology 2013, 166, 286292.

159. Defoirdt, T.; Boon, N.; Bossier, P.; Verstraete, W. Aquaculture 2004, 240, 69-88.

160. Bhattarai, H. D.; Ganti, V. S.; Paudel, B.; Lee, Y. K.; Lee, H. K.; Hong, Y.; Shin, H. W. World Journal of Microbiology and Biotechnology 2007, 23, 243-249.

161. Nishida, T.; Morita, N.; Yano, Y.; Orikasa, Y.; Okuyama, H. FEBS Letters 2007, 581, 4212-4216.

162. Ledyard, K. M.; Butler, A. Journal of Biological Inorganic Chemistry 1997, 2, 9397.

163. Bottcher, T.; Clardy, J. Angewandte Chemie International Edition 2014, 53, 35103513. 
164. Gu, Q.; Fu, L.; Wang, Y.; Lin, J. Journal of Agricultural and Food Chemistry 2013, $61,11645-11652$.

165. Evident, A.; Surico, G. Journal of Natural Products 1986, 49, 938-939.

166. He, R.; Wang, B.; Wakimoto, T.; Wang, M.; Zhub, L.; Abe, I. Journal of the Brazilian Chemical Society 2013, 24, 1926-1932.

167. Chen, Y.-H.; Liou, S.-E.; Chen, C.-C. European Food Research and Technology 2004, 218, 589-597.

168. Liu, H.; Chen, J.; Deng, Z.; Huang, H.-R.; Lin, W.-H. Journal of Chinese Pharmaceutical Sciences 2010, 19, 482-486.

169. Furtado, N. A. J. C.; Vessecchi, R.; Tomaz, J. C.; Galembeck, S. E.; Bastos, J. K.; Lopes, N. P.; Crotti, A. E. M. Journal of Mass Spectrometry 2007, 42, 1279-1286.

170. Wang, G.; Dai, S.; Chen, M.; Wu, H.; Xie, L.; Luo, X.; Li, X. Chemistry of Natural Compounds 2010, 46, 583-585.

171. Takaya, Y.; Furukawa, T.; Miura, S.; Akutagawa, T.; Hotta, Y.; Ishikawa, N.; Niwa, M. Journal of Agricultural and Food Chemistry 2006, 55, 75-79.

172. Jayatilake, G. S.; Thornton, M. P.; Leonard, A. C.; Grimwade, J. E.; Baker, B. J. Journal of Natural Products 1996, 59, 293-296.

173. Stark, T.; Hofmann, T. Journal of Agricultural and Food Chemistry 2005, 53, 72227231.

174. Lee, Y.-H. Studies on the bioactive constituents of the fermented broth of three marine bacterial species isolated in Taiwan, Masters Thesis, 2008.

175. Smaoui, S.; Mathieu, F.; Elleuch, L.; Coppel, Y.; Merlina, G.; Karray-Rebai, I.; Mellouli, L. World Journal of Microbiology and Biotechnology 2012, 28, 793-804.

176. Caballero, E.; Avendao, C.; Menndez, J. C. Tetrahedron: Asymmetry 1998, 9, 967981.

177. Pedras, M. S. C.; Smith, K. C.; Taylor, J. L. Phytochemistry 1998, 49, 1575-1577.

178. Izumida, H.; Imamura, N.; Sano, H. Journal of Antibiotics 1996, 49, 76-80.

179. Houston, D. R.; Eggleston, I.; Synstad, B.; Eijsink, V. G.; van Aalten, D. M. The Biochemical Journal 2002, 368, 23-27.

180. Izumida, H.; Nishijima, M.; Takadera, T.; Nomoto, A. M.; Sano, H. Journal of Antibiotics 1996, 49, 829-831.

181. Houston, D. R.; Synstad, B.; Eijsink, V. G. H.; Stark, M. J. R.; Eggleston, I. M.; van Aalten, D. M. F. Journal of Medicinal Chemistry 2004, 47, 5713-5720. 